\title{
$A$
}

Alzheimer's Disease

International

The global voice on dementia

\section{World Alzheimer Report 2016}

Improving healthcare for people living with dementia

COVERAGE, QUALITY AND COSTS NOW AND IN THE FUTURE

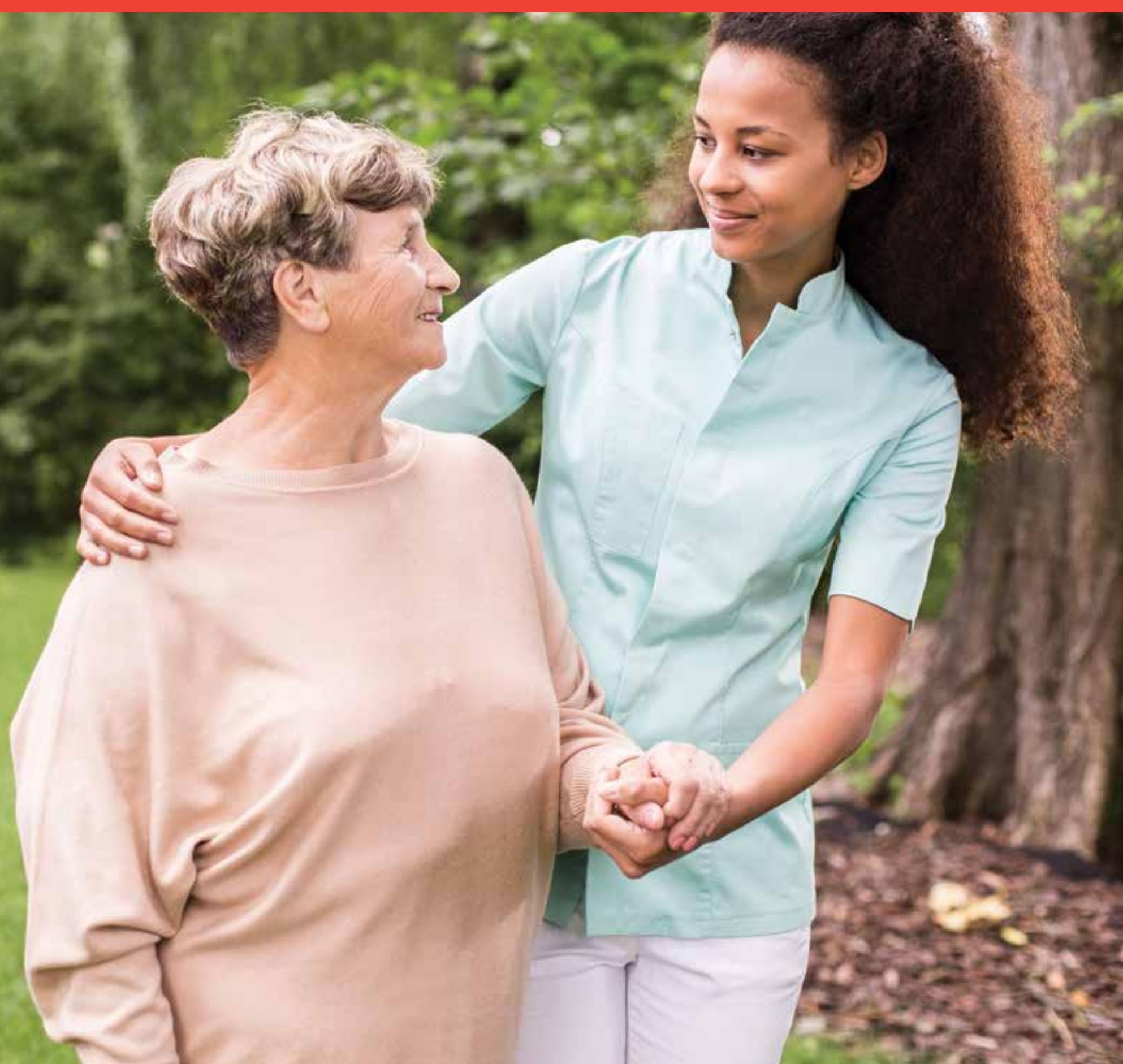




\section{Authors}

\section{Prof Martin Prince}

The Global Observatory for Ageing and Dementia Care, King's College London, UK

\section{Ms Adelina Comas-Herrera}

Personal Social Services Research Unit (PSSRU),

London School of Economics and Political Science, UK

\section{Prof Martin Knapp}

Personal Social Services Research Unit (PSSRU),

London School of Economics and Political Science, UK

Dr Maëlenn Guerchet

The Global Observatory for Ageing and Dementia Care, King's College London, UK

Ms Maria Karagiannidou

The Global Observatory for Ageing and Dementia Care, King's College London, UK

\section{Chapter 1}

Martin Prince

\section{Chapter 2}

Martin Prince, Maria Karagiannidou

\section{Chapter 3}

Maëlenn Guerchet, Maria Karagiannidou

\section{Chapter 4}

Martin Prince, Maria Karagiannidou

\section{Chapter 5}

Martin Prince, Maria Karagiannidou

\section{Chapter 6}

Adelina Comas-Herrera, Martin Knapp

\section{Chapter 7}

Adelina Comas-Herrera, Martin Knapp, Martin Prince

\section{Chapter 8}

Martin Prince

The World Alzheimer Report 2016 was independently researched and authored by the Global Observatory for Ageing and Dementia Care and the PSSRU at the London School of Economics and Political Sciences, with contributions listed above. The evidence reported and the inferences drawn in Chapters 1-7 are the responsibility of the authors alone. Chapter 8 was developed by the authors with additional input from Alzheimer's Disease International.

Published by Alzheimer's Disease International (ADI), London.

September 2016.

Copyright (๑) Alzheimer's Disease International

\section{Acknowledgements}

For chapter 6, the authors would like to acknowledge invaluable contributions from Emiliano Albanese, Sara Allin, Hoyoung An, Stefanie Becker, Cynthia Blick, Larry Chambers, Maneesha Chhikara, Eva Cyhlarova, Emily Freeman, Bo Hu, Binna Kim, Hanna Kim, Ki Woong Kim, You Joung Kim, Andreas Kopp, Mariana Lopez-Ortega, Maria Lopez-Quiroga, Klara Lorenz, Kaeyun Park, Ruru Ping, Anna Rupert, Tara P. Sani, DY Suharya, Natalie Warrick, Marc Wortmann, Jie Zheng.

For chapter 7, the authors would like to acknowledge Eva Cyhlarova, Daniel Chisholm and Amritpal Rehill, and the members of ADl's Medical and Scientific Advisory Panel (MSAP).

This report was supported financially by GE Healthcare, Roche, Janssen, Lundbeck, Lilly and Biogen for which ADI is very grateful. $\mathrm{ADI}$ and the authors are fully responsible for the content.

Design - David O'Connor - www.daviddesigns.co.uk

Cover photo - Photographee.eu - Shutterstock 


\section{Foreword}

Today, 47 million people live with dementia worldwide, more than the population of Spain. This number is projected to increase to more than 131 million by 2050, as populations age. Dementia also has a huge economic impact. The total estimated worldwide cost of dementia is US\$818 billion, and it will become a trillion dollar disease by 2018 .

The huge majority of people with dementia have not received a diagnosis, and so are unable to access care and treatment. Even when dementia is diagnosed, the care provided is too often fragmented, uncoordinated, and unresponsive to the needs of people living with dementia, their carers and families. This is unacceptable.

This World Alzheimer Report 2016 reviews the state of healthcare for dementia around the world, and recommends ways that it can be improved. There is a clear and urgent need to improve the coverage of healthcare around the world, for people living with dementia now and those who will be in the future. Through cost modelling, the report shows that these improvements are affordable and achievable, but governments and societies need to effect transformative change to deliver them. It is essential that this happens.

We are grateful to the authors from The Global Observatory for Ageing and Dementia Care at King's College London and the Personal Social Services Research Unit at the London School of Economics and Political Science for producing this report. We appreciate the support of our sponsors - GE Healthcare, Roche, Janssen, Lundbeck, Lilly and Biogen - which made the report possible.

ADI, the global federation of 85 Alzheimer associations, is committed to ensuring that dementia becomes an international health priority. We believe national dementia plans are the first step towards ensuring all countries are equipped to enable people to live well with dementia, and help to reduce the risk of dementia for future generations. There is now a growing list of countries which have such provision in place or are developing national dementia plans, but it is not enough. We hope that the adoption of a Global Plan on Dementia by the World Health Organization in 2017 will commit member states to act on many of the recommendations contained in this report.

Around the world, we need to drive forward improvements in healthcare and social care, as well as eliminating the stigma around dementia and ensuring that people living with dementia are included in society and that their human rights are recognised everywhere.

We are committed to ensuring prevention, care and inclusion happen today, and a cure tomorrow.
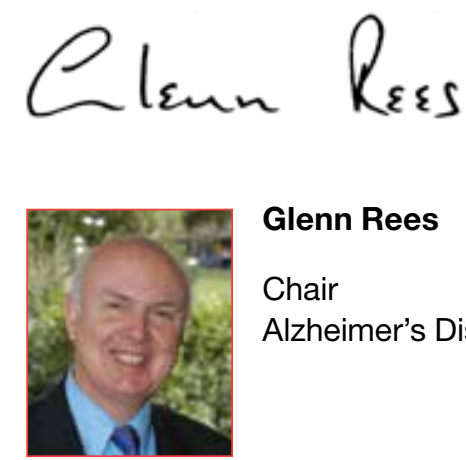

\section{Glenn Rees}

Chair

Alzheimer's Disease International 


\section{Contents}

Executive summary 1

\section{CHAPTER 1}

Introduction 6

Healthcare in context 6

Structural barriers to the delivery of effective healthcare for older people 7

Purposes of healthcare for dementia 8

Healthcare resources 8

Functions and processes of healthcare for dementia 9

Principles of healthcare for dementia 9

Health system level interventions to improve the quality of dementia care 11

Conclusion 17

\section{CHAPTER 2}

\section{The role of primary care in the dementia} healthcare system 21

Objectives and search strategy 21

Search results, and characteristics of the eligible studies 21

Framework for presentation of research findings on the role of primary care in dementia healthcare 27

Detection and diagnosis 27

Post-diagnostic care and support 34

Continuing care 36

Summary and discussion 39

\section{CHAPTER 3}

\section{Care coordination and case management for people with dementia 46}

Objectives and search strategy 46

Search results, and characteristics of the eligible studies 47

What is the evidence to support case management (cost-)

effectiveness? 47

Implementation of case management 54

Summary and discussion 55

\section{CHAPTER 4}

\section{Acute general hospital care for people with dementia 58}

Background 58

How often are people with dementia admitted to hospital? 58

Are older people with dementia at increased risk of harm during a hospital admission, and what are the likely mechanisms? 60

What are the excess healthcare costs associated with acute hospital care for people with dementia, and what are the principal drivers? 61

How might admissions to hospital be avoided? 62

For those people with dementia who are admitted to hospital, what might reduce harm, and improve outcomes? 64 


\section{CHAPTER 5}

\section{Palliative care $\mathbf{7 0}$}

Introduction 70

What is palliative care? 70

How, and when, is palliative care applicable to dementia care? 71

Advanced care planning 72

End-of-life care 76

Summary and conclusion 80

\section{CHAPTER 6}

\section{Dementia care in Canada, China, Indonesia, Mexico, South Africa, South Korea and Switzerland 84}

Introduction 84

Dementia care in Canada 84

Dementia care in China 87

Dementia care in Indonesia 91

Dementia care in Mexico 94

Dementia care in South Africa 96

Dementia care in South Korea 100

Dementia care in Switzerland 104

\section{CHAPTER 7}

Cost implications of the dementia healthcare pathways 110

Care pathways modelling 110

Costing methods 113

Results 115

\section{CHAPTER 8}

\section{Summary and conclusion 122}

Introduction - the scope of this report 122

Summary of review findings 123

Discussion and conclusion 127 


\section{Alzheimer's Disease International}

\section{World Alzheimer Report 2016 Improving healthcare for people living with dementia}

COVERAGE, QUALITY AND COSTS NOW AND IN THE FUTURE

\section{The Global Observatory for Ageing and Dementia Care}

The Global Observatory for Ageing and Dementia Care, hosted at the Health Service and Population Research Department, King's College London, was founded in 2013. Supported by Alzheimer's Disease International, and King's College London, the Observatory has a tripartite mission:

1. To build upon ADI's $10 / 66$ Dementia Research Group program of population-based and intervention research in low and middle income countries, maximising the impact that research findings from our data can have upon policy and practice.

2. To develop, evaluate, and promote primary care and community interventions for people with dementia.

3. To synthesise global evidence for policymakers and public, in particular, continuing and developing our role in the preparation of high impact evidence-based reports for Alzheimer's Disease International (World Alzheimer Reports 2009, 2010, 2011, 2013, 2014 and 2015, and Nutrition and dementia), the World Health Organization (Dementia: a public health priority, 2012) and other relevant intergovernmental organisations. 


\section{Executive summary}

\section{Findings from the reviews}

\section{Models of healthcare delivery}

- Healthcare for people with dementia needs to be:

- Continuous: treatment options, care plans and needs for support must be monitored and reviewed as the condition evolves and progresses.

- Holistic: treating the whole person, not single conditions, organs or systems, and mindful of that person's unique context, values and preferences.

- Integrated: across providers, levels of care, and health and social care systems.

- Currently, healthcare systems struggle to provide adequate coverage of diagnostic services, and care is too often fragmented, uncoordinated, and unresponsive to the needs of people with dementia and their families.

- In high income countries, dementia healthcare systems tend to be highly specialised (care is provided by specialist physicians - geriatricians, neurologists and psychiatrists), from diagnosis onwards, with very little formal recognition of the role of primary care services, or allocation of tasks to this sector. This is probably also true for low and middle income countries, where diagnostic coverage is low.

- As the numbers of people affected and the demand for services increase, it is unlikely that full coverage of dementia healthcare services can be attained or afforded using the current specialist care model.

\section{The role of primary care}

- Dementia is currently under-detected, underdiagnosed, under-disclosed, under-treated and under-managed in primary care.

- When primary care physicians do take responsibility for dementia care, evidence suggests that the care has similar outcomes to that provided by specialists.

- Recognition of dementia in primary care can be boosted by in-service education and training.

- Indicated screening using cognitive tests can support timely diagnosis. However, general screening of all older attendees cannot currently be recommended.
- In most settings, dementia diagnosis is not explicitly recognised as being within the capacity of non-specialist services. Nevertheless, we identified several successful examples of memory clinics established in primary care, and run by primary care physicians supported by nurse practitioners.

- The post-diagnostic phase bridges from the 'diagnosis well-made' to a system of continuing care in the context of declining function and increasing needs for care and support.

- The potential benefits of the full range of postdiagnostic support activities have yet to be evaluated.

- Primary care services struggle to deliver high quality continuing care for people with dementia, even in systems where their role has been made more explicit.

- There have, as yet, been no evaluations of case management located within primary care.

- Attention needs to be given to the optimal roles of specialists within a more task-shifted and task-shared healthcare model. Task-shifting is defined as delegating selected tasks to existing or new health professional cadres with either less training or narrowly tailored training. This may involve shifting tasks from higher- to lower-skilled health workers - for example, from a neurologist to a primary care physician - or creating new professional roles, so tasks can be shifted from workers with more general training to workers with specific training for a particular task - for example, from a primary care physician to a dementia case manager.

- Task-shifted models of care require specialist support. Specialist services will need to take on a more prominent role in training, mentoring and supervising non-specialists, with explicit referral guidelines and pathways.

\section{Care coordination, through case management}

- The effectiveness of case management remains unclear as research is lacking. Positive effects of case management (reduced or delayed transition into care homes, better adherence to care standards, and reduced unmet needs) were found in some studies.

- There is a lack of evidence regarding the impact of case management on the efficiency with which healthcare is delivered, mainly because most studies do not report on the relevant outcomes. 
- Effects of case management on hospitalisation were generally not significant and the absence of evidence on cost-effectiveness studies is striking.

- Evidence to date suggests that effectiveness may be enhanced when there is:

- A manageable caseload for delivering interventions with the required intensity;

- A clear role definition with adequate preparation and training; and

- Empowerment of the case manager to access and coordinate care across providers and sectors.

- Future evaluations need to include a comprehensive set of process and outcome measures, which should include service utilisation and cost, effective components of case management, as well as clinical and quality of life outcomes for the person with dementia and carer.

\section{Hospital care}

- People with dementia are more likely to be admitted to general hospital than people of similar age and medical infirmity, particularly for falls-related accidents and injuries, urinary tract and respiratory infections, and chronic disease complications that might have been averted with better management in the community.

- People with dementia are less likely to be admitted for interventional procedures that could enhance quality of life, including cataract surgery, vascular catheterisation and stenting, cholecystectomy, and cancer care.

- In high income countries the costs of healthcare are substantially higher for people with dementia than age-matched controls, with a substantial proportion of costs arising from hospitalisation.

- The process of hospital care is more complicated for people with dementia, with significant cost implications. They have longer hospital stays, and require more nursing resources than others.

- People with dementia are particularly vulnerable to harm and poor outcomes in the context of an admission, particularly from hospital acquired infections, delirium, agitation and falls, all of which impact adversely on length of stay.

- Mortality rates are exceptionally high during admission and somewhat higher after discharge. However, the high mortality rates may reflect, in part, a tendency to admit people with dementia to hospital at the very end-of-life.

- More research is need into service and system level interventions to avoid hospitalisation, specifically of people with dementia. Community interventions have been mostly ineffective, although there is more evidence to support multidisciplinary assessment and management, than case management.
- Emergency Departments are often the portal of admission for people with dementia, and represent a last chance to prevent unnecessary hospitalisation. The literature highlights the need for comprehensive multidimensional geriatric assessment, including detection of dementia and delirium.

- 'Hospital at home' refers to services provided by health professionals in the person's own home, in situations when inpatient hospitalisation would otherwise be necessary. While we identified several examples of such services being established for people with dementia, we could find no formal evaluations.

- Reducing rates of hospitalisation for people with dementia will likely require community-based and outreach services that are resource-intensive and maintained over relatively long periods of time. Costs then would be shifted from acute hospital to community health and social care, which would require adjustments to budgets and resource allocation.

- For people with dementia who are admitted to general hospital, there is a tension between prioritisation of task-centred acute care for the cause for admission, and the acknowledged need to provide person-centred dementia care.

- Advocated actions are mainly at the systems level, focusing on managerial and workforce development; providing an appropriate care environment; fostering a positive care culture; changing attitudes; and cultivating a better understanding of the challenges for the person with dementia, for carers, and for inpatient healthcare staff.

- Most reviews and reports emphasise that simply introducing a mental health liaison service, or a dementia specialist nurse, or a special dementia care unit will not suffice. These need to be properly integrated into the wider hospital and health service management structure.

- Concern is expressed in all recent reviews at the lack of rigorous evaluation of services that commissioners are advocating and providers are implementing. Well-conducted large scale randomised controlled trials, providing clear evidence of cost-effectiveness are largely lacking.

\section{Palliative and end-of-life care}

- Concerns have been raised regarding the lack of access for people with dementia to good quality end-of-life care, specifically specialist palliative care services, although there is some evidence, from some high income countries, that the situation may be improving. 
- The applicability of a palliative approach to dementia care continues to be debated, given the lack of consensus regarding the definition of 'advanced' dementia and the lack of a clearly demarcated 'end-of-life' phase.

- There may be no specific palliative phase; the specific goals of dementia care can include, at various phases, and to different degrees, prolonging life, improving function, and achieving comfort (palliation).

- People with dementia should be encouraged and enabled to exercise their autonomy in options for future care, consistent with their values and preferences, and it should be emphasised that the palliative care agenda is focused upon their choices, and their quality of life, rather than cost savings.

- Early discussions with family carers that acknowledge the likely future loss of decisionmaking capacity and their increasing role as proxy decision-makers would assist carers in assuming this role, and enhance their ability to judge the person with dementia's best interests.

- Calls have been made for a better systematisation of palliative care for people with dementia, with structured care pathways, good practice supported by evidence, and identification of appropriate outcomes to allow the effects of interventions to be measured.

- More clarity is needed regarding the division of responsibilities among different health and social care disciplines.

- There is also a policy gap regarding end-of-life care for people with dementia. The focus is on living well with dementia, with relatively less attention to the complex medical, social and ethical management of the physical decline that leads to death.

- There is an urgent need for more research, specific to the dementia field, regarding: preferences of people with dementia, and how these can be elicited; the implementation, benefits and harms of advanced care planning; and the relative costs and benefits of palliative care assessments and services in the more advanced phases of the condition. Current good practice guidelines are almost entirely based upon expert opinion and consensus.

\section{Dementia care pathways and the health system context}

Reviews of the care for people with dementia in Canada, China, Indonesia, Mexico, South Africa, South Korea and Switzerland have identified key challenges to the implementation of better healthcare pathways for people with dementia:
- In most of the countries, the low levels of awareness and training of healthcare staff contribute to low rates of diagnosis, as dementia is considered a normal part of ageing. For those who are diagnosed, the lack of professional knowledge about treatment and care options may also deny people access to post-diagnostic care, treatment and support.

- Access to healthcare for people with dementia remains a problem for some parts of the population in most of the countries. Access can be restricted as result of the financing arrangements (particularly in low and middle income countries, some people have inadequate or no public health cover at all, and, even in high income countries, the out-ofpocket payments can be too high for those in low incomes). People from some ethnic groups and people living in care homes have more difficulties accessing appropriate care in most countries.

- Geographic inequities (poor availability of care in rural and remote areas) remain a problem even in high income countries, although there are examples of the use of technology to improve this.

- In all the countries except for Canada and South Africa, primary care does not have a gatekeeping role and people are able to access specialist care directly, which may result in people accessing care that is unnecessarily expensive, or even accessing the wrong specialists. The ease of access to specialist care, combined with a perception that primary care is of lower quality, may be important barriers to the development of task-shifted care pathways.

\section{The costs of implementing a task- shifted dementia healthcare pathway}

We estimated the costs of implementing a dementiaspecific healthcare task-shifted pathway in in Canada, China, Indonesia, Mexico, South Africa, South Korea and Switzerland. The pathway was based on the literature reviews conducted as part of this report and it involves:

- Diagnosis: mostly carried out in primary care by primary care physicians and case managers, with some people referred to specialist care.

- Initial treatment and post-diagnostic support: an assessment for anti-dementia drugs, postdiagnostic support package, and carer training and support).

- Continuing care: anti-dementia medication reviews, management of behavioural and psychological symptoms and case management.

- End-of-life care.

- A proportion of people, those with more complex dementia and co-morbidities, would continue to access a specialist care pathway. 
We compiled unit costs for each of the countries, complemented with international estimates when local unit costs were not available. Results from costing the pathway in each of the countries show that:

- The costs of the task-shifted pathways are relatively low compared to overall healthcare spending. We have estimated that the cost of the pathway in 2015, per person diagnosed, would range from $\$ 39$ per year in Mexico (or $\$ 3.90$ per person with dementia), to $\$ 2,113$ in South Korea (\$1,057 per person with dementia).

- The prescription costs of anti-dementia drugs are very high in some of the countries (China, Indonesia, South Africa and South Korea), representing more than $80 \%$ of the cost of the pathway. This is in part because of drugs remaining under patent, lack of consolidated purchasing, and reluctance to use generic medicines. This is aggravated in some countries by doctors using additional prescription fees to supplement their incomes. If, by 2030 , the use of generic medicines was the norm, the cost of the task-shifted care pathway would be $40 \%$ lower than that of the specialist pathway in all three HIC, making increased coverage more affordable.

\section{Conclusions and recommendations}

Four main themes emerged from the reviews conducted for this report:

\section{Systematisation of care processes}

Systematisation should include:

- standards of care at different phases of the condition;

- role specification ('who does what');

- clear referral indications and pathways; and

- relevant process and outcome indicators to be measured.

\section{Managing complexity}

- Much more effort needs to be applied to the effective management of complex multimorbidities (multiple health problems) in dementia healthcare, in particular chronic physical health conditions. There is evidence that chronic physical health conditions are undermanaged for people with dementia, with missed opportunities to improve function and avoid acute crises leading to hospitalisation (for example, nutrition, hydration, falls, infection, delirium and medication management).

\section{Need for more research}

- Researchers should work with policymakers and providers to ensure that the innovations that they propose to evaluate are policy relevant, fully implementable in the context of the research evaluation, and capable of being taken to scale in the event that effectiveness and cost-effectiveness are demonstrated.

\section{Coverage, costs and efficiency}

- Increasing the coverage of dementia care will increase total costs to the health system, since more people will be being treated. This, coupled with the increasing numbers of people living with dementia, is likely to be a key driver of trends in healthcare costs.

- In this context, a move towards a less specialised, more task-shifted model of care can be advocated on two grounds:

- First, mobilising the untapped potential of the non-specialist primary care workforce can alleviate resource constraints, enabling scaling up to take place (especially critical for low and middle income countries).

- Secondly, this strategy is likely to optimise productive efficiency. Under either scenario, the unit costs of care are assumed to fall.

- Over time, as tasks are shifted successfully to the primary care level, commissioners will be able to shift budgets from secondary to primary care and per capita costs of care may fall. In reality though, the main benefits of task-shifting may be the unlocking of resource capacity to meet the increasing demand.

- There is also the possibility that task-shifted and task-shared care may be of higher quality; more local, more holistic and personalised, and more comprehensive, integrated and continuous.

- To improve coverage using a task-shifted approach requires that health systems provide universal health coverage, good access to care for those in rural areas and from disadvantaged groups and, crucially, that primary healthcare has a central (and gatekeeping role) in health systems.

- Scaling up dementia care would seem to be affordable, in principle, in all countries included in our review.

- The cost of anti-dementia drugs had a large impact on the total cost of the dementia healthcare pathway where low cost generic versions of acetylcholinesterase inhibitors and memantine were not yet available. 
We need to focus on achieving high coverage of dementia diagnosis and continuing care, both to ensure access to current evidence-based treatments and support, and to create systems and platforms with the capacity to deliver, with equity, much more effective treatments in the future. 


\section{CHAPTER 1 \\ Introduction}

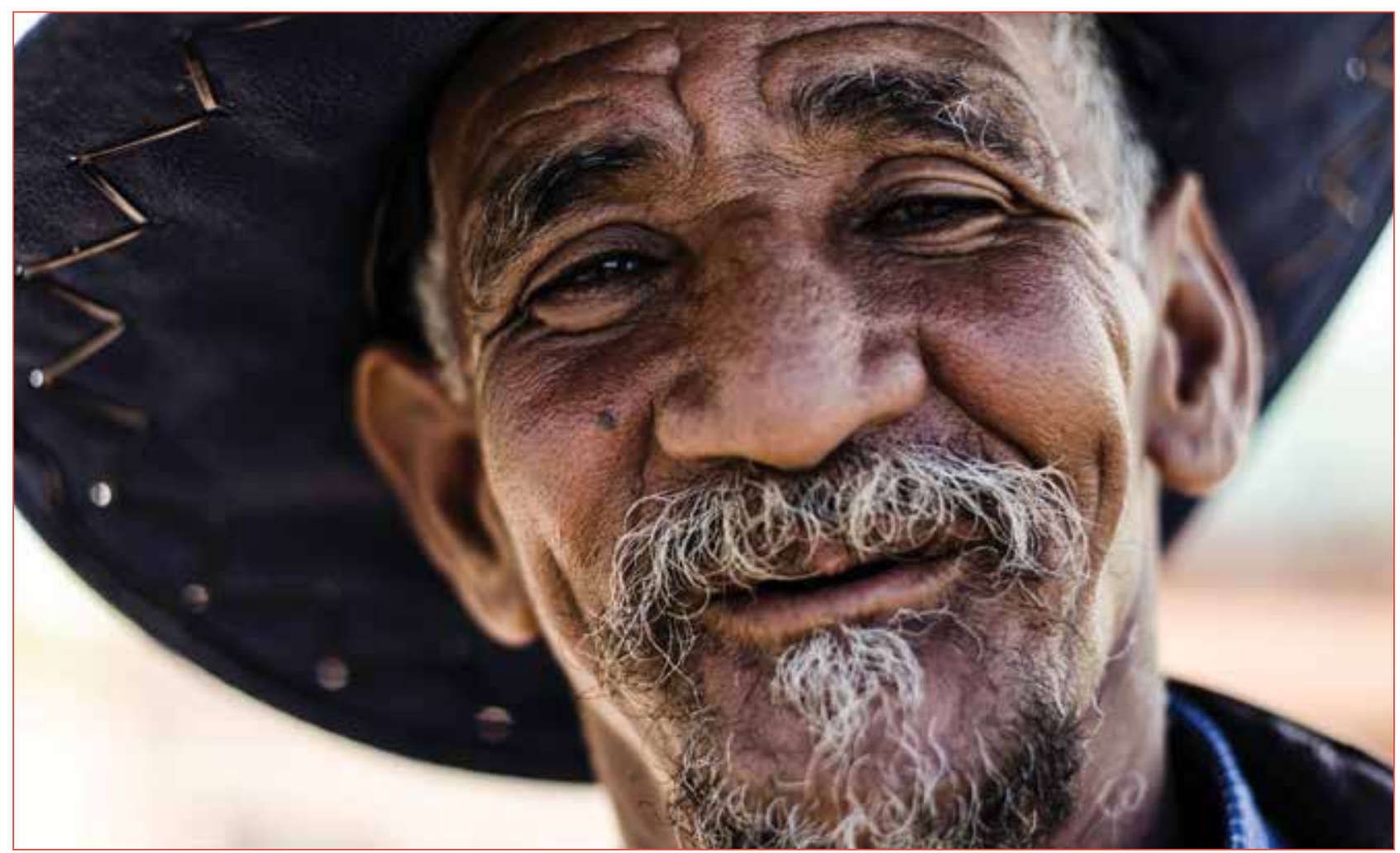

\subsection{Healthcare in context}

Narratives and reviews of dementia care systems have tended to emphasise social care, whether provided by unpaid family carers, or services that are developed to support, supplement or substitute their core role in the journey of care. This was the topic of the World Alzheimer Report $2013^{1}$. The focus is understandable in many ways. The goal of 'living well with dementia' is achieved when care is person-centred, seamless and co-ordinated, and when the needs of people with dementia, and their carers, are anticipated and met in a timely fashion throughout the course of the condition. Much remains to be done to achieve this objective - long term care systems around the world are too often fragmented, unresponsive, and of inadequate quality, and coverage of core support services is low, particularly in less well-resourced low and middle income countries (LMIC) ${ }^{1}$. There is also a fiscal imperative; $80-85 \%$ of the global societal costs of dementia (currently estimated to be US $\$ 818$ billion) arise from the direct costs of social care services, and the informal unpaid inputs of family carers ${ }^{2}$. In high income countries (HIC) informal care and the direct costs of social care (community homecare, and residential care) make similar contributions to total costs. In LMIC, the costs of informal care predominate, since a structured formal social care sector has, as yet, not been developed.
Less attention, relatively speaking, is paid to the systems and services that deliver healthcare for people with dementia. Currently, only $10-15 \%$ of total societal costs arise from healthcare, regardless of setting ${ }^{2}$.

Healthcare costs are modest because:

1. Diagnostic coverage is low. In most HIC, only 40$50 \%$ of people living with dementia have received a diagnosis. In LMIC there are few available estimates, but diagnostic coverage is unlikely to exceed $5-10 \%$ in most settings ${ }^{3-5}$. Diagnostic coverage is important, since this is the gateway to planning for, and receipt of, health and social care services, across the disease course. Increasing the coverage of timely dementia diagnosis is a priority for most current national and regional policies and plans.

2. Dementia specialist care is underdeveloped in LMIC. There are very few geriatricians, neurologists and psychiatrists, and few hospital or communitybased services dedicated to diagnosis and continuing care ${ }^{6-8}$. Coverage of continuing care services remains low in $\mathrm{HIC}$, in part because of low diagnostic coverage, but also because specialist services struggle to provide continuous and responsive care to rapidly increasing numbers of people with dementia? .

3. Even interventions with a strong evidence-base (for example acetylcholinesterase inhibitors and 
memantine) are not being delivered to all who might benefit, while others have scarcely been implemented at all (carer education, training and support).

4. Other interventions that have been proposed and considered in some health systems (for example early post-diagnostic support, cognitive stimulation, and case management/coordination) remain thinly evidenced, particularly as regards their costeffectiveness, and have not, as yet, been taken to scale in most health systems.

5. There are, as yet, no treatments that alter the course of dementia. Following on from the G7-led Global Action on Dementia, development of such treatments is an intergovernmentally agreed global public health priority ${ }^{10}$. The distribution of health and social care costs for dementia is strikingly different to those, for example, of cancer care, where the aim is remission or cure, often through the use of expensive drugs and diagnostic technologies. In the event that such treatments are identified for dementia, we will need to have delivery systems capable of providing high coverage, with equity.

The salience of healthcare to achieving better outcomes for people living with dementia is indicated by the results of a recent research prioritisation exercise, led by WHO for the G7 Global Action on Dementia legacy process, eight of the top 20 research avenues identified related to diagnosis, or the delivery, or quality of dementia care. Most of these research avenues either primarily concerned healthcare services, or involved potential inputs from healthcare services (see Box 1.1)

\subsection{Structural barriers to the delivery of effective healthcare for older people}

The Madrid International Plan of Action on Ageing called for the elimination of social and economic inequalities in access to healthcare and the development of healthcare and long-term care to meet the needs of older persons ${ }^{11}$. It is important to acknowledge that the goal of age-appropriate healthcare for all is far from being achieved ${ }^{12}$. The fitness for purpose of health services and systems for older adults with complex, interacting, chronic medical and social problems remains open to question ${ }^{13}$. Ageist attitudes and beliefs; that ill health is inevitable, intervention ineffective, and improved outcomes inherently less valuable; are widespread even among older people and healthcare professionals ${ }^{14}$. Health services are often not adequately orientated to the assessment and management of complex cognitive, physical and mental multimorbidities, and the provision of continuing rather than curative care ${ }^{13,15}$. Structural barriers to accessing healthcare include the high cost of chronic disease care when incomes are insecure,
Box 1.1

Dementia research priorities relevant to the healthcare sector (WHO Research Prioritization exercise)

- Identify clinical practice and health systembased interventions that would promote a timely and accurate diagnosis of dementia in primary healthcare practices. (Diagnosis)

- Evaluate the relative effectiveness and identify the optimal models of care and support for people with dementia and their carers in the community (e.g. collaborative care, integrated health and social care, case management) across the disease course. (Delivery of care)

- Identify strategies to anticipate and deliver effective and cost-effective late life and end of life care for people with dementia, including advance care planning. (Delivery of care)

- Determine the most effective interventions for educating, training and supporting formal and informal carer(s) of people with dementia. (Quality of care)

- Determine and ensure optimal use of psychological and pharmacological treatments for Behavioral and Psychological symptoms of Dementia (BPSD) to maximize patients' quality of life and caregiver burden reduction. (Quality of care)

- Understand the role of assistive and technological devices, including e-health and mobile health technology strategies, for people with dementia and/or their carer(s). (Delivery of care)

- Develop and evaluate policies, investments and plans for increasing the capacity, knowledge, skills and interest of the health and social care workforce in the field of dementia. (Quality of care)

- Establish norms and standards for the highest quality of care in residential and nursing homes and approaches to assist families of people with dementia to determine the optimal time to consider placement. (Quality of care) 
healthcare is financed by out of pocket payments and insurance coverage is incomplete ${ }^{16-18}$.

\subsection{Purposes of healthcare for dementia}

In the USA, the Advisory Council for Alzheimer's

Research, Care and Dementia interdisciplinary

Dementia Measures Work Group recently defined the objectives of clinical care as:

"preserving, to the maximum possible extent, cognitive and functional abilities, reducing the frequency, severity, and adverse impact of neuropsychiatric and behavioral symptoms, sustaining the best achievable general health, reducing risks to health and safety, and enhancing caregiver wellbeing, skill, and comfort with managing the patients with dementia in partnership with health care providers." 19

\subsection{Healthcare resources}

In many high income country health systems it is possible to discern two branches of dementia specialist healthcare service, which have been characterised as an 'early intervention' stream (mainly outpatient memory clinics, focussing on early differential diagnosis and early intervention to minimise future harm, risk and cost for the patient) and a 'serious mental illness' stream (co-ordinating community care in the more advanced stages of the disease treating severe and complex disorders with high levels of risk and co-morbidity) ${ }^{20}$.

There are very few comparable data available internationally regarding the extent of specialist healthcare resources for dementia care. This will change, with the establishment in 2016/17 of the WHO Global Dementia Observatory, with one core activity being to obtain detailed information from Ministries of Health on healthcare resources, and coverage of services.

In the UK a national audit of memory clinic services indicated that, in 2014 there were 222 memory clinics (one for every 3400 people with dementia) ${ }^{9}$. Numbers of assessments increased $31 \%$ in one year (2013-2014), but without any equivalent increase in resourcing or capacity. Average waiting time for assessment and diagnosis post assessment both increased slightly over the same period, as did the range of waiting times (from one week to 32 weeks). In the Netherlands, where this process was monitored between 1998 and 2009, the number of clinics increased from 12 to 63 , the number of new clients seen annually has risen from 1,700 to 14,175 , and the estimated proportion of all incident cases of dementia in the Dutch population that receive a formal diagnosis through a memory clinic rose from $5 \%$ to $27 \%{ }^{21}$. Such specialist services have also begun to be developed in low and middle income countries, typically on western lines ${ }^{22}$, but in a sporadic and unplanned fashion, and with low levels of national coverage. Thus, in India there were estimated, in 2013 , to be approximately 100 memory clinics nationally (approximately one clinic per 37,000 people with dementia), two-thirds supported by a pharmaceutical company ${ }^{23}$. Almost all the federal government super specialty hospitals, with neurology and psychiatry services, had a memory clinic or specialty clinic for people with dementia, but with almost no clinics in other government hospitals ${ }^{23}$. In China, a survey of 36 tier 3 hospitals (randomly selected from 995 nationwide) indicated that only one sixth had functioning memory clinic services, and that there were only a small number of neurologists with competencies as dementia practitioners ${ }^{24}$. This would suggest around 166 memory clinics nationally, or one for every 48,000 people with dementia. Only $0.1 \%$ of outpatients received a diagnosis of dementia. After the institution of a training programme memory clinic services were introduced in all of the hospitals, and the proportion of outpatients diagnosed increased fourfold, to $0.4 \%{ }^{24}$. In the 30 hospitals previously without memory clinics the proportion of outpatients diagnosed increased from $0.03 \%$ to $0.38 \%$. Overall, the proportion of patients diagnosed according to standard procedures increased from $23.1 \%$ to $97.5 \%$. The proportion of those diagnosed with Alzheimer's disease prescribed acetylcholinesterase inhibitors increased from $19.7 \%$ to $66.6 \%$ and receiving memantine from $4.1 \%$ to $21.5 \%$.

The three studies described here confirm the general sense that:

1. Services in many high income countries provide comprehensive geographic coverage, but may struggle to meet increasing demand

2. In middle income countries, services are very limited, and are largely restricted to tertiary care hospitals in major population centres.

The default option, worldwide, is for healthcare for people with dementia to be provided by primary healthcare services. Again, we do not know what proportion of diagnoses, and continuing care for dementia is being provided by primary care practitioners (PCPs). In North America, it seems that PCPs may play an important role, in part because of difficulties in accessing specialist services ${ }^{25-28}$. For low and middle income countries it seems likely that diagnosis in primary care is currently very infrequent, and as such, while general healthcare may be being provided, there would also be almost no dementiaspecific structured continuing care and support provided at this level of the health system ${ }^{29,30}$. 


\subsection{Functions and processes of healthcare for dementia}

\section{Dementia risk reduction}

Prevention is traditionally the province of government public health and disease control agencies. However, the healthcare sector, in particular primary care, has an important role in promotion, prevention and early intervention with respect to the emerging consensus on modifiable risk factors for dementia (hypertension, diabetes, smoking, and underactivity) ${ }^{31,32}$.

\section{Detection and diagnosis}

The diagnosis of dementia requires a careful medical history and examination, cognitive testing, and assessment of functional impairment. Progressive dementia needs to be distinguished from normal ageing. Differential diagnosis entails exclusion of other possible causes of cognitive decline (for example, delirium or depression) and possible causes of secondary dementia need to be identified and treated where present. Formal diagnoses, and dementia subtyping are often made by specialist teams working in memory clinics or other diagnostic services, and in some healthcare settings access to certain dementia drugs, services and benefits are dependent upon this. However, non-specialists, particularly in the primary care sector have an important part to play. While screening for dementia remains controversial (see section 2.4), there is broad agreement that, if appropriate, it is best conducted in primary care ${ }^{33}$. In many health systems, primary healthcare services are the natural 'first port of call' for those seeking help for a new health problem, and PCPs play an important gate-keeper role, deciding which patients should and should not be referred on for specialist assessment and treatment. In a case-note study from the UK, 96\% of patients on a primary care register with confirmed or suspected dementia had their diagnosis first made in primary care, and two-thirds of those identified in primary care were then referred immediately for specialist attention ${ }^{34}$.

\section{Managing comorbidity (and complexity)}

People with dementia are highly likely to be living with complex multimorbidities, with both mental and chronic physical health conditions. It is important that these are addressed, to minimise cognitive and functional disabilities, to prevent and treat newly emerging behavioural symptoms, and to optimise quality of life. This needs to be done in a holistic manner, accounting for the preferences of people with dementia and carers, and with coordination to increase efficiency, reduce burden on people with dementia, and limit potential adverse effects.

\section{Avoiding unnecessary and/or counterproductive patterns of use of healthcare services}

In many HIC settings, avoidance of hospitalisation (particularly emergency department attendance and non-elective admission) of people living with dementia has become an explicit policy aim, with recommendations to better manage admissions, reduce length of stay, and facilitate discharge. While the hazards of hospitalisation and the poor outcomes achieved are increasingly understood, it is also possible that people with dementia may be being denied the right to receive hospital-based medical interventions that might improve their overall functioning and quality of life (through a variety of mechanisms including diagnostic overshadowing, misperceived contraindications, and failure to address lack of capacity to consent). Even where hospitalizations might be better avoided, or shortened, alternative home-based care options (for example, 'hospital at home') need to be developed, evaluated and resourced.

\section{Interactions with social care}

Health and social care assessments and interventions should be closely aligned. Carer demands and carer strain increase when morbidity is under-diagnosed and undertreated (for example pain, bowel and bladder function, sensory impairments, and behavioural and psychological symptoms). Services that supplement or substitute for informal care (home care, respite care, residential care) are resource- and costintensive, and healthcare professionals are needed to provide input into social care needs assessments. Post-diagnostic support, case management, and education, and training and support interventions for carers can bolster informal care, reduce the need for supplementary support and transition into care homes, prevent consequential physical and mental health problems, and increase the efficiency with which healthcare services are used. These are all examples of services that fall on the cusp between health and social care. While the professionals who carry out and lead these activities may be located within either the health or social care sectors, their success will depend critically on the extent of intersectoral integration and coordination.

\subsection{Principles of healthcare for dementia}

\section{A public health approach}

A public health model for dementia care prioritises meeting population level needs, rather than merely optimising the quality of care for the minority who access high quality specialist care. There is, therefore, a focus upon increasing coverage (the proportion of those in need that receive care), and effective coverage 
(the proportion of those in need whose needs are met). Note that diagnostic coverage places a ceiling on treatment coverage, since, without a diagnosis, it is not possible to deliver comprehensive structured dementia care (see Figure 1.1). Levels of treatment coverage will therefore be lower than the levels of diagnostic coverage provided in previous sections, since many of those diagnosed are not in receipt of appropriate continuing care. Levels of effective coverage will be lower still. Increasing coverage requires promoting demand (help-seeking) through increased awareness, scaling up the supply of diagnostic and care services to meet the demand, and a reduction in the barriers to access. Aside from coverage, the success of scaling up initiatives are conventionally judged upon the equity with which care is delivered (equitable access to services based only upon need), and the outcomes achieved.

Figure 1.1

Dementia diagnostic and treatment coverage

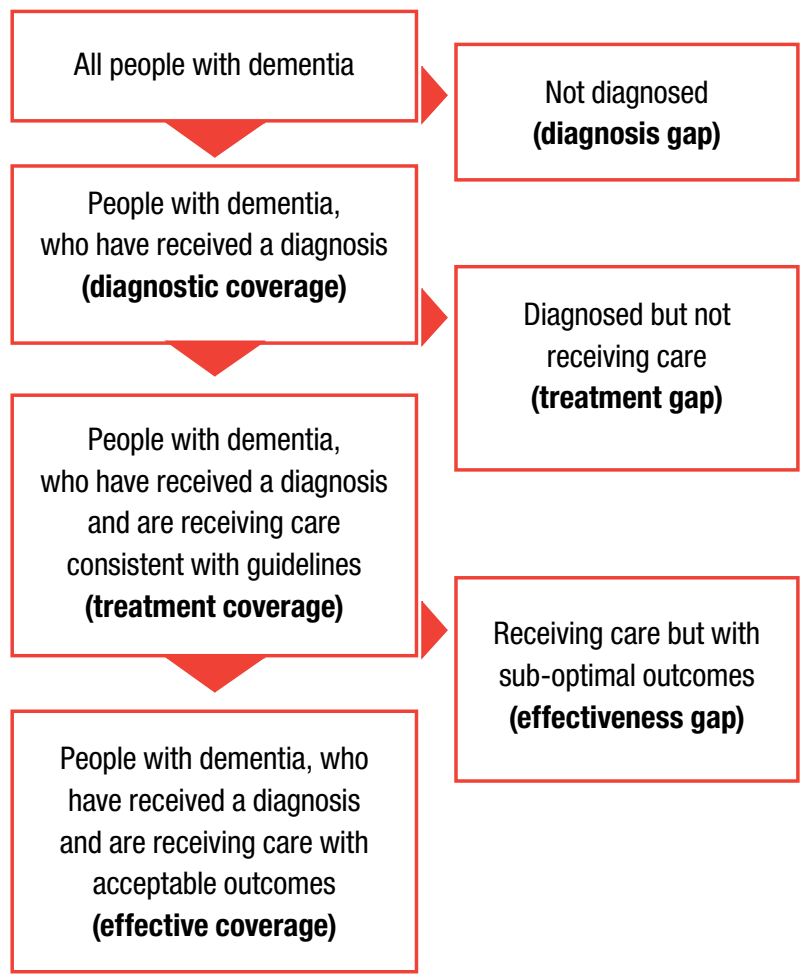

Currently, within HIC, models of health service care for dementia tend to be highly specialised, from diagnosis onwards, with very little formal recognition of the role of primary care services, or allocation of tasks to this sector. There are many potential limitations to this approach. It is unlikely that full coverage of services could be attained, and efficiency has probably not been optimised. Those who have received a diagnosis often do not receive seamless and continuing care, which is beyond the capacity and reach of specialist services working in isolation. The specialist model of dementia care does not facilitate care-coordination for those with complex multimorbidities, which is a core function of primary healthcare. In most LMIC, specialist services are far too under-resourced to have the capacity to deal with current levels of need, and demand (numbers affected) is likely to increase more rapidly than the development of the specialist workforce. When existing healthcare resources are not well-matched to the local healthcare need, then services become less accessible, and even when they are accessible, they are less affordable. Some degree of task-shifting to non-specialist healthcare workers will therefore be an essential component of scaling up services in resource-poor settings ${ }^{35,36}$. Collaborative or shared-care models distribute tasks between primary and secondary care services in a structured and organized fashion.

\section{Task-shifting}

Task-shifting is defined as delegating selected tasks to existing or new health professional cadres with either less training or narrowly tailored training ${ }^{37}$. This may involve shifting tasks from higher- to lower-skilled health workers (e.g. from a neurologist specialist doctor to a PCP), or creating new professional cadres, whereby tasks are shifted from workers with more general training to workers with specific training for a particular task (e.g. from a PCP to a dementia case manager). The two underlying assumptions are that the unit cost of the task-shifted option is cheaper, and that the quality of care and its outcomes are equivalent. The less-specialised cadre are generally more numerous, and hence have the capacity to alleviate the resource constraints that are barriers to achieving increased coverage. In technical terms, the primary objective of task-shifting is to increase productive efficiency, that is, to increase the volume of healthcare services provided at a given quality and cost, or, alternatively, to provide the same level of healthcare services at a given quality, but at a lower cost ${ }^{37}$. Hence task-shifting can be a relevant strategy for resource-limited LMIC (with the aim of increasing coverage). Evidence from LMIC indicates that, with adaptation and appropriate training and supervision, it is feasible for interventions developed to be delivered by specialist doctors to be taken on by non-specialists (and non-doctors) without an adverse effect on clinical outcomes ${ }^{37-39}$. Although this literature is growing, as the authors of one review point out the evidence remains of moderate extent and quality, and more rigorous research is required ${ }^{37}$. One of the key findings from the review of task-shifted care was that quality of care tended to suffer when the complexity of the intervention increased ${ }^{37}$. The quality of training is critical, and there is a need for ongoing support to maintain motivation and fidelity. Barriers to task-shifting included institutional and professional resistance.

In better resourced $\mathrm{HIC}$, it might be assumed that the main objective of task-shifting might be to reduce costs. However, coverage levels of dementia services need to increase, and as the numbers of people with 
dementia increase inexorably, resource limitations will become increasingly apparent. A key objective of taskshifting is to reduce the time needed to scale up the health workforce, because the cadres performing the shifted tasks require less training ${ }^{37}$. It is quicker and cheaper to train practice nurses to carry out structured diagnostic assessments in primary care, than to train greatly increased numbers of neuropsychologists and neurologists. For these and other reasons (localism, person-centred care, and care coordination) there is increasing interest in task-shifted community-based models of care for older people.

\section{Task-sharing}

In reality, almost all task-shifted models of service delivery include an element of task-sharing between specialist and non-specialist services. As a minimum, this requires a commitment to training, and ongoing supervision and support. There also need to be clearly defined referral protocols, to cater for instances where the complexity or severity of a case, and/or the assessments and interventions required exceeds the non-specialist's competence to provide safe and effective care. Specialists are often involved in the design, and sometimes the governance and management, of task-shifted models of care ${ }^{40}$. In collaborative, or shared care models specialists and non-specialists work together to provide a service, with the roles and activities of each, and their interaction carefully designed. Such services may be led by specialists or non-specialists. A critical feature is effective sharing of information between patient, and specialist and non-specialist. This is best achieved through a single health information system, sometimes held by the patient. From the point of view of productive efficiency, the optimal skill mix is the combination of health professionals that produce a given level of healthcare services at a particular quality for the lowest cost.

\section{An integrated and co-ordinated approach}

The World Health Organization has defined integrated care as

\footnotetext{
"a concept bringing together inputs, delivery, management and organization of services related to diagnosis, treatment, care, rehabilitation and health promotion. Integration is a means to improve services in relation to access, quality, user satisfaction and efficiency." 41
}

Horizontal integration refers to the linkage of different disciplines or elements of care at the same level of care, for example mental and physical healthcare, or health and social care. Vertical integration refers to the linkage of care at different levels of specialisation, for example primary, secondary, and tertiary healthcare).
Integrated care is closely related to the concept of continuity of care, which is often best viewed through the patient's perspective of navigating their way through the health and social care systems. There are at least three relevant components to continuity of care $^{41}$ :

1. Continuity of information (best achieved by a single information system, or by shared access to records and highly effective communication),

2. Continuity across the primary-secondary care interface (collaborative care models, clear and responsive referral protocols and pathways, effective communication and discharge planning from specialist to generalist care), and

3. Provider continuity, seeing the same professional each time, with the opportunity to establish a therapeutic, trusting relationship (a role often filled by the primary care physician, a key worker, or case manager).

There is ample evidence that dementia care systems have failed to achieve acceptable levels of integration ${ }^{42}$. Care processes are characterised by fragmentation; primary and secondary care health services, and social care often operate relatively autonomously with too little communication, and some duplication of activities ${ }^{43,44}$. There are often unacceptable delays in accessing specialist services ${ }^{9,45-47}$, and, in some systems, structural barriers to making referrals from primary care ${ }^{19,25}$. Multimorbidity is highly prevalent among people with dementia, and poses challenges for integrated management of chronic cognitive, mental and physical health conditions ${ }^{48-51}$. Multimorbidity increases sharply with age, and is strongly associated with impaired quality of life ${ }^{52}$, disability, dependence ${ }^{53}$ and mortality ${ }^{54}$. Those with multimorbidity account for $96 \%$ and those with more than five conditions for $68 \%$ of US Medicare expenditure, and unnecessary hospitalisations increase exponentially with increasing multimorbidity ${ }^{55,56}$. Rigid application of clinical practice guidelines for single disorders may contribute to polypharmacy, adverse drug interactions and unnecessary cost ${ }^{57}$. A holistic approach has been advocated, with comprehensive assessment, leading to well-integrated continuing care, focussing first and foremost upon patient preferences in an effort to streamline care and increase its acceptability ${ }^{58,59}$.

\subsection{Health system level interventions to improve the quality of dementia care}

\section{Case management}

The Case Management Society of America defines case management as "a collaborative process of assessment, planning, facilitation, care coordination and advocacy for options and services to meet an individual's and family's comprehensive health needs 
through communication and available resources to promote quality cost-effective outcomes". 60

The case manager promotes integration of care, first, through provider continuity. They are a constant point of contact and reference for the patient and their family, while multiple services might be involved in providing care. Their core roles include advocacy, communication, education, identification of service resources and service facilitation ${ }^{60}$. They help the patient and family to negotiate the complexities of the care system, promote self-management, and can help ensure that care is efficient, and prioritised in a way that is consistent with individual values and preferences. There is often an element of taskshifting implicit in case management, since the case manager is an example of a new professional cadre with specific training and skills for a defined set of tasks. In dementia care, there is particular interest in the concept of case managers operating at the level of primary care ${ }^{61,62}$. Primary care physicians are the first health system contact for early diagnosis and management of dementia, but primary healthcare systems are not yet equipped to deal with the diverse needs of patients and carers across the course of the condition. Case management could, in principle, increase the capacity of primary healthcare to attend to these needs, improve the quality of dementia care, and provide cost-effective coordination of services.

\section{Care pathways}

\section{What is a care pathway?}

The concept of the care pathway has become increasingly influential in many domains of health service management and research, including the delivery of care for chronic conditions. The fundamental principle is to apply a structured and organised approach to the planning, resourcing and delivery of continuing care. While every patient goes through a care process, and these vary among patients with particular conditions, care pathways are about planning and managing those processes, in advance, for defined groups of individuals. Operational management, end-to-end, of a care process differs from the more conventional activity of managing care units (in healthcare terms, hospitals, primary healthcare facilities or services).

There are several definitions of care pathways. Schrijvers et al refer to "process innovations that focus on improving the organisation of care processes"63. The European Pathway Association defines a care pathway as "a complex intervention for the mutual decision making and organization of care processes for a well-defined group of patients during a well-defined period"64,65. In the UK, the term "integrated care pathway" is used to emphasise the coordination of different elements along the pathway, "a multidisciplinary outline of anticipated care, placed in an appropriate timeframe, to help a patient with a specific condition or set of symptoms move progressively through a clinical experience to positive outcomes" 66 . However, others consider this tautologous; all care pathways are by definition integrated, given that avoidance of fragmented care processes is one of the main objectives ${ }^{63}$. This aspect is highlighted by the European Pathway Association's defining characteristics of a care pathway ${ }^{65}$ :

- An explicit statement of the goals and key elements of care based on evidence, best practice and patient expectations

- The facilitations of the communication and coordination of roles, and sequencing the activities of the multidisciplinary care team, patients and their relatives

- The documentation, monitoring, and evaluation of variances and outcomes

- The identification of relevant resources

A care pathway approach to continuing care comprises $^{63}$ :

1. a care plan for each individual patient (patient planning and protocol);

2. the planning of care in care pathways (patient group planning and control);

3. the capacity planning of professionals, equipment and space (resource planning and control);

4. the planning of the number of patients to be treated and care activities to be carried out (patient volume planning and control), and

5. the long-term policy of the institution (strategic planning).

Not all healthcare activities lend themselves to a care pathway approach, since not all care is provided for a "well-defined patient group" and a "well-defined period of time". There is clearly a world of difference, in this respect, between inpatient surgery for inguinal hernia, and dementia care. For continuing care of chronic conditions, care plans may need to be drawn up and delivered flexibly, contingent upon differing needs, clinical trajectories and responses to intervention. A 'stepped care' approach is often used, whereby a patient first receives the most effective, least invasive, least expensive and shortest form of assessment or intervention, given the nature and severity of the problem. Following review assessment and/or intervention can be escalated to the next level where necessary. 


\section{How might a care pathway approach be applicable to dementia care?}

Dementia care would seem, at first pass, an unpromising candidate for application of the care pathway approach ${ }^{67}$. Patients present and are diagnosed at different stages in the disease process. The course of the condition can be highly variable, in terms of deterioration in cognitive and functional abilities, and onset of behavioural and psychological symptoms. The impact on the individual and their family, and the consequent need for additional care and support, will be highly context dependent. Services strive to deliver person-centred care throughout, emphasising the need to elicit, understand and respond to changing needs in the context of values and preferences. Far from a 'well-defined time period', the need for care starts with help-seeking prior to diagnosis, and extends across the disease course, to death and beyond. And yet, within limits, there are aspects of the evolution of the condition, and the needs for evidence-based intervention and support at particular phases of the process that are predictable. The course of dementia tends, by definition, to be progressive, although there may be 'plateau' periods. For dementia, monitoring, care and support needs to be continuous, but particular activities may be indicated at particular phases of the condition. Recent developments to the care pathway approach include a distinction between highly structured fixed time care pathways (e.g. inguinal hernia surgery) and non-fixed time but phase-oriented care pathways ${ }^{63}$, which would be more applicable for dementia care.

The overall objective of a care pathway would be to provide seamless high quality care that is responsive, flexible and continuing, with the aim of maximising independence and participation, and optimising health and quality of life for patient and carers throughout.

\section{Phase-orientated care for people with dementia}

People with dementia have a right to a timely diagnosis, well made ${ }^{68}$. The concept of a timely diagnosis was advanced by the INTERDEM group, conducting an analysis of 'The primary care diagnosis of dementia in Europe' using multidisciplinary, multinational expert groups, to establish the potential for a consensus guideline ${ }^{69}$.

"Timely diagnosis is defined as the time when the patient or caregiver and the primary care physician recognize that a dementia syndrome may be developing. The preference for timely diagnosis implies that methodologies should concentrate not on population screening, but on a speedy response to the first reported signs of changed behaviour and functioning in the patient." 69

Among the proposed benefits of a timely diagnosis is the relief gained from better understanding of symptoms that have led to concern ${ }^{68}$. A diagnosis is well made when the process of diagnosis and diagnostic disclosure is perceived and experienced as positive and helpful by patient and family. This may take time, since acceptance may be preceded by denial, anger, and grief. Good practice for disclosing dementia diagnosis should include: preparation; integrating family members; exploring the patient's perspective; disclosing the diagnosis; responding to patient reactions; focusing on quality of life and wellbeing; planning for the future; and communicating effectively ${ }^{70}$. Other benefits of a timely diagnosis are the opportunities to engage in health promotion, optimise current medical management, maximise decision making autonomy, plan for the future, and obtain information about available support services ${ }^{68}$. This implies the need for a physical health and medication review, a capacity assessment where indicated, initiation of advanced care planning, and signposting to community care services. There is evidence to support the effectiveness of certain interventions early in the disease course - these include carer education, training and support, the prescription of acetylcholinesterase inhibitors for those who meet criteria, peer support groups for people with dementia, behavioural activation for depressive reactions, and, possibly, cognitive stimulation therapy. The Scottish Government has made a commitment to delivering a minimum of one year post-diagnostic support, informed by the Alzheimer Scotland 5 Pillars Model $^{71}$ (understanding the illness and managing symptoms; planning for future decision making; supporting community connections; peer support; and planning for future care), and co-ordinated by a Link Worker.

Since the course of the condition, and the emergence of complications, is not easy to predict, all people living with dementia, and their family carers need regular reviews, to monitor changes in cognitive and functional ability, to optimise mental and physical health and wellbeing through health promotion and managing comorbidity, to attend to nutrition and hydration, to identify, assess and manage the emergence of behavioural and psychological symptoms, and to reassess unmet needs for care and support. The care inputs over this period of continuing care will depend upon the results of these reviews, but there should also be facilitated access to needs-driven advice, support and reassessment in the intervals between assessments.

Dementia is an incurable and life-limiting illness, and the World Health Organization states that 'every person with a progressive illness has a right to palliative

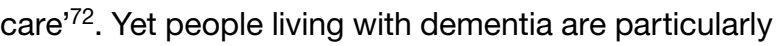
unlikely to have access to palliative care services at the end of life ${ }^{1}$. Palliative care affirms life and regards dying as a normal process; intends neither to hasten nor postpone death; provides relief from pain and other 
distressing symptoms; offers a support system to help patients live as actively as possible until death, and to help the family cope during the patient's illness and in their own bereavement ${ }^{73}$. Evidence suggests that while carers can be resilient in the face of bereavement, intervention and support services are needed most in the period before the patient's death ${ }^{74}$. Nevertheless, a palliative care approach may be appropriate across the illness course, with early advanced care planning, and continuing review of care preferences.

\section{Benefits and risks of a care pathway approach}

There are multiple potential benefits associated with the introduction of care pathways:

1. An increase in the coherence and consistency of care between and among services, using evidencebased guidelines

2. Improvements in the quality of care, through the application and monitoring of quality standards and outcomes

3. Improvements in the responsiveness of care, through better resource planning and allocation, and identification and removal of bottlenecks in the system

4. The efficiency of care (and costs), through precise and optimal role definition, better coordination, and avoidance of duplication

There is empirical evidence to support these benefits. In Belgium, 309 healthcare workers reported on 103 care processes for different health conditions in 49 hospitals, using the Care Process Self Evaluation Tool (CPSET) to rate care processes according to their degree of organisation ${ }^{75}$. Care processes that were supported by formal care pathways were 8.9 times more likely to rate highly on the coordination of care, 6.7 times more likely to rate highly on follow-up/ continuity of care, and 4.3 times more likely to rate highly for overall care process quality.

On the other hand, there are legitimate concerns that an over-concrete application of a care pathway approach may lead to the mechanisation and dehumanisation of care, removal of personal choice and abandoning of an aspiration for a person-centred approach, and the rationing of access to care. Samsi and Manthorpe ${ }^{67}$, in reviewing the applicability of care pathways to dementia care highlighted the multiple possible meanings that might be attached to the concept by service providers and service users; a mechanism for the management and containment of uncertainty and confusion, useful for the professional as well as the person with dementia; a manual for sequencing care activities; a guide to consumers, indicating eligibility for care activities, or a guide to self-management for dementia dyads, indicating the appropriateness of care activities; and a manual for "walking with" the person with dementia.

\section{Examples of care pathways for dementia}

While there are many examples of dementia care service guidelines, few of these would qualify as meeting the defining characteristics of a care pathway. We have identified three examples, which, at least in part fulfil these criteria.

\section{The Queensland University of Technology Clinical Practice Guidelines and Care Pathways for People with Dementia Living in the Community $^{76}$}

This care pathway was developed in collaboration with State Government (Queensland Health). Caveats are emphasised in a set of fundamental principles that include recognition that people with dementia, their carers and families are central to making choices about care, and that service responses need to recognise people's individual care journeys. It is acknowledged that the guidelines and pathways do not encompass all care scenarios, and should be used flexibly. The pathways focus on non-pharmacological care only. The pathways are strongly evidence-based with a systematic review of existing guidelines, and formal evidence quality assessment. 'Practice tips' are also provided, which constitute advice on good clinical practice based upon multidisciplinary expert opinion from the guideline development group. Assessment tools are suggested to facilitate and monitor the delivery of an effective continuum of care.

This care pathway is 'phase-orientated' with three phases identified:

a. Recognition, Assessment and Diagnosis Phase

b. Post Diagnosis, Monitoring, Management and Care Phase

c. The Advanced Phase

For each phase separate but interactive pathways are provided for the general practitioner (primary care physician), the health professional (specialist), and the care worker (social care professional). The recommended management strategies at each phase are summarised in Table 1.1. The full pathway document ${ }^{76}$ includes comprehensive clinical algorithms, in the form of flow charts signifying the assessments, management decisions and management actions (including explicit referral protocols) that need to be taken at each stage.

\section{Quality Improvement in Neurology - Dementia Measures Work Group Measurement Set for Dementia Management (copyrighted by the American Medical Association) ${ }^{19}$}

The Advisory Council for Alzheimer's Research, Care and Dementia, established after the passage of the 
Table 1.1

Queensland University of Technology Clinical Practice Guidelines and Care Pathways for People with Dementia Living in the Community ${ }^{76}$

\begin{tabular}{|c|c|c|}
\hline Phase & $\begin{array}{l}\text { Management Strategies for Persons } \\
\text { with Dementia }\end{array}$ & Strategies for Carer support \\
\hline $\begin{array}{l}\text { Recognition, assessment and diagnosis } \\
\text { phase }\end{array}$ & $\begin{array}{l}\text { Detection } \\
\text { Assessment } \\
\text { Investigation of comorbidities } \\
\text { Functional assessment } \\
\text { Differential diagnosis } \\
\text { Informing the patient and carer }\end{array}$ & \\
\hline $\begin{array}{l}\text { Postdiagnosis, monitoring, management } \\
\text { and care phase }\end{array}$ & $\begin{array}{l}\text { Treatment of co-morbidities } \\
\text { Behavioural management } \\
\text { Maintenance of function } \\
\text { Legal issues/ Decision making capacity } \\
\text { Service provision }\end{array}$ & $\begin{array}{l}\text { Interventions to support the carer } \\
\text { Impact of caring on sexual relationships } \\
\text { Respite care } \\
\text { Abuse and neglect } \\
\text { Financial assistance }\end{array}$ \\
\hline Advanced phase & $\begin{array}{l}\text { A palliative approach } \\
\text { Hydration and nutrition } \\
\text { Fever and infection } \\
\text { Symptom management } \\
\text { Transition to residential care }\end{array}$ & $\begin{array}{l}\text { Decision making/advanced directives } \\
\text { Grief and loss }\end{array}$ \\
\hline
\end{tabular}

USA National Alzheimer's Project Act, recommended quality measures suitable for evaluating and tracking dementia care in clinical settings. An interdisciplinary Dementia Measures Work Group has developed a measurement set applying to continuing care after dementia has been diagnosed ${ }^{19}$. The premise for this work was that; "health care for persons with dementia is inconsistent, often suboptimal, and largely unplanned; ethnic and socioeconomic disparities are important influences on the quality of dementia care; partnership with caregivers is integral to improving care; and that the well-being and behavioural stability of patients with dementia is strongly influenced by the well-being of their caregivers; and comprehensive integrated care and quality improvement initiatives must be explicit and practical"19. It includes all stages of dementia in a single measure set, but calls for functional staging (mild, moderate or severe dementia) in planning care. It highlights the importance of palliative care concepts to guide care prior to the advanced stages of illness. The measurement set specifies annual reassessment and updating of interventions and care plans for dementia-related problems that affect carers as well as people with dementia. For most measures, care quality is indicated by the proportion of eligible patients whose documented care meets the identified goal. The Work Group considered that while patient-reported outcomes were a desirable feature of quality performance assessment, the heterogeneity of the condition and its management precluded their adoption ${ }^{19}$. The focus on process measures alone might be considered to be a weakness, but, as such, the measure set does provide the outline of a prototypical structured care pathway. While this is not an explicitly phase-orientated pathway, the indicators fall into five categories of decision making (Table 1.2): 1) assessment of the person with dementia postdiagnosis (measures 1-4 and 6), 2) management of neuropsychiatric symptoms (measure 5), 3) patient safety (measures 7 and 8), 4) palliative care and endof-life issues (measure 9), and 5) caregiver issues (measure 10).

\section{The World Health Organization Mental Health Gap Action Programme (mhGAP) evidence based guidelines and intervention guide ${ }^{77}$}

The WHO mhGAP guidelines address nine priority mental, neurological and substance use disorders; dementia, depression, psychosis, bipolar disorders, epilepsy, alcohol use disorders, drug use disorders, self-harm/suicide, developmental and behavioural disorders, and other significant emotional or medically unexplained complaints. They have been developed specifically for use by health-care providers working in non-specialised healthcare settings after adaptation for national and local needs. The explicit purpose is to reduce the treatment gap for these conditions. The guidelines comprise an expert consensus (from the international Guideline Development Group) of those elements of a package of care that are both evidencebased and feasible, in principle, of being delivered by non-specialists healthworkers in this context ${ }^{35,36,78}$. The guidelines are transparently and strongly based on evidence from systematic reviews of the literature. Extensive supporting resources are provided on the 
Table 1.2

Measure title and description of the final 10 dementia measures (measures copyrighted by the American Medical Association)

\begin{tabular}{|c|c|}
\hline Measure title & Description \\
\hline 1. Staging of dementia & $\begin{array}{l}\text { Percentage of patients, regardless of age, with a diagnosis of dementia, whose severity of } \\
\text { dementia was classified as mild, moderate or severe at least once during the } 12 \text { month period }\end{array}$ \\
\hline 2. Cognitive assessment & $\begin{array}{l}\text { Percentage of patients, regardless of age, with a diagnosis of dementia, for whom an assessment } \\
\text { of cognition is performed and the results are reviewed at least once within a } 12 \text { month period }\end{array}$ \\
\hline 3. Functional status assessment & $\begin{array}{l}\text { Percentage of patients, regardless of age, with a diagnosis of dementia, for whom an assessment } \\
\text { of functional status is performed and the results are reviewed at least once within a } 12 \text { month } \\
\text { period }\end{array}$ \\
\hline $\begin{array}{l}\text { 4. Neuropsychiatric symptom } \\
\text { assessment }\end{array}$ & $\begin{array}{l}\text { Percentage of patients, regardless of age, with a diagnosis of dementia, for whom an assessment } \\
\text { of neuropsychiatric symptoms is performed and the results are reviewed at least once within a } 12 \\
\text { month period }\end{array}$ \\
\hline $\begin{array}{l}\text { 5. Management of neuropsychiatric } \\
\text { symptoms }\end{array}$ & $\begin{array}{l}\text { Percentage of patients, regardless of age, who have one or more neuropsychiatric symptoms who } \\
\text { received or were recommended to receive an intervention for neuropsychiatric symptoms within a } \\
12 \text { month period }\end{array}$ \\
\hline 6. Screening for depressive symptoms & $\begin{array}{l}\text { Percentage of patients, regardless of age, with a diagnosis of dementia, who were screened for } \\
\text { depressive symptoms within a } 12 \text { month period }\end{array}$ \\
\hline $\begin{array}{l}\text { 7. Counseling regarding safety } \\
\text { concerns }\end{array}$ & $\begin{array}{l}\text { Percentage of patients, regardless of age, with a diagnosis of dementia, or their caregiver(s), who } \\
\text { were counselled regarding safety concerns within a } 12 \text { month period }\end{array}$ \\
\hline 8. Counseling regarding risks of driving & $\begin{array}{l}\text { Percentage of patients, regardless of age, with a diagnosis of dementia, or their caregiver(s), who } \\
\text { were counselled regarding the risks of driving and the alternatives to driving at least once within a } \\
12 \text { month period }\end{array}$ \\
\hline $\begin{array}{l}\text { 9. Palliative care counseling and } \\
\text { advance care planning }\end{array}$ & $\begin{array}{l}\text { Percentage of patients, regardless of age, with a diagnosis of dementia, or their caregiver(s), who } \\
\text { 1) received comprehensive counselling regarding ongoing palliation and symptom management } \\
\text { and end of life decisions and 2) have an advance care plan or surrogate decision-maker in the } \\
\text { medical record or documentation in the medical record that the patient did not wish or was not } \\
\text { able to name a surrogate decision-maker or provide an advanced care plan within } 2 \text { years of initial } \\
\text { diagnosis or assumption of care }\end{array}$ \\
\hline 10. Caregiver education and support & $\begin{array}{l}\text { Percentage of patients, regardless of age, with a diagnosis of dementia, whose caregiver(s) were } \\
\text { provided with education on dementia disease management and health behaviour changes and } \\
\text { were referred to additional resources for support within a 12-month period }\end{array}$ \\
\hline
\end{tabular}

WHO mhGAP website (http://www.who.int/mental_ health/mhgap/en/)

The accompanying mhGAP Intervention Guide (mhGAP-IG), also developed through a systematic review of evidence followed by an international consultative and participatory process, is a technical tool developed by WHO to assist in implementation of mhGAP. Its purpose is described as "integrated management of priority conditions using protocols for clinical decision-making", and as such essentially constitutes a care pathway, structured around an assess $>$ decide $>$ manage structure. For dementia, the Intervention Guide provides an initial assessment and management guide (does the person have dementia/another priority mental disorder/BPSD? Are cardiovascular disease and risk factors present? Does the person suffer from other physical conditions? Is the caregiver experiencing strain or in need of support?
'Red flags' are indicated for the need for immediate referral to specialist services, where available (unusual presentations, suspicion of delirium). Detailed guidance is then provided for the process of identifying dementia, providing psychosocial interventions (managing BPSD, and interventions for carers), and pharmacological interventions. There is also a detailed plan for routine follow-up reviews. The intervention guide (http://www.who.int/mental_health/publications/ mhGAP_intervention_guide/en/) is currently available in Arabic, English, French, Japanese, Persian, Portuguese, and Spanish.

\section{The Dementia Measures Work Group concluded:}

"The emphasis on dementia management in this measurement set recognizes the enormous challenge dementia presents to individual patients and their caregivers, health care providers, public health, and government and private insurers. While patients, 
caregivers, and health professionals await more effective disease-modifying treatments for patients with dementia, adherence to the measures outlined here will improve the quality of life for patients and caregivers with dementing illnesses." 19

There are additional potential benefits. If standard evidence and guideline-based care pathways are adopted within a healthcare system, it become possible to monitor the treatment gap (the inverse of treatment coverage - see Figure 1). This is a critical issue. Most health systems have been focusing on diagnostic coverage, which is, currently, easier to measure. However, diagnosis without a pathway leading to assured and effective treatment and care is, at best, a wasted effort. If routine assessment of suitable outcome measures is introduced into the care pathway, then it also becomes possible to measure effective coverage, which is the ultimate goal for any healthcare system.

\subsection{Conclusion}

This introductory overview of healthcare systems for people living with dementia has identified the importance of healthcare in general, and of primary healthcare in particular to the maintenance of health and wellbeing, and achievement of the best quality of life for people with dementia and their carers. There are, however, many problems with dementia healthcare systems as currently constituted. The first is that they are not yet capable of delivering adequate coverage of basic healthcare services for people with dementia. This is true for diagnosis, but there are also challenges in delivering care that is responsive, continuous and of appropriate quality (meeting guidelines and service standards). We have seen that task-shifting and tasksharing, including but not limited to increasing the role and competencies of primary healthcare services within the system, is likely to be a core strategy for increasing diagnostic and treatment coverage. Case management may be an important strategy for improving integration and coordination of care, and increasing treatment coverage. The introduction of evidence-based care pathways, linked to process and outcome indicators, should help to improve adherence to healthcare quality standards, and allow transparent monitoring of treatment coverage and effective treatment coverage.

This overview defines the agenda for this World Alzheimer Report:

We will

1 conduct a scoping review of recent research evidence on the role of primary care within the dementia healthcare system. This will include evidence regarding the effectiveness of primary care services in the detection and diagnosis of dementia, and in the provision of continuing care. We will also assess evidence on strategies and interventions to enhance the quality of care provided by primary healthcare services. Finally, we shall seek to identify any studies that compare aspects of the quality of care provided by non-specialist versus specialist services, against the criterion of 'non-inferiority', that is that the processes and outcomes achieved should be at least no worse than those achieved by specialist services - a critical justification for taskshifted care.

2 conduct a scoping review of recent research evidence regarding the effectiveness of case management, wherever it is located within the health and social care system, with respect to outcomes for people with dementia and their carers, and evidence for improved efficiency of delivery of health and social care.

3 conduct a scoping review of hospitalisation of people with dementia seeking to clarify the extent of and reasons for hospitalisation, the associated harms, the excess healthcare costs, the effectiveness of approaches to avoid hospitalisation, and reduce harm and improve outcomes for those who are admitted.

4 review the latest evidence on palliative and end-oflife care for people living with dementia, updating the review that we conducted for the 2013 World Alzheimer Report ${ }^{1}$.

5 define outline healthcare pathways for people living with dementia for relatively well-resourced $\mathrm{HIC}$, and less well-resourced LMIC settings. For selected HIC (Canada, South Korea, Switzerland) we will propose and compare two model pathways, one based on a specialist model of care, and one on a more task-shifted/task-shared counterfactual, with more roles performed by non-specialists, estimating the increasing costs of care from 2015 to 2031, accounting for projected increased in the numbers of people living with dementia, and a projected increase in diagnostic coverage from $50 \%$ to $75 \%$. For selected LMIC (China, Indonesia, Mexico, South Africa), we shall assume that, currently, dementia healthcare is provided for only a small proportion of people, using a HIC model of specialist care. We will then estimate the increasing costs from 2015 to 2031 , assuming that the increased coverage (from $5 \%$ in low income countries and $10 \%$ in middle income countries, to $50 \%$ ) is achieved through implementation of task-shifted care pathways, as recommended by the World Health Organization Mental Health Gap Action Plan (mhGAP).

This agenda is, we believe, highly relevant to the future of dementia healthcare, worldwide. 
Health and social care systems around the world share three key challenges

- Improving the coverage of care

- Improving the quality of care

- Achieving the first two objectives, while limiting, and rendering affordable, the costs of health and social care in the context of population ageing

These challenges can only be met by increasing the cost efficiency with which care is delivered, and developing future-proof, sustainable financing models. Coverage and equity of access should be important considerations throughout. Policy decisions regarding the scope and ambition, and the design and delivery of services for people with dementia, should be evidencebased. Economic models need to be developed to guide policy decisions, indicating the incremental costs of scaling up different service models. These will vary between settings, depending upon the cost of the service (driven mainly by staff costs), existing coverage levels, and the nature of cost savings where these are to be anticipated.

The multidisciplinary work group established by the Alzheimer's Foundation of America and the Alzheimer's Drug Discovery Foundation to review evidence for screening implementation and to evaluate the implications of routine dementia detection for healthcare redesign called for an effort to "Define 'ownership' of dementia in the layout of health care". In their view

"From the standpoint of health care delivery, initial screening for cognitive impairment is most practical in the primary care setting... The best setting for further diagnostic evaluation and comprehensive management is unclear, however... The workgroup encourages systematic consideration of the respective roles of primary and specialty care in the long-range management of dementia patients, as part of the work of the National Alzheimer's Project Act implementation plan. The discussion should include consideration of primary care-specialty care partnerships, specialized chronic care manager roles within primary care, and research on identifying specific subgroups of patients and families who require ongoing complex or specialized management."

\section{References}

1 Prince M, Prina M, Guerchet M. World Alzheimer Report 2013. Journey of Caring. An analysis of long-term care for dementia. London: Alzheimer's Disease International, 2013.

2 Prince M, Wimo AG M, Ali G-C, Wu Y-T, Prina M. World Alzheimer Report 2015. The Global Impact of Dementia. An Analysis of Prevalence, Incidence, Cost and Trends. London: Alzheimer's Disease International, 2015.

3 Nakamura AE, Opaleye D, Tani G, Ferri CP. Dementia underdiagnosis in Brazil. Lancet 2015; 385: 418-9.

4 Jitapunkul S, Chansirikanjana S, Thamarpirat J. Undiagnosed dementia and value of serial cognitive impairment screening in developing countries: A population-based study. Geriatr Gerontol Int 2009; 9: 47-53.

5 Dias A, Patel V. Closing the treatment gap for dementia in India. Indian J Psychiatry 2009; 51: 93-7.

6 World Health Organization. WHO-AIMS - Mental health systems in selected low- and middle- income countries: a WHO-AIMS crossnational analysis. Geneva: World Health Organization, 2009 http:// apps.who.int/iris/bitstream/10665/44151/1/9789241547741_eng. pdf (accessed Dec 8, 2016).

7 Janca A, Aarli JA, Prilipko L, Dua T, Saxena S, Saraceno B. WHO WFN Survey of neurological services: a worldwide perspective. $J$ Neurol Sci 2006; 247: 29-34.

8 World Health Organization Department of Ageing and Life-Course and Health Workforce Department. Health Workforce for Ageing Populations. Geneva: World Health Organization, 2016 http:// www.who.int/ageing/health-systems/who-health-workforceageing-populations.pdf (accessed Dec 8, 2016).

9 Hodge S, Hailey E. Second English National Memory Clinics Audit Report. London, UK: Royal College of Psychiatrists, 2015.

10 The World Dementia Council. The World Dementia Council's YearOn Report 2014/15. 2015 https://s3-eu-west-1.amazonaws.com/ media.dh.gov.uk/network/353/files/2015/03/WDC-Annual-Report. pdf (accessed Aug 13, 2016).

11 United Nations. Report of the Second World Assembly on Ageing, Madrid 8-12 April 2002. New York: United Nations, 2002.

12 World Health Organization. World Report on Ageing and Health Geneva: World Health Organization, 2016.

13 Prince MJ, Wu F, Guo Y, et al. The burden of disease in older people and implications for health policy and practice. Lancet 2015; 385: 549-62.

14 Centre for Policy on Ageing. Ageism and age discrimination in secondary health care in the United Kingdom. A review from the literature commissioned by the Department of Health. London: Centre for Policy on Ageing, 2009.

15 Beaglehole R, Epping-Jordan J, Patel V, et al. Improving the prevention and management of chronic disease in low-income and middle-income countries: a priority for primary health care. Lancet 2008; 372: 940-9.

16 Albanese E, Liu Z, Acosta D, et al. Equity in the delivery of community healthcare to older people: findings from 10/66 Dementia Research Group cross-sectional surveys in Latin America, China, India and Nigeria. BMCHealth ServRes 2011; 11: 153.

17 Roy K, Chaudhuri A. Influence of socioeconomic status, wealth and financial empowerment on gender differences in health and healthcare utilization in later life: evidence from India. SocSciMed 2008; 66: 1951-62.

18 Dachs JN, Ferrer M, Florez CE, Barros AJ, Narvaez R, Valdivia $M$. Inequalities in health in Latin America and the Caribbean: descriptive and exploratory results for self-reported health problems and health care in twelve countries. RevPanamSalud Publica 2002; 11: 335-55.

19 Odenheimer G, Borson S, Sanders AE, et al. Quality improvement in neurology: dementia management quality measures. Neurology 2013; 81: 1545-9.

20 Banerjee S, Willis R, Matthews D, Contell F, Chan J, Murray J. Improving the quality of care for mild to moderate dementia: an evaluation of the Croydon Memory Service Model. Int $J$ GeriatrPsychiatry 2007; 22: 782-8.

21 Ramakers IH, Verhey FR. Development of memory clinics in the Netherlands: 1998 to 2009. Aging MentHealth 2011; 15: 34-9.

22 Nair G, Van Dyk K, Shah U, et al. Characterizing cognitive deficits and dementia in an aging urban population in India. Int $J$ Alzheimers Dis 2012; 2012: 673849. 
23 Shaji KS, Jotheeswaran AT, Girish N, et al. The Dementia India Report 2010 - prevalence, impact, costs and services for dementia. Alzheimer's and Related Disorders Society of India $2010 \mathrm{http}: / /$ www.alzheimer.org.in/assets/dementia.pdf (accessed Aug 14, 2016).

24 Jia J, Zuo X, Jia X-F, et al. Diagnosis and treatment of dementia in neurology outpatient departments of general hospitals in China. Alzheimers Dement J Alzheimers Assoc 2016; 12: 446-53.

25 Franz CE, Barker JC, Kim K, et al. When help becomes a hindrance: Mental health referral systems as barriers to care for primary care physicians treating patients with alzheimer's disease. Am J Geriatr Psychiatry 2010; 18: 576-85.

26 Massoud F, Lysy P, Bergman H. Care of dementia in Canada: a collaborative care approach with a central role for the primary care physician. J Nutr Health Aging 2010; 14: 105-6.

27 Lee L, Kasperski MJ, Weston WW. Building capacity for dementia car e: Training program to develop primary care memory clinics. Can Fam Physician 2011; 57: e249-52.

28 Rockwood K, Keren R. Dementia services in Canada. Int J Geriatr Psychiatry 2010; 25: 876-80.

29 Shaji KS, Smitha K, Praveen Lal K, Prince M. Caregivers Of Patients With Alzheimer's Disease : A Qualitative Study From The Indian 10/66 Dementia Research Network. Int J Geriatr Psychiatry 2002; 18: 1-6.

30 Patel V, Prince M. Ageing and mental health in a developing country: who cares? Qualitative studies from Goa, India. Psychol Med 2001; 31: 29-38.

31 Travers C, Martin-Khan M, Lie D. Barriers and enablers of health promotion, prevention and early intervention in primary care: Evidence to inform the Australian national dementia strategy. Australas J Ageing 2009; 28: 51-7.

32 Prince M, Albanese E, Guerchet M, Prina M. World Alzheimer Report 2014. Dementia and Risk Reduction. An analysis of Protective and Modifiable Risk Factors. London: Alzheimer's Disease International, 2014.

33 Borson S, Frank L, Bayley PJ, et al. Improving dementia care: the role of screening and detection of cognitive impairment. Alzheimers Dement J Alzheimers Assoc 2013; 9: 151-9.

34 Wilcock J, Iliffe S, Turner S, et al. Concordance with clinical practice guidelines for dementia in general practice. Aging MentHealth 2009; 13: 155-61.

35 Dua T, Barbui C, Clark N, et al. Evidence-based guidelines for mental, neurological, and substance use disorders in low- and middle-income countries: summary of WHO recommendations. PLoSMed 2011; 8: e1001122.

36 Prince MJ, Acosta D, Castro-Costa E, Jackson J, Shaji KS. Packages of care for dementia in low- and middle-income countries. PLoSMed 2009; 6: e1000176.

37 Fulton BD, Scheffler RM, Sparkes SP, Auh EY, Vujicic M, Soucat A. Health workforce skill mix and task shifting in low income countries: a review of recent evidence. HumResourHealth 2011; 9:1. doi: 10.1186/1478-4491-9-1.: 1-9.

38 Kredo T, Adeniyi FB, Bateganya M, Pienaar ED. Task shifting from doctors to non-doctors for initiation and maintenance of antiretroviral therapy. Cochrane Database Syst Rev 2014; : CD007331.

39 van Ginneken N, Tharyan P, Lewin S, et al. Non-specialist health worker interventions for the care of mental, neurological and substance-abuse disorders in low- and middle-income countries. Cochrane Database Syst Rev 2013; : CD009149.

40 Lund C, Tomlinson M, De SM, et al. PRIME: a programme to reduce the treatment gap for mental disorders in five low- and middle-income countries. PLoSMed 2012; 9: e1001359.

41 Gröne O, Garcia-Barbero, M. Trends in Integrated Care Reflections on Conceptual Issues. Copenhagen: World Health Organization.

42 Department of Health. Living well with dementia. A National Dementia Strategy. London, UK: Department of Health, 2009.

43 Parmar J, Dobbs B, McKay R, et al. Diagnosis and management of dementia in primary care: Exploratory study. Can Fam Physician 2014; 60: 457-65.

44 Aminzadeh F, Molnar FJ, Dalziel WB, Ayotte D. A Review of Barriers and Enablers to Diagnosis and Management of Persons with Dementia in Primary Care. Can Geriatr J 2012; 15: 85-94.

45 Lee L, Hillier LM, Stolee P, et al. Enhancing dementia care: A primary care-based memory clinic. J Am Geriatr Soc 2010; 58: 2197-204.
46 Prorok JC, Hussain M, Horgan S, Seitz DP. 'I shouldn't have had to push and fight': health care experiences of persons with dementia and their caregivers in primary care. Aging Ment Health 2016; : 1-8.

47 Manthorpe J, Samsi K, Campbell S, et al. From forgetfulness to dementia: Clinical and commissioning implications of diagnostic experiences. Br J Gen Pract 2013; 63: e69-75.

48 Bunn F, Burn AM, Goodman C, et al. Comorbidity and dementia: a scoping review of the literature. BMC Med 2014; 12. DOI:10.1186/ s12916-014-0192-4.

49 Schubert CC, Boustani M, Callahan CM, et al. Comorbidity profile of dementia patients in primary care: Are they sicker? $\mathrm{J} \mathrm{Am}$ Geriatr Soc 2006; 54: 104-9.

50 Poblador-Plou B, Calderon-Larranaga A, Marta-Moreno J, et al. Comorbidity of dementia: A cross-sectional study of primary care older patients. BMC Psychiatry 2014; 14 (1) (no pagination). DOI:http://dx.doi.org/10.1186/1471-244X-14-84.

51 Prince M, Acosta D, Ferri CP, et al. The association between common physical impairments and dementia in low and middle income countries, and, among people with dementia, their association with cognitive function and disability. A 10/66 Dementia Research Group population-based study. Int $J$ GeriatrPsychiatry 2010; published online July 29.

52 Fortin M, Bravo G, Hudon C, et al. Relationship between multimorbidity and health-related quality of life of patients in primary care. QualLife Res 2006; 15: 83-91.

53 Wolff JL, Boult C, Boyd C, Anderson G. Newly reported chronic conditions and onset of functional dependency. J AmGeriatrSoc 2005; 53: 851-5.

54 Caughey GE, Ramsay EN, Vitry Al, et al. Comorbid chronic diseases, discordant impact on mortality in older people: a 14year longitudinal population study. J Epidemio/Community Health 2010; 64: 1036-42.

55 Partnership for Solutions. Chronic Conditions: Making the Case for Ongoing Care. The Robert Wood Johnson Foundation; Johns Hopkins University, 2004.

56 Wolff JL, Starfield B, Anderson G. Prevalence, expenditures, and complications of multiple chronic conditions in the elderly. Arch Intern Med 2002; 162: 2269-76.

57 Boyd CM, Darer J, Boult C, Fried LP, Boult L, Wu AW. Clinical practice guidelines and quality of care for older patients with multiple comorbid diseases: implications for pay for performance. JAMA 2005; 294: 716-24.

58 Fortin M, Soubhi $\mathrm{H}$, Hudon C, Bayliss EA, van den AM Multimorbidity's many challenges. BMJ 2007; 334: 1016-7.

59 Abellan van KG, Rolland Y, Houles M, Gillette-Guyonnet S, Soto $M$, Vellas $B$. The assessment of frailty in older adults. ClinGeriatrMed 2010; 26: 275-86.

60 Case Management Society of America. What is a case manager? (web resource). http://www.cmsa.org/Home/CMSA/ WhatisaCaseManager/tabid/224/Default.aspx (accessed Aug 16, 2016).

61 Robinson L, lliffe S, Brayne C, et al. Primary care and dementia: 2. Long-term care at home: psychosocial interventions, information provision, carer support and case management. Int $J$ GeriatrPsychiatry 2010; 25: 657-64.

62 Khanassov V, Vedel I, Pluye P. Case management for dementia in primary health care: a systematic mixed studies review based on the diffusion of innovation model. Clin Interv Aging 2014; 9: 915-28.

63 Schrijvers G, van Hoorn A, Huiskes N. The care pathway: concepts and theories: an introduction. Int J Integr Care 2012; 12 e192.

64 Vanhaecht K. The impact of clinical pathways on the organisation of care processes. 2007. https://lirias.kuleuven. be/bitstream/123456789/252816/1/PhD+Kris+Vanhaecht.pdf (accessed Dec 8, 2016).

65 Vanhaecht K, Panella M, van Zelm R, Sermeus W. An overview on the history and concept of care pathways as complex interventions. Int J Care Pathw 2010; 14: 117-23.

66 Middleton S, Barnett J, Reeves D. What is an integrated care pathway? Bandolier 2001; 3.

67 Samsi K, Manthorpe J. Care pathways for dementia: current perspectives. Clin Interv Aging 2014; 9: 2055-63.

68 Prince M., Bryce R, Ferri C. World Alzheimer Report 2011: The benefits of early diagnosis and intervention. London: Alzheimer's Disease International, 2011. 
69 De LJ, Wind AW, lliffe S, et al. The primary care diagnosis of dementia in Europe: an analysis using multidisciplinary, multinational expert groups. Aging MentHealth 2008; 12: 568-76.

70 Lecouturier J, Bamford C, Hughes JC, et al. Appropriate disclosure of a diagnosis of dementia: identifying the key behaviours of 'best practice'. BMCHealth ServRes 2008; 8: 95.

71 Alzheimer's Scotland. 5 Pillars Model of Post-Diagnostic Support. 2013. http://www.alzscot.org/campaigning/five pillars (accessed Aug 16, 2016).

72 World Health Organization. Better Palliative Care for Older People. Geneva: World Health Organization, 2004.

73 World Health Organization. WHO definition of palliative care. Website http://www.who.int/cancer/palliative/definition/en/. Accessed August 2013. 2009.

74 Schulz R, Mendelsohn AB, Haley WE, et al. End-of-life care and the effects of bereavement on family caregivers of persons with dementia. N Engl J Med 2003; 349: 1936-42.

75 Vanhaecht K, De Witte K, Panella M, Sermeus W. Do pathways lead to better organized care processes? J Eval Clin Pract 2009; 15: 782-8.

76 Abbey J, Palk E, Carlson L, Parker D. Clinical Practice Guidelines and Care Pathways for People with Dementia Living in the Community. Brisbane, Australia: Queensland University of Technology, 2008 http://eprints.qut.edu.au/17393/1/17393.pdf (accessed Aug 14, 2016).

77 World Health Organization. WHO Mental Health Gap Action Programme (mhGAP). 2009. http://www.who.int/mental_health/ mhgap/en/ (accessed Aug 16, 2016).

78 Patel V, Thornicroft G. Packages of care for mental, neurological, and substance use disorders in low- and middle-income countries: PLoS Medicine Series. PLoSMed 2009; 6: e1000160. 


\section{CHAPTER 2}

\section{The role of primary care in the dementia healthcare system}

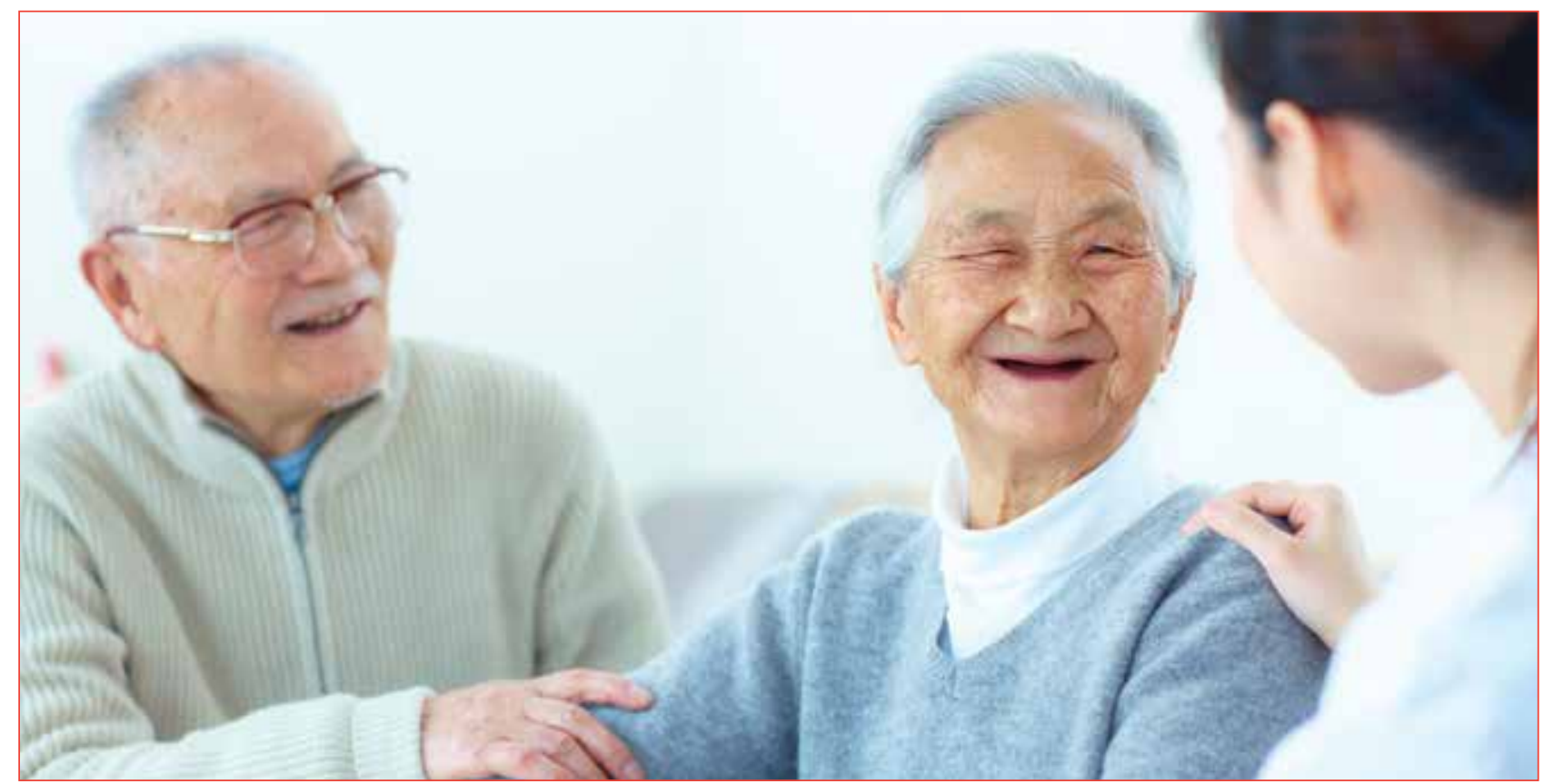

\subsection{Objectives and search strategy}

We carried out a systematic scoping review to identify research relevant to the diagnosis and management of dementia in primary care, with the additional aims of comparing the quality of care and its outcomes between primary care and specialist secondary care services, and identifying promising strategies for the enhancement of the quality and outcomes of primary healthcare. We were interested in all types of relevant research, including observational and descriptive studies, qualitative research, service descriptions, intervention development and intervention or service evaluation, whether using randomised, controlled or non-controlled designs.

We contacted a scoping review to map the existing literature, using the following search strategy.

We used the search terms "((dementia OR Alzheimer*) AND (primary care))" seeking publications since 1980. We searched Ovid Medline, PubMed, PsycINFO and Cochrane databases. Following this, we conducted a search with Google Scholar to find 'grey' literature and articles in other databases than those mentioned above (reports and policy papers). We also checked the annual World Alzheimer Reports for any relevant publications.

\section{Inclusion criteria}

- Studies conducted in primary care, or with a clear focus or relevance to primary care assessment, detection, diagnosis or management of dementia

- A clear focus on people with dementia, Alzheimer's disease, or cognitive impairment. Some publications referring to the management of frail or dependent older people were included when people with dementia or cognitive impairment were referred to specifically in stratified analyses.

- English language resources

\section{Exclusion criteria}

- A focus on older people, generically, rather than on people with dementia in primary care

\subsection{Search results, and characteristics of the eligible studies}

The search retrieved 10,454 abstracts. In the first phase we excluded 5,838 publications after review of titles and abstracts, on the basis of obvious irrelevance or duplication. The remaining 4,616 abstracts were double screened by MK and MP for relevance. After reviewing titles and abstracts, and hard copies where relevant, these were limited to 234 relevant papers.

Of these 37 (16\%) were reviews, and 10 (4\%) provided evidence-based guidance, the remaining 187 (80\%) describing primary research. Primary research studies 
were largely (79\%) carried out in five countries; the USA (60 studies, 32\%), the UK (39 studies, 21\%), Germany (21 studies, 11\%), the Netherlands (15 studies, $8 \%$ ) and Canada (13 studies, 7\%). Although 23 countries were represented, all bar six (three from Thailand, and one each from Malaysia, China and India), were conducted in high income countries. Regionally, 99 studies were conducted in Europe, 73 in North America, 16 in Asia (including 5 from Australia), and none in Latin America or Africa. Ten studies were carried out prior to 2000, 25 studies from 2000-2004, 40 studies from 2005-2009, and 112 studies from 2010 onwards.

The distribution of this literature is summarised in Table 2.1 below.

Table 2.1

Eligible studies by study design

\begin{tabular}{|l|l|l|}
\hline Type of study & $\begin{array}{l}\text { Number of } \\
\text { publications }\end{array}$ & $\begin{array}{l}\text { Percentage } \\
\text { of total }\end{array}$ \\
\hline Descriptive studies & & \\
\hline Intervention development & 2 & $1.1 \%$ \\
\hline Service description & 6 & $3.2 \%$ \\
\hline Qualitative or mixed methods & 16 & $8.5 \%$ \\
\hline Quantitative & 62 & $33.2 \%$ \\
\hline Evaluative studies & & \\
\hline Screening tool & 26 & $13.9 \%$ \\
\hline Intervention evaluation & 25 & $13.4 \%$ \\
\hline Service evaluation & 16 & $8.6 \%$ \\
\hline RCT protocol & 9 & $4.8 \%$ \\
\hline RCT & 25 & $13.4 \%$ \\
\hline Total & 181 & $100.0 \%$ \\
\hline
\end{tabular}

The quantitative descriptive studies comprised mainly studies of recognition and/or recording of diagnosis in primary care (14 studies), surveys of general practitioners or other primary care providers to assess attitudes, knowledge or practice regarding diagnosis and/or management of dementia (14 studies), aspects of the quality of care provided, and how it may be benchmarked (8 studies), prescribing patterns (six studies), and the prediction/identification of dementia cases using health information system data (three studies). Eight of the qualitative studies examined attitudes, beliefs and experiences relating to diagnosis from the service user or provider perspective, while the remainder explored different aspects of dementia care and management.

Evaluative studies were dominated by studies of the effectiveness or relative effectiveness of different screening tools for dementia applied in primary care settings. This was also the topic of seven reviews ${ }^{1-7}$. Most of the published evaluations of interventions or services (40 studies) used non-randomised designs. We identified 26 publications referring to 17 randomised controlled trials, the design features and main findings of which are summarised in Table 2.2 below. The findings of the more important trials are presented and discussed in more detail in the later sections of this chapter.

\section{Abbreviations:}

AChEls: Acetylcholinesterase Inhibitors

AD: Alzheimer's disease

ADL: Activities of Daily Living

AOR: Adjusted Odds Ratio

BPSD: Behavioural and Psychological

Symptoms of Dementia
CG: Control Group
GP: General Practitioner
HR: Hazard Ratio
IG: Intervention Group

IRR: Incidence Rate Ratio

MCI: Mild Cognitive Impairment

MMSE: Mini-Mental State Examination

MoCA: Montreal Cognitive Assessment

NH: Nursing Home

PHC: Primary Healthcare

PHP: Primary Healthcare Physician

PN: Practice Nurse

PPV: Positive Predictive Value

PWD: People With Dementia

QoL: Quality of Life

RCT: Randomised Controlled Trial

The randomised controlled trials can be divided into three broad groups, with some overlap given the complexity of some of the interventions. These trials evaluated the effectiveness of

1. practice-based educational interventions on detection, diagnosis and/or management of dementia (five trials ${ }^{8,10-13}$ ),

2. additional dedicated practitioner time, best understood as case management (but variously described as case management, collaborative care, care consultation, or comprehensive geriatric assessment and management) more or less integrated into primary care services, on service utilisation, care quality and outcomes for the person with dementia and carer (five trials ${ }^{14-20}$ ), and

3. psychosocial interventions (counselling and support), provided in the context of primary care on outcomes for the person with dementia and carer (four trials ${ }^{21-27}$ ). 
Table 2.2a

Randomised controlled trials relevant to the detection, diagnosis or management of dementia in primary care

\section{Education or training}

\begin{tabular}{|c|c|c|c|c|}
\hline Trial title & Author, Year & Intervention & Results & \\
\hline $\begin{array}{l}\text { Effectiveness } \\
\text { of education } \\
\text { interventions in } \\
\text { improving detection } \\
\text { and management of } \\
\text { dementia in primary } \\
\text { care, UK }\end{array}$ & Downs, $2006^{8}$ & $\begin{array}{l}\text { Education interventions } \\
\text { to improve detection and } \\
\text { management of dementia } \\
\text { in PHC. Electronic tutorial vs } \\
\text { decision support software } \\
\text { (DSS) vs practice-based } \\
\text { workshops (PBW) vs control }\end{array}$ & $\begin{array}{l}\text { DSS and PBW IGs both } \\
\text { showed increased rates of } \\
\text { detection compared with CG. } \\
\text { No effect of any intervention } \\
\text { on concordance with } \\
\text { guidelines }\end{array}$ & $\begin{array}{l}\text { Cluster RCT, } 36 \text { general } \\
\text { practices }\end{array}$ \\
\hline \multirow[t]{2}{*}{ IDA, Germany } & Vollmar, $2007^{9}$ & $\begin{array}{l}\text { Effectiveness of three hours } \\
\text { training in dementia diagnosis } \\
+/-2 \text { hours additional training } \\
\text { on dementia treatment/ } \\
\text { management, based on an } \\
\text { evidence-based guideline } \\
\text { on GP knowledge regarding } \\
\text { diagnosis and treatment }\end{array}$ & $\begin{array}{l}\text { There was a significant pre- } \\
\text { post increase in knowledge } \\
\text { scores, greater for those } \\
\text { receiving the augmented } \\
\text { training }\end{array}$ & $\begin{array}{l}137 \mathrm{GPs}, 90 \text { of whom } \\
\text { received the additional } \\
\text { training on dementia therapy }\end{array}$ \\
\hline & Vollmar, $2010^{10}$ & $\begin{array}{l}\text { Online blended learning with } \\
\text { quality clusters vs QCs alone } \\
\text { on knowledge gain }\end{array}$ & $\begin{array}{l}\text { Blended learning not } \\
\text { superior to QCs alone, but } \\
\text { those using online material } \\
\text { had gain in knowledge }\end{array}$ & Cluster RCT. 166 GPs. \\
\hline $\begin{array}{l}\text { General practice- } \\
\text { based intervention } \\
\text { for suspecting and } \\
\text { detecting dementia, } \\
\text { France }\end{array}$ & $\begin{array}{l}\text { Rondeau, } \\
2008^{11}\end{array}$ & $\begin{array}{l}\text { Effect of a two hour group } \\
\text { educational meeting } \\
\text { conducted by specialists } \\
\text { focussing on the use of } \\
\text { a battery of four brief } \\
\text { neuropsychological tests vs } \\
\text { 'usual practice' on suspicion } \\
\text { of dementia, and diagnostic } \\
\text { accuracy }\end{array}$ & $\begin{array}{l}\text { Suspicion of dementia higher } \\
\text { in IG ( } 36.4 \% \text { vs. } 26.8 \%, p< \\
0.0001) \text {. PPV of suspected } \\
\text { dementia was similar in IG } \\
(60.9 \%) \text { and CG }(64.4 \%) \text {. No } \\
\text { increase in overall diagnostic } \\
\text { yield following referral. }\end{array}$ & $\begin{array}{l}\text { Cluster RCT, } 684 \text { PCPs. } 353 \\
\text { IG, } 331 \text { CG All of the GPs } \\
\text { were then asked to recruit } \\
\text { the next five patients aged } \\
75 \text { or over presenting with } \\
\text { a spontaneous memory } \\
\text { complaint, or who were } \\
\text { reported to have this } \\
\text { problem by an informant. }\end{array}$ \\
\hline EVIDEM-ED & Wilcock, $2013^{12}$ & $\begin{array}{l}\text { Effect of tailored educational } \\
\text { intervention based upon } \\
\text { educational needs assessment } \\
\text { on detection and management }\end{array}$ & $\begin{array}{l}\text { No effects on documented } \\
\text { evidence-based } \\
\text { management (two or more } \\
\text { reviews - AOR } 0.94,95 \% \mathrm{Cl} \text { : } \\
0.33-2.62 \text { ) or case detection } \\
\text { rates (IRR } 1.03,95 \% \mathrm{Cl} \text { : } \\
0.57-1.86 \text { ) }\end{array}$ & $\begin{array}{l}23 \text { practices, (Cluster } \\
\text { randomised) } 1072 \text { PWD. } 12 \\
\text { months. }\end{array}$ \\
\hline $\begin{array}{l}\text { Case Finding of } \mathrm{MCl} \\
\text { and Dementia and } \\
\text { Subsequent Care, NL }\end{array}$ & $\begin{array}{l}\text { Van den } \\
\text { Dungen, } 2016^{13}\end{array}$ & $\begin{array}{l}\text { Effect of two evening } \\
\text { postgraduate training } \\
\text { sessions for PCPs on } \\
\text { detection, diagnosis and } \\
\text { early management of } \mathrm{MCl} \\
\text { and dementia. IG received } \\
\text { additional screening and } \\
\text { referral by PNs in Phase } 2 \text {. } \\
\text { Phase } 2 \text { outcomes were } \\
\text { mental health effects of case } \\
\text { finding and subsequent care. }\end{array}$ & $\begin{array}{l}\text { Non-significant increase in } \\
\text { detection of dementia or } \\
\mathrm{MCl} \text { (RR } 1.51,95 \% \mathrm{Cl} \text { : } 0.60 \text { - } \\
3.76) \text {. Increased detection } \\
\text { apparent for } \mathrm{MCl} \text { (RR } 1.61 \text {, } \\
95 \% \mathrm{Cl}: 1.21-2.13 \text { ), but not } \\
\text { dementia (RR 1.04, } 95 \% \\
\mathrm{Cl} \text { : } 0.68-1.57) \text {. Differences } \\
\text { in mental health outcomes } \\
\text { following additional Phase } 2 \\
\text { screening and care, but only } \\
32 \% \text { of patients participated } \\
\text { in this phase. }\end{array}$ & $\begin{array}{l}\text { Cluster RCT. } 15 \text { PHCs. 7PHCs } \\
\text { and } 326 \text { patients IG, } 8 \text { PHCs } \\
321 \text { patients CG. } 12 \text { months } \\
\text { endpoint for detection. }\end{array}$ \\
\hline
\end{tabular}


Table 2.2b

Randomised controlled trials relevant to the detection, diagnosis or management of dementia in primary care

\section{Case management}

\begin{tabular}{|c|c|c|c|c|}
\hline Trial title & Author, Year & Intervention & Results & \\
\hline $\begin{array}{l}\text { Cleveland } \\
\text { Alzheimer's } \\
\text { Managed Care } \\
\text { Intervention, USA }\end{array}$ & Bass, $2003^{14}$ & $\begin{array}{l}\text { Effect of Alzheimer's } \\
\text { Association care consultation } \\
\text { linked to managed care health } \\
\text { services on service utilisation, } \\
\text { satisfaction with managed } \\
\text { care, carer depression and } \\
\text { strain }\end{array}$ & $\begin{array}{l}\text { IG had fewer Kaiser Permanente } \\
\text { case management consultations. No } \\
\text { effect on physician visits, ED visits, or } \\
\text { hospitalisation } \\
\text { IG had higher satisfaction with quality } \\
\text { of health plan services, type of services, } \\
\text { and information received - particularly } \\
\text { those who had not received a dementia } \\
\text { diagnosis } \\
\text { IG carers had greater reduction in } \\
\text { depression, and non-spouse carers had } \\
\text { greater reduction in strain }\end{array}$ & $\begin{array}{l}157 \text { PWD and their } \\
\text { primary family } \\
\text { carers, } 12 \text { months } \\
\text { endpoint }\end{array}$ \\
\hline $\begin{array}{l}\text { Dementia In } \\
\text { Primary Care, USA }\end{array}$ & $\begin{array}{l}\text { Callahan, } \\
2006^{15}\end{array}$ & $\begin{array}{l}\text { Collaborative care. Advanced } \\
\text { practice nurse integrated in } \\
\text { PHC vs enhanced usual care }\end{array}$ & $\begin{array}{l}\text { Lower BPSD in IG. Lower carer strain. No } \\
\text { effect on carer depression. More AChEls } \\
\text { and antidepressants prescribed to IG. No } \\
\text { effect of intervention on PWD cognition, } \\
\text { depression, ADL, hospitalisation, NH } \\
\text { placement, or death }\end{array}$ & $\begin{array}{l}153 \text { older adults with } \\
\text { AD. } 12 \text { and } 18 \text { month } \\
\text { endpoints }\end{array}$ \\
\hline \multirow[t]{3}{*}{ ACCESS-Trial, USA } & $\begin{array}{l}\text { Vickrey, } \\
2006^{16}\end{array}$ & $\begin{array}{l}\text { Effect of disease-based } \\
\text { management program by } \\
\text { case managers on quality } \\
\text { of care and outcomes. Case } \\
\text { management vs usual care }\end{array}$ & $\begin{array}{l}\% \text { of guideline recommendations. met } \\
\text { was higher for IG, with higher care quality } \\
\text { on } 21 / 23 \text { guidelines . Higher proportion of } \\
\text { IG received assistance from community } \\
\text { agencies. PWD QoL, caregiving quality, } \\
\text { and social support were higher for IG, and } \\
\text { unmet caregiving assistance needs lower. } \\
\text { No effect on carer QoL. }\end{array}$ & $\begin{array}{l}\text { Cluster RCT. } 18 \\
\text { PHCs and } 408 \text { PWD } \\
\text { and their carers. } 12 \\
\text { month endpoint }\end{array}$ \\
\hline & $\begin{array}{l}\text { Chodosh, } \\
2006^{17}\end{array}$ & $\begin{array}{l}\text { Effect of a comprehensive } \\
\text { dementia care management } \\
\text { model on PCPs knowledge, } \\
\text { attitudes about dementia, } \\
\text { and perception of quality of } \\
\text { dementia care }\end{array}$ & $\begin{array}{l}\text { IG PCPs had better knowledge about } \\
\text { assessing decision-making capacity than } \\
\text { CG PCPs. IG PCPs viewed PWD as more } \\
\text { difficult to manage in primary care than } \\
\text { CG PCPs. There were no other differences } \\
\text { in knowledge, attitudes, or care quality } \\
\text { perceptions. }\end{array}$ & $\begin{array}{l}232 \text { PCPs, } 129 \text { from } \\
9 \text { IG clinics; } 103 \text { from } \\
9 \text { CG clinics. } 9 \text { month } \\
\text { endpoint }\end{array}$ \\
\hline & $\begin{array}{l}\text { Chodosh, } \\
2012^{18}\end{array}$ & $\begin{array}{l}\text { Secondary analysis of IG to } \\
\text { determine factors associated } \\
\text { with improved care quality }\end{array}$ & $\begin{array}{l}\text { Case management uptake was } \\
\text { associated with higher care quality. } \\
\text { Additional coordinated interactions with } \\
\text { PHC and community agency staff yielded } \\
\text { even higher quality }\end{array}$ & \\
\hline $\begin{array}{l}\text { Dutch EASYcare } \\
\text { study, NL }\end{array}$ & Perry, $2008^{19}$ & $\begin{array}{l}\text { Effect of home-based } \\
\text { comprehensive geriatric } \\
\text { assessment (CGA) and } \\
\text { management on dementia } \\
\text { diagnosis }\end{array}$ & $\begin{array}{l}\text { Secondary analysis. Increased rate of } \\
\text { new detections in intervention arm 19/66 } \\
\text { vs } 4 / 47 \text { (RR } 3.38,95 \% \text { Cl: } 1.23-9.30 \text { ) }\end{array}$ & $\begin{array}{l}151 \text { vulnerable older } \\
\text { adults. } 6 \text { months } \\
\text { follow up }\end{array}$ \\
\hline $\begin{array}{l}\text { Alzheimer's } \\
\text { Association } \\
\text { Collaborative Care, } \\
\text { USA }\end{array}$ & $\begin{array}{l}\text { Fortinsky, } \\
2009^{20}\end{array}$ & $\begin{array}{l}\text { Effect of 'dementia care } \\
\text { consultants' provided by } \\
\text { local Alzheimer's Association } \\
\text { chapters on nursing home } \\
\text { placement, and carer } \\
\text { outcomes }\end{array}$ & $\begin{array}{l}\text { Less likely to have NH placement (AOR } \\
0.40,95 \% \mathrm{Cl}: 0.14-1.18) \text {. No effect on } \\
\text { carer self-efficacy, carer depression or } \\
\text { strain }\end{array}$ & $\begin{array}{l}84 \text { family carers. } \\
\text { Cluster RCT. } \\
12 \text { months. } \\
\text { Implementation } \\
\text { problems - high } \\
\text { turnover, and care } \\
\text { plans not discussed } \\
\text { with physicians }\end{array}$ \\
\hline
\end{tabular}


Table 2.2c

Randomised controlled trials relevant to the detection, diagnosis or management of dementia in primary care

\begin{tabular}{|c|c|c|c|c|}
\hline Trial title & Author, Year & Intervention & Results & \\
\hline REACH, USA & Burns, $2003^{21}$ & $\begin{array}{l}\text { Effect of patient behaviour } \\
\text { management only vs patient } \\
\text { behaviour management } \\
\text { plus caregiver stress-coping } \\
\text { management on caregiver outcomes }\end{array}$ & $\begin{array}{l}\text { Caregivers who received the } \\
\text { patient behaviour management } \\
\text { component only had significantly } \\
\text { worse outcomes for general } \\
\text { well-being and a trend toward } \\
\text { increased risk of depression. Both } \\
\text { arms showed reduced impact } \\
\text { from care recipient behaviours }\end{array}$ & $\begin{array}{l}\text { RCT. } 167 \text { caregiver/ } \\
\text { care recipient dyads. } \\
24 \text { months }\end{array}$ \\
\hline \multirow[t]{2}{*}{ IDA, Germany } & Donath, $2010^{22}$ & $\begin{array}{l}\text { Training of GPs and } \\
\text { recommendation of carer } \\
\text { counselling and support groups. } 3 \\
\text { arms, A. diagnostic training only, B } \\
\text { and C. Diagnostic and treatment/ } \\
\text { management training with } \\
\text { instruction to refer to carer support } \\
\text { groups and counselling immediately } \\
\text { or after } 1 \text { year. Effectiveness on } \\
\text { care process variables (adherence } \\
\text { to treatment guidelines, and carer } \\
\text { access to counselling and support). }\end{array}$ & $\begin{array}{l}\text { High adherence to diagnostic } \\
\text { and therapeutic guidelines in all } \\
\text { three intervention arms. } 4-5 \text { fold } \\
\text { higher access to support groups } \\
\text { and counselling in groups B and } \\
\text { C. Low use of other community } \\
\text { support services with no between } \\
\text { group differences }\end{array}$ & $\begin{array}{l}\text { Cluster RCT. } 129 \text { GPs } \\
\text { and } 390 \text { PWD. } 2 \text { year } \\
\text { endpoint }\end{array}$ \\
\hline & Menn, $2012^{23}$ & $\begin{array}{l}\text { Effectiveness on nursing home } \\
\text { placement, and outcomes for the } \\
\text { carer and person with dementia }\end{array}$ & $\begin{array}{l}\text { No difference in nursing home } \\
\text { placement, mortality, cognition, } \\
\text { ADL, carer burden, or HRQOL. } \\
\text { Service use and costs similar } \\
\text { between all three groups }\end{array}$ & $\begin{array}{l}\text { As above, two year } \\
\text { endpoint for nursing } \\
\text { home placement, and } \\
\text { four year endpoint } \\
\text { for cost and other } \\
\text { outcomes }\end{array}$ \\
\hline \multirow[t]{3}{*}{ DAISY, Denmark } & Waldorff, $2012^{24}$ & $\begin{array}{l}\text { Effect of early psychosocial } \\
\text { counselling and support provided } \\
\text { to people with very mild dementia } \\
\text { in the post-diagnostic period on } \\
\text { person with dementia cognition, } \\
\text { depression and QoL, and carer } \\
\text { depression and QoL. Control support } \\
\text { or support + DAISY intervention } \\
\text { (multi-faceted and semi-tailored } \\
\text { counselling education and support) }\end{array}$ & $\begin{array}{l}\text { No differences on any primary or } \\
\text { secondary outcomes }\end{array}$ & $\begin{array}{l}330 \text { PWD and their } \\
\text { main caregivers. } 12 \\
\text { month endpoint }\end{array}$ \\
\hline & Phung, $2013^{25}$ & As above & $\begin{array}{l}\text { No differences on any primary or } \\
\text { secondary outcomes }\end{array}$ & $\begin{array}{l}\text { As above. } 36 \text { month } \\
\text { endpoint }\end{array}$ \\
\hline & Sogaard, $2014^{26}$ & $\begin{array}{l}\text { Early psychosocial intervention } \\
\text { (psychosocial counselling and } \\
\text { support) on costs from a societal } \\
\text { perspective }\end{array}$ & $\begin{array}{l}\text { Not cost-effective. None of the } \\
\text { cost or QOL outcomes differed } \\
\text { between the two arms. }\end{array}$ & $\begin{array}{l}\text { As above. } 36 \text { month } \\
\text { endpoint. }\end{array}$ \\
\hline $\begin{array}{l}\text { Effects of a } \\
\text { psychological } \\
\text { intervention in a } \\
\text { primary health } \\
\text { care center } \\
\text { for caregivers } \\
\text { of dependent } \\
\text { relatives, Spain }\end{array}$ & $\begin{array}{l}\text { Rodriguez- } \\
\text { Sanchez, } 2013^{27}\end{array}$ & $\begin{array}{l}\text { Effect of group cognitive behavioural } \\
\text { therapy (CBT), administered in PHC } \\
\text { by a psychologist with PCP or PN } \\
\text { co-therapists vs treatment as usual } \\
\text { on caregiver mood, dysfunctional } \\
\text { thoughts, quality of life and strain }\end{array}$ & $\begin{array}{l}\text { IG had lower psychological } \\
\text { morbidity and dysfunctional } \\
\text { thoughts. No significant between } \\
\text { group differences in caregiver } \\
\text { strain or quality of life }\end{array}$ & $\begin{array}{l}\text { RCT. } 125 \text { caregivers } \\
\text { (83 randomised to IG, } \\
42 \text { to } \text { CG). } 9 \text { - } 11 \text { week } \\
\text { endpoint }\end{array}$ \\
\hline
\end{tabular}


Table 2.2d

Randomised controlled trials relevant to the detection, diagnosis or management of dementia in primary care Task-shifting (non-specialist vs specialist care)

\begin{tabular}{|c|c|c|c|c|}
\hline Trial title & Author, Year & Intervention & Results & \\
\hline \multirow[t]{3}{*}{ AD-Euro, NL } & $\begin{array}{l}\text { Meeuwsen, } \\
2012^{28}\end{array}$ & $\begin{array}{l}\text { Usual care provided by } \\
\text { multidisciplinary memory } \\
\text { clinic or PHC GP. Effect on } \\
\text { carer QoL and caregiver } \\
\text { sense of competence }\end{array}$ & $\begin{array}{l}\text { QoL was non-significantly higher } \\
\text { and burden non-significantly } \\
\text { lower in memory clinic }\end{array}$ & $\begin{array}{l}175 \text { patients with } \\
\text { a new diagnosis } \\
\text { of mild/moderate } \\
\text { dementia living } \\
\text { in community. } 12 \\
\text { months endpoint. }\end{array}$ \\
\hline & $\begin{array}{l}\text { Meeuwsen, } \\
2013^{29}\end{array}$ & $\begin{array}{l}\text { Comparing cost } \\
\text { effectiveness }\end{array}$ & $\begin{array}{l}\text { Costs were non-significantly } \\
\text { cheaper, and quality of life } \\
\text { years lost marginally greater } \\
\text { in the memory clinic arm. No } \\
\text { evidence was found that memory } \\
\text { clinics were more cost-effective } \\
\text { compared to general practitioners } \\
\text { with regard to post-diagnosis } \\
\text { treatment and coordination of } \\
\text { care of patients with dementia in } \\
\text { the first year after diagnosis. }\end{array}$ & As above \\
\hline & $\begin{array}{l}\text { Meeuwsen, } \\
2014^{30}\end{array}$ & $\begin{array}{l}\text { Comparing content of } \\
\text { dementia care }\end{array}$ & $\begin{array}{l}\text { PWD attending memory clinics } \\
\text { were more likely to be prescribed } \\
\text { cognitive enhancer medication, } \\
\text { more likely to receive information } \\
\text { about their condition, and more } \\
\text { likely to be advised to attend } \\
\text { Alzheimer cafes }\end{array}$ & As above \\
\hline \multicolumn{5}{|l|}{ Other interventions } \\
\hline Trial title & Author, Year & Intervention & Results & \\
\hline $\begin{array}{l}\text { Video decision support } \\
\text { tool for advance care } \\
\text { planning in dementia, USA }\end{array}$ & Volandes, $2009^{31}$ & $\begin{array}{l}\text { Effect of video decision } \\
\text { support tool vs. narrative } \\
\text { alone on advanced care } \\
\text { planning of older people } \\
\text { in the event of developing } \\
\text { severe dementia }\end{array}$ & $\begin{array}{l}\text { IG more likely to opt for palliative } \\
\text { care ( } 86 \% \text { vs } 64 \%) \text { and less likely } \\
\text { to opt for life prolonging care } \\
\text { ( } 4 \% \text { vs } 14 \%)(A O R \text { for palliative } \\
\text { care } 3.9,95 \% \mathrm{Cl}: 1.8-8.6) \text {. IG } \\
\text { were more likely to maintain their } \\
\text { preferences when reinterviewed } \\
\text { six weeks later }\end{array}$ & $\begin{array}{l}200 \text { older } \\
\text { people with PHC } \\
\text { appointments at } \\
4 \text { PHC. Pre-and } \\
\text { post-intervention, } \\
\text { with further } 6 \text { week } \\
\text { reassessment of } \\
\text { preferences }\end{array}$ \\
\hline $\begin{array}{l}\text { Comparing the mini } \\
\text { mental state examination } \\
\text { and the Montreal } \\
\text { cognitive assessment } \\
\text { to screen for cognitive } \\
\text { impairment in older } \\
\text { patients at cardiovascular } \\
\text { risk, France }\end{array}$ & Golstein, $2015^{32}$ & $\begin{array}{l}\text { Effectiveness of MMSE } \\
\text { vs MoCA in detecting } \\
\text { cognitive impairment in } \\
\text { older outpatients with high } \\
\text { cardiovascular risk }\end{array}$ & $\begin{array}{l}\text { Compared with physician } \\
\text { judgement, MMSE detected } \\
\text { cognitive impairment with } 97 \% \\
\text { sensitivity and } 9 \% \text { sensitivity and } \\
\text { MoCA } 94 \% \text { specificity and } 9 \% \\
\text { sensitivity }\end{array}$ & $\begin{array}{l}111 \text { patients aged } \\
65 \text { and over at high } \\
\text { cardiovascular risk } \\
\text { and prescribed } \\
\text { cardiovascular } \\
\text { prevention in } \\
\text { primary care }\end{array}$ \\
\hline preDIVA, NL & $\begin{array}{l}\text { Van Charante, } \\
2016^{33}\end{array}$ & $\begin{array}{l}\text { Effects of practice-based } \\
\text { nurse led cardiovascular } \\
\text { intervention on the } \\
\text { incidence of dementia, and } \\
\text { disability score }\end{array}$ & $\begin{array}{l}\text { No effect on the incidence of } \\
\text { dementia (HR } 0.92,95 \% \mathrm{Cl} \text { : } \\
0.71-1.19 \text { ) or disability scores. } \\
\text { Neither was there any effect } \\
\text { of the intervention on incident } \\
\text { cardiovascular disease (HR } 95 \% \\
\text { Cl: } 1.06,0.86-1.31 \text { ) }\end{array}$ & $\begin{array}{l}\text { Cluster RCT. } 116 \\
\text { general practices } \\
\text { with } 3526 \\
\text { participants aged } \\
70-78 \text { years }\end{array}$ \\
\hline
\end{tabular}




\subsection{Framework for presentation of research findings on the role of primary care in dementia healthcare}

To present the key findings of this large and complex literature in the most informative way, we have divided the healthcare provided for people with dementia and their carers into three phases:

\section{Detection and diagnosis}

2. Early post-diagnostic care and support

3. Continuing care

For each phase we describe studies that

a) assess the quality of care provided by non-specialist health workers in primary care services, and its outcomes. These are mainly cross-sectional quantitative descriptive studies.

b) compare the quality of care delivered by nonspecialists in primary care, and its outcomes, with that provided by specialists in secondary or tertiary care. These are mainly non-randomised quantitative comparisons of patient groups first diagnosed, and/ or managed by PCPs versus specialist clinicians (geriatricians, psychiatrist or neurologists). We only identified one randomised controlled trial in this category.

c) describe, and/or evaluate the effectiveness of system or service level innovations designed to enhance the quality of healthcare provided for people with dementia in primary care. These comprised randomised controlled trials, controlled trials, pre- and post-implementation evaluations, and service descriptions.

\subsection{Detection and diagnosis}

\section{Studies of the quality of dementia diagnosis processes and outcomes in primary care}

Recognition of dementia in primary care has been confirmed to be low in many studies conducted in high income countries. The typical design of such studies is that older patients seen in primary care are given a research diagnostic assessment, and this is then compared with the PCPs contemporaneous clinical judgment, and/or recording of information suggesting a clinical diagnosis in primary care medical records. In a systematic review of 15 such studies conducted mainly in Europe and North America, the pooled proportion of dementia cases identified by PCPs was $73.4 \%(95 \% \mathrm{Cl}: 62.6-82.9 \%)^{34}$. Moderate to severe dementia (81.2\%) was more likely to have been detected than mild dementia (45.1\%). Diagnoses were even less likely to have been recorded in the patient notes (37.9\%, 95\% Cl: $26.8-49.6 \%)$. It should be noted (despite the title of the review) that these were not studies of diagnostic accuracy per se, since there was no requirement that the GP should have carried out a formal diagnostic assessment. Indeed, the lack of such an assessment may be one explanation for modest recognition rates. Another limitation that is rarely discussed in these studies relates to the concept of an external 'gold standard' - even specialists working in memory clinics sometimes show surprisingly low levels of diagnostic agreement with each other ${ }^{35}$. Some of the cases identified by the research diagnostic assessment may not have been considered by the PCPs to have warranted a 'timely' diagnosis. These were also studies of 'unassisted' PCP diagnosis, meaning that no structured diagnostic program was in place, and no training was offered. Findings of these studies therefore reflect a likely ceiling on levels of recognition with routine, unmodified primary care for older persons.

Cognitive testing may play an important part in refining the accuracy of GP assessments. In a survey conducted of GP referrals to a UK specialist memory service, in only $20 \%$ was there evidence of cognitive testing having been performed at primary care prior to referral ${ }^{36}$. Overall $37 \%$ of PCP referrals were diagnosed with dementia, but this was $56 \%$ for those that had been cognitively tested by the PCP and $32 \%$ for those that had not. A further audit from the same specialist memory service studied the impact of National Institute for Health and Clinical Excellence/Social Care Institute for Excellence (NICE/SCIE) guidelines (2006) and the National Dementia Strategy (2009) on PCP referral behaviour ${ }^{37}$. While over the two year period from 2008 to 2010 PCP referrals had increased, the proportion diagnosed with dementia fell, and there was no increase in the use of cognitive testing.

\section{Studies comparing the quality and outcomes of non-specialist and specialist dementia diagnosis}

Two non-randomised studies compared aspects of the quality of the diagnostic process and/or its outcomes for groups of people first diagnosed by non-specialist primary care doctors, compared to those managed by specialist geriatricians, neurologists and psychiatrists. These indicate some potential concerns regarding diagnostic process in primary care. The largest of these was a secondary analysis of US Medicare data using a $5 \%$ random sample of patients with two or more claims for Alzheimer's disease and a diagnosis of cognitive decline in the previous three years made either by specialists (neurologist, psychiatrist, or geriatrician $-n=2593$ ) or non-specialists $(n=$ $13,961)^{38}$. Patients first diagnosed with cognitive decline by specialists had a significantly shorter time to Alzheimer's diagnosis, after matching for age, gender, comorbidity and baseline service costs (mean: 3.5 versus 4.6 months, $p<0.0001$ ). All cause medical care costs peaked in the year after diagnosis, and in the year before death. After matching, patients diagnosed 
by specialists had significantly lower average total allcause medical costs in the first 12 months after their cognitive decline diagnosis $(\$ 19,824$ versus $\$ 25,863, p$ $<0.0001)$.

The quality of the dementia diagnostic process for those managed by non-specialist services is also called into question by a study of the use of a nonspecific 'dementia not otherwise specified' (DNOS) diagnostic category in the New England Veterans Affairs Health Care System ${ }^{39}$. Aside from valid uncertainty, this coding may reflect an inadequate assessment, with adverse consequences for access to dementia subtype-specific treatment and advice. The DNOS coding was applied as a final diagnosis by $41 \%$ of primary care physicians versus $27 \%$ of neurologists. Conversely, $30 \%$ who saw a non-specialist first, $48 \%$ who saw a psychiatrist first, and $63 \%$ who saw a neurologist first were given a diagnosis of Alzheimer's disease. When 100 randomly selected DNOS case records were examined in detail, the initial diagnosis was made by a non-specialist in $74 \%$, and of these cases cognitive testing was carried out in only $12 \%$ of first visits and $2 \%$ of follow-ups. While, overall, it was adjudged that subtype-specific diagnoses could have been provided for $48 \%$ of DNOS diagnoses, this was the case for only $7 \%$ at initial non-specialist assessment, due to inadequate information in the case record.

\section{Studies evaluating the effectiveness of system or service level innovations to enhance the quality of dementia detection and diagnosis in primary care, and its outcomes}

\section{Screening}

The use of routine screening in primary care, to boost detection, remains highly controversial $4,40,41$. Several brief cognitive tests have been proposed as feasible for use in primary care, with reasonable evidence for their validity ${ }^{4-7}$. However, there are concerns regarding their suitability for use in LMIC, where low education and illiteracy may be obstacles to successful administration ${ }^{42,43}$. In 2013 , the US Preventive Services Task Force updated its previous 2003 guidance on screening for cognitive impairment in older adults, based upon an extensive and fully systematic evidence review ${ }^{4}$. Screening programmes must be shown to deliver net benefit for those screened; however, the Task Force found no studies that directly addressed the possible adverse psychological effects of screening (as opposed to attitudes towards screening), or adverse effects from false-positive or false-negative testing. Screening programmes should also demonstrate beneficial impact on clinical decision-making and behaviour; however, the Task Force also identified no trials that examined the direct effect of screening on patient, caregiver, and clinician decision-making outcomes. (There is, however, some evidence that PCPs are much less likely to act upon screening evidence of cognitive impairment, compared with other impairments such as falls risk, hearing, urinary incontinence and low $\operatorname{mood}^{44}$.) The current recommendation therefore is against routine screening on the grounds that the benefits of earlier diagnosis may be modest, that there has been no adequate or systematic study of the possible harms associated with screening and diagnosis, and that the cost-effectiveness of the process has not been established. The last two of these concerns are well-founded, based on absence of evidence. The first is more contested. The Task Force took the view that while AChEls, memantine, complex caregiver interventions, and cognitive stimulation all have evidence to support their use in mild to moderate dementia, the clinical importance of their benefit is unclear. Alongside the clinical benefits from early intervention, a wider perspective of the benefits of earlier diagnosis should also take into account the right to a diagnosis, the potential for advanced care and financial planning while the person with dementia still has capacity to decide these matters, the opportunity to optimise medical care including attention to physical comorbidities, better knowledge of available services, and the more timely delivery of additional support and care when the need should arise $\mathrm{A1,42}^{4}$

Two published audits of the results of screening programs illustrate some of the problems with efficiency and cost-effectiveness. In the USA, patients attending routine primary care through Veterans Affairs (VA) services were offered screening using the Mini-Cog $45.97 \%$ agreed to be screened, and $26 \%$ were screen positive. Of these, only $28 \%$ agreed to further detailed evaluation. A high proportion of these were then diagnosed with dementia $(75 \%)$ or cognitive impairment (19\%). From 8,342 veterans offered the screening, 432 new cases of dementia (5\%) were identified. In the UK, a different approach was used in a case-finding program introduced in 33 primary healthcare centres in Surrey Downs. Registered patients were invited specifically for screening on the basis of elevated risk defined as age over 65 , with a diagnosis of diabetes, hypertension, heart disease, Parkinson's disease, stroke or TIA ${ }^{46}$. Screening was carried out using the Mini-Cog and a functional assessment questionnaire, with abnormal scores on both being considered positive screening outcomes. $12 \%$ of the practice population were identified as at risk, and sent invitation letters. Of these, only $30 \%$ attended the screening, among whom $18 \%$ were screen positive. These were reviewed by GPs who concluded that $57 \%$ were suitable for referral to memory clinic services for a diagnostic assessment. $80 \%$ accepted this assessment. Again the overwhelming majority were diagnosed with either dementia (62\%) or MCI (33\%). From the 6657 
registered patients, 101 new cases of dementia were identified (1.5\%).

In both studies, the screening process was deemed acceptable to patients who participated, with no obvious evidence of harms, although these were not systematically ascertained ${ }^{45,46}$. Of note, in the USA VA program, 118 veterans who passed the screening examination still requested a further evaluation, and of these $70 \%$ were diagnosed with dementia and $18 \%$ with cognitive impairment ${ }^{45}$. The screening process was considered to be worthwhile by primary care staff, and to be feasible with little additional workload; however, additional resources were provided for the screening ${ }^{45,46}$. Results of the two audits suggest that, while routine screening of attendees at primary care has a much higher uptake than a targeted invitation to screening of registered patients, those who respond with interest to an invitation are more likely to take up an offer of more detailed assessment, if screen positive. In both examples, though, there was considerable attrition through the various stages, and the clinical status of those who declined screening or diagnostic assessment is unknown ${ }^{45,46}$. The positive predictive value for the group finally attending diagnostic evaluation is very high. However, the additional yield may be modest; in the UK Surrey Downs example it was estimated that the additional 101 cases identified increased the proportion of dementia cases diagnosed in the district from 49 to $52 \%$, with an incremental cost per patient diagnosed of $£ 2,465$ (US $\$ 3,211$ ) per case ${ }^{46}$. Set against this, both audits reported a substantial 'ripple effect' with a large increase in referrals to dementia diagnostic services by primary care practitioners, outside of the screening program $^{45,46}$.

There are relatively few empirical studies of the predictors of refusal of cognitive screening. In one US study ${ }^{47}, 554$ participants of whom $10.3 \%$ refused screening, had previously been administered the Perceptions Regarding Investigational Screening for Memory in Primary Care Questionnaire (PRISM$\mathrm{PC})$. Older age, scepticism regarding the benefits of dementia screening, scepticism regarding the benefits of other forms of screening (colon cancer and depression), and belief that there were no effective treatments for Alzheimer's disease were associated with refusal. There was no association with PRISM$\mathrm{PC}$ scores on concerns regarding stigma, loss of independence, or suffering arising from dementia screening and its results.

There is currently interest in the feasibility of using routine health information and demographic data to stratify primary care patient populations according to their risk for dementia, such that costly screening activities can be targeted more appropriately. Only one of the several studies that we identified used a robust screening efficiency analysis ${ }^{48}$. In 377 UK general practices with 930,395 patients aged 60-95 years without a recording of dementia, cognitive impairment or memory symptoms at baseline, risk algorithms were developed to predict the incidence of dementia over 5 years for two age groups (60-79 and 80-95 years). The model was then validated on a separate cohort of 264,224 patients from practices that did not contribute to the development cohort. Potential predictors included sociodemographic, cardiovascular, lifestyle and mental health variables. Discrimination was good for those aged 60-79; predictors included age, sex, social deprivation, smoking, BMI, heavy alcohol use, anti-hypertensive drugs, diabetes, stroke/TIA, atrial fibrillation, aspirin use, and depression. The algorithm had a high negative predictive value, but lower positive predictive value, hence would be mostly applicable for 'ruling out' those at very low risk from further testing or intensive preventative activities at most risk thresholds. Discrimination was poor for the 80-95 years model.

The conclusions of the US Task Force seem reasonable. Routine screening should not be carried out, other than for the purpose of carefully controlled and informative research. Definitive evidence, sufficient to influence policy and practice will come from welldesigned randomised controlled trials. In this respect, we identified one relevant protocol for a randomised controlled trial. The objective of the $\mathrm{CHOICE}$ trial is to determine the cost-effectiveness of dementia screening in primary care and its impacts on mental health and quality of life ${ }^{49} .4,000$ people aged 65 and over will be randomised to receive telephone cognitive screening (with referral to a memory clinic for diagnostic assessment, as indicated), or no screening, and followed up over 12 months.

\section{Education and training}

All but two of the five trials of educational interventions had already been included in a systematic review from $2011^{50}$, and were discussed in the World Alzheimer Report 2011 that focused on the case for earlier diagnosis $^{42}$. The main conclusion of these reviews was that educational and training interventions targeting primary care practitioners may have a modest impact on detection 8,11 , particularly when they include an active and continuing practice-based component (e.g. practice-based workshops or decision support tools - see Box 2.1 for an example) as opposed to standard continuing medical education. This conclusion is to some extent contradicted by the null results of the more recently published large cluster randomised controlled trial of the flexible and multi-faceted EVIDEM-ED intervention in the UK ${ }^{12}$. Another recent cluster randomised controlled trial of a continuing medical education intervention in the Netherlands failed to show any significant impact on diagnosis rates for $\mathrm{MCl}$ and dementia overall, with the trend towards improvement accounted for by increased diagnosis of $\mathrm{MCl}$ rather than dementia ${ }^{13}$. 
Further developments to enhance recognition and diagnosis of dementia in primary care need to be based upon a clear understanding of underlying barriers, which are complex and multifactorial. We identified two recent systematic reviews on this topic ${ }^{52,53}$. Both reviews highlighted the importance of patient factors, PCP factors and system

\section{Box 2.1}

\section{An example of active and continuing practice based development. The Canadian Mild Dementia Knowledge Transfer Toolkit}

In Canada, a Mild Dementia Knowledge Transfer Toolkit has been developed to improve PCPs' knowledge and skills in the assessment, diagnosis and initial management of mild dementia ${ }^{51}$. The toolkit includes assessment tools, a data gathering form, and relevant Canadian Dementia Guidelines. The toolkit is introduced by memory clinic specialists in the primary care centres. PCPs are then encouraged to put it into use. A memory clinic assistant demonstrated use of the toolkit on the first patients. Later assessments were conducted jointly and then independently by the non-specialists. Assessments, diagnoses and management plans were then reviewed with the specialists. This performance-orientated, context-relevant aspect of the learning experience was highly rated by participants.

characteristics, alongside the intrinsically complex biomedical, psychosocial, and ethical nature of the condition $^{52,53}$. Key themes, common to both reviews included a lack of PCP confidence in their ability to diagnose and manage the condition (see also Box 2.2), time constraints, discomfort with disclosing the diagnosis, concerns regarding stigma and other potential adverse effects of a diagnosis, therapeutic nihilism, lack of post-diagnostic support systems for the person with dementia and/or carer, and lack of support for the PCP in managing the condition (see Table 2.2a).

The first conclusion of the reviews was that education and training needed to focus more on PCP perceptions and attitudes that impact directly on their motivation to make a diagnosis, given that technical abilities may not be the critical limiting issue: "it is easy to imagine how uncertainty amongst clinicians who do not deal with it regularly might arise. This, dovetailed with the inherent stigma and apprehension about making a wrong diagnosis and disclosing the diagnosis with aptitude and empathy, seems to be the font of insecurities that make PCPs reluctant or unable at times to recognise dementia earlier. So, rather than simply augmenting clinical knowledge, educational interventions should ideally be more attitudinal, focusing on enhancing PCPs' perceptions of their suitability and ability to make the diagnosis, and the value of doing so in a timely manner".52

Second, there was a concern that most efforts to improve recognition in primary care have been isolated, and limited in scope, duration and intensity ${ }^{53}$. Oneoff educational and training efforts are unlikely to be impactful, and because, on average, each PCP will encounter only a small number of patients with recent onset and undiagnosed dementia each year, 'learning from experience' cannot be relied upon ${ }^{52}$. Interventions tend to target only a subset of barriers, and often with only modest intensity and very limited coordination. System barriers were alluded to commonly by PCPs in studies in varied European as well as North American health systems ${ }^{52,53}$. While some of these arose within

Box 2.2

\section{Californian primary care practitioners attitude to diagnosing and managing dementia, compared with other chronic conditions}

In three California healthcare organisations, 164 PCPs' views about primary care for dementia were analysed and compared with views about care for heart disease and diabetes mellitus ${ }^{54}$. PCPs considered patients with dementia more difficult to manage, were less likely to believe that their organisation had expertise or referral pathways to manage dementia, and could provide care coordination, and were markedly less confident that they could improve the quality of life of patients with dementia. They were more sceptical of the value of routine screening for dementia, but were more likely to see opportunities for improvement in their ability to manage dementia than other conditions. Improving primary care management of dementia should directly address PCP concerns about expertise and referral resources, difficulty of care provision, and PCP views about prospects for patient improvement. 
primary care, more often they referred to difficulties in accessing or communicating with specialist dementia diagnostic and support services. Detection and diagnosis pathways that rely upon PCPs identifying cognitive impairment, and then referring to specialist teams for formal diagnosis and dementia sub-typing, and care planning, depend critically upon good communication and access between primary care and specialist services. Too little attention has been given to establishing, resourcing and coordinating the systems of care that people with a timely diagnosis could access. Meeting this challenge will need coordinated and sustained action, ideally through the framework of a national dementia strategy and plan ${ }^{53}$. In England an analysis of dementia diagnoses recorded on primary care Quality Outcome framework registers (from 2006/7 to 2011/12), and antidementia drug prescription rates showed that both increased significantly from 2009, with a 4\% rise in 2010 and a $12 \%$ rise in $2011^{55}$. Increases in antidementia drug prescriptions correlated closely with increases in diagnoses at district (primary care trust) level. While a direct causal effect could not be established, there was a marked change in trends before the launch of the strategy ${ }^{55}$.

Key elements of a strategic approach to improving detection and diagnosis of dementia in primary care would include locating responsibility for dementia diagnosis, care planning and coordination in primary care, and supporting their ability to do this through case management (e.g. specialist memory nurses, working in primary care), and/or shared (or collaborative) care in which primary and secondary care services work together in a closely integrated way to deliver services according to an agreed protocol, with clearly defined roles and responsibilities, consultation and referral pathways. In the UK, PCPs were much more likely to view earlier diagnosis more favourably when there had been supportive interactions with specialist care services ${ }^{52}$.

\section{Structured diagnostic services in primary care (primary care memory clinics)}

There are several documented examples of dementia diagnostic services established in primary care. The rationale for this approach is, first, that specialist memory clinic services, although greatly expanded in most high income countries, have been struggling to meet the increased demand for assessments, arising from ageing populations and increasing awareness. Second, an assessment in the more familiar environment of primary care (or, sometimes, at home) may be more convenient and less challenging for patients. Third, PCPs are usually well acquainted with their patients' medical and personal histories and family circumstances, facilitating assessment of cognitive decline and its impacts. Finally, in principle, equivalent diagnostic assessments conducted by non-specialists should be cheaper than those carried out by specialists, and hence more cost-effective, assuming similar levels of effectiveness. Two types of model have been demonstrated, a task-shifted model, in which PCPs are responsible for making the diagnosis, and task-shifted models in which this and related activities are shared to some extent between PCPs and specialists.

Task-shifted primary care memory clinic models have several common elements ${ }^{62}$. The assessment is carried out in the primary care facility, or at home. The PCP is responsible for allocating the diagnosis, but is supported by a nurse practitioner, who may be a primary care practice nurse, or a specialist 'memory nurse' recruited or seconded from the specialist sector. Their role is, typically, to coordinate the assessment process, engage with the patient and family, and to conduct cognitive and other evaluations. In effect, their role is one of case management for the diagnostic process, ensuring that the PCP's time is used efficiently. There is an implicit stepped care element to all of the services; for complex cases, specialist services are always available to provide advice to the $\mathrm{PCP}$, or to accept referrals.

Beyond these generic elements, there are important differences between the service models. In Ontario, the Canadian Centre for Family Medicine Family Health Team has established a primary care memory clinic essentially along specialist memory clinic lines ${ }^{63}$. Referrals to the clinic are made by PCPs. There is multidisciplinary input (PCP, nurse, social worker and pharmacist), and detailed neuropsychological and social care needs assessments are carried out on all patients. After a structured assessment process lasting approximately two hours, diagnosis is reached in a multidisciplinary consensus meeting. All requirements of Canadian consensus guidelines on dementia assessment and management are met, including diagnostic, post-diagnostic support and follow-up. A similar model was applied in six practices in Central New South Wales, Australia, where case identification using the GPCOG was followed by an invitation for a formal structured assessment by a specialist memory nurse working in primary care, comprising the CAMCOG clinical and cognitive test battery and assessment of ADL, quality of life and mood, and a carer assessment. The mean length of the assessment was around 90 minutes for patients and one hour for carers ${ }^{64}$. Multi-disciplinary case discussion and care planning with the primary care team were then based on assessment findings reported by the specialist memory nurse.

In contrast, in Bristol UK, where primary care led dementia services were piloted in 11 of 55 primary care centres between 2012 and 2013, and then rolled out across the city, the dementia diagnostic service 
Table 2.3

Barriers to the diagnosis of dementia in primary care ${ }^{52,53}$

\begin{tabular}{|c|c|c|c|}
\hline Themes & Patient factors & Primary care physician factors & System characteristics \\
\hline $\begin{array}{l}\text { Lack of support } \\
\text { available to patient, } \\
\text { carer or PCP }\end{array}$ & & $\begin{array}{l}\text { Lack of knowledge about community } \\
\text { support services }\end{array}$ & $\begin{array}{l}\text { Lack of access to community } \\
\text { support services } \\
\text { Limited access to secondary } \\
\text { care services } \\
\text { Absence of multidisciplinary } \\
\text { teams to enhance } \\
\text { management } \\
\text { Perceived need for dementia } \\
\text { care coordinator to assist } \\
\text { with this }{ }^{56}\end{array}$ \\
\hline Therapeutic nihilism & & $\begin{array}{l}\text { PCPs often express the view that there } \\
\text { are no available treatments or benefits } \\
\text { to diagnosis, which therefore could do } \\
\text { more harm than good. } \\
\text { Evidence that these attitudes can lead to } \\
\text { delay in timely diagnosis } 57,58 \text {. } \\
\text { In one UK survey, in } 2000 \text { only } 52 \% \\
\text { of PCPs felt that timely diagnosis was } \\
\text { worthwhile } 59 \text {. }\end{array}$ & \\
\hline Time constraints & & & $\begin{array}{l}\text { Not enough time ring- } \\
\text { fenced to carry out tests, } \\
\text { assessments and reviews }\end{array}$ \\
\hline Financing & $\begin{array}{l}\text { Patients and their families may } \\
\text { struggle to afford the costs } \\
\text { of specialist referral in some } \\
\text { healthcare systems. } \\
\text { In the US Medicare system, work } \\
\text { with caregivers is not reimbursed } \\
\text { unless the patient is present. }\end{array}$ & $\begin{array}{l}\text { Inadequate financial remuneration } \\
\text { (especially in countries where PCPs are } \\
\text { paid according to services they provide). }\end{array}$ & $\begin{array}{l}\text { Billing and reimbursement } \\
\text { systems discourage } \\
\text { adherence to care quality } \\
\text { standards }{ }^{60} \text {. } \\
\text { Payment and coding } \\
\text { structures need to be } \\
\text { redesigned to reflect the } \\
\text { work providers need to do to } \\
\text { provide high quality care. }\end{array}$ \\
\hline Stigma & $\begin{array}{l}\text { Concerns regarding stigma may } \\
\text { be one factor deterring or delaying } \\
\text { help seeking }\end{array}$ & $\begin{array}{l}\text { PCP concerned about 'labelling', and } \\
\text { often assuming that a diagnosis would } \\
\text { not be wanted until so severe as to be } \\
\text { self-evident }\end{array}$ & \\
\hline Diagnostic uncertainty & $\begin{array}{l}\text { Intrinsic complexity. Blurring with } \\
\text { normal ageing in the early stages. }\end{array}$ & $\begin{array}{l}\text { Low confidence in diagnostic ability. } \\
\text { Trepidation regarding the potential } \\
\text { adverse consequences of misdiagnosis }\end{array}$ & $\begin{array}{l}\text { Too little training in the basic } \\
\text { medical training curriculum }\end{array}$ \\
\hline $\begin{array}{l}\text { Disclosing the } \\
\text { diagnosis }\end{array}$ & & $\begin{array}{l}\text { PCPs often report discomfort in doing } \\
\text { this. } \\
\text { Euphemistic terms are often used, or } \\
\text { PCPs focus on discussing management } \\
\text { with no formal diagnosis communicated. } \\
\text { Diagnosis is more likely to be } \\
\text { communicated to carer than patient. } \\
\text { More training in this area seen by PCPs } \\
\text { as a high priority } 61\end{array}$ & \\
\hline
\end{tabular}


is provided fully integrated within the normal primary care clinics, and diagnosis is reached by the GP, with no multidisciplinary input (other than that of a specialist memory nurse) after an average of around four 10 minute appointments with patients and carers ${ }^{65}$.

Preparation, training and support to establish the services also differed. In Canada this comprised a five day intensive training and mentoring program (see Box 2.3). In Bristol PCPs attended an introductory three hour training workshop. Ongoing training and support, particularly peer to peer workshops led by GPs with a special interest were seen as valuable.

The evaluation of these three models has been minimal, comprising mainly limited process data and qualitative and/or quantitative assessment of service satisfaction in small samples of patients and their carers ${ }^{63-65}$. A common finding across all three programs was that the primary care service seemed acceptable to patients and carers, and, in Bristol ${ }^{65}$, as acceptable as that provided by specialist services. In Ontario, non-urgent referrals were seen within at most two to three months from referral, compared with the four to six month wait time for a non-urgent consultation with a geriatrician in the region ${ }^{63}$.

Subjective experiences were generally positive; in Australia, for example, $85 \%$ or more of patients gave positive ratings for the length of the examination, the usefulness of the assessment, the experience of assessment, and their willingness to recommend the process to others ${ }^{64}$. The work of the memory nurse was generally highly valued by patients, carers and PCPs. In Bristol, both PCPs and specialist memory clinic providers raised concerns about the possibility of misdiagnosis in primary care, given the much more cursory assessment than that carried out by specialist services, but this was not formally evaluated ${ }^{65}$. In Ontario, geriatricians reviewed assessments of 30 patients, and were in almost complete concordance with diagnoses and management plans ${ }^{63}$.

The Gnosall Surgery primary care memory clinic in the UK is perhaps the best documented example of a task-shared/collaborative care model for dementia diagnosis ${ }^{67}$. The monthly primary care memory clinic is supported by a practice-based nurse case manager ('eldercare facilitator'), and a specialist psychiatrist. The PCP reviews initial memory complaints, takes the decision to refer to the case manager for further assessment and subsequently to refer to the memory clinic, reviews the memory clinic assessment and agrees a shared care plan with the psychiatrist. The case manager conducts initial assessments, coordinates the memory clinic, and is responsible for coordinating delivery of the care plan, liaising with patient and family throughout. The visiting psychiatrist conducts the memory clinic assessment, and agrees a shared care plan with the PCP.
Box 2.3

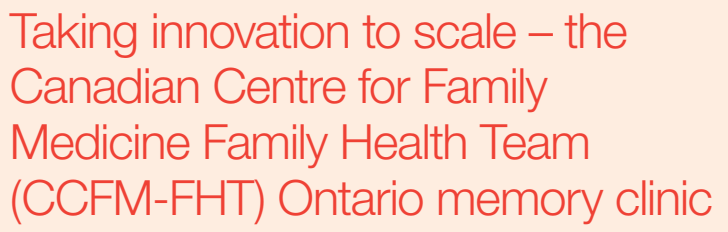

The CCFM memory clinic has developed, implemented and evaluated a 5-day training program to assist other FHTs to implement their own primary care memory clinics ${ }^{66}$. This targets the multidisciplinary FHT team, and comprises a 2-day workshop aimed to increase knowledge and skill related to the assessment and management of cognitive impairment, followed by a 3-day mentorship program. Aside from didactic training, each team works through eight case studies of increasing complexity over the 2-day workshop. Facility-specific implementation issues are discussed, based upon a precompleted online needs assessment survey. The mentorship program comprises an observership session at the CCFM memory clinic with remote video access to assessments, and participation in the consensus discussions. A few weeks later, the multidisciplinary team in each new memory clinic is mentored by the CCFM team as they conduct patient assessments during the first two days of their memory clinic. On this visit a presentation is made to the other members of the FHT explaining the role of the new memory clinic to encourage "buy-in".

Ongoing mentorship support is provided to each new clinic as they begin to apply their new knowledge and skills to their practice setting. A 'community of practice' has been established allowing primary care memory clinic providers to meet, share experiences, problem-solve, and receive one-day booster sessions.

The main benefits claimed for this model were that assessment delays are minimised and attendance rates are nearly $100 \%{ }^{68}$. The case manager develops expertise on the range of local services and how to access them. The surgery has identified $100 \%$ of the predicted dementia prevalence for the population. Service users report high levels of satisfaction. Managing the service in the familiar environment of the GP Health Centre helps reduce the fear and stigma that might be associated with attending a psychiatric clinic. Gnosall Surgery's use of all secondary healthcare for all older patients is substantially less than predicted, and older people who were admitted had shorter lengths of stay. 
NHS England commissioned a review of three contrasting diagnostic service models and their costs, comparing the Gnossal Surgery model with a specialist care led service with limited input from PCPs with a 'special interest', and a traditional specialist memory clinic $^{68}$. The Gnosall Surgery model at an estimated cost per patient of $£ 396$ was no more expensive, and possibly cheaper than the alternatives, £877 and £491 respectively. Following the success of the Gnosall Memory Clinic model, it is being rolled out throughout the district for 163 PCPs in 41 practices, with a total population of approximately 360,000 . The scaled up service will require six case managers, and a total annual budget of approximately $£ 865,000^{68}$.

\section{Use of videoconferencing technology (telemedicine) for dementia diagnosis}

A randomised controlled trial was conducted in Australia to assess the validity of diagnoses made by specialists, remotely, using video conferencing technology to interview patients and carers ${ }^{35}$. After receiving a diagnosis based on face to face interview, 205 patients referred by their PCPs to a memory clinic were randomised to receive an additional consultation, either face to face or by videoconference. Each specialist physician had access to the patient chart and the results of a battery of standardised cognitive assessments administered face to face by the clinic nurse. Levels of agreement for the videoconference group (Percentage agreement $=0.71$; weighted Kappa $=0.52 ; \mathrm{P}<.0001)$ and for the face to face interview (Percentage agreement $=0.70$; weighted $\mathrm{Kappa}=0.50$; $\mathrm{P}<.0001)$ were both statistically significant, and did not differ significantly from each other $(P=0.84)$. The conclusion, therefore, was that the videoconference diagnosis was not inferior to face to face assessment. Previous studies have shown that preliminary standardised cognitive and functional assessment tools can also be reliably administered and scored via videoconferencing. Remote specialist assessment by videoconferencing is therefore a promising technology, with a variety of applications, most particularly to provide specialist inputs into primary care diagnostic services, including those in rural and remote areas.

\subsection{Post-diagnostic care and support}

\section{Evidence for the quality of post-diagnostic care in primary care}

The importance of post-diagnostic support as part of the continuum of care has only recently begun to be highlighted. Alzheimer Scotland's influential 5 Pillars Model ${ }^{69}$ defines the key elements as understanding the illness and managing symptoms; planning for future decision making; supporting community connections; peer support; and planning for future care. The Scottish Government's commitment to delivering a minimum of one year post-diagnostic support, informed by this model, does not appear to have led, as yet, to any published evaluations of the effectiveness and impact of this complex intervention. Post-diagnostic support requires coordinated input from health and social care professionals, and it is unclear as yet where in the system such services should be located.

In the evaluation of the Bristol primary care memory clinics (see also section 2.4 above) there was evidence from some carer and patient narratives that less time was spent on disclosing, clarifying and discussing the diagnosis in the primary care service, and hence that the process of supporting patients through the assessment was more thorough in secondary than in primary care ${ }^{65}$. However, post-diagnostic support was lacking across both primary and specialist care service models, other than some signposting to community agencies, and advanced care planning ${ }^{65}$. Where provided, this came from the memory nurses. No carers or patients reported receiving support from their GP. There was a strong sense, from professionals as well as patients and carers that the service was focused upon diagnosis, with little structured aftercare or support. Only those with a diagnosis of Alzheimer's disease were offered follow-up, to review cognitive enhancer medication.

\section{Evidence for the relative quality and outcomes of post-diagnostic care provided by primary care and specialist dementia care services}

We identified one randomised controlled trial of the relative effectiveness of primary and specialist care during the early post-diagnostic period, the AD-Euro trial conducted in the Netherlands ${ }^{70}$. Two hundred and twenty people with mild to moderate dementia, newly diagnosed in a memory clinic, were to be randomised to receive routine follow-up care by their primary care provider, or their local specialist memory clinic service. This was a completely pragmatic trial; no training was provided to primary care providers, and there were no trial protocols to guide management in either arm. However, memory clinic care in the Netherlands is based on the specialist Dutch Dementia guideline of the Dutch Institute for Healthcare Improvement. Outcome assessments were carried out at 6 and 12 months; the main outcomes were the quality of life of the person with dementia, measured using the QoL$A D$ and self-perceived carer strain measured using the Sense of Competence Questionnaire (SCQ). To establish cost-effectiveness a cost-utility analysis was carried out using utilities generated by the EuroQol instrument (EQ-5D), from a societal perspective, that is taking into account health service and formal care service utilisation, and the costs of unpaid informal care.

175 people with dementia and their primary carers were included in the trial. Most $(84 \%)$ of the trial 
participants had mild or very mild dementia. There were no significant differences in the primary outcomes between primary care and memory clinic groups ${ }^{28}$. The quality of life of the people with dementia in the memory clinic group was higher $(+0.5$ points, $95 \% \mathrm{Cl}$ : -0.7 to +1.6$)$ and carer strain lower $(-2.4$ points, $95 \% \mathrm{Cl}$ : -5.8 to +1.0 ) than in the primary care group. There were small but statistically significant differences in carer depression, state and trait anxiety levels at 12 months favouring the primary care group. However, these were unlikely to be clinically significant, and may have been accounted for by differential loss to follow-up. No other secondary outcomes (behavioural symptoms and depression in the person with dementia, and the quality of life of the carer) differed between the two arms of the trial at six or 12 months follow-up.

In a subsequent publication the care inputs were compared between the two arms of the trial ${ }^{30}$. This revealed that, compared with those in the primary care arm, those in the memory clinic arm were more likely to have used cognitive enhancer medication during the follow-up period (RR 1.56, 95\% Cl: 1.18-2.07), to have information and explanations provided to their carer (RR 1.53, 95\% Cl: 1.04-2.25), and to have visited an Alzheimer Café (RR 3.10, 95\% Cl: 0.96-10.09). There were no significant differences in use of home care, day care, physiotherapy or occupational therapy. Similar proportions in each arm were admitted to nursing home or residential care.

From a societal perspective, compared to general practitioners' care, treatment by the memory clinics was on average marginally and non-significantly cheaper $(-1024,95 \% \text { Cl: }-7723 \text { to }+5674)^{29}$. However, when assessed using the EQ-5D, quality adjusted life years were non-significantly lower for memory clinic care $(-0.025$ points, $95 \% \mathrm{Cl}$ : -0.114 to +0.064$)$. The incremental cost-effectiveness point estimate from the bootstrap simulation was euro 41,442 per QALY (quality-adjusted life year) lost if one would use memory clinic care instead of general practitioner care. The only cost components that differed significantly between the two groups were hospital inpatient admissions and memory clinic visits (substantially higher in the memory clinic arm), and primary care visits (higher in the primary care arm). However, any healthcare cost savings were more than offset by the non-significantly higher cost of informal care and nursing home care in the primary care arm.

There are some weaknesses. Although this was not highlighted in the publications, the trial seems to have under-recruited, with 175 rather than the targeted 220 patient and carer dyads included. However, loss to follow-up was only $9 \%$ against the projected $30 \%$ allowed for in the sample size calculations, so loss of power to detect clinically significant differences should not have been critical. The study only recruited people with dementia diagnosed in memory clinics, with a full work up reported back to primary care, which may have enhanced the quality of care provided by GPs compared with those clients they had diagnosed themselves without referral to a memory clinic.

\section{Evaluations of interventions designed to enhance the quality of post-diagnostic support in primary care}

\section{Psychosocial interventions}

We identified two trials of psychosocial carer interventions provided through primary care services in the early post-diagnostic phase. Neither trial showed evidence of any benefit for people with dementia or their carers, for any relevant outcomes. The German IDA trial was entirely pragmatic, and although the training of GPs in the two intervention arms resulted in an impressive uptake of carer counselling and support $^{22}$, this was generally for only one or two sessions, perhaps accounting for the lack of evidence of effectiveness ${ }^{23}$. The Danish DAISY trial examined the effect of multifaceted and semi-tailored psychosocial support for the person with dementia and their carer for one year in the immediate post-diagnostic period. Although the authors refer to implementation problems a high proportion of dyads completed the full intervention program ${ }^{24}$. Failure to select for those with unmet needs for support may have contributed to the clear lack of clinical and cost-effectiveness of this intervention ${ }^{25,26}$.

\section{Video decision support tools for advanced care planning}

Advanced care planning, and advanced directives regarding care are complicated by the difficulty that many may experience in comprehending the lived experience of late stage dementia. In the USA, a randomised controlled trial was conducted of the effect of adding a video of a person with late stage dementia to a structured narrative describing some of the typical features of late stage dementia ${ }^{31}$. The video depicted a person with advanced dementia, living in a care home, who had lost the ability to speak and mobilise, and needed feeding assistance. After viewing the video and hearing the narrative (intervention group, $n=94$ ), or hearing the narrative only (control group, $n=106$ ), the participants, who were attendees at primary care centres aged 65 and over, without moderate or severe cognitive impairment, were asked to state their preferences for goals of care in the event of developing advanced dementia. The options were: life prolonging care, limited care, and comfort care. Life prolonging care, was described as aiming to prolong life at any cost. Limited care was described as aiming to maintain physical functioning, and included treatments such as admission to hospital, intravenous fluids, and antibiotics but not resuscitation or treatment in the 
intensive care unit. The third option, comfort care, was described as aiming to maximise comfort and to relieve pain only. Participants randomised to the video arm were more likely to select comfort care $(86 \%$ vs $64 \%$ in the control group), and less likely to choose either limited care ( $9 \%$ vs $19 \%)$, or life prolonging care $(4 \%$ vs $14 \%)$. Six weeks later, decisions made by the video group were found to be more stable than those made by the control group. Knowledge about advanced dementia, which was low at baseline, increased to a greater extent in the video group than in the control group.

The study has limitations. The authors acknowledge that the content of the video is likely to impact on decision making. The depiction of only one example cannot convey the range of living circumstances and quality of life experiences of people living with advanced dementia. The video was prepared with an expert steering group of medical professionals, which did not include people with dementia or their carers. Finally, only $9 \%$ of participants had received a diagnosis of dementia, whereas, in clinical practice, this would be the context (post-diagnosis) in which advanced care planning would be most likely to take place. Nevertheless, the structured and standardised manner in which the information is conveyed would be likely to have a useful application in the delivery of contextual information, by non-specialists in primary care.

\subsection{Continuing care}

\section{Evidence for the quality of continuing care in primary care}

In the UK National Health Service, an annual dementia review was introduced into Quality and Outcomes Framework (QOF) guidelines for primary care, with a pay-for-performance link to remuneration. The review should comprise an appropriate physical and mental health review, coordination with secondary care if appropriate, and an assessment of impact on carers, and carer's needs for information. A survey was conducted of 52 practices in 7 primary care trusts in Greater Manchester. Case-notes of 911 people with dementia, of whom 745 were at least 15 months post-diagnosis and hence eligible for a review, were scrutinised for evidence of adherence to QOF guidelines ${ }^{71}$. While $80 \%$ of eligible patients had had an annual review, only $51 \%$ had a social care review, and $61 \%$ a discussion with carers. Despite a high prevalence of vascular comorbidity, over a quarter of patients were prescribed antipsychotic medication, usually for unclear indications, and only $57 \%$ of these had had a medication review in the past 6 months. Adherence to depression guidelines was particularly weak. Thus, although a high proportion of patients received reviews, the quality of those reviews was suboptimal ${ }^{71}$. Case reviews were less likely to be carried out, and overall quality of care was lower for patients with vascular dementia as opposed to Alzheimer's disease, and for those registered with single-handed practices.

In another publication, the same research group assessed the quality of primary care management of cardiovascular comorbidity in the subset of 700 people with dementia with one or more diagnosed vascular disease or risk factor ${ }^{72}$. Quality of care was measured on 30 indicators from the UK Quality and Outcomes Frameworks (QOFs) for hypertension, coronary heart disease, stroke, diabetes mellitus, atrial fibrillation, heart failure, and smoking. These included monitoring and control of risk factors, checking for complications, and provision of evidence-based treatments. Level of care received by people with dementia was significantly lower compared with those without dementia for 22 of 30 indicators; most notably for measurement processes. Overall quality of vascular care was lower for those in care homes, and those with fewer comorbid physical conditions. There is also evidence from a smaller and weaker study in the USA that access to lipid lowering drugs may be lower for people with dementia than others ${ }^{73}$. Those with dementia had a much lower likelihood of taking lipid lowering drugs in the previous year (AOR 0.39, 95\% $\mathrm{Cl}$ : 0.16-0.95) after adjusting for age, sex, education, visit with PCP within the past year, and clinical and lifestyle variables that might be proxies for need of lipid lowering (self-reported heart disease, stroke or transient ischemic attacks, hypertension, smoking, and alcohol consumption). While this might reflect a prescribing bias, the finding might also be explained by a protective effect of lipid lowering drugs on dementia incidence, or a tendency for lipid levels to fall with the onset of dementia.

\section{Studies comparing the quality of continuing care provided by non-specialist and specialist services}

In Alberta, Canada, people with dementia are supported by Primary Care Networks (PCNs), Geriatric Assessment Teams (GATs), and Community Care (CC) services. Eighty-one referrals from PCNs to a GAT service were scrutinised through systematic case note reviews for evidence of adherence to the guidelines of the Third Canadian Consensus Conference on the Diagnosis and Treatment of Dementia ${ }^{74}$. Sixty-nine of the patients were diagnosed by the specialist GAT service with dementia, 41 of whom had also had a diagnosis recorded by the PCP (sensitivity 59\%). Compared to the GAT service, the PCN service was significantly less likely to have carried out cognitive testing, assessed activities of daily living, assessed BPSD, assessed decision making capacity, explored driving status, or wandering, assessed capacity, explored advanced care planning, assessed caregiver coping or strain, or referred to community care 
services. Other than assessing capacity and carer strain, guideline targets were met in nearly all cases assessed by specialist GAT services.

In a recent USA study of unmet carer needs, 307 patient-carer dyads were surveyed upon referral to a dementia care program ${ }^{75}$. Only $32 \%$ of carers reported confidence in managing dementia-related problems, while $19 \%$ knew how to access support from community services, and these proportions did not vary significantly according to source of referral. However, those referred by geriatricians were more likely $(42 \%)$ than an internist or family practitioner $(13 \%)$ or a neurologist or psychiatrist $(16 \%)$ to agree that their provider helped them work through dementia care problems. There was no difference in carer strain, carer depression, carer self-efficacy score, or behavioural and psychological symptoms according to type of referring provider. Compared with those managed by PCPs or geriatricians, carers of individuals referred by neurologists or psychiatrists also less frequently agreed that the individual's regular doctor understood how dementia complicates other health conditions, that they had received advice about handling dementia-related problems or about what to expect in the future, and that they were aware of services to help provide care.

Surveys of management decisions in response to vignettes of agitated people with dementia were conducted on small samples of primary care physicians, geriatric psychiatrists, and neurologists in North Carolina ${ }^{76,77}$. This work was conducted in the mid-1990s, casting some doubt on the current relevance of the findings. PCPs were less likely to recommend access to a dementia support group and respite day care than others, while neurologists were more likely to recommend nursing home placement than all other groups. All groups saw neuroleptic medication as the first line of treatment (55\%), while only $22 \%$ recommended psychosocial interventions.

\section{Evaluations of innovations designed to enhance the quality of continuing care in primary care}

\section{Educational interventions}

Systematic reviews concur that educational interventions targeting primary care providers, on their own, generally have no discernible impact on guideline adherence or evidence-based management ${ }^{8,12,22}$. Improvements in care quality were only seen in one trial, where primary care provider education was coupled with ongoing case management support integrated into primary care ${ }^{16}$.

\section{Case management}

We identified five randomised controlled trials of case management interventions centred around primary care $^{14-16,19,20}$ (see also Table 2.2b), and three controlled trials without randomisation ${ }^{78-81}$. See also Chapter 3 for a broader review of case management interventions.

Each of the randomised controlled trials indicated at least some relevant benefits. These included higher rates of detection of dementia ${ }^{19}$, improved adherence to management guideline recommendations ${ }^{15,16}$, (limited) evidence of benefits for people with dementia $^{15,16}$, lower carer depression and/or strain ${ }^{14,15}$ or unmet needs for carer support ${ }^{16}$, and a lower rate of nursing home placement ${ }^{20}$. Findings were not, however, consistent among studies, perhaps attributable to differences in the design, targeting and degree of implementation of the intervention. One salient issue may be the extent to which the additional case management support is effectively integrated with and supportive of the delivery of primary healthcare, and community social care ${ }^{18}$. In one trial, dementia care consultants provided by Alzheimer's Association chapters seemed to have worked relatively independently, and care plans faxed to PCPs were rarely discussed with patients or carers $^{20}$. Home based assessment for specific carer needs and linkage to community care organisations seemed to be critically important for improvement in carer mastery ${ }^{82}$. Critically, none of the trials of primary care case management included an assessment of the cost-effectiveness of the interventions provided. In the most comprehensive assessment of service utilisation, there was no effect on utilisation of primary care or hospital healthcare services, but generic case management and health promotion services provided by the primary care provider were used less often, presumably since this service was provided more effectively by the dementia case manager ${ }^{14}$. Reduction in unmet caregiving assistance and more assistance from community agencies, as noted in the ACCESS-Trial would imply higher costs, alongside potential benefit ${ }^{16}$. The ongoing German DELPHi-MV trial will be the first to assess the cost-effectiveness, alongside the efficacy and efficiency of implementing a support system initiated and coordinated by a nurse dementia care manager for persons with dementia who live at home ${ }^{83}$. Primary outcomes are quality of life, behavioural and psychological symptoms of dementia, pharmacotherapy, and carer strain, and a comprehensive evaluation of cost-effectiveness is planned.

In a study conducted in two community-based primary care practices, the effectiveness of nurse-practitioner co-management compared with management by PCP alone was studied, specifically for patients with comorbidities $^{81}$. The care approach for all patients was based on the Assessing Care of Vulnerable Elders (ACOVE)-2 model: case finding, delegation of data collection, structured visit notes, physician and patient education, and linkage to community resources. 458 patients aged 75 and older screened positive 
for at least one condition: falls, urinary incontinence, dementia, and depression. Half had received nursepractitioner co-management. Quality of care was assessed against ACOVE-3 quality indicators, using medical record review. Quality scores for all conditions (falls, $80 \%$ vs $34 \%$; UI, $66 \%$ vs $19 \%$; dementia, $59 \%$ vs $38 \%$ ) except depression (63\% vs $60 \%$ ) were significantly higher for patients who were co-managed by a nurse practitioner. The program for people with dementia comprises a dementia registry, structured needs assessments of individuals in the registry and their caregivers, individualised dementia care plans that are monitored and revised, and open access for support and advice ${ }^{84}$. For 150 people with dementia, the most common recommendations in the initial care plans were referrals to support groups (73\%) and the Alzheimer's Association (73\%), caregiver training (45\%), and medication adjustment (41\%).

The US Partners in Dementia Care (PDC) program ${ }^{78,79}$ involves a collaboration between Veterans Affairs (VA) Medical Centers and Alzheimer's Association chapters, to support veterans with dementia living in the community and receiving primary care from the VA, and their caregivers. Care-coordination provided by care coordinators from the VA health system working in tandem with coordinators from the Alzheimer's Association social care support system. The VA Medical Centers had primary responsibility for health concerns (medication management, accessing healthcare services and using them effectively, disease management), whereas the care coordinator from the Alzheimer's Association chapter had primary responsibility for assisting carers with social care concerns (carer strain, accessing family support and information services and using them effectively). The aim was to integrate healthcare and community services while strengthening the informal care network and providing information, coaching, and emotional support to caregivers. The program targeted both patients and carers. PDC was evaluated in a controlled trial in which five matched communities were allocated to PDC (two sites) or treatment as usual (three sites) with outcomes assessed at 6 and 12 months. The initial sample was 508 veterans with diagnosed dementia, and 486 carers. PDC veterans had significantly less adverse outcomes than those receiving usual care (including reduced relationship strain, depression and unmet needs, and less embarrassment about memory problems) particularly for more impaired veterans after six months, with further improvements noted to 12 months ${ }^{79}$. Intervention group carers had significant improvements in unmet needs, carer strain, depression, and support resources through to six months with more limited improvements in the second six months of follow-up ${ }^{78}$.

A pragmatic quasi-experimental controlled study of case management supplementing care provided by PCPs was carried out in the Netherlands from 2011-
2013 ${ }^{80}$. In 2008, the Dutch Ministry of Healthcare had stipulated that case management had to be part of usual care for persons with dementia in all regions by the end of 2011. At the end of this roll-out period, the investigators compared outcomes for 521 people with dementia and their carers, over a two-year follow-up period, for regions where case management had still not yet been implemented (control group, $\mathrm{n}=73$ ), compared with regions implementing two different models of case management. These were intensive case management (CM) provided by a single organisation specialising in dementia care $(n=234)$, and linkage case management where health and social care agencies collaborate to appoint case managers authorised to work across the entire system $(n=214)$. Case managers in the intensive CM systems generally worked full-time, whereas those in the linkage CM systems worked part-time integrating this work with another role such as a district nurse. Average caseloads were similar; 53.9 patients (SD 23.3) for linkage CM and 61.6 (SD 16.7) for intensive CM. There were no differences among the three groups in behavioural and psychological symptoms, carer psychological morbidity, transition into a care home, or mortality. Carer quality of life scores were higher for intensive CM than linkage CM recipients. Intensive CM, but not linkage CM, was associated with fewer total needs, met and unmet care needs compared with the control group.

In a recent systematic review of case management for dementia in primary care, the authors identified likely effective components, linked to a concept of 'high intensity case management' 85 . This comprised; a caseload of fewer than 50 patients per fulltime equivalent case manager; regular meetings with the informal carer and the person with dementia, at least half of which should be face to face; education on health conditions and self-management; close contact with the PCP; proactive and timely follow-up; and follow-up with patients during hospitalisations and short-term admissions to care homes.

The results of an evaluation of an attempt to integrate case management into routine primary care in the UK (the EVIDEM project ${ }^{86,87}$ ) illustrates the problems encountered when case managers' previous experience is insufficiently orientated to the role, when there is not enough protected time allocated to the case management role, and where there is no clear mandate to case manage across all relevant services. As the investigators candidly pointed out 'little case management took place' ${ }^{87}$, with low levels of recruitment, few meetings with people with dementia and their carers, missed opportunities to identify and address unmet needs, and almost no interaction with other services ${ }^{86}$. 


\section{Psychosocial interventions for carers}

A recent systematic review identified three evaluations of psychosocial interventions for supporting carers of people with dementia, delivered, as part of continuing care, in the primary care setting ${ }^{88}$. Two were randomised controlled trials ${ }^{21,27}$ (see also Table 2.2c), and one an uncontrolled pre- post-implementation assessment of a translation of proven intervention model into routine primary care ${ }^{89}$. In contrast to carer support interventions delivered in the immediate postdiagnostic phase, these continuing care interventions generally show evidence of benefit.

A small RCT conducted in two Spanish primary care facilities indicated quite impressive effects of group cognitive behavioural therapy, administered in primary care by a psychologist with non-specialist primary care staff co-therapists on carer psychological morbidity and dysfunctional thoughts ${ }^{27}$. The Resources for Enhancing Alzheimer's Caregiver Health (REACH) trial conducted in the Veteran's Administration (VA) health system in the USA demonstrated that supplementing patient behaviour management training with carer stress coping was associated with better general well-being and a non-significant trend towards reduced depression symptoms ${ }^{21}$. The REACH II randomised controlled trial later provided evidence of efficacy for a much more intensive multicomponent behavioural intervention for dementia caregivers using education, support, and skills training to address safety, social support, problem behaviours, carer depression, and health ${ }^{90}$. Subsequently, in the REACH VA study, the REACH II model was implemented in the primary care context in 24 VA Medical Centers in 15 states $^{89} .53$ staff members, mainly social workers, psychologists or nurses performed the interventions, with 127 carers enrolled at the 24 facilities. The intervention comprised nine one-hour individual home sessions, three half-hour individual telephone sessions, and five one-hour monthly telephone support group sessions. From baseline to six months, carers reported significantly decreased burden, depression, impact of depression on daily life, caregiving frustrations, and number of troubling dementia-related behaviours. However, the standardised effect sizes, while statistically significant were small (0.22-0.33). There were no statistically significant changes in carer general health or social support, or safety for the person with dementia. No information is provided on the uptake of the intervention or coverage achieved, and there was no cost-benefit analysis. The large majority of carers who participated (96\%) believed that the program should be provided by the VA to all carers.

\section{Use of technology}

Baseline data from 227 people who had screened positive for dementia from the DELPHi-MV intervention group and received a standardised computer-assisted needs assessment, indicated a high number of unmet needs with over $90 \%$ having three or more unmet needs, particularly in the domains of "nursing treatment and care" (38\%), "social counselling and legal support" (20\%), and "pharmacological treatment and care" $(15 \%)^{91}$. The computer-assisted needs assessment is linked to a rule-based decision support system that supports the compilation of the individual intervention plan by suggesting corresponding specific interventions to the general practitioner. Its introduction in the intervention group was associated with an $85 \%$ increase in the number of specific interventions recommended to the $\mathrm{GPs}^{92}$.

A study conducted among PCPs in Canada, examined the effect of a Driving and Dementia Toolkit on knowledge, confidence and anticipated change in patient assessment ${ }^{93}$. The toolkit comprised background information on the topic, information on local resources and how to access them, a guide to a screening assessment of older drivers' safety, and a list of frequently asked questions. The toolkit was made available online and in printed format. Knowledge and confidence increased significantly for most of the toolkit content questions. There was also a clear intent on the part of study participants to begin including additional pertinent questions in the patient/carer interview when assessing a patient's fitness to drive. Satisfaction ratings with the toolkit rated an average of $8.4 / 10$

\subsection{Summary and discussion}

Primary healthcare services have always played an important role in dementia care, and will continue to do so. The questions addressed in this scoping review have to do with assessing the quality of the care provided across the care pathway, comparing care quality and its outcomes for non-specialist and specialist care, and identifying promising avenues for enhancing the quality of care provided in primary care. A secondary set of questions arise from the evidence presented in this section of the report. What should be the role of primary care? Can this and should this be made more explicit? Is there scope for tasks and activities carried out by specialist services to be shifted towards or shared with non-specialists at the primary care level?

It is important to note that the sections of this chapter that address the quality of care provided by primary care and compare this with specialist care describe in essence the status quo, in which the roles and responsibilities of primary care with respect to dementia care have generally not been explicitly defined, where basic curriculum and in-service training has been limited, and when care processes are not supported by evidence-based clinical guidelines or care pathways. In this respect, the sections of this chapter that describe strategies to enhance the quality of care and its outcomes are particularly relevant. 
There is no doubt that dementia is currently underdetected, under-diagnosed, under-disclosed, undertreated and under-managed in primary care ${ }^{53}$. That having been said, where PCPs do take responsibility for dementia care there is at least some evidence to suggest that this is not notably inferior in its outcomes to that provided by specialists, even though care processes may be less scrupulously adhered to. There is evidently much scope for improvement, with some well evaluated examples of system and service level innovations to support a more prominent role of primary care services in diagnosis, post-diagnostic and continuing care.

Recognition of dementia in primary care can be boosted by in-service education and training, which seeks to alter attitudes and perceptions as well as provide technical skills, and that has a practice-based component with specialists guiding and mentoring non-specialists to assume the responsibility for recognition and diagnosis. Indicated screening using cognitive tests can support timely diagnosis by responding to concerns raised by patients and carers. However, general screening, of all older attendees or all those registered to a primary care service cannot currently be recommended, and should not be carried out, in advance of more research evidence on benefits, harms and cost-effectiveness. There are several successful examples of memory clinics established in primary care, and run by PCPs supported by nurse practitioners. A key issue here may be whether dementia diagnosis is a task that is explicitly recognised as within the capacity of non-specialist services - a recent review of guidelines ${ }^{53}$ suggest that Canada may be unique in asserting that the typical presentations of the most common types of dementia can be accurately diagnosed by PCPs, even in the early stages of the disease, with clinical evaluation, brief cognitive testing, basic laboratory tests, and structural neuroimaging, as appropriate. It may be for that reason that some of the more innovative approaches to scaling up primary care diagnosis are currently originating from that country $51,63,66,94$. In England, local commissioning practices have now given rise to some diverse task-shifted and task-shared diagnostic service models. Of note, the Gnossal Surgery model, while primary care-based still requires all diagnoses to be made by a specialist psychiatrist ${ }^{67}$. We could find no studies that had explicitly compared the accuracy of diagnoses made by non-specialists and specialists. Such studies should focus on mild dementia, where diagnostic uncertainty is greatest, and, given the lack of a gold standard (with modest levels of diagnostic agreement between specialists ${ }^{35}$ ) should determine the predictive validity of diagnoses made by specialists and non-specialists, assessing whether diagnosed cases progress in impairment and needs for care ${ }^{95}$. There is also a need for more research to be carried out into good practice for diagnostic disclosure, ensuring a 'diagnosis well made' with respect to appropriate information, clearly delivered, anticipating and addressing negative impacts, and signposting sources of support. It is unclear whether or how this can be achieved in primary care. Several studies indicate underperformance, and a need for more training and support for this important activity.

The post-diagnostic phase is, in principle, an important phase of the care pathway, bridging from the 'diagnosis well-made' to a system of continuing care and support in the context of declining cognitive and functional abilities and increasing need for care and support. This phase was the focus for the only randomised controlled trial that compared, in the Netherlands, post-diagnostic dementia care services provided by non-specialists in primary care with those provided by specialists from memory clinic services ${ }^{70}$. The results of this 'non-inferiority' trial were largely reassuring in that the outcomes of the care provided by PCPs were no worse than those for care provided by specialists ${ }^{28}$, and costs were similar ${ }^{29}$. However, some care processes were more commonly adhered to by specialists (antidementia medication, information provided to carer, and referral to community support) ${ }^{30}$. The tentative conclusion was that models of care during this phase could be determined by the preferences of people with dementia and carers, and regional and national policy priorities. The potential benefits of the full range of post-diagnostic support activities (as for example advocated by Alzheimer Scotland in their ' 5 pillars' model) have yet to be evaluated. However, the results of two large randomised controlled trials conducted in Germany ${ }^{23}$ and Denmark ${ }^{24}$ are concerning in this regard. In contrast to a large body of evidence suggesting that psychosocial education, training and support interventions are moderately effective in improving carer outcomes, no benefits for either the person with dementia or the carer could be identified from their implementation in the early post-diagnostic phase, and the interventions were not cost-effective. Post-diagnostic support needs to be thought through carefully, since needs and preferences will vary considerably among people with dementia and their carers during this phase. It may be that service responses need to be more bespoke and targeted, based upon assessment and monitoring, rather than seeking to deliver a uniform post-diagnostic care pathway for all.

There is ample evidence that primary care services struggle to deliver high quality continuing care for people with dementia, even in systems where their role has been made more explicit, such as through the UK Quality Outcomes Framework ${ }^{71,72}$, and the Canadian Consensus Conference on the Diagnosis and Treatment of Dementia ${ }^{74}$. It is also clear that educational interventions alone have no discernible impact on guideline adherence and evidence based management. Case management interventions 
do, however, seem to offer some promise in that regard $^{15,16}$. Case management, when delivered with appropriate intensity, with a clear mandate to work across health and social care services, and by case managers with appropriate skills and enough time to focus on care management activities, can deliver better outcomes for carers and (less consistently) people living with dementia. In the primary care context case managers can act as a task-shifting, capacity increasing device, freeing up the PCP from time-consuming routine assessment, education and support, and care coordination activities.

However, despite much high quality research over the last 15 years, important questions remain unanswered.

1. Is case management cost-effective? Although an increase in the efficiency of care is a key objective of case management, the relevant outcomes have not been assessed in most studies. This would require an evaluation of avoidance of undesirable, unnecessary or potentially harmful patterns of service utilisation (for example duplication of care, emergency department attendance and avoidable hospital admissions - see also Chapter 4), and, crucially, an economic evaluation of the costeffectiveness of the intervention. Most of the models evaluated imply either the creation of a new cadre of specialist case managers, or the partial diversion of part-time case managers from their primary roles in the system. There are therefore cost, resourcing and service planning implications. Most of the models evaluated are, in effect demonstration studies, and we do not yet know whether they could, or should be taken to scale.

2. What type of case manager, and what model of case management works best? There is considerable variability in the models that have been evaluated, and much uncertainty as to which would be optimal. Common sense would suggest that the ability to focus full-time on case management would limit distractions, and lead to a more rapid acquisition of role competencies, and there is some indirect evidence from the studies we reviewed to support this. The primary location of the case manager within the health system may be a critical factor, and this varies between studies, probably reflecting the prevailing dementia care models in the countries concerned. Thus, in the USA, case managers were located either within the health system (sometimes from specialist services, but more usually in the primary care sector of a Health Maintenance Organization), or a voluntary sector care provider (e.g. the Alzheimer's Association), or both. In the Netherlands, two models seem to have come about, one providing intensive case management from a specialist dementia care service provider, and the other case management commissioned from a consortium of health and social care providers including primary care, but primarily located in a variety of sectors ${ }^{80}$. In the UK, there has been particularly strong interest in a model of case management located in primary care ${ }^{52,86,96}$. Case management integrated in primary care clearly has appeal when, as in England, this is the location of the register of all of the diagnosed cases, and when the whole population is registered to a single primary care provider. If dementia care coordination were to be a mandated role for primary care, then the capacity of the service to deliver this would be greatly increased if supported by co-management by PCPs and case managers.

3. How can information technology support the implementation of case management? Health information systems to support effective case management are often alluded to as challenges in the studies described, but with few explicit examples or evaluations of innovations. Such technologies can be used to structure assessments, support decision-making, facilitate caseload management, and monitor and improve adherence to guidelines, service standards and care pathways. A critical issue in the coordination of care across services is the ability to access and share information across providers ${ }^{78,79}$.

4. At which phase or phases of the condition would case management be most effective and most indicated, and would the model, content and delivery of case management need to be modified for specific subgroups? Most evaluated case management programs recruited communitydwelling older people with dementia, without regard to disease type or stage, and some have excluded those without an identifiable primary informal caregiver. None have stratified their findings according to patient subgroups.

5. Should case management (particularly at the level of primary care) be provided for frail and/or dependent older people in general, or, in programs specifically constructed for people with dementia? The former approach might be more effective in promoting the integrated delivery of holistic and person-centred healthcare. Dementia and cognitive impairment are highly prevalent in this patient group, and make the greatest contribution to functional impairment, needs for care, and complexity in delivering health and social care. Case management can be effective, and cost-effective ${ }^{97,98}$. While such evaluations are not usually stratified by disorder, positive benefits have been shown for the identification of dementia ${ }^{19}$, and for meeting dementia care quality indicators ${ }^{81}$. On the other hand, it is often emphasised, correctly, that dementia is 'not just another diagnosis', but one with particularly profound implications for the intensity and orientation of future care ${ }^{41,99}$. As such, perhaps people with dementia need access to case 
management services with specialist knowledge and skills, and adequate resources to meet their complex needs.

Throughout the literature on healthcare management of dementia, there is surprisingly little focus on the integrated care of physical, mental and cognitive comorbidities, with the effective care of chronic physical conditions particularly neglected. This limitation appears to be pervasive. There is clear evidence for a high prevalence of multimorbidity ${ }^{100}$, some evidence of more limited access to treatment and monitoring for diabetes and eye care ${ }^{100}$, and suboptimal management in primary care of cardiovascular disease and its risk factors ${ }^{72}$. However, as was noted in a recent scoping review on management of comorbidities

"Less is known about service organisation and delivery or the views and experiences of people with dementia and their family carers... There is a need for more research looking at the ways in which having dementia impacts on clinical care for other conditions and how the process of care and different services are adapting to the needs of people with dementia and comorbidity. People with dementia should be included in the debate about the management of comorbidities in older populations and there needs to be greater consideration given to including them in studies that focus on age-related healthcare issues" 100 .

A review of dementia clinical guidelines highlights their general lack of applicability to older patients among whom multimorbidities are particularly common ${ }^{101}$. While most of the guidelines considered the specific needs of older persons, only $60 \%$ reported evidencebased treatment recommendations for one or more comorbidity, and only $32 \%$ considered multiple morbidities. Education and training programmes for PCPs, to the extent to which they include aspects of continuing care, seem to give little or no attention to the challenges of delivering holistic, person-centred care to people with dementia and multimorbidities $8,12,13$. Case management interventions attend, to varying degrees, to physical health through medication management, promoting self-management and healthy behaviours, and encouraging efficient use of healthcare services. However, the health outcomes considered are generally dementia-specific.

While the focus of this chapter has been upon the role that is, and could be, played by generalists in primary care, thought also needs to be given to the optimal role of specialists within a more task-shifted and task-shared model of care provision. Neurologists, psychiatrists and geriatricians play an important part, to varying degrees in different health systems, in delivering diagnostic, post-diagnostic and continuing care services. Dementia care is a sub-speciality area for all three of these medical disciplines, and not all such specialist clinicians will have the relevant experience, knowledge and skills. This may be particularly true for low and middle income countries with less well developed specialist dementia care systems ${ }^{102}$.

For those that have developed these skills (which are not formally accredited in most systems), there is often a tacit assumption that neurologists, psychiatrists and geriatricians have equivalent competencies across the comprehensive range of assessment and management activities that might be required. This seems improbable, and some of the studies identified in this review highlight differences in management styles and care quality between the three groups. Geriatricians might be expected to be particularly competent at assessing and managing complex multimorbidities; psychiatrists at assessing and managing behavioural and psychological symptoms, and neurologists at making difficult diagnoses, identifying rare neurological disorders, and distinguishing other forms of primary brain disease. Of course, there are also likely to be high levels of generic skills shared among all three groups.

Within a more task-shifted model of dementia healthcare, it would make sense for much of the activity where specialist expertise is generic among the three disciplines to be taken on by non-specialists in primary care, while ensuring that the relevant specialist expertise is sought for particular assessment and management problems. Task-shifted models of care require specialist support, both while they are being established (design, training and, in effect, handing over the task), and continuously thereafter (referral, supervision, mentoring and support). Within a resource-limited system, this requires some modification of specialist roles and responsibilities, away from frontline patient care, and towards capacitybuilding activities. In low and middle income countries, where specialist care is underdeveloped, and the diagnosis and treatment gap is most pronounced, the specialist care sector workforce will need to be strengthened, numerically and in terms of skills development to take on this role. In HIC, there may be potential, over time, to decommission and/or reorientate some components of specialist care services, to the extent that task-shifted primary carebased services are proven to provide cost-effective care of equivalent quality. This is not yet a relevant consideration for most LMIC. At the same time, policymakers in these settings should treat calls for investment in western models of specialist orientated care ${ }^{103,104}$ with due caution. The belief reported by one specialist in an article in The Hindu newspaper in India, that dementia management ".. is done best by qualified professionals (including neurologists and psychiatrists trained in dementia care) in memory clinics"104 requires careful and critical examination, 
particularly with respect to the need to scale up access to these services.

In Chapter 7 we present the results of a cost-modelling exercise comparing, in $\mathrm{HIC}$, the cost implications of scaling up dementia healthcare services for people with dementia in HIC for more and less-task shifted systems of service delivery, and for LMIC assessing the costs of scaling up task-shifted systems of care.

\section{References}

1 Brodaty H, Low LF, Gibson L, Burns K. What is the best dementia screening instrument for general practitioners to use? Am J Geriatr Psychiatry 2006; 14: 391-400.

2 Cotter VT, Clark CM, Karlawish JH. Cognitive function assessment in individuals at risk for Alzheimer's disease. J Am Acad Nurse Pract 2003; 15: 79-86.

3 Harvan JR, Cotter V. An evaluation of dementia screening in the primary care setting. J Am Acad Nurse Pract 2006; 18: 351-60.

4 Lin JS, O'Connor E, Rossom RC, et al. Screening for Cognitive Impairment in Older Adults: An Evidence Update for the U.S. Preventive Services Task Force. Rockville (MD): Agency for Healthcare Research and Quality (US), 2013

5 Mitchell AJ, Malladi S. Screening and case finding tools for the detection of dementia. Part I: evidence-based meta-analysis of multidomain tests. Am J Geriatr Psychiatry 2010; 18: 759-82.

6 Mitchell AJ, Malladi S. Screening and case-finding tools for the detection of dementia. Part II: Evidence-based meta-analysis of single-domain tests. Am J Geriatr Psychiatry 2010; 18: 783-800.

7 Yokomizo JE, Simon SS, Bottino CM de C. Cognitive screening for dementia in primary care: a systematic review. Int Psychogeriatr IPA 2014; 26: 1783-804.

8 Downs M, Turner S, Bryans M, et al. Effectiveness of educational interventions in improving detection and management of dementia in primary care: cluster randomised controlled study. BMJ 2006; 332: 692-6.

9 Vollmar HC, Grassel E, Lauterberg J, et al. [Multimodal training of general practitioners--evaluation and knowledge increase within the framework of the dementia management initiative in genera medicine (IDA)]. ZArztIFortbildQualitatssich 2007; 101: 27-34.

10 Vollmar HC, Mayer H, Ostermann T, et al. Knowledge transfer for the management of dementia: a cluster-randomised trial of blended learning in general practice. Implement Sci 2010; 5: 1.

11 Rondeau V, Allain H, Bakchine S, et al. General practice-based intervention for suspecting and detecting dementia in France. Dementia 2008; 7: 433-50.

12 Wilcock J, lliffe S, Griffin M, et al. Tailored educational intervention for primary care to improve the management of dementia: the EVIDEM-ED cluster randomized controlled trial. Trials 2013; 14: 397.

13 van den Dungen $P$, Moll van Charante EP, van de Ven PM, van Marwijk HWJ, van der Horst HE, van Hout HPJ. Case Finding of Mild Cognitive Impairment and Dementia and Subsequent Care; Results of a Cluster RCT in Primary Care. PloS One 2016; 11: e0156958.

14 Bass DM, Clark PA, Looman WJ, McCarthy CA, Eckert S. The Cleveland Alzheimer's managed care demonstration: outcomes after 12 months of implementation. The Gerontologist 2003; 43 . 73-85.

15 Callahan CM, Boustani MA, Unverzagt FW, et al. Effectiveness of collaborative care for older adults with Alzheimer disease in primary care: a randomized controlled trial. Jama 2006; 295 2148-57.

16 Vickrey BG, Mittman BS, Connor KI, et al. The effect of a disease management intervention on quality and outcomes of dementia care: a randomized, controlled trial. Ann Intern Med 2006; 145 713-26.

17 Chodosh J, Berry E, Lee M, et al. Effect of a dementia care management intervention on primary care provider knowledge, attitudes, and perceptions of quality of care. J Am Geriatr Soc 2006; 54: 311-7.

18 Chodosh J, Pearson ML, Connor KI, et al. A dementia care management intervention: Which components improve quality? Am J Manag Care 2012; 18: 85-94.

19 Perry M, Melis RJF, Teerenstra S, et al. An in-home geriatric programme for vulnerable community-dwelling older people improves the detection of dementia inprimary care. Int $J$ Geriatr Psychiatry 2008; 23: 1312-9.

20 Fortinsky RH, Kulldorff M, Kleppinger A, Kenyon-Pesce L. Dementia care consultation for family caregivers: collaborative model linking an Alzheimer's association chapter with primary care physicians. Aging Ment Health 2009; 13: 162-70.

21 Burns R, Nichols LO, Martindale-Adams J, Graney MJ, Lummus A. Primary care interventions for dementia caregivers: 2-year outcomes from the REACH study. The Gerontologist 2003; 43 547-55. 
22 Donath C, Grassel E, Grossfeld-Schmitz M, et al. Effects of general practitioner training and family support services on the care of home-dwelling dementia patients--results of a controlled cluster-randomized study. BMC Health Serv Res 2010; 10: 314.

23 Menn P, Holle R, Kunz S, et al. Dementia care in the general practice setting: a cluster randomized trial on the effectiveness and cost impact of three management strategies. Value Health $\mathrm{J}$ Int Soc Pharmacoeconomics Outcomes Res 2012; 15: 851-9.

24 Waldorff F, Buss D, Eckermann A, et al. Efficacy of psychosocial intervention in patients with mild Alzheimer's disease: The multicentre, rater blinded, randomised Danish Alzheimer Intervention Study (DAISY). BMJ 2012; 345: 1-14.

25 Phung KTT, Waldorff FB, Buss DV, et al. A three-year follow-up on the efficacy of psychosocial interventions for patients with mild dementia and their caregivers: the multicentre, rater-blinded, randomised Danish Alzheimer Intervention Study (DAISY). BMJ Open 2013; 3: e003584.

26 Sogaard R, Sorensen J, Waldorff FB, et al. Early psychosocial intervention in Alzheimer's disease: Cost utility evaluation alongside the Danish Alzheimer's Intervention Study (DAISY). BMJ Open 2014; 4. DOI:10.1136/bmjopen-2013-004105.

27 Rodriguez-Sanchez E, Patino-Alonso MC, Mora-Simon S, et al. Effects of a psychological intervention in a primary health care center for caregivers of dependent relatives: a randomized trial. The Gerontologist 2013; 53: 397-406.

28 Meeuwsen EJ, Melis RJF, Van Der Aa GCHM, et al. Effectiveness of dementia follow-up care by memory clinics or general practitioners: randomised controlled trial. BMJ 2012; 344: e3086.

29 Meeuwsen E, Melis R, van der Aa G, et al. Cost-effectiveness of one year dementia follow-up care by memory clinics or general practitioners: economic evaluation of a randomised controlled trial. PloS One 2013; 8: e79797.

30 Meeuwsen EJ, Melis RJF, Meulenbroek O, Rikkert MGMO. Comparing content of dementia care after diagnosis: memory clinics versus general practitioners. Int J Geriatr Psychiatry 2014; 29: 437-8.

31 Volandes AE, Paasche-Orlow MK, Barry MJ, et al. Video decision support tool for advance care planning in dementia: randomised controlled trial. BMJ 2009; 338: b2159.

32 Golstein C, Duhot D, Steichen O. A randomized trial comparing the mini mental state examination and the montreal cognitive assessment to screen for cognitive impairment in older patients at cardiovascular risk. J Hypertens 2015; 33: e439.

33 van Charante EPM, Richard E, Eurelings LS, et al. Effectiveness of a 6-year multidomain vascular care intervention to prevent dementia (preDIVA): a cluster-randomised controlled trial. Lancet Lond Engl 2016; published online July 26. DOI:10.1016/S01406736(16)30950-3.

34 Mitchell AJ, Meader N, Pentzek M. Clinical recognition of dementia and cognitive impairment in primary care: A metaanalysis of physician accuracy. Acta Psychiatr Scand 2011; 124: 165-83.

35 Martin-Khan M, Flicker L, Wootton R, et al. The Diagnostic Accuracy of Telegeriatrics for the Diagnosis of Dementia via Video Conferencing. J Am Med Dir Assoc 2012; 13: 487.e19-487.e24.

36 Fisher $\mathrm{CAH}$, Larner AJ. Frequency and diagnostic utility of cognitive test instrument use by GPs prior to memory clinic referral. Fam Pract 2007; 24: 495-7.

37 Menon R, Larner AJ. Use of cognitive screening instruments in primary care: The impact of national dementia directives (NICE/ SCIE, National Dementia Strategy). Fam Pract 2011; 28: 272-6.

38 Kirson NY, Desai U, Ristovska L, et al. Assessing the economic burden of Alzheimer's disease patients first diagnosed by specialists. BMC Geriatr 2016; 16: 138.

39 Butler D, Kowall NW, Lawler E, Michael Gaziano J, Driver JA. Underuse of diagnostic codes for specific dementias in the Veterans Affairs New England healthcare system. J Am Geriatr Soc 2012; 60: 910-5.

40 Boustani M. Dementia screening in primary care: Not too fast! $J$ Am Geriatr Soc 2013; 61: 1205-7.

41 Borson S, Frank L, Bayley PJ, et al. Improving dementia care: the role of screening and detection of cognitive impairment. Alzheimers Dement J Alzheimers Assoc 2013; 9: 151-9.

42 Prince M., Bryce R, Ferri C. World Alzheimer Report 2011: The benefits of early diagnosis and intervention. London: Alzheimer's Disease International, 2011.
43 Prince M, Acosta D, Ferri CP, et al. A brief dementia screener suitable for use by non-specialists in resource poor settings-the cross-cultural derivation and validation of the brief Community Screening Instrument for Dementia. Int J GeriatrPsychiatry 2011; 26: 899-907.

44 Eichler K, Scrabal C, Steurer J, Mann E. Preventive health risk appraisal for older people and impact on GPs' patient management: A prospective study. Fam Pract 2007; 24: 604-9.

45 McCarten JR, Anderson P, Kuskowski MA, McPherson SE, Borson S. Screening for cognitive impairment in an elderly veteran population: Acceptability and results using different versions of the mini-cog. J Am Geriatr Soc 2011; 59: 309-13.

46 Kallumpuram S, Sudhir Kumar CT, Khan B, Gavins V, Khan A, lliffe $S$. Targeted case finding for dementia in primary care: Surrey Downs dementia diagnosis project. BMJ Qual Improv Rep 2015; 4. DOI:10.1136/bmjquality.u209827.w4086.

47 Fowler NR, Boustani MA, Frame A, et al. Effect of patient perceptions on dementia screening in primary care. J Am Geriatr Soc 2012; 60: 1037-43.

48 Walters K, Hardoon S, Petersen I, et al. Predicting dementia risk in primary care: development and validation of the Dementia Risk Score using routinely collected data. BMC Med 2016; 14. DOI:10.1186/s12916-016-0549-y.

49 Fowler NR, Harrawood A, Frame A, et al. The Indiana University Cognitive Health Outcomes Investigation of the Comparative Effectiveness of dementia screening (CHOICE) study: Study protocol for a randomized controlled trial. Trials 2014; 15. DOI:10.1186/1745-6215-15-209.

50 Perry M, Draskovic I, Lucassen P, Vernooij-Dassen M, van AT, Rikkert MO. Effects of educational interventions on primary dementia care: A systematic review. Int J GeriatrPsychiatry 2011; 26: 1-11.

51 Chesney TR, Alvarado BE, Garcia A. A mild dementia knowledge transfer program to improve knowledge and confidence in primary care. J Am Geriatr Soc 2011; 59: 942-4.

52 Koch T, lliffe S, Evidem-Ed project. Rapid appraisal of barriers to the diagnosis and management of patients with dementia in primary care: a systematic review. BMC Fam Pract 2010; 11: 52

53 Aminzadeh F, Molnar FJ, Dalziel WB, Ayotte D. A Review of Barriers and Enablers to Diagnosis and Management of Persons with Dementia in Primary Care. Can Geriatr J 2012; 15: 85-94.

54 Harris DP, Chodosh J, Vassar SD, Vickrey BG, Shapiro MF. Primary care providers' views of challenges and rewards of dementia care relative to other conditions. J Am Geriatr Soc 2009; 57: 2209-16.

55 Mukadam N, Livingston G, Rantell K, Rickman S. Diagnostic rates and treatment of dementia before and after launch of a national dementia policy: an observational study using English national databases. BMJ Open 2014; 4. DOI:10.1136/ bmjopen-2013-004119.

56 Olafsdottir M, Foldevi M, Marcusson J. Dementia in primary care: why the low detection rate? Scand J Prim Health Care 2001; 19: 194-8.

57 Cahill S, Clark M, O'Connell H, Lawlor B, Coen RF, Walsh C. The attitudes and practices of general practitioners regarding dementia diagnosis in Ireland. Int J Geriatr Psychiatry 2008; 23: 663-9.

58 Iliffe S, Wilcock J, Haworth D. Obstacles to shared care for patients with dementia: a qualitative study. Fam Pract 2006; 23 : 353-62.

59 Renshaw J, Scurfield P, Cloke L, Orrell M. General practitioners' views on the early diagnosis of dementia. Br J Gen Pract J R Coll Gen Pract 2001; 51: 37-8.

60 Odenheimer G, Borson S, Sanders AE, et al. Quality improvement in neurology: dementia management quality measures. Neurology 2013; 81: 1545-9.

61 Allen M, Ferrier S, Sargeant J, Loney E, Bethune G, Murphy G. Alzheimer's Disease and Other Dementias: An Organizational Approach to Identifying and Addressing Practices and Learning Needs of Family Physicians. Educ Gerontol 2005; 31: 521-39.

62 Dodd E, Cheston R, Ivanecka A. The assessment of dementia in primary care. J Psychiatr Ment Health Nurs 2015; 22: 731-7.

63 Lee L, Hillier LM, Stolee P, et al. Enhancing dementia care: A primary care-based memory clinic. J Am Geriatr Soc 2010; 58: 2197-204. 
64 Convery P, Pond D, Goode S. A feasibility study of a nursing intervention to assist General practitioners with best practice identification and management of dementia. University of Newcastle, 2013 http://www.dementiaresearch.org.au/images/ dcrc/output-files/629-digp5_report.pdf (accessed Dec 8, 2016).

65 Dodd E, Cheston R, Fear T, et al. An evaluation of primary care led dementia diagnostic services in Bristol. BMC Health Serv Res 2014; 14: 592.

66 Lee L, Weston WW, Hillier LM. Developing memory clinics in primary care: An evidence-based interprofessional program of continuing professional development. J Contin Educ Health Prof 2013; 33: 24-32.

67 Benbow SM, Jolley D, Greaves IC, Walker E. Closing the diagnosis gap and improving care: The primary care memory clinic. Prog Neurol Psychiatry 2013; 17: 27-30.

68 NHS England. Models of Dementia Assessment and Diagnosis: Indicative Cost Review. NHS England, 2015 https://www.england. nhs.uk/wp-content/uploads/2015/09/mods-demntl-assessmntdiag-cost.pdf (accessed Dec 8, 2016).

69 Alzheimer's Scotland. 5 Pillars Model of Post-Diagnostic Support 2013. http://www.alzscot.org/campaigning/five_pillars (accessed Aug 16, 2016).

70 Meeuwsen EJ, German P, Melis RJ, et al. Cost-effectiveness of post-diagnosis treatment in dementia coordinated by Multidisciplinary Memory Clinics in comparison to treatment coordinated by general practitioners: an example of a pragmatic trial. J Nutr Health Aging 2009; 13: 242-8.

71 Connolly A, lliffe S, Gaehl E, et al. Quality of care provided to people with dementia: Utilisation and quality of the annual dementia review in general practice. Br J Gen Pract 2012; 62 e91-8.

72 Connolly A, Campbell S, Gaehl E, et al. Under-provision of medical care for vascular diseases for people with dementia in primary care: A cross-sectional review. Br J Gen Pract 2013; 63: e88-96.

73 Rodriguez EG, Dodge HH, Birzescu MA, Stoehr GP, Ganguli $M$. Use of lipid-lowering drugs in older adults with and without dementia: A community-based epidemiological study. J Am Geriatr Soc 2002; 50: 1852-6.

74 Parmar J, Dobbs B, McKay R, et al. Diagnosis and management of dementia in primary care: Exploratory study. Can Fam Physician 2014; 60: 457-65.

75 Jennings LA, Reuben DB, Evertson LC, et al. Unmet needs of caregivers of individuals referred to a dementia care program. $J$ Am Geriatr Soc 2015; 63: 282-9.

76 Colenda CC, Leist JC, Rapp SR. Survey of physician practices for community-dwelling agitated dementia patients. Int J Geriatr Psychiatry 1996; 11: 635-44.

77 Colenda CC, Rapp SR, Leist JC, Poses RM. Clinical variables influencing treatment decisions for agitated dementia patients: Survey of physician judgments. J Am Geriatr Soc 1996; 44: 1375-9.

78 Bass DM, Judge KS, Snow A, et al. Caregiver outcomes of partners in dementia care: Effect of a care coordination program for veterans with dementia and their family members and friends. J Am Geriatr Soc 2013; 61: 1377-86.

79 Bass DM, Judge KS, Snow AL, et al. A controlled trial of Partners in Dementia Care: veteran outcomes after six and twelve months. Alzheimers Res Ther 2014; 6: 9.

80 MacNeil Vroomen J, Bosmans JE, van de Ven PM, et al. Community-dwelling patients with dementia and their informal caregivers with and without case management: 2-year outcomes of a pragmatic trial. J Am Med Dir Assoc 2015; 16: 800.e1-8.

81 Reuben DB, Ganz DA, Roth CP, McCreath HE, Ramirez KD, Wenger NS. Effect of nurse practitioner comanagement on the care of geriatric conditions. J Am Geriatr Soc 2013; 61: 857-67.

82 Connor KI, McNeese-Smith DK, Vickrey BG, et al. Determining care management activities associated with mastery and relationship strain for dementia caregivers. J Am Geriatr Soc 2008; 56: 891-7.

83 Eichler T, Thyrian JR, Dreier A, et al. Dementia care management: going new ways in ambulant dementia care within a GP-based randomized controlled intervention trial. Int Psychogeriatr IPA 2014; 26: 247-56.

84 Reuben DB, Evertson LC, Wenger NS, et al. The University of California at Los Angeles Alzheimer's and Dementia Care program for comprehensive, coordinated, patient-centered care: Preliminary data. J Am Geriatr Soc 2013; 61: 2214-8.
85 Khanassov V, Vedel I, Pluye P. Case management for dementia in primary health care: a systematic mixed studies review based on the diffusion of innovation model. Clin Interv Aging 2014; 9: 915-28.

86 Iliffe S, Robinson L, Bamford C, et al. Introducing case management for people with dementia in primary care: A mixedmethods study. Br J Gen Pract 2014; 64: e735-41.

87 Bamford C, Poole M, Brittain K, et al. Understanding the challenges to implementing case management for people with dementia in primary care in England: a qualitative study using Normalization Process Theory. BMC Health Serv Res 2014; 14: 549.

88 Greenwood N, Pelone F, Hassenkamp AM. General practice based psychosocial interventions for supporting carers of people with dementia or stroke: a systematic review. BMC Fam Pract 2016; 17. DOI:10.1186/s12875-015-0399-2.

89 Nichols LO, Martindale-Adams J, Burns R, Graney MJ, Zuber J. Translation of a dementia caregiver support program in a health care system--REACH VA. Arch Intern Med 2011; 171: 353-9.

90 Belle SH, Burgio L, Burns R, et al. Enhancing the quality of life of dementia caregivers from different ethnic or racial groups: a randomized, controlled trial. AnnInternMed 2006; 145: 727-38.

91 Eichler T, Rene Thyrian J, Hertel J, et al. Unmet Needs of Community-Dwelling Primary Care Patients with Dementia in Germany: Prevalence and Correlates. J Alzheimers Dis 2016; 51: 847-55.

92 Eichler T, Thyrian JR, Fredrich D, et al. The benefits of implementing a computerized intervention-management-system (IMS) on delivering integrated dementia care in the primary care setting. Int Psychogeriatr IPA 2014; 26: 1377-85.

93 Byszewski AM, Graham ID, Amos S, et al. A continuing medical education initiative for Canadian primary care physicians: The Driving and Dementia Toolkit: A pre- and postevaluation of knowledge, confidence gained, and satisfaction. J Am Geriatr Soc 2003; 51: 1484-9.

94 Rockwood K, Keren R. Dementia services in Canada. Int J Geriatr Psychiatry 2010; 25: 876-80.

95 Jotheeswaran AT, Williams JD, Prince MJ. The predictive validity of the 10/66 dementia diagnosis in Chennai, India: a 3-year follow-up study of cases identified at baseline. Alzheimer DisAssocDisord 2010; 24: 296-302.

96 Koch T, lliffe S. Dementia diagnosis andmanagement: A narrative review of changing practice. Br J Gen Pract 2011; 61: e513-25.

97 Hebert R, Raiche M, Dubois MF, Gueye NR, Dubuc N, Tousignant $M$. Impact of PRISMA, a coordination-type integrated service delivery system for frail older people in Quebec (Canada): A quasi-experimental study. JGerontolB PsycholSciSocSci 2010; 65B: 107-18.

98 Melis RJ, van Eijken MI, Teerenstra S, et al. A randomized study of a multidisciplinary program to intervene on geriatric syndromes in vulnerable older people who live at home (Dutch EASYcare Study). J GerontolA Bio/SciMedSci 2008; 63: 283-90.

99 Phelan EA, Debnam KJ, Anderson LA, Owens SB. A systematic review of intervention studies to prevent hospitalizations of community-dwelling older adults with dementia. Med Care 2015; 53: 207-13.

100 Bunn F, Burn AM, Goodman C, et al. Comorbidity and dementia: a scoping review of the literature. BMC Med 2014; 12. DOI:10.1186/ s12916-014-0192-4.

101 Damiani G, Silvestrini G, Trozzi L, Maci D, lodice L, Ricciardi W. Quality of dementia clinical guidelines and relevance to the care of older people with comorbidity: evidence from the literature. Clin Interv Aging 2014; 9: 1399-407.

102 Jia J, Zuo X, Jia X-F, et al. Diagnosis and treatment of dementia in neurology outpatient departments of general hospitals in China. Alzheimers Dement J Alzheimers Assoc 2016; 12: 446-53.

103 Manes $F$. The huge burden of dementia in Latin America. Lancet Neurol 2016; 15: 29.

104 Special Correspondent. More memory clinics and day centres required for dementia care. The Hindu. 2013; published online Sept 21. http://www.thehindu.com/news/national/karnataka/ more-memory-clinics-and-daycare-centres-required-fordementia-care/article5151011.ece (accessed Aug 16, 2016). 


\section{CHAPTER 3}

\section{Care coordination and case management for people with dementia}

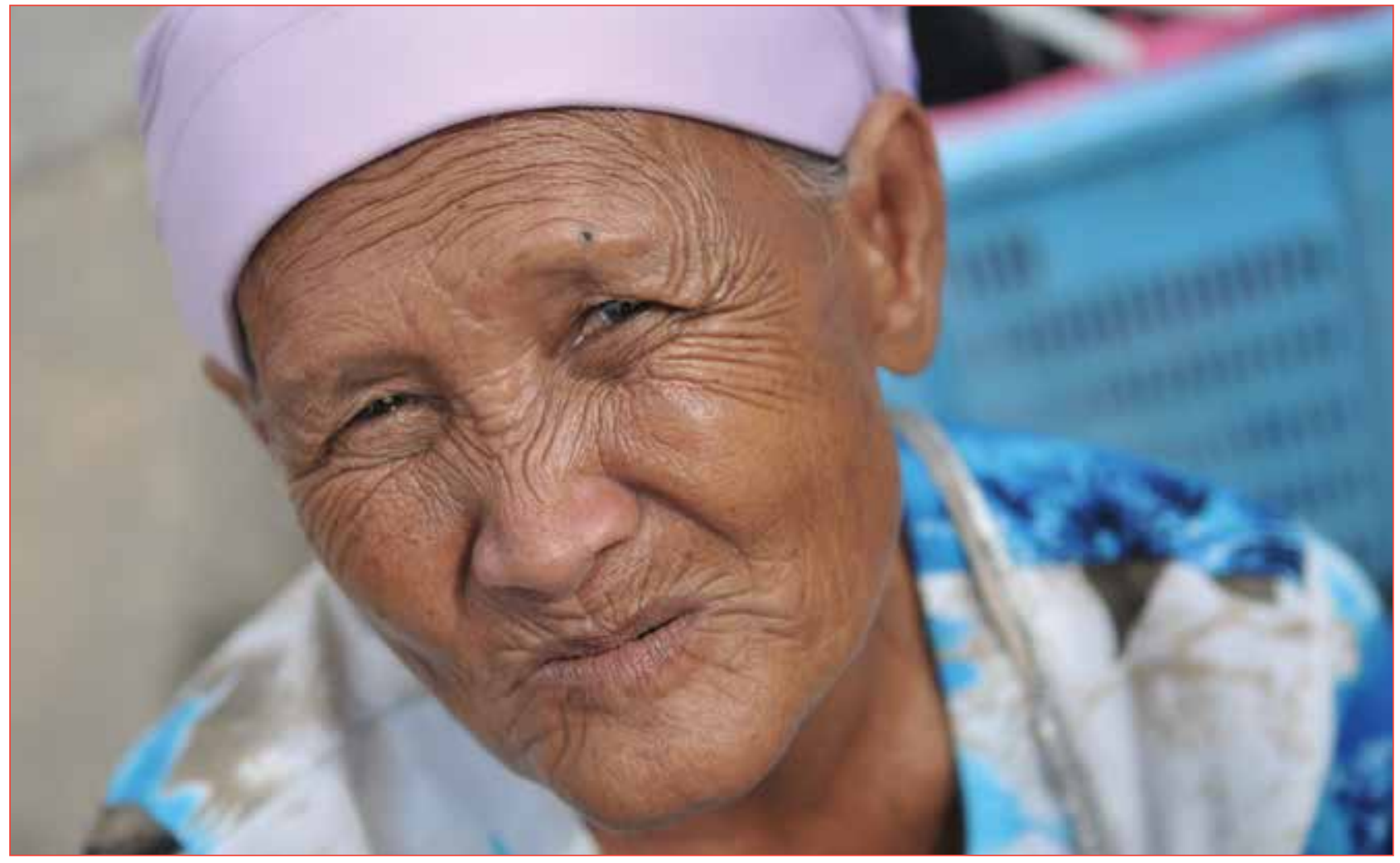

Care coordination, through case management, has been presented as a means of improving care and reducing costs. The Case Management Society of America (CMSA) describes case management as "a collaborative process of assessment, planning, facilitation and advocacy for options to meet an individual's health need through communication and available resources to promote quality cost-effective outcomes"1.

Case management has numerous potential benefits for people with dementia: reducing the burden of the disease; managing the evolution of needs over the disease course; facilitating access to services; and providing advice (including decision-making regarding end of life). Over the last decades, research on case management has been conducted within primary care and specialist care settings, and in the community, studying its effect on outcomes for people with dementia, their carers, and service utilisation. Case management for people with dementia and their carers has been advocated in dementia care strategies or national Alzheimer's Plans in several countries including Australia ${ }^{2}$, England ${ }^{3}$, France $^{4}$, Denmark ${ }^{5}$ or Mexico $^{6}$ (see http://www.alz.co.uk/alzheimer-plans for the full list).

\subsection{Objectives and search strategy}

We carried out a review of recent research evidence regarding the effectiveness of case management, wherever it is located within the health and social care system, with respect to outcomes for people with dementia and their carers, and evidence for improved efficiency of delivery of health and social care. We were interested in a wide range of outcomes, including, for the person with dementia (quality of life, behaviour, mortality), the carer (quality of life, strain, mood), and for service use (hospitalisation, transfer into a care home, and overall costs). All types of relevant research were of interest, especially systematic reviews and randomised controlled trials (RCTs).

We conducted a scoping review in order to map the existing literature, using the following search strategy.

We used the search terms 'dementia OR Alzheimer's disease' AND 'case management OR care management OR care coordination', seeking papers published from 1980 onwards. We searched Ovid Medline, PubMed, PsycINFO and Cochrane databases. Following this, a search with the use of Google Scholar was conducted to find 'grey' literature 
and articles in other databases than those mentioned above (reports and policy papers).

\section{Inclusion criteria}

- Studies with a clear focus or relevance to case management and care coordination

- A clear focus on older people with dementia, Alzheimer's disease, or cognitive impairment

- English language resources

\section{Exclusion criteria}

- A focus on older people rather than on people with dementia

- Editorials, Opinion pieces

\subsection{Search results, and characteristics of the eligible studies}

Overall, the search retrieved 5,007 abstracts. First, we excluded 3,048 publications after review of titles and abstracts, which were duplicates, conference abstracts and other non-relevant abstracts. The remaining 1,959 abstracts were double screened by MK and MG for relevance. After reviewing titles and abstracts, and hard copies if necessary, 90 publications were identified as meeting our inclusion criteria.

Among those publications, 17 were reviews (qualitative, quantitative, or mixed), 16 described case management approaches, 32 described RCTs of the effectiveness of case management, and 25 provided other relevant evidence on implementation of case management programmes using study designs other than RCTs. Randomised controlled trials were mainly conducted in High Income Countries $(n=26$, including the United States of America, Canada, the United Kingdom, Finland, and the Netherlands) and most of the case management interventions included care coordination as well as support programmes, counselling or education $(n=25)$.

\subsection{What is the evidence to support case management (cost-) effectiveness?}

The number of reviews on case management is now substantial. In addition to the two reviews ${ }^{7,8}$ described in previous World Alzheimer Reports ${ }^{9,10}$, we identified four more recent reviews from the current search ${ }^{11-15}$. Although overlapping in terms of the individual studies included, these reviews have come to differing conclusions about the effectiveness of case management.

Following the CMSA definition of case management, Pimouguet et al. ${ }^{7}$ reviewed a total of 12 trials focussing on the efficacy of case management for community dwelling people with dementia and their carers in terms of healthcare costs, institutionalisation and hospitalisation. Among those, only four reported a positive impact of case management on time to transfer into a care home, duration of care home admission, or care home admission rate. The evidence was considered too weak to allow any conclusion regarding the efficacy of case management for people with dementia and their carers on costs and resource utilisation. Somme et al. ${ }^{8}$ conducted a more restricted review on the impact of case management programs, that include case identification, standardised multidimensional assessment, and the development, implementation, and monitoring and reassessment of an individualised care plan, on clinical outcomes and utilisation of resources by people with dementia. Only six RCTs (also identified in the first review ${ }^{7}$ ) were included, of which four reported moderately significant effects on clinical outcomes or resource utilisation. The authors highlighted that the degree of integration between health and social service organisations and the intensity of case management appeared to be related to greater efficacy. Each of these reviews ${ }^{7,8}$ were descriptive and did not perform any metaanalyses.

After systematic review, a meta-analysis conducted by Tam-Tham et al. ${ }^{13}$ pooled the effects of 17 RCTs to evaluate the effectiveness of dementia case management compared with usual care on reducing long-term care placement, hospitalisation, and emergency department visits, and on delaying time to long-term care placement and hospitalisation. The overall pooled relative risk (RR) of long-term care placement estimated was not significant $(R R=0.94$, 95\% Cl: 0.85-1.03, $\mathrm{p}=0.227$ ) for dementia case management compared to usual care. However, when follow-up duration was below 18 months, a significant reduction in risk of long-term care placement was found ( $R R=0.61,95 \% \mathrm{Cl}: 0.41-0.91, p=0.015)$. No significant effect of dementia case management was found on hospitalisation and emergency department visits. It was therefore concluded that dementia case management showed only a short-term positive effect on long-term care placement among older people with dementia living in the community and that other types of resource utilisation needed further investigation.

More recently, Reilly et al. ${ }^{15}$ in a Cochrane review on case management approaches to home support for people with dementia highlighted that 'case management' is often used fairly approximately in the literature and is usually defined in a multifaceted way. Their review was therefore guided by the definition of case management as 'any intervention delivered in the community (not in hospital or residential care settings) predominantly focused on the planning and co-ordination of care required to meet the identified needs of the person with dementia'. The primary objective was to evaluate the effectiveness of case management approaches to home support 
Table 3.1

Randomised controlled trials relevant to care coordination/case management approaches for people with dementia living at home

Country
UK (London)
Author
Hinchliffe ${ }^{31}$
Year
1995 (Year of publication
not year of study)

Intervention

Individualised care

package for the carer and the person with dementia, including medication, psychological technique, and social measures.

Care management tasks: assessment, care planning, implementation/ management of care plan, arranging/allocating services, case closure (discharged back to the GP)

Care manager: planning by multidisciplinary team, implementation by psychiatrist

Duration: 4 months. $\mathrm{N}=22$

\section{Control}

Waiting list, received a delayed intervention package at 16 weeks.

\section{Follow-up}

4 and 8 months

Participant Outcomes

Neuropsychiatric

symptoms.

\section{Carer Outcomes}

General Health, Change in mental health.

\section{Main Results}

Improvement in behavioural difficulties of the participant and improvement in carer's mental health after intervention.

\section{Study, Country}

Medicare Alzheimer's Disease Demonstration, USA

Author

Newcomer, Yordi, Shelton \& Miller ${ }^{18-20,32-34}$

Year

1997-2001 (Years of publication)

Intervention

Two case-management models:

- Model A (low reimbursement - high caseload) - sites operated with a target case-manager-to-client ratio of 1:100 and had a monthly community service reimbursement limit or cap from USD290 through USD489 per month per participant

- Model B (high reimbursement - low caseload) - sites operated with a target case-manager-to-client ratio of 1:30 and a slightly higher reimbursement limit of from USD430 through USD699 per month per participant

Care management tasks: assessment, care planning, implementation/management of care plan, arranging/ allocating services, case budget management/budget holding, monitoring the implementation of the care plan. Large orientation to assessment, client monitoring, care planning and situational problem-solving.

Care manager: nurses, social workers, mental health professionals, gerontology specialists

Duration: Unclear - Demonstration operational December 1989 -November 1994. $\mathrm{N}=4151$

Control

Usual care. $\mathrm{N}=3944$

Follow-up

\section{$6,12,18,24$ and 36 months}

\section{Participant Outcomes}

Mortality, Home entry rates, Use of home care services, Day care use, Assisted living housing use, Annual mean number of emergency department visits, Medicare expenditures.

\section{Carer Outcomes}

Burden, Depression, Annual mean number of hospital admissions, Annual mean length of hospital stay.

\section{Main Results}

Greater likelihood of community service use.

Small reduction in caregiver burden and depression over 36 months after intervention for some sites.

No effect on nursing home entry rates for treatments overall.

Lower likelihood of any hospitalisation during the study period for caregivers in the intervention. For those who were hospitalised, no significant differences in the number of caregivers' hospitalisations, hospital length of stay, or Medicare payments.

Country
Canada
Author
Chu
Year

2000 (Year of publication)

Intervention

Early Home Care Program includes case management, occupational therapy physical therapy social work, nursing, respiratory therapy in-home respite, and out-of-home respite, homemaking, personal care assistance, volunteer service and psychiatric consultation

Care management tasks: care planning, implementation/ management of care plan, arranging/allocating services, monitoring the implementation of the care plan

Care manager: social worker, occupational therapist, nurse

Duration: 18 months. $\mathrm{N}=37$

Control

Information package on community resources. $\mathrm{N}=38$

Follow-up

\section{$3,6,10,14$ and 18 months}

\section{Participant Outcomes}

Well-being, Cognition, Activities of Daily Living, Neuropsychiatric Symptoms, Number using services, Length of time participants remained in the community.

\section{Carer Outcomes}

Well-being.

\section{Main Results}

Caregivers in the treatment group felt less burdened at six months, Institutionalisation was delayed for patients (with mild to moderate impairment) in the treatment group 
Table 3.1 (continued)

Randomised controlled trials relevant to care coordination/case management approaches for people with dementia living at home

\section{Study, Country \\ Effects of supporting community- living demented patients and their caregivers, Finland}

\section{Author}

Eloniemi-Sulkava $^{22}$

Year

2001

Intervention

Programme of systematic, comprehensive support by a dementia family care $\mathrm{co}$ ordinator who had access to the physician and co-ordinated the care, services and support of the families.

Care management tasks: assessment, care planning, implementation/management of care plan, arranging/allocating services

Care manager: registered nurse with public health background and extensive training

Duration: 2 years. $\mathrm{N}=53$

Control

Usual services (community care by municipal social and healthcare system or private). $\mathrm{N}=47$

Follow-up

1 and 2 years

\section{Participant Outcomes}

Cognition (MMSE), Death at home, Placement in longterm institutions, Time to institutionalisation / maintenance of community residence.

\section{Carer Outcomes}

Burden.

\section{Main Results}

Rate of institutionalisation was significantly lower in the intervention group during the first months.

Benefit of the intervention decreased with time.

\section{Study, Country}

Cleveland Alzheimer's managed care demonstration, USA (Ohio)

Author

Bass, Clark \& Judge ${ }^{16,35,36}$

Year

2003 (Year of publication)

Intervention

Telephone-based care consultation delivered within a partnership between a managed care health system and an Alzheimer's Association

Case management tasks: assessment, care planning, implementation and monitoring of care plan.

Care manager: care consultants/ assistants

Duration: 12 months. $\mathrm{N}=94$

Control

Usual managed care services. $\mathrm{N}=63$

Follow-up

12 months

\section{Participant Outcomes}

Depression, Cognition, Satisfaction with services, Use of services, Hospital admissions, Physician visits, Emergency department visits.

\section{Carer Outcomes}

Strain and depression, satisfaction with types of services.

\section{Main Results}

Decrease in selected but not all, service utilisation, and decrease in caregiver depression.

Effects of the intervention intensified for satisfaction outcomes and care-related strain outcomes.

Reduced feeling of embarrassment and isolation for intervention participants.

Fewer physician visits, less emergency department visits or hospital admissions, higher satisfaction with managed care services, and decreased depression and strain for intervention participants.

\section{Study, Country}

Dementia Care Management Programme, Hong Kong SAR China

Author

Chien ${ }^{27}$

Year

2005-2006

\section{Intervention}

Dementia care management programme (educational and supportive group for carers)

Care management tasks: Assessment, care planning, implementation and monitoring of care plan

Care manager: case manager (who received 32 hours of formal training) with a nurse

Duration: 6 months. $\mathrm{N}=44$

Control

Standard care with 6 months educational sessions. $\mathrm{N}=44$

Follow-up

6 months

\section{Participant Outcomes}

Cognition (MMSE), Neuropsychiatric symptoms, Length of institutionalisation over past 6 months to a residential care home or hospital unit at 6 and 12 months, Length of institutionalisation to a residential care home or hospital unit, Use of services, Institutionalisation over past 6 months.

\section{Carer Outcomes}

Quality of Life, Burden, Social support.

Main Results

Over the 12-month follow-up period:

Participants in the dementia care program showed significantly greater improvements in symptoms and institutionalization rates,

Caregivers reported significantly greater improvements in quality of life and burden. 
Table 3.1 (continued)

Randomised controlled trials relevant to care coordination/case management approaches for people with dementia living at home

\section{Study, Country}

Care Management for Patients With Alzheimer Disease and Their Family Caregivers, USA (Indianapolis)

\section{Author}

Callahan ${ }^{17}$

Year

2006

Intervention

Collaborative care management

Case management tasks: case finding, assessment, financial assessment, care planning, implementation and monitoring of care plan, arranging/allocation of services, review, case closure.

Care manager: geriatric nurse practitioner Duration: 12 months. $\mathrm{N}=84$

Control

Augmented usual care. $\mathrm{N}=69$

Follow-up

6,12 and 18 months

\section{Participant Outcomes}

Cognitive functioning, Neuropsychiatric symptoms, Depression, Activities of Daily Living, Cholinesterase inhibitor use, Healthcare use (physician or nurse visits), Numbers died, Number of admissions to hospital, to nursing home, Length of hospital stay.

\section{Carer Outcomes}

Mood, Satisfaction of Primary Care.

\section{Main Results}

Intervention patients were more likely to receive cholinesterase inhibitors and antidepressants, and had significantly fewer behavioural and psychological symptoms of dementia.

Intervention caregivers reported significant improvements in distress and showed improvement in depression.

No group differences were found for depression, cognition, activities of daily living, or on rates of hospitalisation, nursing home placement, or death.
Study, Country

ACCESS-Trial, USA (California)

Author

Vickrey, Duru \& Chodosh ${ }^{21,37,38}$

Year

2006 (Year of publication)

Intervention

Chronic care model and linkages with community resources and multi-agency co-ordination, including dementia care managers, formal procedures for communication within and between organisations and agencies, included adherence to 23 dementia guideline recommendations, Internet-based care management, collaborative care planning with carers, carer self-management support, on-going follow-up and provider education.

Care management tasks: case finding/screening, assessment, care planning, implementation/management of care plan.

Care manager: social workers who received formal training Duration: 18 months or until case closed or no longer enrolled in programme. $\mathrm{N}=238$

Control

Usual care. $\mathrm{N}=170$

Follow-up

\section{2,18 months}

\section{Participant Outcomes}

Cognition (MMSE), Behaviour, Quality of life, Cholinesterase inhibitor use, Service use at 18 months, Institutionalisation/ nursing home stays, Hospital admissions/inpatient utilisation, Emergency department visits, Use of one or more community services.

\section{Carer Outcomes}

Quality of life, Social support, Number of participants in carer support group, Informal caregiving hours per month, Healthcare in the home per month, Confidence in care-giving, Mastery, Satisfaction, Adherence to guidelines, Knowledge about dementia.

\section{Main Results}

Patient health-related quality of life, overall quality of patient care, caregiving quality, social support, and level of unmet caregiving assistance needs were better for participants in the intervention group. Caregiver health-related quality of life did not differ between the 2 groups.

No significant differences in the mean monthly cost of healthcare and caregiving services for intervention versus usual care patients. 
Table 3.1 (continued)

Randomised controlled trials relevant to care coordination/case management approaches for people with dementia living at home

\begin{tabular}{l}
\hline Study, Country \\
\hline Dementia Family Care \\
Programme, Hong Kong SAR \\
China \\
Author \\
\hline Chien ${ }^{26}$ \\
Year \\
\hline 2007-2009 \\
Intervention \\
Case manager assigned \\
to families - home visits, \\
health and educational needs \\
assessment, education about \\
dementia, support programme \\
for effective dementia care \\
Case management tasks: \\
assessment, care planning, \\
implementation and monitoring \\
of care plan \\
Care manager: nurse \\
Duration : 6 months. N=46 \\
Control
\end{tabular}

Routine care. $\mathrm{N}=46$

Follow-up

1 week, 12 and 18 months

Participant Outcomes

Cognition (MMSE),

Neuropsychiatric symptoms,

Family Caregiving Burden, Social support, Utilisation of services, Length of institutionalisation to a residential care home or hospital unit.

\section{Carer Outcomes \\ Quality of Life. \\ Main Results}

Participants in the intervention group reported significantly greater improvements in clients' symptoms and institutionalisation rates, and caregivers' quality of life and burden, at 18-month follow-up.

Country
India (Goa)
Author
Dias $^{30}$
Year
2008 (Year of publication)
Intervention

Stepped-care model aiming at improving awareness an knowledge of carers regarding dementia, providing emotional support to carers, to maximise their caregiving resources and improve caregiving skills

Care management tasks: case finding, implementation and monitoring of care plan

Care manager: Healthcare assistant (trained for a week), supervised by psychiatrists and counsellor

Duration: 6 months minimum. $\mathrm{N}=41$

Control

Only education and information regarding dementia. Placed on waiting list to receive intervention after 6 months.

Follow-up

3 and 6 months

Participant Outcomes

Functional ability, Neuropsychiatric symptoms.

\section{Carer Outcomes}

Mental health, Burden

Main Results

Significant reduction of mental health and neuropsychiatric symptoms in the intervention group. Non-significant reductions in the burden, functional ability and neuropsychiatric symptoms. Nonsignificant reduction in the total number of deaths in people with dementia in the intervention arm.
Study, Country

Multicomponent Support Program for Elderly Couples with Dementia, Finland

Author

Eloniemi-Sulkava ${ }^{23}$

Year

2009

\section{Intervention}

Family care co-ordinator, geriatrician's medical investigations and treatments, goal-oriented support group meetings for spouse carers and individual tailored services.

Care management tasks: case finding/screening, assessment, care planning, implementation/ management of care plan, arranging/allocating services.

Care manager: trained public health registered nurse with extensive training

Duration: maximum 24 months. $\mathrm{N}=63$

Control

Usual services (community care by municipal social and healthcare system or private). $\mathrm{N}=62$

Follow-up

\section{6,12 and 24 months}

\section{Participant Outcomes}

Functional ability (12 months), Neuropsychiatric symptoms (12 months), Numbers and \% of deaths of people with dementia, number and $\%$ of people institutionalised, Costs of municipal healthcare and social care services (total Euros per year), Time to institutionalisation, Use and cost of services from intervention budget.

\section{Carer Outcomes}

Burden, Number of deaths

\section{Main Results}

At 1.6 years, a larger proportion in the control group than in the intervention group was in longterm institutional care.

At 2 years, the difference was no longer statistically significant. Intervention led to reduction in use of community services and expenditures. When the intervention costs were included, the differences between the groups were not significant. 
Table 3.1 (continued)

Randomised controlled trials relevant to care coordination/case management approaches for people with dementia living at home

\section{Study, Country}

MIND (Maximising Independence at Home) Pilot, USA (Baltimore)

\section{Author}

Samus \& Tanner ${ }^{39}, 40$

Year

\section{8-2010}

The MIND study was 'awaiting classification' in the Cochrane review ${ }^{15}$

\section{Intervention}

Care coordination - individualised care planning, referral and linkage to services, provision of dementia education and skill building strategies, care monitoring by an interdisciplinary team.

Care management tasks: case finding/ screening, assessment, care planning, implementation/management of care plan.

Care manager: non-clinical community workers

Duration: 18 months. $\mathrm{N}=74$

Control

Augmented usual care. $\mathrm{N}=114$

Follow-up

\section{5, $9,14.5$ and 18 months}

\section{Participant Outcomes}

Neuropsychiatric symptoms, Depression, Quality of life, Time to transfer from home, Unmet care needs.

\section{Carer Outcomes}

Burden, Depression, Carer unmet needs, Quality of life.

\section{Main Results}

Significant delay in time to transition from home in the intervention group.

Significant reductions in the proportions of unmet needs and significant improvement in quality of life in the intervention group.

No difference in the percentage of caregiver unmet needs, nor caregiver depression, burden or quality of life.
Study, Country

Effectiveness of case management among older adults with early symptoms of dementia and their primary informal caregivers, Netherlands

Author

Jansen $^{25}$

Year

2011 (Year of publication)

Intervention

Case management delivered by district nurses who had a co-ordinating function consisting of assessment, giving advice and information, planning, co-ordination, organising collaboration and monitoring of care.

Care management tasks: assessment, care planning, implementation/ management of care, arranging/allocating services, monitoring the implementation of the care plan.

Care manager: district nurse

Duration: 12 months. $\mathrm{N}=54$

Control

Usual care. $\mathrm{N}=45$

Follow-up

6 and 12 months

\section{Participant Outcomes}

Quality of life, Number institutionalised, Number died, Mean number of days in hospital per month, Use of primary care, Use of services.

\section{Carer Outcomes}

Quality of life, Psychological well-being, Burden, Sense of competence.

Main Results

No statistically significant and clinically relevant differences over time between the two groups. 
for people with dementia from the perspective of the patients, carers and staff compared with other forms of treatments (including treatment as usual, standard community treatment and other non-case management interventions). All relevant RCTs and economic evaluations including both people with all types of dementia and their carers were included. A total of 13 randomised studies including 9615 participants were eligible for inclusion, four from the US $^{16-21}$, four in Europe ${ }^{22-25}$, three in Hong Kong ${ }^{26-}$ ${ }^{28}$, one in $\mathrm{Canada}^{29}$ and one in India ${ }^{30}$. Most of the studies ${ }^{16-23,25,26,28,29}$ had a duration of 12 months or more while the longest lasted three years ${ }^{18-20}$. Case managers were employed from various professional groups. Three studies were based in primary care centres $17,21,25$ and case managers were based in dementia resource centres in two studies ${ }^{26,27}$. Almost all trials included face-to-face visits or home visits 22-27,30; only one reported solely telephone-based case management delivered within a partnership between a managed care system and an Alzheimer's Association ${ }^{16}$. See Table 3.1 for the full description of those studies (intervention, control group, care management tasks, and outcomes). After assessment of the risk of bias, it was concluded that all were subject to performance bias as in any psychosocial intervention with non-blinded participants or case managers. However, the overall risk of detection bias (blinding of outcome assessors) was low.

The main results of the meta-analyses are summarised below.

- People in the case management group were significantly less likely to be institutionalised at 6 months (OR 0.82, 95\% Cl: 0.69-0.98) and 18 months (OR $0.25,95 \% \mathrm{Cl}: 0.10-0.61$ ). The effects at $10-12$ months (OR $0.95,95 \% \mathrm{Cl}: 0.83-1.08$ ) or 24 months (OR 1.03, 95\% Cl: 0.52-2.03) were not significant.

- One trial ${ }^{27}$ showed a significant reduction in the number of days per months in a residential home or hospital unit in the case management group at six months (mean difference $-5.80,95 \% \mathrm{Cl}$ : -7.93 to -3.67), 12 months (mean difference $-7.70,95 \% \mathrm{Cl}$ : -9.38 to -6.02 ) but not 18 months (mean difference $0.17,95 \% \mathrm{Cl}:-0.92$ to +1.26$)$. However, another trial $^{23}$ reported no significant difference between the two groups regarding time to transition into a care home (HR 0.66, 95\% Cl: 0.38-1.14).

- No difference was found in the odds of hospitalisation at six months (OR 1.06, 95\% Cl: 0.61-1.84), 12 months (OR 0.87, 95\% Cl: 0.59-1.30) or 18 months (OR 0.76, 95\% Cl: 0.53-1.10).

- No significant effects were found on mortality among people with dementia at 4-6, 12, 18-24 or 36 months.
- No significant effects were found on the quality of life of the person with dementia or carer at 4-6, 12, 18-24 or 36 months.

- Some evidence of benefit for carer strain was found at six months (standardised mean difference $-0.07,95 \% \mathrm{Cl}:-0.12$ to -0.01 ) but this would not be considered clinically significant, and there was no evidence of longer term benefit. Additionally, case management was found effective at reducing behaviour disturbances at 18 months in two trials (standardised mean difference $-0.35,95 \% \mathrm{Cl}$ : -0.63 to $-0.07, p=0.01$ ).

- A greater improvement in carer depression/ mood measures at 18 months (standardised mean difference $-0.08,95 \% \mathrm{Cl}:-0.16$ to -0.01 , $\mathrm{p}=0.03$ ) was found in the case management group. However, this effect is small and unlikely to be of clinical significance.

- Some evidence was found regarding reduced cost of services at 12 months (standardised mean difference $-0.07,95 \% \mathrm{Cl}:-0.12$ to -0.01 ) in two trials and incurred lower dollar expenditure for the total three years (mean difference $-705.00,95 \% \mathrm{Cl}$ : -1170.31 to $-239.69, p=0.003$ ) in one trial.

The overall conclusions of this review were that there is some evidence that case management is beneficial for both the person with dementia and their carer at improving some outcomes at certain time points. However, the heterogeneity between interventions, outcomes measures and length of follow-up across the 13 included RCTs was important.

Two additional studies ${ }^{39-41}$ were identified by Reilly et al. during their systematic review. One study was ongoing in the $\mathrm{UK}^{41}$ at the time and showed that the model of case management evaluated was unlikely to be sustainable in general practice under current conditions. A definitive trial was therefore not recommended. The second study, the Maximising Independence at Home (MIND) pilot randomised trail ${ }^{39,40}$ assessed whether dementia care coordination delays time to transition from home, reduces unmet needs in older people with memory disorders and reduces caregiving burden in informal carers. Details of the study are included in Table 3.1. The study included around 300 community-living older people and their carers in Baltimore, who were followed for 18 months. Participants randomised to case management had significant delay in time to all-cause transition from home, and the adjusted risk of leaving home was decreased by $37 \%$ compared to the control group (HR 0.63, 95\% Cl: 0.42 to 0.94). Significant reductions in the proportions of unmet needs in safety and legal/advance care domains were also found in the intervention group. However, unmet carer needs declined in both groups, and there was no statistically significant difference between groups. Improvement in quality of life for intervention participants was 
reported $^{39}$. No difference was found in most carer burden measures, depression or quality of life. Only a modest clinically-meaningful impact on informal carer time spent with the care recipient was found ${ }^{40}$.

Further evidence on the effectiveness of case management in primary care has been provided by controlled trials without randomisation ${ }^{42-45}$ and one RCT focusing on carer outcomes only ${ }^{46}$, as described in the case management section of Chapter 2 (see section 2.6). Whether the intervention was comprised of care management by a nurse-practitioner ${ }^{45}$, a collaboration between Veterans Affairs Medical Centers and Alzheimer's associations ${ }^{42,43}$ or case management supplementing usual care ${ }^{44}$, all of these studies showed a positive effect on at least some relevant outcomes, including comorbidities, adverse events, unmet needs, carer strain, depression, behavioural and psychological symptoms, transition into care homes, and mortality. The RCT reporting on the efficacy of an individualised dementia care consultation intervention for family carers of people with dementia living in the community ${ }^{46}$ also showed positive effects on nursing home admission and carer outcomes.

Case management is only one model of support for people living with dementia and their carers. Earlier this year, Goeman et al. ${ }^{14}$ conducted a systematic review on the effectiveness of a support worker role for people with dementia and their carers. This review covered all the of the models of support for community-dwelling people with dementia and their carers including case managers, care workers, counselling support and multi-team integrated care. 36 studies were included and carefully described. The heterogeneity of the studies and high risk of bias impeded meta-analyses. The essential components shared by support models with a positive effect on carer strain and quality of life were: long term interventions, face to face contact, individualised education and support based on needs, multidisciplinary teams, health service/clinical background of support workers, ongoing follow-up and interprofessional and inter-sectoral collaborations. A lack of cost-effectiveness studies was highlighted by the authors.

If positive effects on participant's and carer's outcomes have been demonstrated in some trials (controlled or not) and meta-analyses, the evidence on the cost-effectiveness of case management interventions for people with dementia and their carers remains very weak because of lack of evidence. In Reilly et al.'s review ${ }^{15}$, only three studies reported data on healthcare costs ${ }^{18,21,23}$. Another systematic review from Knapp and colleagues ${ }^{47}$ on dementia care costs and outcomes found little economic evidence on the cost-effectiveness of non-pharmacological interventions for people with dementia, especially strategies focussing on care organisation and support such as direct payments or case management. Long term studies of cost-effectiveness of case management interventions were suggested. Recently, new evidence from the 'Partners in Dementia Care' (PDC) intervention (a telephone-based care coordination and support service delivered through partnerships between Veterans Health Administration medical centers and local Alzheimer's Association chapters) in the United States was published ${ }^{48}$. This cost analysis of the PDC intervention in a 30-month trial involving five VHA medical centers aimed at examining whether PDC reduced direct Veterans Health Administration (VHA) healthcare costs compared with usual care. A total of 434 veterans aged 50 and older with dementia and their carers and 165 controls were included. During the study, intervention participants showed higher VHA costs than usual-care participants both before and after the intervention but they did not differ significantly regarding change in costs from pre- to post-baseline periods. The conclusion was that PDC met veterans' needs without significantly increasing VHA healthcare costs.

\subsection{Implementation of case management}

Case management has been designed to increase the capacity of Primary Healthcare (PHC) to cope with the complex needs of people with dementia, to improve the quality of dementia care, and to develop costeffective and efficient ways to coordinate services ${ }^{1}$. Although effectiveness has been demonstrated in some studies, implementation of case management programmes can be challenging ${ }^{49}$. A mixed-methods review from Khassanov et al. ${ }^{50}$ sought to identify the conditions limiting and facilitating successful case management implementation in PHC. As already reported in Chapter 2 (see section 2.6), low intensity, large caseload and approach have impeded the implementation of case management interventions.

Two recent qualitative studies provide further insight into the facilitators and barriers to the delivery of case management for people with dementia ${ }^{51,52}$. In the UK, the CAREDEM feasibility study assessed the introduction of a successful United States' case management model to primary care ${ }^{17,53}$. The intervention was delivered by a social worker and nurses, and comprised needs assessment of the person with dementia and their carers, creation of a personal care or support plan, prioritisation and initiation of actions to provide support, and a systematic follow-up of the plan and actions. Interviews were carried out with case managers, people who had dementia, carers and health and social care professionals before, during and after introduction of case management. A lack of clarity 
over the nature and scope of case management from case managers and practices and a lack of resources, skills and training to deliver the intervention, variable investment in the intervention and limited reflection and feedback on the case manager role were identified as key barriers to implementation ${ }^{52}$. Case managers had difficulties identifying and acting on unmet needs of people with dementia and their carers, with limited training and supervision to remedy this skills gap. Most stakeholders considered case management worthwhile but all expressed a lack of clarity over the remit of case managers and their overlap with existing roles. Primary care teams were not engaged and case managers provided little feedback on the approach to members of the primary care team ${ }^{52}$.

In the Netherlands, a qualitative evaluation was conducted of the implementation of two different case management models; the linkage model (a network in which multiple case management providers are active and the case manager acts as a mediator between the client and the multiple care agencies) and the combined intensive case management/joint agency model (a network in which case management and care services are nested in one independent organisation) ${ }^{51}$. Semi-structured interviews were performed with case managers, project leaders, health insurers and municipalities. Implementation was facilitated in the intensive model by the independence of the case management organisation while the presence of multiple competing case management providers in the linkage model impeded the implementation. Impeding factors were more prominent in the linkage model, related to the organisational structure of the dementia care network and how partners collaborated with each other. As a result the intensive case management model seemed easier to implement as case managers were more able to provide quality of care, were less constrained by competitiveness of other care organisations and worked more closely with the expert team than in the linkage model.

Essential components and preconditions of case management for people with dementia were investigated by Verkade et al. ${ }^{54}$ using a different methodology: a Delphi consensus survey. A list of components was selected through a literature review and a focus group, before being validated by 35 experts. After three rounds, a consensus was found on 61 (of 75 statements). Information, support and counselling, coordination of the care provided and, to a lesser extent, practical help were identified as the essential components of case management for people with dementia. Vision, care relationship, structured methodology, integration of case management into the healthcare chain, and the case manager's level of training and expertise were essential preconditions to case management. One of the key aspects of providing case management services was a patientcentred approach.

\subsection{Summary and discussion}

In absence of a disease course modifying treatment for dementia, and considering the increasing number of people with dementia globally ${ }^{55}$, interventions and strategies aiming at improving the efficiency and effectiveness of care for people with dementia are much needed. Although case management has been implemented in some countries as part of national strategies or Alzheimer's plans over the last decade, the evidence for effectiveness is modest. Positive effects in terms of reduced or delayed transition into care homes and reduced unmet needs were found in some studies, while the effects on hospitalisation and mortality were generally not significant. The evidence on the benefits on carer strain and psychological morbidity, and the quality of life of the person with dementia and their carer seem weak. While a few studies indicated a modest reduction in healthcare costs in the medium term, the lack of costeffectiveness studies is striking.

Inconsistencies or weaknesses in the evidence on the effectiveness of case management can probably be partly explained by the considerable heterogeneity among trials in the interventions studied, outcomes measured and duration of followup. The application of the term case management itself can be, as highlighted by Reilly et al. ${ }^{15}$, fairly loose. Case management models ranged from interventions focusing on support and education for carers of people with dementia ${ }^{7,56}$ to a much more comprehensive approach providing support and education alongside the development and monitoring of a care plan by a multidisciplinary team ${ }^{8,15}$. As the nature of case management interventions also seem to impact the implementation and effectiveness of these programmes, it might be timely to 'reframe' the concept of case management in more functional terms, as suggested by Bamford et al., as a 'dynamic, collective activity that involves numerous inter-related people and agencies and an ongoing shaping of social processes' 52 for which the multilevel coordination of care would be an essential component. More research needs to be undertaken to clarify the effective components of case management, and its delivery. Evidence to date suggest that these are likely to include; a manageable caseload for delivering interventions with the required intensity; clear role definition with adequate preparation and training; and empowerment of the case manager to access and coordinate care across providers and sectors. These factors should be borne in mind when developing new services. Most importantly, no opportunity should be lost for rigorous evaluation of this promising service innovation, whether as part of a research experiment 
(a randomised controlled trial), or a roll out into routine care. Arguably, the necessary level of system integration and support may be hard to achieve in the experimental context, so non-randomised evaluations of 'real world' scale up may have much to offer. Studies need to include a comprehensive set of process and outcome measures, which should include service utilisation and cost, in addition to clinical and quality of life outcomes for the person with dementia and their carer. Increased consistency in outcome measures would support future evidence synthesis through meta-analysis.

\section{References}

1. Case Management Society of America. Standard of Practice for Case Management. 2010.

2. Conference AHM. National framework for action on dementia: 2006 - 2010. Sydney: NSW Department of Health on behalf of AHMC.; 2006.

3. Health. Do. Transforming the Quality of Dementia Care: Consultation on a National Dementia Strategy. London: 2008.

4. Plan «Alzheimer et maladies apparentées » 2008-2012. Paris 2008.

5. Vogel A, Waldemar G. Nationalt videnscenter for demens. 2009.

6. Gutiérrez Robledo LM, Arrieta Cruz I, (coords.). Plan de acción Alzheimer y otras demencias. México. 2014. México. : 2014.

7. Pimouguet C, Lavaud T, Dartigues JF, Helmer C. Dementia case management effectiveness on health care costs and resource utilization: a systematic review of randomized controlled trials. J Nutr Health Aging. 2010;14(8):669-76.

8. Somme D, Trouve H, Drame M, Gagnon D, Couturier Y, SaintJean $O$. Analysis of case management programs for patients with dementia: a systematic review (Structured abstract). Alzheimer's and Dementia [Internet]. 2012; 8(5):[426-36 pp.]. Available from: http://onlinelibrary.wiley.com/o/cochrane/cldare/articles/DARE12012045000/frame.html.

9. Prince M, Bryce R, Ferri C. World Alzheimer Report 2011 - The benefits of early diagnosis and intervention. London: 2011.

10. Prince M, Prina AM, Guerchet M. World Alzheimer Report 2013 - Journey of Caring: An analysis of long-term care for dementia. London: 2013.

11. Khanassov V, Vedel I. Family Physician-Case Manager Collaboration and Needs of Patients With Dementia and Their Caregivers: A Systematic Mixed Studies Review. [Review]. Annals of Family Medicine. 2016;14(2):166-77.

12. Khanassov V, Vedel I, Pluye P. Case management for dementia in primary health care: a systematic mixed studies review based on the diffusion of innovation model (Provisional abstract). Database of Abstracts of Reviews of Effects [Internet]. 2014; (2):[915-28 pp.]. Available from: http://onlinelibrary.wiley.com/o/cochrane/ cldare/articles/DARE-12014040503/frame.html.

13. Tam-Tham H, Cepoiu-Martin M, Ronksley PE, Maxwell CJ, Hemmelgarn BR. Dementia case management and risk of long-term care placement: a systematic review and metaanalysis (Provisional abstract). International Journal of Geriatric Psychiatry [Internet]. 2013; 28(9):[889-902 pp.]. Available from: http://onlinelibrary.wiley.com/o/cochrane/cldare/articles/DARE12013051467/frame.html.

14. Goeman D, Renehan E, Koch S. What is the effectiveness of the support worker role for people with dementia and their carers? A systematic review. BMC Health Serv Res. 2016;16.

15. Reilly S, Miranda-Castillo C, Malouf R, Hoe J, Toot S, Challis D, et al. Case management approaches to home support for people with dementia. [Review]. Cochrane Database of Systematic Reviews. 2015;1.

16. Bass DM, Clark PA, Looman WJ, McCarthy CA, Eckert S. The Cleveland Alzheimer's managed care demonstration: outcomes after 12 months of implementation. Gerontologist. 2003;43(1):7385.

17. Callahan CM, Boustani MA, Unverzagt FW, Austrom MG, Damush TM, Perkins AJ, et al. Effectiveness of collaborative care for older adults with Alzheimer disease in primary care: a randomized controlled trial. JAMA. 2006;295(18):2148-57.

18. Newcomer R, Miller R, Clay T, Fox P. Effects of the Medicare Alzheimer's disease demonstration on Medicare expenditures. Health Care Financ Rev. 1999;20(4):45-65.

19. Newcomer R, Spitalny M, Fox P, Yordi C. Effects of the Medicare Alzheimer's Disease Demonstration on the use of communitybased services. Health Serv Res. 1999;34(3):645-67.

20. Newcomer R, Yordi C, DuNah R, Fox P, Wilkinson A. Effects of the Medicare Alzheimer's Disease Demonstration on caregiver burden and depression. Health Services Research [Internet]. 1999; 34(3):[669-89 pp.]. Available from: http://onlinelibrary.wiley. com/o/cochrane/clcentral/articles/088/CN-00308088/frame. html.

21. Vickrey BG, Mittman BS, Connor KI, Pearson ML, Della Penna $\mathrm{RD}$, Ganiats TG, et al. The effect of a disease management intervention on quality and outcomes of dementia care: a randomized, controlled trial. Ann Intern Med. 2006;145(10):71326. 
22. Eloniemi-Sulkava U, Notkola IL, Hentinen M, Kivela SL, Sivenius J, Sulkava R. Effects of supporting community-living demented patients and their caregivers: A randomized trial. Journal of the American Geriatrics Society. 2001;49(10):1282-7.

23. Eloniemi-Sulkava U, Saarenheimo M, Laakkonen ML, Pietila $\mathrm{M}$, Savikko N, Kautiainen $\mathrm{H}$, et al. Family care as collaboration: effectiveness of a multicomponent support program for elderly couples with dementia. Randomized controlled intervention study. J Am Geriatr Soc. 2009;57(12):2200-8

24. Hinchliffe $A C H$, I. L.; Blizard, B.; Livingston, G. Behavioural complications of dementia - can they be treated? . Int J Geriatr Psychiatry. 1995;10:839-47.

25. Jansen AP, Hout HP, Nijpels G, Rijmen F, Dröes RM, Pot AM, et al. Effectiveness of case management among older adults with early symptoms of dementia and their primary informal caregivers: a randomized clinical trial. International journal of nursing studies [Internet]. 2011; 48(8):[933-43 pp.]. Available from: http:// onlinelibrary.wiley.com/o/cochrane/clcentral/articles/481/CN00812481/frame.html.

26. Chien WT, Lee IY. Randomized controlled trial of a dementia care programme for families of home-resided older people with dementia. J Adv Nurs. 2011;67(4):774-87.

27. Chien WT, Lee YM. A disease management program for families of persons in Hong Kong with dementia. Psychiatr Serv. 2008;59(4):433-6.

28. Lam LC, Lee JS, Chung JC, Lau A, Woo J, Kwok TC. A randomized controlled trial to examine the effectiveness of case management model for community dwelling older persons with mild dementia in Hong Kong. International Journal of Geriatric Psychiatry [Internet]. 2010; 25(4):[395-402 pp.]. Available from: http://onlinelibrary.wiley.com/o/cochrane/clcentral/articles/264/ CN-00768264/frame.html.

29. Chu P, Edwards J, Levin R, Thomson J. The use of clinical case management for early stage Alzheimer's patients and their families. American-Journal-of-Alzheimer's-Disease [Internet]. 2000; 15(5):[284-90 pp.]. Available from: http://onlinelibrary.wiley. com/o/cochrane/clcentral/articles/580/CN-00322580/frame. html.

30. Dias A, Dewey ME, D'Souza J, Dhume R, Motghare DD, Shaji KS, et al. The effectiveness of a home care program for supporting caregivers of persons with dementia in developing countries: a randomised controlled trial from Goa, India. PLoS One. 2008;3(6):e2333.

31. Hinchliffe ACH, I. L.; Blizard, B.; Livingston, G. Behavioural complications of dementia-can they be treated? Int J Geriat Psychiatry. 1995;10(10).

32. Miller R, Newcomer R, Fox P. Effects of the Medicare Alzheimer's Disease Demonstration on nursing home entry. Health Services Research [Internet]. 1999; 34(3):[691-714 pp.]. Available from: http://onlinelibrary.wiley.com/o/cochrane/clcentral/articles/323/ CN-00316323/frame.html.

33. Shelton P, Schraeder C, Dworak D, Fraser C, Sager MA Caregivers' utilization of health services: Results from the medicare Alzheimer's disease demonstration, Illinois site. Journal of the American Geriatrics Society. 2001;49(12):1600-5.

34. Yordi C, DuNah R, Bostrom A, Fox P, Wilkinson A, Newcomer R Caregiver supports: outcomes from the Medicare Alzheimer's disease demonstration. Health Care Financing Review [Internet]. 1997; 19(2):[97-117 pp.]. Available from: http://onlinelibrary.wiley. com/o/cochrane/clcentral/articles/722/CN-00332722/frame. html.

35. Clark PA, Bass DM, Looman WJ, McCarthy CA, Eckert S. Outcomes for patients with dementia from the Cleveland Alzheimer's Managed Care Demonstration. Aging Ment Health. 2004;8(1):40-51.

36. Judge KS, Bass DM, Snow AL, Wilson NL, Morgan R, Looman WJ, et al. Partners in dementia care: a care coordination intervention for individuals with dementia and their family caregivers. Gerontologist. 2011;51(2):261-72.

37. Duru OK, Ettner SL, Vassar SD, Chodosh J, Vickrey BG. Cost evaluation of a coordinated care management intervention for dementia. Am J Manag Care. 2009;15(8):521-8.

38. Chodosh J, Berry E, Lee M, Connor K, DeMonte R, Ganiats T, et al. Effect of a dementia care management intervention on primary care provider knowledge, attitudes, and perceptions of quality of care. J Am Geriatr Soc. 2006;54(2):311-7.
39. Samus QM, Johnston D, Black BS, Hess E, Lyman C, Vavilikolanu $A$, et al. A multidimensional home-based care coordination intervention for elders with memory disorders: The Maximizing Independence at Home (MIND) pilot randomized trial. The American Journal of Geriatric Psychiatry. 2014;22(4):398-414.

40. Tanner JA, Black BS, Johnston D, Hess E, Leoutsakos J-M, Gitlin $\mathrm{LN}$, et al. A randomized controlled trial of a community-based dementia care coordination intervention: Effects of MIND at home on caregiver outcomes. The American Journal of Geriatric Psychiatry. 2015;23(4):391-402.

41. Iliffe S, Waugh A, Poole M, Bamford C, Brittain K, Chew-Graham $C$, et al. The effectiveness of collaborative care for people with memory problems in primary care: results of the CAREDEM case management modelling and feasibility study. Health Technol Assess. 2014;18(52):1-148.

42. Bass DM, Judge KS, Lynn Snow A, Wilson NL, Morgan R, Looman WJ, et al. Caregiver outcomes of partners in dementia care: Effect of a care coordination program for veterans with dementia and their family members and friends. Journal of the American Geriatrics Society. 2013;61(8):1377-86.

43. Bass DM, Judge KS, Snow AL, Wilson NL, Morgan RO, Maslow $\mathrm{K}$, et al. A controlled trial of Partners in Dementia Care: veteran outcomes after six and twelve months. Alzheimers Res Ther. 2014;6(1):9.

44. MacNeil Vroomen J, Bosmans JE, van de Ven PM, Joling KJ, van Mierlo LD, Meiland FJ, et al. Community-dwelling patients with dementia and their informal caregivers with and without case management: 2-year outcomes of a pragmatic trial. J Am Med Dir Assoc. 2015;16(9):800 e1-8.

45. Reuben DB, Evertson LC, Wenger NS, Serrano K, Chodosh J, Ercoli L, et al. The University of California at Los Angeles Alzheimer's and Dementia Care program for comprehensive, coordinated, patient-centered care: Preliminary data. Journal of the American Geriatrics Society. 2013;61(12):2214-8.

46. Fortinsky RH, Kulldorff M, Kleppinger A, Kenyon-Pesce L. Dementia care consultation for family caregivers: collaborative model linking an Alzheimer's association chapter with primary care physicians. Aging Ment Health. 2009;13(2):162-70.

47. Knapp M, lemmi V, Romeo R. Dementia care costs and outcomes: a systematic review. Int J Geriatr Psychiatry. 2013;28(6):551-61.

48. Morgan RO, Bass DM, Judge KS, Liu CF, Wilson N, Snow AL, et al. A Break-Even Analysis for Dementia Care Collaboration: Partners in Dementia Care. J Gen Intern Med. 2015;30(6):804-9.

49. Grol RP, Bosch MC, Hulscher ME, Eccles MP, Wensing M. Planning and studying improvement in patient care: the use of theoretical perspectives. The Milbank Quarterly. 2007;85(1):93138.

50. Khanassov V, Vedel I, Pluye P. Barriers to Implementation of Case Management for Patients With Dementia: A Systematic Mixed Studies Review. Ann Fam Med. 2014;12(5):456-65.

51. Van Mierlo LD, Meiland FJ, Van Hout HP, Droes RM. Towards personalized integrated dementia care: a qualitative study into the implementation of different models of case management. BMC Geriatrics. 2014;14:84

52. Bamford C, Poole M, Brittain K, Chew-Graham C, Fox C, Iliffe $\mathrm{S}$, et al. Understanding the challenges to implementing case management for people with dementia in primary care in England: a qualitative study using Normalization Process Theory. BMC Health Serv Res. 2014;14:549.

53. Waugh A, Austin A, Manthorpe J, Fox C, Stephens B, Robinson $L$, et al. Designing a complex intervention for dementia case management in primary care. BMC Family Practice. 2013;14:101.

54. Verkade PJ, van Meijel B, Brink C, van Os-Medendorp $\mathrm{H}$, Koekkoek B, Francke AL. Delphi research exploring essential components and preconditions for case management in people with dementia. BMC Geriatrics. 2010;10:54.

55. Prince M, Wimo A, Guerchet M, Ali G-C, Wu Y-T, A.M. P. World Alzheimer Report 2015 - The Global Impact of dementia: an analysis of prevalence, incidence, costs and trends. London: 2015.

56. Brodaty H, Green A, Koschera A. Meta-analysis of psychosocial interventions for caregivers of people with dementia. J Am Geriatr Soc. 2003;51(5):657-64. 


\section{CHAPTER 4}

\section{Acute general hospital care for people with dementia}

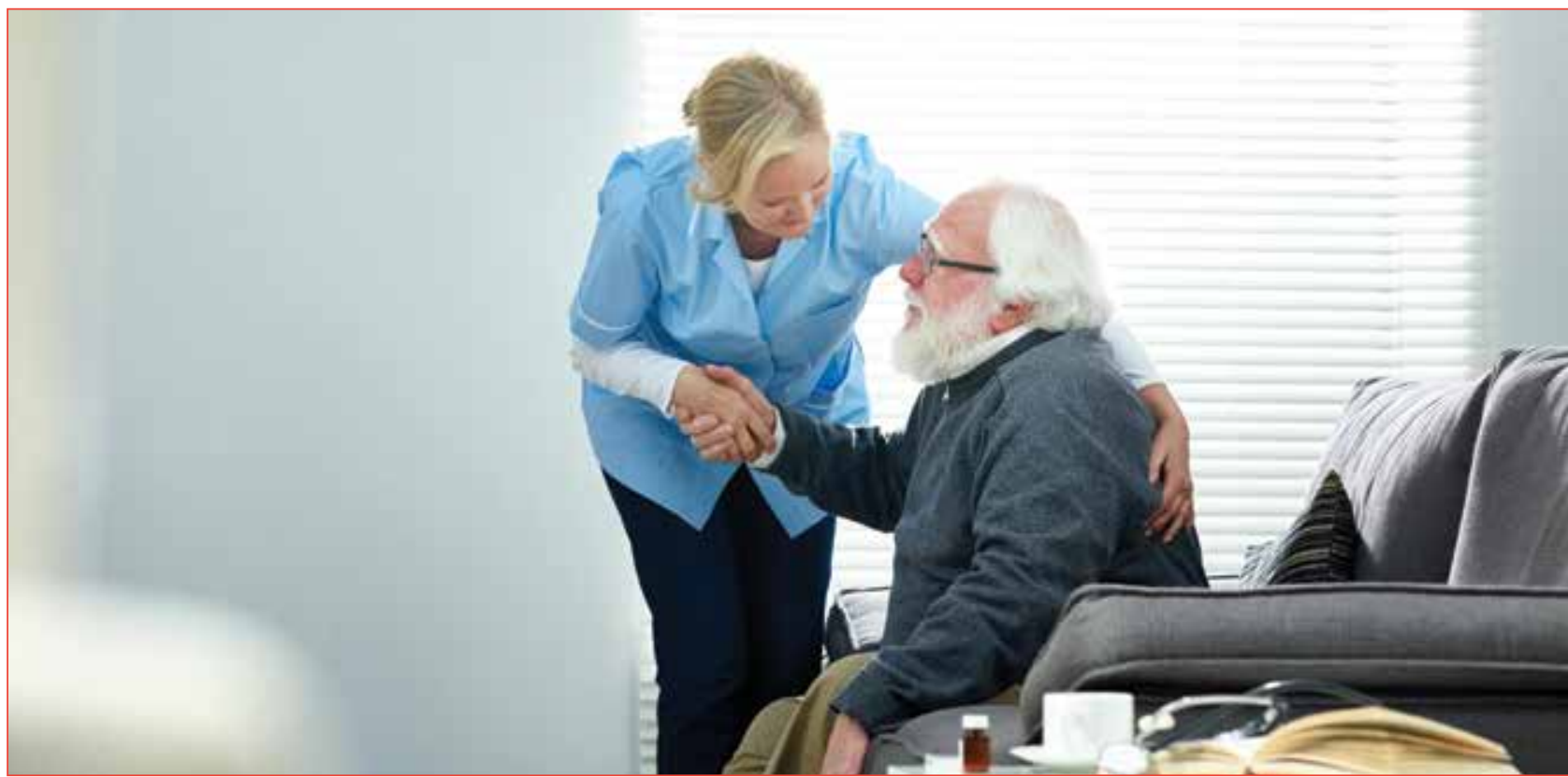

\subsection{Background}

With demographic ageing, older people account for an increasing proportion of acute general hospital admissions, amounting in higher income countries to up to two-thirds of the inpatient population. Acute care is frequently delivered to frail older people, with chronic multimorbidities and complex needs for care. People with dementia are over-represented in this older inpatient population, for complex reasons. This is a matter of concern because of the many complications and generally adverse outcomes for acute admissions of people with dementia, and the higher than average costs arising from their longer than average length of stay in hospital. Clearly, unnecessary admissions should be avoided; at the same time, not all hospital admissions are avoidable, and people with dementia have the right to acute care that will improve their quality of life, when the need arises. It is therefore also necessary to attend to the quality of care that people with dementia receive in hospital.

\section{In this section of the review, we sought to answer five questions:}

- How often are people with dementia admitted to hospital, and what proportion of older general hospital inpatients are affected by the condition? What are the main reasons for admission?

- Are older people with dementia at increased risk of harm when admitted, and what are the likely mechanisms?
- What are the excess healthcare costs associated with acute hospital care for people with dementia, and what are the principal drivers of these high costs?

- How might admissions to hospital be avoided?

- For those people with dementia who are admitted to hospital, which interventions and systems of care might reduce harm, and improve outcomes, including the quality of life and satisfaction of people with dementia and their carers? Is there also evidence that interventions can reduce length of stay and costs?

\subsection{How often are people with}

\section{dementia admitted to hospital, and} what proportion of older general hospital inpatients are affected by the condition? What are the main reasons for admission?

Since many people with dementia are frail and have complex medical comorbidities, their hospital admission rate is higher than for similarly aged people without dementia, both for all cause and 'potentially avoidable' admissions ${ }^{1-5}$. In a recent US cohort study, covering the period 1994-2007, hospital admission rates were 419 per 1000 person years for people with dementia, compared to 200 per 1000 person years for similarly aged controls ${ }^{3}$. Most studies control for age, sex and indicators of general health status that may 
predict admission (comorbidity indices and propensity scores); after adjusting for such factors, it seems that people with dementia are still around one and a half times more likely to be admitted ${ }^{2-4}$. There is also some evidence from the USA that hospital admission rates among people with dementia have been rising over time ${ }^{6}$. There are few published data from low and middle income countries. Analysis of health service utilisation data from the 10/66 Dementia Research Group prevalence studies ${ }^{7}$, carried out for this review, reveals that, while admission rates are lower than in high income countries, older people with dementia are generally at greater risk than others of hospital admission. Other than in Beijing, China there was no clear evidence that they experienced longer length of stay (see Table 4.1).

The prevalence of dementia among general hospital inpatients has been surprisingly little studied, and estimates vary greatly depending upon the type of inpatient setting studied and the screening and diagnostic methodology ${ }^{8}$. Nevertheless, it seems likely that older people with dementia are over-represented among hospital inpatients compared with the general population; in one of the larger studies, from the UK, age-specific prevalence was $16.4 \%$ for men and $29.6 \%$ for women aged $70-79$, rising to $48.8 \%$ and $75.0 \%$ for 90 years or older 9 .
A recent systematic review identified seven studies that had compared identified causes of admission among inpatients of general hospitals with dementia, and similarly aged inpatients without dementia ${ }^{10}$. Three of the studies were from the USA, two from France and two from the UK. There was reasonably consistent evidence across studies that orthopaedic crises (falls and fractures), respiratory crises (particularly infection), and urological factors (particularly infection) were over-represented among admissions of people with dementia. There was some evidence that acute cardiac syndrome and admissions for cardiovascular indications in general were under-represented among people with dementia. The largest study by far used French primary care and national medical insurance databases to compare admission rates and cause of admission for 258,809 people with a diagnosis of dementia and 88,296 controls ${ }^{2}$. Admissions were more common for people with dementia linked to the following diagnostic groups; nervous system, urology, orthopaedics, respiratory medicine, cardiology, endocrinology and infectious disease. Drilling down into these diagnostic groups revealed a pattern of lower admission rates for elective intervention procedures including cardiac and vascular catheterisation (RR 0.5), cataracts (RR 0.7), hernias (RR 0.8), cholecystectomy (RR 0.7), and radiotherapy (RR 0.5) or chemotherapy (RR 0.6) for cancer. There were particularly high

Table 4.1

Admission rates, average lengths of stay and relative risk of admission for people with dementia in low and middle income countries (unpublished data from 10/66 Dementia Research Group population based surveys)

\begin{tabular}{|l|l|l|l|}
\hline Setting & $\begin{array}{l}\text { Admission rates per } 1000 \\
\text { person years }\end{array}$ & $\begin{array}{l}\text { Adjusted* RR of admission } \\
\text { (people with dementia vs } \\
\text { others) }\end{array}$ & $\begin{array}{l}\text { Mean difference in length of stay } \\
\text { in days (people with dementia } \\
\text { vs others) }\end{array}$ \\
\hline Cuba & 48 & $0.42(0.16-1.15)$ & $+6.0(-2.3$ to +14.4$)$ \\
\hline Dominican Republic & 164 & $1.51(0.78-2.94)$ & $-2.5(-8.6$ to +3.6$)$ \\
\hline Puerto Rico & 396 & $1.66(1.01-2.71)$ & $-1.3(-5.4$ to +2.9$)$ \\
\hline Peru (urban) & 92 & $0.97(0.27-3.42)$ & $-2.2(-12.9$ to +8.5$)$ \\
\hline Peru (rural) & 0 & - & - \\
\hline Venezuela & 272 & $1.51(0.73-3.11)$ & $+4.0(-2.7$ to +10.6$)$ \\
\hline Mexico (urban) & 44 & $0.56(0.07-4.71)$ & $-9.2(-25.0$ to +13.9$)$ \\
\hline Mexico (rural) & 92 & $1.90(0.39-9.32)$ & $+2.8(-4.6$ to +10.3$)$ \\
\hline China (urban) & 284 & $2.25(0.90-5.62)$ & $+33.0(+9.6$ to +56.4$)$ \\
\hline China (rural) & 0 & - & - \\
\hline India (urban) & 108 & $3.19(0.64-15.95)$ & $+1.75(0.55-5.52)$ \\
\hline India (rural) & 148 & $\begin{array}{l}1.46(1.10-1.93) \\
\mathrm{I}^{2}=6.0 \%\end{array}$ & $+9.6(-3.2$ to +22.4$)$ \\
\hline Pooled estimates & Median 26\%, IQR 15-62\% & & $-1.0(-4.1$ to +2.0$)$ \\
\hline
\end{tabular}

*Adjusted for age, sex and number of limiting long-term conditions 
rates of admission for head injury (RR 3.0), fractures and sprains (RR 2.2), bowel obstruction (RR 2.2), respiratory infection (RR 2.9), urinary tract infection (RR 2.0), and nutritional and metabolic disorders (RR 2.5). In a similar data linkage study from the UK, using Hospital Episode Statistics, the most common clinical classifications for inpatients with dementia were urinary tract infection, pneumonia, chronic renal failure, fractured neck of femur, syncope, superficial injury, acute bronchitis, acute cerebrovascular disease, and non-specific chest pain. Among these conditions, urinary tract infections made a particularly notable contribution to excess length of stay and falls, while bronchitis and cerebrovascular disease had the most marked effect on excess mortality.

Two other studies from the USA focused upon causes of potentially avoidable hospitalisation (PAH), with divergent findings $\mathrm{s}^{3,11}$. In a cohort study of 3019 older people enrolled into an integrated care plan the association between dementia and PAH (1.78, 95\% $\mathrm{Cl}$ : 1.38-2.31) was even stronger than that for all cause admissions (1.41, 95\% Cl: 1.23-1.61). Among the causes of $\mathrm{PAH}$, admissions for bacterial pneumonia, congestive heart failure, dehydration, duodenal ulcer, and urinary tract infection, were significantly higher among those with dementia. In a cross-sectional comparison of Medicare claims data for 195,024 beneficiaries with dementia, and the same number of controls, those with dementia were significantly more likely to have admissions for diabetes short-term complications (OR 1.43, 95\% Cl: 1.31-1.57), diabetes long-term complications (OR 1.08, 95\% Cl: 1.02-1.14), and hypertension (OR 1.22, 95\% Cl: 1.08-1.38), but less likely to have potentially avoidable hospitalisations for chronic obstructive pulmonary disease (COPD)/ asthma (OR 0.85, 95\% Cl: 0.82-0.87) and heart failure (OR 0.89, 95\% Cl: 0.86-0.92) ${ }^{11}$. Risks of PAH increased significantly with comorbidity burden, suggesting that these chronic conditions become harder to manage and control effectively in the context of multiple other conditions.

The overall picture is one in which people with dementia are more likely to be admitted as inpatients to general hospital than people of similar age and medical infirmity, particularly for accidents and injuries arising from falls, for urinary tract and respiratory infections, and for chronic disease complications that might have been averted with better management in the community. Infections, which predispose to delirium and falls, have a particular impact on length of stay. On the other hand, people with dementia are less likely to be admitted for interventional procedures that have the capacity to enhance quality of life, including cataract surgery, vascular catheterisation and stenting, cholecystectomy, and cancer care. This would be justified were these interventions to be much less feasible (for example because of impaired capacity, problems with consent, lack of cooperation, and poor adherence), were adverse events to be more frequent, and/or outcomes to be sub-optimal for people living with dementia. While such beliefs may influence treatment decisions, we could find no hard evidence from published studies to support this.

\subsection{Are older people with dementia at increased risk of harm during a hospital admission, and what are the likely mechanisms?}

Delirium is one of the key adverse and potentially avoidable events experienced at much higher rates by people with dementia during their hospital admissions ${ }^{12,13}$. This may be in part because of the reasons for admission for people with dementia, and their high rates of multimorbidity and polypharmacy. However, people with dementia are more vulnerable to delirium for any given type or degree of physical morbidity. Delirium, and its mental and behavioural consequences, may be an important driver of increased length of stay ${ }^{12,14}$. Both delirium and dementia (by dint of cognitive impairment, hypoactive states, and behavioural and psychological symptoms) can reduce capacity for informed consent, and impair motivation and compliance with investigations, procedures, treatments and rehabilitation. Confinement to bed, whether due to restraint, sedation or hypoactive states, increases the risk of pneumonia and bedsores. Urinary incontinence can lead to bedsores or urinary tract infections from catheterisation. Agitation is recognised as a cause of post-operative surgical complications. Hospital inpatients with dementia are around three times more likely to experience a fall during their admission, and when this occurs, lengths of stay are more than doubled from around 13 to around 30 days $^{15}$.

Mortality rates are exceptionally high during admission $^{9,15}$ and somewhat higher after discharge ${ }^{16}$. However, a causal link between the admission and death is hard to establish. The very high mortality rates during admission may reflect, in part, a tendency to admit people with dementia at the very end stage of the disease process. Thus, the impending death may have precipitated the admission, rather than the admission contributing to the death. There have been relatively few studies of place of death for people with dementia. A systematic review published in 2014 identified that 16 to $51 \%$ died in hospital in studies conducted in UK, US and various European countries, with deaths in care homes being the most frequent outcome ${ }^{17}$. A more recent and extensive study from the UK indicated a reversal in a previous trend for an increasing proportion of deaths in hospital, from 2006 onwards, with around $40 \%$ of deaths occurring in hospital by $2011^{18}$. Again the commonest place of death was a care home, and deaths at home were unusual. There are no published data from low or 
middle income countries. Analysis of verbal autopsies conducted for the 10/66 Dementia Research Group population-based cohort studies in Latin America, India and China ${ }^{19}$, carried out for this review, indicate that deaths in hospital are at least as common as in high income countries (Table 4.2). However, deaths at home were the mode in most sites, with almost no deaths in care home settings. People with dementia were less likely to die in hospital than others (surprisingly no similar comparisons seem to have been carried out in high income countries). The notable exception was Beijing, China, where most deaths occurred in hospital, and this outcome was more likely for people with dementia.

When discharged from hospital, people with dementia are more likely to suffer a critical loss of independence, and increased needs for care. This includes a near fourfold risk of requiring high levels of homecare ${ }^{13}$, and at least a twofold increased risk of being discharged to nursing home or residential care ${ }^{20,21}$. These studies are more than 30 years old; more recent estimates from the UK using Hospital Episode Statistics, controlling carefully for clinical status, suggest a more modest 1.4 times increased risk ${ }^{15}$. Data from the same study suggested that failed discharges (defined as readmission within 30 days) are also more common for people with dementia both for elective admissions (8.2 vs $3.8 \%$ ) and for non-elective admissions (25.0 vs $17.0 \%)^{15}$.

\subsection{What are the excess healthcare costs associated with acute hospital care for people with dementia, and what are the principal drivers?}

It is clear from analyses of comprehensive US Medicare data that the costs of healthcare in general are substantially higher for people with dementia than age-matched controls ${ }^{1,4,5}$, and that a substantial proportion of these costs arise from hospitalisation 1. In the first study, using data from 1999, total mean annual beneficiary payments were 3.3 times higher for people with dementia compared to those without dementia (US\$9,922 vs US\$2,995) adjusting for age, gender, ethnicity and comorbidity ${ }^{1}$. While dementia was associated with higher payments for all types of expenditure, mean adjusted inpatient hospitalisation expenditures were 3.5 times higher for people with dementia (US $\$ 5,335$ vs US $\$ 1,523)$, accounting for $55 \%$ of the total excess expenditure. The second study, covering the period 2009-2014, stratified the costs with respect to timing of dementia diagnosis ${ }^{5}$. The increased utilisation and costs (both for all healthcare services and for inpatient admissions) is apparent for at least the year prior to diagnosis, reaches a peak in the year after diagnosis, and then declines but still to an elevated level compared with matched controls ${ }^{5}$. Total healthcare costs were 1.4 times higher in the year prior to diagnosis (US $\$ 15,091$ vs US\$10,662), 2.9 times higher in the year after diagnosis (US $\$ 27,126$ vs US $\$ 9,274$ ) and 1.8 times higher one to two years after diagnosis (US $\$ 17,527$ vs US\$9,930). Inpatient admission costs were 1.7 times higher in the year prior to diagnosis (US\$7,243 vs US\$4,320), 3.4 times higher in the year after diagnosis

Table 4.2

Proportion of deaths among people with dementia occurring in hospital, and relative risk of this event, from low and middle income countries. Unpublished data from the 10/66 Dementia Research Group surveys

\begin{tabular}{|l|l|l|}
\hline Setting & $\begin{array}{l}\text { Proportion of deaths among people with } \\
\text { dementia, occurring in hospital }\end{array}$ & $\begin{array}{l}\text { RR of death in hospital (dementia vs } \\
\text { others) }\end{array}$ \\
\hline Cuba & $41.4 \%$ & $0.88(0.80-0.97)$ \\
\hline Dominican Republic & $29.1 \%$ & $0.89(0.81-0.97)$ \\
\hline Peru (urban) & $31.0 \%$ & $0.66(0.44-0.98)$ \\
\hline Peru (rural) & $83.3 \%$ & $0.96(0.70-1.32)$ \\
\hline Venezuela & $16.2 \%$ & $0.83(0.71-0.97)$ \\
\hline Mexico (urban) & $31.3 \%$ & $0.86(0.66-1.12)$ \\
\hline Mexico (rural) & $23.1 \%$ & $0.90(0.72-1.12)$ \\
\hline China (urban) & $86.0 \%$ & $1.21(1.07-1.38)$ \\
\hline China (rural) & $2.7 \%$ & $0.90(0.82-1.00)$ \\
\hline India (urban) & $13.4 \%$ & $0.99(0.79-1.25)$ \\
\hline Pooled estimates & Median 26\%, IQR 15-62\% & $0.92(0.88-0.96)$ \\
\hline
\end{tabular}


(US $\$ 11,540$ vs US $\$ 3,391$ ) and 1.8 times higher one to two years after diagnosis (US $\$ 6,699$ vs US $\$ 3,682$ ).

The process of hospital care is more complicated for people with dementia, with significant cost implications ${ }^{8}$. They experience substantially longer hospital stays $4,13,20-22$, and require more nursing resources than others ${ }^{13,22}$. Impact of dementia on length of stay was most extensively demonstrated in a recent analysis of Hospital Episode Statistics from the UK National Health Service ${ }^{15}$; adjusting for age, gender and clinical status, mean lengths of stay were $27 \%$ longer for inpatients with dementia (13.6 vs 10.7 days), but with substantial national variation. The excess length of stay was as high as $85 \%$ in some regions ${ }^{15}$. The authors of the UK report attempted to calculate the annual cost to the National Health Service, taking into account costs incurred from excess lengths of stay, excess readmissions, and the impact of excess falls. In this context, 'excess' referred to the incremental adverse outcome for a person with dementia compared with a person without dementia of the same age, sex and clinical status. For 2010 the costs for excess lengths of stay were $£ 117.3$ million, those for excess readmissions $£ 122.5$ million, and those for excess falls £25.0 million, amounting to £264.8 million overall. On the one hand, these almost certainly represent an underestimation of the incremental costs given the likely under-detection and under-recording of dementia during hospital admissions ${ }^{15}$. On the other hand, while the authors of the report refer to 'the excess costs incurred by the NHS occasioned by differences in the way dementia patients are treated'15, one should be cautious in equating 'excess' with 'avoidable'. While it is appropriate to aim to eliminate the differential, at least some of the incremental costs may be intrinsic to the complexities of inpatient dementia care.

\subsection{How might admissions to hospital be avoided?}

Hospital admissions might, in theory, be avoided in at least four ways:

1. Deterioration in health, such as would necessitate an admission, might be averted by better management in the community. Ambulatory care sensitive conditions (ACSCs) are chronic conditions for which it may be possible to prevent acute exacerbations and reduce the need for hospital admission. An emergency admission for an ACSC is often considered to be an indicator of poor quality primary and community care. Examples of ACSCs relevant to the care of older people with dementia include; dehydration, urinary tract infection (UTI), bacterial bronchopneumonia, exacerbation of Chronic Obstructive Pulmonary Disease (COPD), congestive heart failure, hypertension, and uncontrolled diabetes and diabetes complications.

2. Even where a clinical indication for acute admission may be present, it may not be in the interests of the person with dementia given the substantial associated risks. Alternative options would be to provide equivalent or near equivalent care at home ('hospital at home'), or to pursue a more palliative course of management. This would require a holistic, person-centred assessment, and the consent of the person with dementia, or an advance care plan, or a judgment of their best interests supported by assent from next-of-kin or other legally constituted authority.

3. A high proportion of people with dementia die in hospital (see previous section). Holistic, palliative, end-of-life care is less available for people with dementia than for older people with more obviously terminal conditions, and the end-of-life is too infrequently acknowledged, discussed, and planned for. The high mortality rate for admissions of people with dementia is likely to reflect, in part, admissions of those near the end of their lives that might, with more planning and support have better been managed in the community (see section on end-oflife care for further information).

4. Although widely acknowledged and discussed, the extent of 'social admissions' to acute inpatient care is hard to estimate. Home care arrangements can break down suddenly through changes in carer circumstances, or care demands exceeding available resources. Residential and nursing care homes can trigger hospital accident and emergency visits and admissions for similar reasons. While it might be tempting to blame such occurrences on a deficit of supplementary social care and support in the community, often anxieties over changes in health status play a part, and the effective and seamless integration of community health and social care is most likely to reduce the incidence of such admissions.

A recent systematic review of interventions to prevent hospitalisations of older people with dementia identified only 10 studies, despite applying quite broad inclusion criteria ${ }^{23}$. All but one were randomised controlled trials, and of small size. Interventions that were applied were heterogeneous, but mainly fell into two groups - case management/care coordination (four trials) and multidisciplinary assessment and management in the community (four trials). The other two trials were of home based occupation therapy and group support for carers. In only half of the trials was hospitalisation a primary outcome, indicating that the intervention was not specifically targeted at this effect. In none of the trials was a reduction in the incidence of hospitalisation convincingly demonstrated. Effects 
were most favourable for multidisciplinary assessment and management, where two trials showed a nonsignificant trend in the direction of lower hospitalisation rates $^{24,25}$, and in one other those randomised to the intervention experienced fewer days in hospital over the two year follow-up period ${ }^{26}$. In the discussion of the largely null findings from this body of research, the review authors noted that insufficient research attention had been accorded to an issue that was now a major policy priority. The interventions tended not to have a clinical medical focus, and did not target the common reasons for admission for people with dementia namely, optimising control of pre-existing chronic conditions, and prevention of unintentional injuries, acute infections and dehydration. Future research needs to have an explicit focus on "keeping persons with dementia out of hospital, whenever possible'23. It was also noted that most of the quite intensive interventions that had been trialled relied upon specialist secondary care providers with little interaction or integration with primary care. It may be that task-shifted and collaborative care models, with a prominent role for primary care, may be at least as effective, while ensuring greater coverage and continuity of care. In an interesting analysis of Medicare data for patients newly diagnosed with a geriatric condition there was an inverse dose response relationship between geriatric care outpatient consultations and emergency department visits. However, geriatric consultation in primary care, where most care was delivered by family medicine was as effective as geriatric specialist care ${ }^{27}$. In England, an ecological correlational study indicated a small but statistically significant inverse correlation between the success of primary care centres in implementing the Quality and Outcomes Framework for dementia recognition and care, and the rate of emergency admissions for dementia, and ambulatory care sensitive conditions ${ }^{28}$.

Emergency Departments (EDs) are often the portal of entry for hospitalisation of people with dementia, and represent, in effect, a last chance to divert an admission that may not be necessary. Assessment in EDs is complicated by multiple factors ${ }^{29}$. The staff may lack expertise in comprehensive multidimensional geriatric assessment, detection of dementia and delirium. The person with dementia may be unable to communicate accurate and comprehensive information, and key informants may or may not be available. Their cognitive impairment may be exacerbated by symptoms of physical ill health, particularly pain, and by the unfamiliar, noisy and busy environment ${ }^{29}$. A recent systematic review into best practice for the management of ED patients with cognitive impairment identified 12 studies, most of which had focused upon the detection of cognitive impairment dementia, and delirium ${ }^{29}$. Detection can be boosted by the use of structured brief screening assessments, such as the Orientation Memory
Concentration test and the Confusion Assessment Method for delirium. However, screening and detection are worthless if they do not then influence subsequent behaviour and outcomes. Worryingly, there is evidence from one study that recognition would not have altered ED management decisions or disposition plans for any of the majority of patients whose cognitive impairment and/or delirium had been missed ${ }^{30}$. Another study identified that information regarding screening findings in the ED relayed to general practitioners did not lead to any appropriate follow-up action ${ }^{31}$. It does not seem that the focus of this otherwise comprehensive review was upon the avoidance of hospital admission, perhaps because there appeared to be no trials that are directly relevant to this question; however, several evaluations of pertinent interventions for frail older people attending ED are mentioned in the discussion ${ }^{29}$. One describes a sociomedical geriatric assessment team working in the ED at Brest University Hospital. Admissions are claimed to be reduced on the basis that such attendances 'usually' result in admission, but the admission rate was only $49 \%$ for those assessed by the team ${ }^{32}$. The other trials focused upon frail older people who were already planned to be discharged from hospital. The feasibility of implementing a comprehensive geriatric assessment in ED, with rapid referral to community agencies had been demonstrated ${ }^{33}$. Such interventions seem to have some benefits over the months following discharge, in terms of lowering nursing home admissions and improving satisfaction with post-discharge care ${ }^{34}$, and reducing functional decline and death ${ }^{35}$. They did not however have any effect on subsequent healthcare utilisation, hospital admission, or costs ${ }^{34,35}$. One carefully matched pre- and post-cohort study, published since the systematic review, evaluated the impact of the TREAT service (Triage and Rapid Elderly Assessment Team) based in the ED at the Royal Free Hospital in the UK ${ }^{36}$. The service was specifically orientated to the avoidance of admission, and appeared to be achieving this objective, with a substantial increase in the same day discharge rate, and a reduction in the length of stay for those who were admitted $^{36}$.

'Hospital at home' refers to in reach services provided by health professionals in the patient's own home, in situations when inpatient hospitalisation would otherwise be necessary. This could include intensive nursing, and therapies, for example intravenous antibiotics and/or fluids, oxygen, and attention to pain control. Conditions addressed in this way include pneumonia, exacerbations of chronic obstructive pulmonary disease, deep vein thrombosis, cellulitis and end-of-life care. Procedurally, the patient would be considered to be admitted to hospital, and would remain under the governance of the hospital services. As with a hospital admission, the treatment is intended to be of limited duration. Hospital at home is delivered under two sets of circumstances; to avoid admission, 
and to provide early, supported discharge from hospital. While there are several descriptions of such services on the internet ${ }^{37,38}$, focused on providing a service for people with dementia, we could find no published formal evaluation. In general, the results of hospital at home services seem very favourable, for medical, surgical, rehabilitation and psychiatric interventions, with reduced mortality, readmission rates and costs, and higher patient and carer satisfaction ${ }^{39}$. The feasibility and effectiveness of delivering hospital at home care for older people with particular conditions has also been demonstrated ${ }^{40}$, with some marginal cost benefits ${ }^{41}$. There is clearly a need for an evaluation of this type of service, specifically for people with dementia; a large randomised controlled trial is currently being conducted in the Netherlands, with results expected in $2018^{42}$.

There is clearly a need for much more research into interventions at the service and system level to avoid hospitalisations, specifically of people with dementia. As so succinctly stated in Phelan et al's review

"We support the prevailing belief among many in the field that dementia is not 'just another diagnosis' on a patient's problem list. Dementia impairs an individual's ability to manage his/ her other chronic conditions, to recognize and articulate the onset of new physical or emotional symptoms, and to seek assistance/care in the face of alterations in one's overall condition. Dementia implies that self-management support must be available. Thus, a diagnosis of dementia should shape the focus and approach to management of all other health issues in the context of routine outpatient care". ${ }^{23}$

While the costs of hospital admission are high and concentrated, it is already apparent that the community-based and/or outreach services required to prevent this outcome are likely to be intensive and maintained over relatively long periods of time. Therefore, while it may be possible, desirable and beneficial to reduce the extent of acute admissions of people with dementia, the potential for cost-savings, which seem to be an important driver of policy focus on this issue at present, may well be illusory. Costs would, however, be shifted from acute hospital to community health and social care, which would require adjustments to budgets and resource allocation. Another important concern is that elective admissions for planned procedures such as cataract surgery may not be being offered to people with dementia as often as they should. It may be that consideration of the needs for such elective procedures should be incorporated into post-diagnostic counselling and advanced care planning, since at that stage, assuming a timely diagnosis, the person with dementia would retain capacity to make an informed decision, and outcomes from the procedure would be likely to be better.

\subsection{For those people with dementia who are admitted to hospital, which interventions and systems of care might reduce harm, and improve outcomes, including the quality of life and satisfaction of people with dementia and their carers?}

In a recent review of the current state of care for people with dementia in general hospital inpatient settings ${ }^{43}$, the fundamental problems were identified as:

a) a tension between prioritisation of task-centred acute care for the indication for admission, and the acknowledged need to provide person-centred dementia care,

b) an insufficient understanding of what constitutes person-centred care,

c) a general lack of requisite knowledge and skills.

Advocated actions were mainly at the systems level, focusing on managerial and workforce development; providing an appropriate care environment; fostering a positive care culture; changing attitudes; and cultivating a better understanding of the challenges for the person with dementia, for carers, and for inpatient healthcare staff ${ }^{43}$. The aspiration would be to effect a transformation such that '(the) cultures of care... are person-centred and where people with dementia are respected, valued and treated with dignity and receive high quality treatment for their medical needs, and do not negatively impact on the dementia'43.

An alternative and complementary analysis ${ }^{44}$ focused more upon the workforce attitudes, behaviours and competencies that needed to be targeted to effect change; detection of dementia and delirium, needs assessment, reduction of external stressors, capacity for effective and focused communication, and productive engagement with family carers. There has been almost no attention paid to the critical issue of patient safety in communication in handovers between healthcare settings (focusing in particular upon medication review, the information needs of everyone involved in the handover, and involvement of carers) ${ }^{45}$. Transfers between inpatient units are common for inpatients with dementia, and should be minimised, but when necessary all relevant information must be communicated effectively in the handover of care.

A striking finding from the published literature was the almost complete absence of the voice of the person with dementia, whose experiences, perceptions and views seem not to have been systematically studied $^{43}$. Given the general acknowledgment of carers' negative experiences of hospital admission, there have also been surprisingly few studies of this phenomenon, and its origins. In a qualitative 
study of 35 carers of 34 patients aged 70 and over, most with dementia, admitted to geriatric, medical or orthopaedic wards at an English NHS acute care hospital, detailed post-discharge open-ended interviews were accompanied by non-participant observation of events and interactions on the ward ${ }^{46}$. This supported the conclusion of recent reviews "Family carers expected a personalised style of care in hospital, which contrasted with the busy experience of an acute hospital ward". Carers did not experience the hospital admission as 'respite'; rather it was seen as a stressful crisis, regardless of the perceived quality of inpatient care, with much disruption in established care routines. While experiences were variable, a common set of themes emerged, constituting a 'cycle of discontent', arising when concerns over care quality occurred in the context of a sense of loss of control. When expectations did not match perception of care, often triggered by key events, this led to suspicion and loss of confidence, followed by hypervigilant monitoring, and a breakdown in relationships, with challenges, expression of anger, conflict and withdrawal. Aside from medical care, carers judged overall quality of care with respect to nutrition and hydration, maintaining safety, approaches to caring for a confused person, and showing warmth. Competence was judged by the ability to manage agitation and control pain. Expectations that the ward would be a place of safety, and that staff would demonstrate appropriate knowledge and skills in communicating with the person with dementia, and in managing confusion and disturbed behaviour, were often not met. Carers who wished to be involved in care were sometimes prevented from being so, and complained of being ignored, patronised, or treated inflexibly. Communication was perceived as inadequate, and orientated more towards discharge planning rather than care during the admission.

\section{The care environment}

In contrast with many modern long-term care facilities, acute care hospital settings have generally not been designed with the needs of people with dementia uppermost in mind. There is nothing 'homely' about the environment, little to orientate inpatients to time, place and person, and much distracting noise and activity, day and night. For these reasons, among others, hospitalisation can be a difficult experience for those with normal cognitive function - all the more so then for those with dementia and/or delirium. There have been various attempts to create more 'dementia-friendly' ward spaces. A redesign carried out for one orthopaedic ward and a healthcare for the elderly ward at the Bradford Royal Infirmary, UK, has been carefully documented ${ }^{47}$, and presented in the context of learning from 23 similar programmes funded under a UK Government initiative through the King's Fund 'Enhancing the Healing Environment' initiative. A design assessment tool generated from this programme (http://www.kingsfund.org.uk/projects/ enhancing-healing-environment/ehe-design-dementia) focuses on whether the ward environment promotes; meaningful interaction between patients, their families and staff; well-being; eating and drinking; mobility; continence and personal hygiene; orientation; calm, safety and security.

Key features of completed projects include:

- projects were co-designed and developed by staff, patients and carers

- 'de-cluttering' by removing unnecessary equipment and furniture to simplify the environment

- improved and flexible lighting schemes, to ensure that all areas are evenly lit, mimicking natural daylight in daytime, and promoting a sleep/wake cycle

- attention to flooring, ensuring that floors are matt and non-slip, and do not create (through light and shade or patterning) artificial visual barriers to those with perceptual disturbances

- 'deinstitutionalising' colour schemes, and using colour accents to demarcate different ward areas and bays.

- Individual bed spaces are personalised, for example with facilities to exhibit family pictures through a television screen, and a memory box with personal artefacts and possessions.

- dividing up common areas into smaller social spaces, for example sections of corridor with seating and reminiscence activities, and a small café for patients and carers.

- Providing points of interest with photographs, and tactile artwork

Of course, a well-designed physical environment does not guarantee good quality care, and psychosocial factors, particularly the presence and visibility of staff, and their meaningful engagement with patients and carers are complementary ${ }^{43}$.

Special units provide specialised care for people with dementia and/or delirium in a custom designed setting. They can in principle have a dual function, providing care for patients presenting with the most difficult management problems, while also conducting training, modelling and disseminating good practice in dementia care throughout the hospital workforce ${ }^{48}$. There have been some limited small-scale evaluations of such units based on a comparison with 'normal care' on general wards within the same hospital ${ }^{49-51}$. These suggest that there may be some benefits with respect to staff knowledge and skills, carer satisfaction with the ward environment and care provided, and, possibly, for the person with dementia, with improvements in nutrition, reductions in behaviour disturbance, and increased mobility with no increase in the incidence of falls. Strikingly, however, there 
was no evidence for reduced length of stay, or lower rates of discharge to a care home ${ }^{49-51}$. Indeed, all of the evaluations mentioned delayed discharge due to problems finding a placement as a significant reason for the lack of reduction in length of stay. One of the more detailed evaluations came from a project at New Cross Hospital, Wolverhampton, UK, which highlighted the need for substantial organisational change to make the unit an effective component of the system, and maximise its impact ${ }^{51}$. Hence, in addition to creating a dementia-friendly ward providing person-centred care, a hospital wide dementia training program was instigated with the trainer based in the dementia unit, outreach was provided to other wards, and there was increased dedicated social work time for discharge planning. Some cost savings were made, mainly through improvements in staff satisfaction, reduction in turnover and sickness absences, and hence a reduced need for temporary agency staff. There were also no formal complaints relating to dementia care on the special unit, which are costly to handle.

\section{Hospital staff}

Staff attitudes and actions (reflecting values and beliefs) are closely related to knowledge and skills, and the need for education and training to develop workforce capacity for dementia care. Care provided by nurses is clearly a crucial element. Nurses too often lack the confidence and competence to assess and manage their patient's special needs. A belief that decline is inevitable will be associated with a failure to identify and diagnose the causes of confusion (dementia versus delirium) and a sense that such individuals are misplaced in 'curative' acute care settings. Disruptive behaviour can impact on nurses' time management and ward routines in a highly taskorientated system, and hence be a source of irritation. In contrast, a 'healthful' perspective identifies cognitive decline (whether acute, acute on chronic or chronic) as pathological, and seeks an underlying cause for acute confusion, considering chronic confusion only when other causes were ruled out. Whether in dementia or delirium, disturbed behaviour is too often interpreted as a nuisance to be controlled through supervision or medication, rather than a valid form of non-verbal communication of unmet needs that need to be ascertained and addressed - for pain control, nutrition, rest, social interaction or reassurance. In short, the person, not the environment is held to blame, a classic category error first described by Kitwood in $1993^{52}$. At the same time, it should be acknowledged that such behaviour can be stressful for nurses, other patients and families, particularly when it involves interference with other patients' privacy, possessions and clinical care $^{48}$. The need for attitudinal change, to avoid labelling and blame, therefore extends well beyond the ward staff.
Communication skills are at the heart of personcentred care. In mechanical terms, this should involve a set of basic skills; approaching in a calm, gentle and relaxed fashion using the person's preferred form of address; speaking directly even if unable to respond; remaining calm if the person appears agitated; communicating in a quiet setting, minimising external distractions, and avoiding moving around; using short simple sentences, and limiting choices ${ }^{44}$. Personcentred care involves much more than this; getting to know the individual, their life history, interests, desires, and values; always being compassionate, respectful, and thinking about things from the person's point of view when delivering care that is individually tailored to their needs. For people with dementia, this will almost always require close interaction with carers. Most reviews point to the contrast between taskorientated systems of acute inpatient care that seek to maintain patient safety and limit length of stay through rigorous check list protocols, and the more flexible, and potentially more time-consuming demands of patient-centred care ${ }^{43,44,53}$. An alternative view is that investment in person-centred care is, in the long-run, time saving; this is plausible, but thinly evidenced ${ }^{43}$.

Recent reviews agree that there is a need for more intensive education and training across the health system to change attitudes and address the deficit in knowledge and skills ${ }^{43,44,53}$. While in service training is necessary and important, a higher profile for and greater commitment towards dementia care in the basic curriculum, reflecting changing patterns of morbidity, would arguably deliver greater and more sustainable benefits, and a workforce fit for purpose. In service training programs are not usually evaluated or published, with a lack of evidence of sustainability of knowledge and competence, leading to a lack of evidence base to inform generalisable good practice ${ }^{43}$. Experiential methods of teaching, involving contact with people with dementia outside of the hospital setting has been advocated ${ }^{54}$. Such 'active learning' initiatives focus on the engagement of staff at an emotional level with the experiences of patients.

\section{Systems and models of care}

\section{Specialist mental health liaison teams}

Specialist mental health liaison teams are a relatively common service in some high income countries, and in England the Department of Health has issued a commissioning call for them to be provided for all acute care hospitals. It is important to note that such services are not restricted to dementia assessment and care, but cover the full range of mental and cognitive comorbidities, with the commonest conditions among the case mix being dementia, depression, delirium and adjustment disorders ${ }^{55}$. There are different models of provision. Some services, providing inreach to make assessments and give advice on management, could 
more properly be termed 'consultation' services. True liaison models should ideally be based on site, and involve a greater degree of day to day interaction and functional integration between the liaison services and the teams providing inpatient care ${ }^{55,56}$. Such teams may comprise specialist nurses, psychiatrists, or be of a multidisciplinary nature ${ }^{55}$. True liaison services confer several potential benefits ${ }^{55}$. They do not rely entirely upon general hospital staff detecting and referring cases for further assessment. The service is generally more responsive, and feedback on assessments is more direct, and continuous. Such services can potentially provide resources and leadership for training and education in the acute hospital setting and promote changes in the structure and culture of care $^{48}$. Direct patient care activities include diagnostic assessment, advice on behavioural management, assessment of capacity, and discharge planning. The evidence base for the effectiveness and costeffectiveness of liaison services for older people is weak, and studies are generally of poor quality. There are few randomised controlled trials, all of which have design flaws ${ }^{55}$. All bar one fail to show any significant benefits in terms of key clinical outcomes or length of stay. The exception is the trial conducted by Slaets et al in the mid-1990s in the Netherlands ${ }^{57}$ where the delivery of a mental health liaison service integrated with geriatric medicine, compared with usual care, was associated with improved physical functioning, a five day shorter length of stay, fewer readmissions, and fewer discharges to nursing homes. Findings from nonrandomised pre-post evaluations with historic controls are generally more favourable, indicating potential for improved clinical outcomes and reductions in length of stay ${ }^{55}$, with some relatively well-designed evaluations providing quite persuasive evidence ${ }^{58,59}$.

\section{Dementia specialist nurses}

A recent review of the potential role of a dementia specialist nurse highlighted the ways in which their set of competencies; advanced assessment skills, sharing information, ethical person centred care, carrying out therapeutic interventions, preventative and health promotion, balancing the needs of the person with dementia and carer; might help to fill gaps in knowledge and skills ${ }^{53}$. Specialist dementia nurses can, in principle, provide comprehensive assessment including dementia specific factors that may increase risk of adverse events, care coordination, oversee all aspects of inpatient care, support carers and engage in discharge planning. There is, however, a tension between the feasibility of providing this focused attention for a potentially very large number of clients, and time spent on advising and training non-specialist staff, raising awareness and changing the culture of care across the hospital as a whole. There is a danger, if the nurse takes on too much frontline care, that other staff may become deskilled ${ }^{53}$. There appears to have been only one evaluation of this type of service, in which one nurse saw approximately 30 new referral patients per month (of whom only a small proportion were diagnosed with dementia), with additional follow up reassessments ${ }^{60}$. A reduction in average length of stay from 11 to nine days was claimed, but the methodology for the comparison was not described ${ }^{60}$.

\section{Systems level interventions for the primary prevention of delirium}

The Hospital Elder Life Programme (HELP) was devised specifically to prevent delirium in frail older inpatients with specific risk factors (defined as those with one or more of cognitive impairment, visual or hearing impairment, reduced mobility, sleep disturbance or dehydration). The intervention is a complex package of enhanced care delivered collaboratively by the healthcare team and the HELP staff members, comprising a nurse specialist, a geriatrician, and trained volunteers. Interventions included a daily visitor program for orientation and social support, exercise for early mobilisation, massage and music to promote sleep, mealtime assistance for feeding and hydration, education for staff and family members, and support for discharge. The effectiveness of the HELP program was demonstrated in a non-randomised controlled trial, in which the incidence of delirium was reduced by $40 \%$ overall (OR, 0.60 ; $95 \% \mathrm{Cl}$ : 0.39 $0.92)^{61}$. Sustained effectiveness has been confirmed following implementation at scale ${ }^{62,63}$. A recent Cochrane systematic review confirmed the quite strong evidence for the effectiveness of such multicomponent interventions (RR 0.69, 95\% Cl: 0.59-0.81), while also highlighting the much more limited evidence, from one small trial, of effectiveness among those with dementia (RR 0.90, 95\% Cl: 0.59-1.36) $)^{64}$. In the original HELP trial ${ }^{61}$, those with severe dementia were excluded, and $59 \%$ of participants had MMSE scores of 25 or over. There is, as yet, no evidence that such interventions reduce length of stay, although this seems quite possible given the effects on delirium prevention. A large trial, including this outcome, with a more rigorous cost-effectiveness evaluation is currently underway in the Netherlands ${ }^{65}$. The HELP intervention has been extensively disseminated, and resource, training and support materials are available online ${ }^{66}$. Despite this, uptake has been surprisingly low outside of North America $^{66}$. In the UK, the National Institute for Health and Clinical Excellence (NICE) has collaborated with HELP to produce a harmonised and updated set of evidence-based guidelines ${ }^{67}$.

Concern is expressed in all recent reviews at the lack of rigorous evaluation of services that commissioners are advocating and providers are implementing. Well-conducted large scale randomised controlled trials, providing clear evidence of cost-effectiveness are largely lacking. There is a body of evidence that quality of care can be improved, with enhanced staff and service-user satisfaction, but evidence on 
the tractability of the key health system economic indicators (length of stay and readmission rates) is much weaker. While there are examples of implementation and innovation in care, this is patchy and piecemeal, with minimal coverage of basic enhancements to the quality of care provided to people with dementia. As noted by Dewing and Dijk, "Currently there seems to be little to celebrate in the way of excellence in dementia care in the general hospital"43. There may be an emerging consensus on the key components of good quality care, but no real evidence on the optimal resources, systems and structures to deliver this at scale, and in a sustainable way. Again, most reviews and reports emphasise that simply introducing a mental health liaison service, or a dementia specialist nurse, or a special dementia care unit is not enough. Indeed, if these are not properly integrated into the wider hospital and health service management structure, with clear ownership, they will struggle to function properly ${ }^{43,53,55}$. What is needed is a wholescale restructuring of the culture of care, which, first and foremost, accords adequate priority, in resources and planning, to the needs of people with dementia. Hence, governance at senior management level is essential, with monitoring of key performance indicators. Careful consideration should be given to every stage of the care pathway, to all of the staff that have contact with patients and carers, and all of the environments and systems that they are likely to encounter during their stay. Education and training of hospital staff to achieve clearly defined competencies appropriate to role needs to be carried out as part of in-service training. However, sustainable changes in culture and practice will only be achieved once this training is a prominent part of the core undergraduate and postgraduate medical and nursing curriculum. Priority should be given, in particular, to a person-centred approach to care, and respectful and productive interaction with carers at all stages of the admission.

\section{References}

1 Bynum JPW, Rabins PV, Weller W, Niefeld M, Anderson GF, Wu AW. The relationship between a dementia diagnosis, chronic illness, medicare expenditures, and hospital use. J Am Geriatr Soc 2004; 52: 187-94.

2 Tuppin P, Kusnik-Joinville O, Weill A, Ricordeau P, Allemand H. Primary health care use and reasons for hospital admissions in dementia patients in france: database study for 2007. Dement Geriatr Cogn Disord 2009; 28: 225-32.

3 Phelan EA, Borson S, Grothaus L, Balch S, Larson EB. Association of incident dementia with hospitalizations. JAMA 2012; 307: 165-72.

4 Zhu CW, Cosentino S, Ornstein K, Gu Y, Andrews H, Stern Y. Use and cost of hospitalization in dementia: longitudinal results from a community-based study. Int J Geriatr Psychiatry 2015; 30 833-41.

5 Lin P-J, Zhong Y, Fillit HM, Chen E, Neumann PJ. Medicare Expenditures of Individuals with Alzheimer's Disease and Related Dementias or Mild Cognitive Impairment Before and After Diagnosis. J Am Geriatr Soc 2016; published online June 13. DOI:10.1111/jgs.14227.
6 Zilberberg MD, Tjia J. Growth in dementia-associated hospitalizations among the oldest old in the United States: implications for ethical health services planning. Arch Intern Med 2011; 171: 1850-1.

7 Albanese E, Liu Z, Acosta D, et al. Equity in the delivery of community healthcare to older people: findings from 10/66 Dementia Research Group cross-sectional surveys in Latin America, China, India and Nigeria. BMCHealth ServRes 2011; 11: 153.

8 Mukadam N, Sampson EL. A systematic review of the prevalence, associations and outcomes of dementia in older general hospital inpatients. Int Psychogeriatr IPA 2011; 23: 344-55.

9 Sampson EL, Blanchard MR, Jones L, Tookman A, King M. Dementia in the acute hospital: prospective cohort study of prevalence and mortality. Br J Psychiatry J Ment Sci 2009; 195: 61-6.

10 Toot S, Devine M, Akporobaro A, Orrell M. Causes of hospital admission for people with dementia: a systematic review and meta-analysis. J Am Med Dir Assoc 2013; 14: 463-70.

11 Lin P-J, Fillit HM, Cohen JT, Neumann PJ. Potentially avoidable hospitalizations among Medicare beneficiaries with Alzheimer's disease and related disorders. Alzheimers Dement $J$ Alzheimers Assoc 2013; 9: 30-8.

12 Margiotta A, Bianchetti A, Ranieri P, Trabucchi M. Clinical characteristics and risk factors of delirium in demented and not demented elderly medical inpatients. J Nutr Health Aging 2006; 10: 535-9.

13 Erkinjuntti T, Wikstrom J, Palo J, Autio L. Dementia among medical inpatients. Evaluation of 2000 consecutive admissions. Arch Intern Med 1986; 146: 1923-6.

14 Saravay SM, Kaplowitz M, Kurek J, et al. How do delirium and dementia increase length of stay of elderly general medical inpatients? Psychosomatics 2004; 45: 235-42.

15 CHKS. An Economic Analysis of the Excess Costs for Acute Care for Patients with Dementia. CHKS, 2012 http://www.chks.co.uk/ userfiles/files/Dementia_an_economic_analysis.pdf (accessed July 17, 2016).

16 Sampson EL, Leurent B, Blanchard MR, Jones L, King M. Survival of people with dementia after unplanned acute hospital admission: a prospective cohort study. Int J Geriatr Psychiatry 2013; 28: 1015-22.

17 Badrakalimuthu V, Barclay S. Do people with dementia die at their preferred location of death? A systematic literature review and narrative synthesis. Age Ageing 2014; 43: 13-9.

18 Sleeman KE, Ho YK, Verne J, Gao W, Higginson IJ. Reversal of English trend towards hospital death in dementia: a populationbased study of place of death and associated individual and regional factors,. BMC Neurol 2014; 14: 59.

19 Ferri CP, Acosta D, Guerra M, et al. Socioeconomic factors and all cause and cause-specific mortality among older people in Latin America, India, and China: a population-based cohort study. PLoSMed 2012; 9: e1001179.

20 Torian L, Davidson E, Fulop G, Sell L, Fillit H. The effect of dementia on acute care in a geriatric medical unit. Int Psychogeriatr IPA 1992; 4: 231-9.

21 Wancata J, Windhaber J, Krautgartner M, Alexandrowicz R. The consequences of non-cognitive symptoms of dementia in medical hospital departments. Int J Psychiatry Med 2003; 33: 257-71.

22 Erkinjuntti T, Autio L, Wikstrom J. Dementia in medical wards. $J$ Clin Epidemiol 1988; 41: 123-6.

23 Phelan EA, Debnam KJ, Anderson LA, Owens SB. A systematic review of intervention studies to prevent hospitalizations of community-dwelling older adults with dementia. Med Care 2015; 53: 207-13.

24 Boustani MA, Sachs GA, Alder CA, et al. Implementing innovative models of dementia care: The Healthy Aging Brain Center. Aging Ment Health 2011; 15: 13-22.

25 Bellantonio S, Kenny AM, Fortinsky RH, et al. Efficacy of a geriatrics team intervention for residents in dementia-specific assisted living facilities: effect on unanticipated transitions. J Am Geriatr Soc 2008; 56: 523-8.

26 Eloniemi-Sulkava U, Saarenheimo M, Laakkonen M-L, et al. Family care as collaboration: effectiveness of a multicomponent support program for elderly couples with dementia. Randomized controlled intervention study. J Am Geriatr Soc 2009; 57: 2200-8.

27 D'Arcy LP, Stearns SC, Domino ME, Hanson LC, Weinberger M. Is geriatric care associated with less emergency department use? $J$ Am Geriatr Soc 2013; 61: 4-11. 
28 Kasteridis P, Mason AR, Goddard MK, Jacobs R, Santos R, McGonigal $G$. The influence of primary care quality on hospital admissions for people with dementia in England: a regression analysis. PloS One 2015; 10: e0121506.

29 Schnitker L, Martin-Khan M, Beattie E, Gray L. What is the evidence to guide best practice for the management of older people with cognitive impairment presenting to emergency departments? A systematic review. Adv Emerg Nurs J 2013; 35 154-69.

30 Hustey FM, Meldon SW, Smith MD, Lex CK. The effect of mental status screening on the care of elderly emergency department patients. Ann Emerg Med 2003; 41: 678-84.

31 Salen $\mathrm{P}$, Heller M, Oller C, Reed J. The impact of routine cognitive screening by using the clock drawing task in the evaluation of elderly patients in the emergency department. J Emerg Med 2009; 37: 8-12.

32 Gentric A, Duquesne F, Graziana A, et al. [A sociomedical geriatric assessment in the emergency units: an alternative to the hospitalization of aged patients?]. Rev Med Interne Fondee Par Soc Natl Francaise Med Interne 1998; 19: 85-90.

33 Mion LC, Palmer RM, Anetzberger GJ, Meldon SW. Establishing a case-finding and referral system for at-risk older individuals in the emergency department setting: the SIGNET model. J Am Geriatr Soc 2001; 49: 1379-86.

34 Mion LC, Palmer RM, Meldon SW, et al. Case finding and referral model for emergency department elders: a randomized clinical trial. Ann Emerg Med 2003; 41: 57-68.

35 McCusker J, Jacobs P, Dendukuri N, Latimer E, Tousignant P, Verdon J. Cost-effectiveness of a brief two-stage emergency department intervention for high-risk elders: results of a quasirandomized controlled trial. Ann Emerg Med 2003; 41: 45-56.

36 Wright PN, Tan G, lliffe S, Lee D. The impact of a new emergency admission avoidance system for older people on length of stay and same-day discharges. Age Ageing 2014; 43: 116-21.

37 Hospital at Home for Older People. http://www.southerntrust. hscni.net/about/3176.htm (accessed July 18, 2016).

38 Innes S. Dementia care of future may be at home. Ariz. Dly. Star http://tucson.com/news/science/health-med-fit/dementia-careof-future-may-be-at-home/article_09b31967-33d1-5049-b37d4d77582a010d.html (accessed July 18, 2016).

39 Caplan GA, Sulaiman NS, Mangin DA, Aimonino Ricauda N, Wilson AD, Barclay L. A meta-analysis of 'hospital in the home'. Med J Aust 2012; 197: 512-9.

40 Leff B, Burton L, Mader SL, et al. Hospital at home: feasibility and outcomes of a program to provide hospital-level care at home for acutely ill older patients. Ann Intern Med 2005; 143: 798-808.

41 Frick KD, Burton LC, Clark R, et al. Substitutive Hospital at Home for older persons: effects on costs. Am J Manag Care 2009; 15: 49-56.

42 ZonMw - Hospital At Home care program for patients with dementia and an acute medical crisis - Samenvatting. http:// www.zonmw.nl/nl/projecten/project-detail/hospital-at-homecare-program-for-patients-with-dementia-and-an-acute-medicalcrisis/samenvatting/ (accessed July 18, 2016).

43 Dewing J, Dijk S. What is the current state of care for older people with dementia in general hospitals? A literature review. Dement Lond Engl 2016; 15: 106-24.

44 Moyle W, Olorenshaw R, Wallis M, Borbasi S. Best practice for the management of older people with dementia in the acute care setting: a review of the literature. Int J Older People Nurs 2008; 3: 121-30.

45 Kuske S, Graf R, Hartig M, Quasdorf T, Vollmar HC Bartholomeyczik S. Dementia considered? Safety-relevant communication between health care settings: a systematic review. J Public Health 2014; 22: 383-93.

46 Jurgens FJ, Clissett P, Gladman JRF, Harwood RH. Why are family carers of people with dementia dissatisfied with general hospital care? A qualitative study. BMC Geriatr 2012; 12: 57.

47 Waller S. Redesigning wards to support people with dementia in hospital. Nurs Older People 2012; 24: 16, 18-21.

48 Gladman J, Porock D, Griffiths A, et al. Care of Older People with Cognitive Impairment in General Hospitals. Final Report NIHR Service Delivery and Organisation programme. National Institute of Health Research/ HMSO, 2012.

49 Zieschang T, Dutzi I, Muller E, et al. Improving care for patients with dementia hospitalized for acute somatic illness in a specialized care unit: a feasibility study. Int Psychogeriatr IPA 2010; 22: 139-46.
50 Gonski PN, Moon I. Outcomes of a behavioral unit in an acute aged care service. Arch Gerontol Geriatr 2012; 55: 60-5.

51 Upton D, Krishnan N, Bray J, Bowen T, Foote C. An evaluation of quality and cost effectiveness of a newly defined suite of care interventions for patients with dementia and their carers in the acute hospital setting developed by The Royal Wolverhampton Hospitals NHS Trust. 2012 http://www.worcester.ac.uk/ documents/Dementia_evaluation_report_for_New_Cross_Vol_1. pdf (accessed July 23, 2016).

52 Kitwood T. Dementia: Management of Behavioural and Psychological Symptoms. Oxford: Oxford University Press, 1993.

53 Griffiths $\mathrm{P}$, Bridges J, Sheldon $\mathrm{H}$, Thompson R. The role of the dementia specialist nurse in acute care: a scoping review. J Clin Nurs 2015; 24: 1394-405.

54 Chater K, Hughes N. Strategies to deliver dementia training and education in the acute hospital setting. J Res Nurs 2012; published online June 11. DOI:10.1177/1744987112446242.

55 Holmes J, Montana C, Powell G, et al. Liaison Mental Health Services for Older People: A Literature review, service mapping and in-depth evaluation of service models. Research report for the National Institute of Health Research Service Delivery and Organisation Programme. NIHR/ HMSO, 2010 http://www.nets. nihr.ac.uk/_data/assets/pdf_file/0017/64502/FR-08-1504-100. pdf.

56 Mujic F, Hanlon C, Sullivan D, Waters G, Prince M. Comparison of liaison psychiatry service models for older patients. Psychiatr Bull 2004; 28: 171-3.

57 Slaets JP, Kauffmann RH, Duivenvoorden HJ, Pelemans W, Schudel WJ. A randomized trial of geriatric liaison intervention in elderly medical inpatients. Psychosom Med 1997; 59: 585-91.

58 Strain JJ, Lyons JS, Hammer JS, et al. Cost offset from a psychiatric consultation-liaison intervention with elderly hip fracture patients. Am J Psychiatry 1991; 148: 1044-9.

59 Singh I, Ramakrishna S, Williamson K. The Rapid Assessment Interface and Discharge service and its implications for patients with dementia. Clin Interv Aging 2013; 8: 1101-8.

60 Elliot R, Adams J. The creation of a Dementia Nurse Specialist role in an acute general hospital. $J$ Psychiatr Ment Health Nurs 2011; 18: 648-52.

61 Inouye SK, Bogardus STJ, Charpentier PA, et al. A multicomponent intervention to prevent delirium in hospitalized older patients. N Engl J Med 1999; 340: 669-76.

62 Inouye SK, Bogardus STJ, Baker DI, Leo-Summers L, Cooney LMJ. The Hospital Elder Life Program: a model of care to prevent cognitive and functional decline in older hospitalized patients. Hospital Elder Life Program. J Am Geriatr Soc 2000; 48: 1697-706.

63 Rubin FH, Williams JT, Lescisin DA, Mook WJ, Hassan S, Inouye SK. Replicating the Hospital Elder Life Program in a community hospital and demonstrating effectiveness using quality improvement methodology. J Am Geriatr Soc 2006; 54: 969-74.

64 Siddiqi N, Harrison JK, Clegg A, et al. Interventions for preventing delirium in hospitalised non-ICU patients. Cochrane Database Syst Rev 2016; 3: CD005563.

65 Strijbos MJ, Steunenberg B, van der Mast RC, Inouye SK Schuurmans MJ. Design and methods of the Hospital Elder Life Program (HELP), a multicomponent targeted intervention to prevent delirium in hospitalized older patients: efficacy and costeffectiveness in Dutch health care. BMC Geriatr 2013; 13: 78.

66 Chen P, Dowal S, Schmitt E, et al. Hospital Elder Life Program in the real world: the many uses of the Hospital Elder Life Program website. J Am Geriatr Soc 2015; 63: 797-803.

67 Yue J, Tabloski P, Dowal SL, Puelle MR, Nandan R, Inouye SK. NICE to HELP: operationalizing National Institute for Health and Clinical Excellence guidelines to improve clinical practice. J Am Geriatr Soc 2014; 62: 754-61. 


\section{CHAPTER 5 \\ Palliative care}

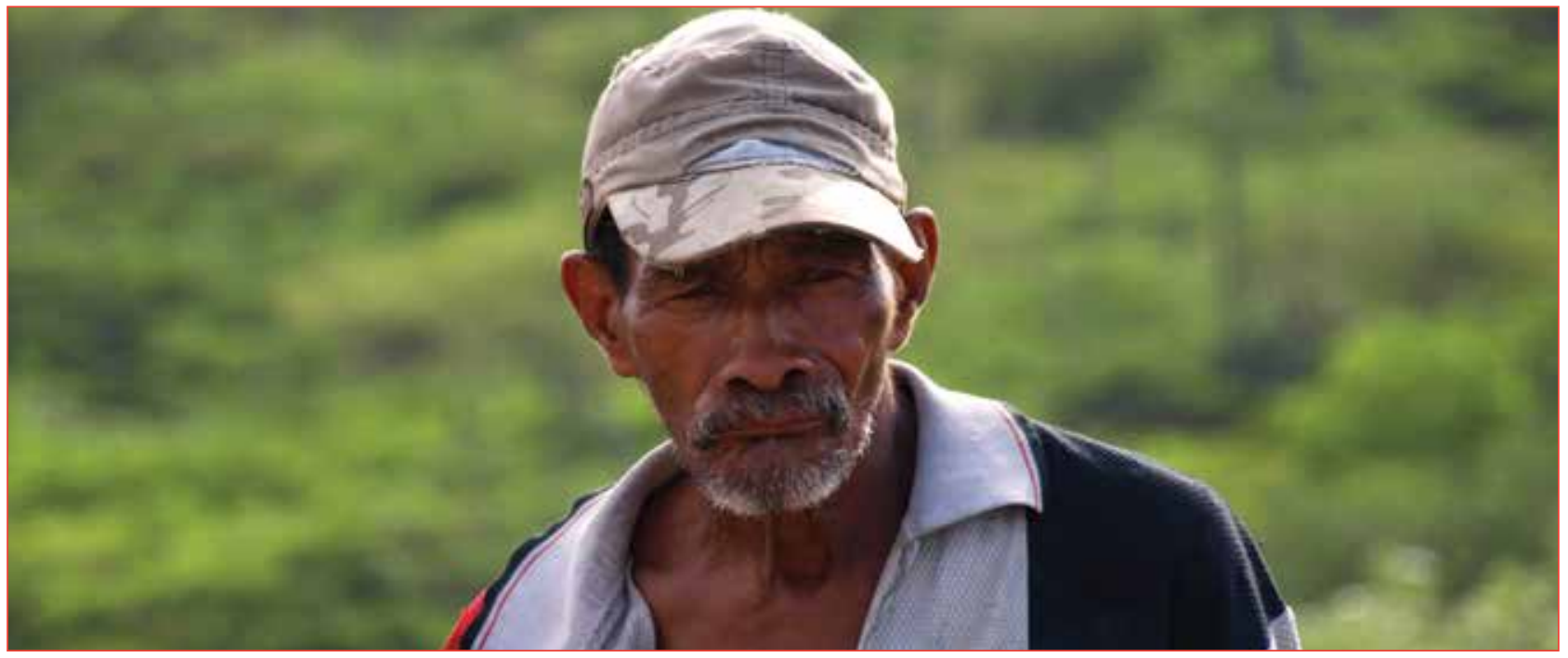

\subsection{Introduction}

There are currently no disease modifying treatments for dementia, which is a life-limiting illness, and deaths with dementia are increasingly common. In the World Alzheimer Report 2013 'Journey of Caring'1, we reviewed the literature on end-of-life care for people with dementia (section 4.2), and considered separately the applicability and use of advanced care planning (section 5.2). These two issues are closely related, since advanced care planning allows people with dementia to think through, and state preferences for future care options. Many important decisions along the dementia journey will need to be taken at a time when the capacity of people with dementia to contribute to them may be significantly compromised ${ }^{2}$. However, these are just two elements of what, in recent reviews and expert consensus exercises has been described as a 'palliative care approach' to dementia care extending across the disease course, from diagnosis to death, and beyond ${ }^{2-4}$.

The interest in a palliative care approach to dementia care has been motivated by concerns that those dying with advanced dementia are often not seen as having a terminal condition, and are much less likely than others to be managed palliatively. Thus, US nursing home residents with dementia were eight times less likely than those with cancer to have donot-resuscitate orders and three times less likely to have do-not-hospitalize orders, and were much more likely to experience burdensome interventions such as tube feeding, laboratory tests and restraints ${ }^{5}$. There have also been problems with lack of access to specialist palliative care, which, historically, has been closely linked to cancer care. In one UK study, only $9 \%$ of people with dementia at the end of life on acute medical wards were referred to palliative care specialists, compared to $25 \%$ of people without cognitive problems ${ }^{6}$.

Our purpose in this chapter is to update and integrate the sections of the World Alzheimer Report 2013, in the context of the emerging consensus around the 'palliative care approach' to dementia care. We conducted a scoping review of the literature (20132016) using the search terms "dementia AND (end of life care OR palliative care)" and "Alzheimer's AND (end of life care OR palliative care)". After excluding duplicates, we identified 2108 unique publications. Review of titles, abstracts and hard copies limited this to 100 relevant publications. Of these, 46 focused on end of life, and/or dying with dementia, 21 had a specific focus on palliative care in advanced dementia, and 18 described research conducted in care homes. Sixty-three publications (63\%) focused on one or other of these themes, reflecting a persistent orientation to the later stages of dementia care. Sixteen studies (16\%) addressed advanced care planning. Strikingly, there were no experimental studies, either using randomised controlled, controlled or quasi-experimental designs to evaluate innovations relating to palliative care in dementia.

\subsection{What is palliative care?}

According to the World Health Organization's definition ${ }^{7}$, palliative care:

- provides relief from pain and other distressing symptoms;

- affirms life and regards dying as a normal process;

- intends to neither hasten nor postpone death; 
- integrates the psychological and spiritual aspects of patient care;

- offers a support system to help patients live as actively as possible until death;

- offers a support system to help the family cope during the patient's illness and in their own bereavement;

- uses a team approach to address the needs of patients and their families, including bereavement counselling, if indicated;

- will enhance quality of life, and may also positively influence the course of illness.

\subsection{How, and when, is palliative care applicable to dementia care?}

The World Health Organization has stated that 'every person with a progressive illness has a right to palliative care'8.

Kydd and Sharp 4 , in a systematic review of policy formulations with respect to the palliative care approach in dementia care, identified, in effect, four main areas of relevance:

1. The WHO definition of palliative care has much in common with fundamental principles of dementia care, including the need for care to become more person-centred and relationship focused, while involving family and carers and attending to their needs.

2. The palliative care approach acknowledges explicitly that dementia is a life-limiting illness, which, if adopted early may help to promote advanced care planning.

3. A palliative care focus encourages more nuanced management of complex physical comorbidity in advanced dementia, avoiding burdensome or futile clinical investigations and interventions, and unnecessary and distressing transitions in the care system.

4. It may secure for people with dementia better access to the expertise of specialist palliative care services in addressing, for example, complex ethical dilemmas, and managing physical complications and distress at the end of life.

However, as subsequent sections of this chapter make clear, we are some way from a general or even widespread acceptance, let alone adoption, of a broadly defined palliative care approach to dementia care. Among dementia care practitioners and researchers, palliative care is often considered to be synonymous with end-of-life care, and relevant only to the advanced phase of the condition ${ }^{9}$. Palliative care practitioners have a much broader view of their roles and functions, and as the WHO definition specifies, palliative care is "applicable early in the course of illness, in conjunction with other therapies that are intended to prolong life, and includes investigations needed to better understand and manage distressing clinical complications" 8 .

Palliative care should, therefore, be about living well as well as dying well with dementia ${ }^{4}$. Kydd and Sharp neatly observe that good dementia care already implicitly reflects a palliative care approach, posing the question "Does reluctance to use the language of palliation reflect a conflict with the message of rehabilitative potential to live well-or is [it] that the language itself is unhelpful because it is poorly understood and can be quite terrifying?"4.

A qualitative study of the views of professionals working in long-term care facilities in six European countries sought to clarify the stage in the disease trajectory when people with dementia might be considered to be eligible for palliative care ${ }^{10}$. Three different time points were commonly identified; early in the disease trajectory; when signs and symptoms of advanced dementia are present; and from the time that curative treatment of co-morbidities is futile. However, there was no consensus within countries, professional disciplines, or even among staff within the same facility.

A recent Delphi expert consensus, convened by the European Association for Palliative Care (EAPC), on optimal palliative care in older people with dementia, made 57 recommendations within 11 domains (applicability of palliative care; person-centred care, communication and shared decision making; setting care goals and advance planning; continuity of care; prognostication and timely recognition of dying; avoiding overly aggressive, burdensome or futile treatment; optimal treatment of symptoms and providing comfort; psychosocial and spiritual support; family care and involvement; education of the healthcare team; societal and ethical issues) ${ }^{3}$. With respect to the applicability of palliative care the consensus was clear - the recommendation being that the palliative care approach should be applied across the disease course (see Box 5.1)

In making these recommendations the EAPC experts also argued for a modification of the traditional palliative care model, which dichotomises curative (disease-modifying) and palliative (symptom management) goals, and sees these as representing distinct phases of care ${ }^{11}$. Instead, they propose three goals for dementia care; prolongation of life, maintenance of function, and comfort; the relative emphasis of which tends to change over the disease course $^{3}$

The main arguments for implementing a palliative care approach early in the disease course include: 
Box 5.1

European Association for Palliative Care White Paper recommendations for applicability of palliative care for people with dementia ${ }^{3}$

1.1 Dementia can realistically be regarded as a terminal condition. It can also be characterized as a chronic disease or, in connection with particular aspects, as a geriatric problem. However, recognizing its eventual terminal nature is the basis for anticipating future problems and an impetus to the provision of adequate palliative care.

1.2 Improving quality of life, maintaining function and maximizing comfort, which are also goals of palliative care, can be considered appropriate in dementia throughout the disease trajectory, with the emphasis on particular goals changing over time.

1. Respect for autonomy is a fundamental principle of human bioethics, as laid down in the Nuremberg Code, requiring that participation in research (and by extension medical care) is on the basis of voluntary, informed consent. The Code carries the qualification that 'the person involved should have the legal capacity to give consent'. Decision-making capacity is a critical issue in dementia care, given progressive cognitive decline. People with dementia are more likely to retain decision-making capacity in the early stages, so advanced care planning, if it is to prioritise the views of the person with dementia, needs, ideally, to feature in the early post-diagnostic phase of care.

2. Advanced care planning has its origins in decisionmaking for end-of-life care ${ }^{12}$. However, it has a much broader application for people with dementia, for whom many important decisions may need to be made after decision-making capacity has been lost, but some time before death.

3. Even if one accepts the particular salience of palliative care to end-of-life care, it is probable that most people with dementia die before reaching the advanced stage of the disease. Survival times from diagnosis range from 2.9 to 7.0 years for mild dementia, 1.5 to 3.0 years for moderate dementia and 1.4-2.4 years for severe dementia ${ }^{13}$, and mortality rates increase with severity ${ }^{14}$. However, at any one time, in a given population, there are many more people with milder as compared with advanced dementia. Given the apparent lack of other direct evidence, for the purposes of this report, we conducted an additional analysis on patterns of mortality in the 10/66 population-based cohort studies in Latin America, India and China ${ }^{15}$. Of 485 deaths among people with dementia, 384 occurred among people with mild dementia at baseline (58\%), 134 among those with moderate dementia (28\%), and only 67 (14\%) among those with severe dementia.

\subsection{Advanced care planning}

\section{What is advanced care planning (ACP)?}

Advanced care planning is defined by the World Health Organization as 'a process to make clear a person's wishes and that will usually take place in anticipation of future deterioration of an individual's condition, with loss of capacity to make decisions and/or ability to communicate wishes to others'. In principle, ACP provides an opportunity to anticipate future decisions relating to health and social care needs, allowing the person with dementia to make choices and feel in control, and provides an opportunity to initiate timely palliative care. Consistent with a person-centred approach to care, advanced care planning should elicit personal values, beliefs, and preferences about current and future care.

\section{Advanced care planning in practice}

ACP can take different forms and lead to different outcomes. Discussions can result in a statement of preferences or wishes (an Advanced Statement or Directive), the appointment of a Lasting Power of Attorney (LPA), or an Advance Decision to Refuse Treatment (ADRT), in specific future circumstances ${ }^{16}$. All of these legal instruments require that at the time of the provision being made, the person retains capacity to make the provision. The instrument would only take effect if the person had subsequently lost decisionmaking capacity (see Box 5.2), and hence could no longer be consulted directly.

An advanced statement or directive is a written or oral statement to communicate to others preferences or wishes related to future care or personal preferences. For example, a person with dementia might express a preference not to be admitted to hospital from their care home, even if that might shorten their life, as long as their comfort could be assured. Preferences cannot be made for acts that may be illegal, such as assisted suicide.

A Lasting Power of Attorney is a nomination in a prescribed form of a person responsible for taking decisions on the behalf of an individual on economic, health or personal matters, in the event of loss of capacity. For example, a person with dementia might appoint their daughter to give or withhold consent for all healthcare investigations and treatments. Any 
decisions taken by the appointed person should be made in the person with dementia's best interests, with the assumption that they would be familiar with their previously stated values and preferences.

An Advance Decision to Refuse Treatment is a decision to refuse certain types of treatment, in certain specified health states, should loss of capacity ensue. For example, a person with dementia might decide to refuse tube feeding, should they lose the ability to swallow, at the end of life. This decision should be made under the supervision of someone who understand the intricacies of the process, and by someone who has mental capacity at the time of the decision.

\section{How widespread is advanced care planning?}

The use of ACP among people with dementia is on the increase in many countries. In a recent study of just over 1000 people with dementia in Belgium, 52\% had made some form of advance care planning (just $6 \%$ initiated by the individual concerned, most having been prompted by a clinician, and only $9 \%$ had a legal representative $)^{18}$. In a survey conducted in 2005 in the USA, $65 \%$ of older people attending a memory service with cognitive impairment or dementia had a durable power of attorney and $56 \%$ a living will ${ }^{19}$. This was a sizeable increase from a US study of nursing home residents in 1996, in which it was reported that only $21 \%$ had a living will, $40 \%$ a 'do-not resuscitate order' and only $6 \%$ a treatment restriction relating to medication, feeding or other interventions ${ }^{20}$. These surveys were conducted in countries with policies in place to encourage ACP, underpinned by legislation. Internationally, there is little available evidence on its use, but this is likely to be highly variable, and much lower in those countries where awareness of dementia is limited, where ACP is not discussed, and where advanced directives may not carry legal force. In dementia care as for other clinical contexts, the use of ACP is much more common among those with better education, and in the USA among white compared with black Americans ${ }^{19}$.

\section{How effective is advanced care planning?}

There is no direct evidence from randomised controlled trials for the effectiveness of advance care planning for people with dementia. A recent systematic review of the effectiveness of ACP for people with cognitive impairment and dementia identified four relevant studies, which did not, in fact, select specifically for people with dementia or cognitive impairment, and did not report any subgroup analyse ${ }^{21}$. Findings are nevertheless of interest, and of tangential relevance. In two studies, use of ACP was associated with a reduction of unnecessary hospital admissions ${ }^{22,23}$, and in one study there was a significant increase in hospice use in the group with ACP in place ${ }^{24}$. Another study
Box 5.2

\section{Decision-making capacity}

For a person to have decision-making capacity, they should

1. Understand the information relevant to making the decision. This could include, the nature of their health condition, the proposed treatment, its potential risks and benefits

2. Retain the information long enough to make a stable and consistent decision

3. Demonstrate that they have weighed up the information to make their choice, consistent with their values and preferences, and free of any outside influence or coercion

4. Be able to communicate their decision

This is a functional assessment ${ }^{17}$, which needs to be carried out separately for each important decision. A person with dementia may lack capacity to manage their finances, while still be able to decide that they would not wish to be resuscitated in the event of a cardiac arrest. Evidently there should be no blanket assumption that people with advanced dementia in general, or a particular person with dementia, lacks capacity to make any decision; this would imply a total loss of autonomy, the avoidance of which should be a key objective of dementia care.

While the clinical judgment of capacity is dichotomous, i.e. that capacity is retained or not retained, in practice patients often have more or less capacity along a continuum, and the ultimate judgement, as to whether the patient has enough capacity to make the decision is often finely balanced, and open to contention, which sometimes has to be resolved through a legal process. People with dementia can be supported to exercise their autonomy by ensuring that every effort is made to enhance their understanding of the information relevant to the choice, and by assisting them with the decision-making process. Decision-making capacity may wax and wane. If a decision can be delayed, until, for example, recovery from an intercurrent illness, then the capacity assessment should be repeated at a more favourable time.

conducted among older medical inpatients showed that advance care planning resulted in having end-oflife wishes more likely to be followed, and in particular that ACP was associated with an improvement in carers' stress, anxiety and depression ${ }^{25}$. A large 
study, linked to the US Health and Retirement Survey indicated that participants who had made an advanced directive, and lacked capacity, were highly likely to receive care consistent with their stated preferences ${ }^{26}$. Studies assessing how ACP can improve outcomes in vulnerable older people are still few, and of limited quality ${ }^{27}$, compared to other clinical populations with life-limiting conditions where the effectiveness of these directives has been studied in more detail. There is an urgent need for high quality trials to be conducted of the effectiveness and cost-effectiveness of ACP in dementia, including the longer term benefits and harms associated with ACP in the early post-diagnostic phase.

\section{Issues in implementing advance care planning}

\section{Optimal timing}

As with issues around the optimal timing for introducing the palliative care approach, there are controversies regarding the best timing for discussions regarding advanced care planning. In principle, ACP should be undertaken with the person who has dementia early in the disease to ensure that their wishes are represented and responded to appropriately. However, such discussion could distress some people, especially if the health or social care professionals do not have the appropriate training or interpersonal skills.

In the wider context of decision-making for end-oflife care older people have expressed worries and difficulties related to; thinking about and discussing death and dying; a perceived link between advance care statements and euthanasia; and the possibility that anticipated preferences might not reflect a readiness to 'disengage' from their lives when the time came ${ }^{12}$. There is also evidence that frail older people may be reluctant to address what they see as hypothetical questions regarding possible scenarios arising in the context of chronic disease care, some of which may be depressing to contemplate 28 . They are, somewhat paradoxically, more willing to confront the more concrete realities of treatment decisions in endof-life care and dispositions to be made after death ${ }^{28}$.

There is limited direct evidence for the acceptability and feasibility of ACP conducted early in the disease course. A pilot study conducted in a UK memory clinic was accompanied by a small qualitative evaluation ${ }^{29}$. All but three of 12 patients considered ACP to be a positive and helpful experience. Perceived benefits included having time to think about the future, feeling relieved and less worried having discussed their preferences and shared them with family and professionals, and reassured about future support. Two patients found discussing the future dispiriting, while another found the exercise too hypothetical.
There was a consensus among patients, carers and staff that ACP should be discussed sooner rather than later. For staff, this should be after the patients had time to think about the diagnosis, but when they were still in contact with the service, and still had the capacity to make decisions about future care. In Ireland, a survey of 133 primary care practitioners (PCPs) revealed that $96 \%$ considered dementia to be a terminal condition, and $61 \%$ thought that early discussions would assist decision-making during the advanced stages ${ }^{30}$. However, respondents were evenly divided on whether ACP should be initiated at the time of diagnoses. While most PCPs felt that their service should be taking the lead in introducing and promoting ACP, they also identified needs for training and support, and a standard format for ACP documentation.

\section{Capacity}

Two studies from the UK attempted to calibrate decision-making capacity for advanced care planning against disease stage as indexed by Mini-Mental State Examination score, with convergent findings that MMSE thresholds of 18-20 best discriminated between those who could and could not engage meaningfully in advanced care planning ${ }^{31,32}$. However, other studies have raised concerns regarding ability to participate for those with even mild or very mild dementia. In a German Memory Clinic, objective tests of decision-making capacity revealed significant problems even among patients with mild cognitive impairment $(\mathrm{MCl})$ and mild dementia, and those with more impaired decision-making capacity generally had a less pronounced desire to participate in decision-making ${ }^{33}$. In another study conducted in a UK memory clinic service, it was noted that participants with mild dementia (mean MMSE score 24) found it difficult to consider preferences and wishes about the end of their lives, with little sense of the potential value of ACP, or how expressing preferences and wishes now could influence care later ${ }^{34}$. People with dementia had difficulty considering their future selves, tending instead to express preferences relating to their current status and care needs. The EAPC consensus acknowledges some of these problems, recommending (3.4) that 'In mild dementia, people need support in planning for the future'3.

\section{Carer and family involvement}

Carers may be involved in advanced care planning in two contexts. First, whether or not the person with dementia retains decision-making capacity, good practice guidance stresses the importance of involving significant others, in particular carers, in the process. Thus the EAPC recommends ${ }^{3}$, inter alia, that

2.2 Shared decision making includes the patient and family caregiver as partners and is an appealing model that should be aimed for. 
2.3 The healthcare team should ask for and address families' and patients' information needs on the course of the dementia trajectory, palliative care and involvement in care.

2.5 Current or previously expressed preferences with regard to place of care should be honoured as a principle, but best interest, safety and family caregiver burden issues should also be given weight in decisions on place of care.

2.6 Within the multidisciplinary team, patient and family issues should be discussed on a regular basis.

3.6 Advance care planning is a process, and plans should be revisited with patient and family on a regular basis and following any significant change in health condition.

When the person with dementia has lost capacity to make a decision, then the carer may act as a proxy decision maker, either informally or legally empowered through a lasting power of attorney. Under such circumstances, they are enjoined to consider the person with dementia's best interests; in essence what they would have wanted had they retained the capacity to decide for themselves. However, there is growing evidence that the views of people with dementia and carers may differ, regarding the locus of decision-making, values and priorities, and patient preferences ${ }^{33-35}$. In the German Memory Clinic Study, people with mild cognitive impairment or mild dementia, and their relatives were asked to rank who should have the greatest say in medical and social care decisions, including stopping driving and relocation to a care home ${ }^{33}$. For medical care decisions, patients wanted to be guided by their physicians. For social care decisions they wanted physicians to have very little influence. For decisions in general they wished their relatives and carers to have little influence, compared to their own wish to participate in the process. The converse was true for relatives. In the UK, Dening et al conducted a qualitative study of generation and prioritisation of preferences for endof-life care by people with dementia alone, carers alone and dyads of people with dementia and their carers $^{34}$. Quality of care, family contact, dignity and respect were ranked as significant themes by all groups. However, for people with dementia the ranking of priorities was: to maintain family links, to maintain independence, to feel safe, not to be a burden, to be treated with respect and dignity, to choose their place of care, to have pleasurable activities, personcentred care, and to be in touch with the world and have a comfortable environment. For carers the order of priorities was: for them to be in control, for the person with dementia to have a good quality of life, to have good quality care, to have a comfortable death, to be treated with respect and dignity and for the carer to be supported. An important theme was the contrast between the prioritisation, by the persons with dementia, of maintaining independence, and, by the carer, of the need to be in control. In the dyad group, it was noted that carers tended to speak on behalf of the person with dementia, thus influencing the consensus. Several carers expressed concerns that an ACP would lead to loss of control at critical junctures, and would be open to misinterpretation by professionals.

Two quantitative studies compared directly the endof-life care preferences of people with dementia (with decision making capacity) with their carers' perceptions of what the person with dementia would prefer. In the UK, researchers compared 60 people with dementia and their carers' preferences regarding three treatment options (antibiotics, cardiopulmonary resuscitation, tube-feeding) in three hypothetical illness scenarios (the 'here and now', severe stroke with coma and terminal cancer) using the Life Support preferences Questionnaire (LPSQ) ${ }^{35}$. Other than for the 'here and now', both people with dementia and carers were uncertain about their treatment preferences, and agreement between person with dementia and carer was low to moderate. Carers tended to overestimate the person with dementia's preference for life-prolonging intervention in the context of severe stroke. Relationship quality, carer distress and burden had no influence on levels of agreement. Conversely, in a similar study conducted in Israel, of people with $\mathrm{MCl}$ and mild dementia, spouse preferences for endof-life care correlated moderately well with patient preferences $^{36}$.

Several studies have identified family and carer issues as potential barriers to the effective implementation of ACP for dementia. This was a frequently occurring theme according to the perceptions of healthcare professionals, who cited the occasional unwillingness of families to engage in $\mathrm{ACP}$, and their unpreparedness for the task. This could be compounded by dysfunctional family dynamics and disagreements between family members ${ }^{37}$. The need for multidisciplinary input was cited, including social work, to better engage families in the process ${ }^{30,37}$. This finding gels with findings from a review of family carer perspectives ${ }^{38}$, which indicated a limited readiness among many to contemplate their relative's death and the process of dying. Nonetheless, in a qualitative study of advanced care planning focused on end-oflife care for nursing home residents with advanced dementia, carers generally understood the relevance and timeliness of discussing options for end-of-life care, and appreciated the opportunity to do so, while also experiencing some discomfort and distress ${ }^{39}$. Preparation for ACP in this context should include an assessment of the carer's readiness to engage, which may be facilitated by a better understanding of the limited life expectancy, and hence the relevance of the discussion ${ }^{39}$. Practitioners should also be sensitive to grief reactions linked to the separation process, in advance of death, following admission to a care 
home. A review has recommended more research to understand the thought processes and emotions of carers, and to enhance understanding of how to engage them with $\mathrm{ACP}^{38}$. It also counsels that 'ACP may not be for everyone' and therefore approaching ACP should be carefully considered by professionals before engaging with families and people with dementia.

EAPC guidelines ${ }^{3}$ recommend that; families need education regarding the progressive course of the dementia and (palliative care) treatment options; this should be a continuous process addressing specific needs in different stages, examining family receptiveness (recommendation 9.3) and that; families need support in their new role as (future) proxy decision maker (9.5).

\section{Healthcare professionals}

A review of the literature on healthcare professionals' perceptions of ACP identified several important issues to be addressed in the early integration and planning for palliative care in dementia ${ }^{37}$. The first of these was a lack of awareness among many healthcare professionals of dementia as a life limiting condition, inhibiting discussion of end-of-life care and ACP. The UK health system Gold Standard Framework prognostic indicator has been recommended as a practical and easy to use tool to identify those that may be nearing the end of life ${ }^{40}$. However, a recent systematic review of prognostic indicators suggests some difficulty in reliably predicting six month mortality among people with advanced dementia; undernutrition and underhydration, comorbidity and dementia severity were the most reliable predictors ${ }^{41}$. The second issue was ethical and moral concerns voiced by some healthcare professionals. These included a hesitancy to discuss death, and a fear of upsetting the people in their care, compounded by moral dilemmas around discussing future goals of care focused on a palliative as opposed to a curative approach. Communication challenges when interacting with people with dementia and their families were also highlighted. Some staff in some studies viewed their role as preserving life, even if this was against the expressed wishes of the patient and their family. There were also concerns expressed that ACP might turn out to be a 'false promise' if there were later problems with implementation, either because they were no longer considered consistent with the patient's current best interests, or because of resource limitations. The review concluded that despite evidence that healthcare professionals recognise the potential benefits of ACP, they struggle with its implementation. There was a great need for education and training of health professionals to improve consistency in practice; regarding dementia as a condition, the illness trajectory, and the concept and process of ACP itself. The need for a structured approach to ACP has also been highlighted, both for recording the outcomes of the process, and the potential utility of ACP toolkits ${ }^{42}$.

The EAPC guidelines ${ }^{3}$ recommend that; the healthcare team in its entirety, including allied health professionals and volunteers, needs to have adequate skills in applying a palliative care approach to dementia (recommendation 10.1); core competencies should be available within a healthcare team, and all individual members should be able to provide at least a baseline palliative care approach (10.2) and that; care plans should be documented and stored in a way that permits access to all disciplines involved in any stage and through transfers of care (3.7).

\subsection{End-of-life care}

\section{Access to palliative care at end-of-life}

As previously noted, it has been stated that those dying with advanced dementia are often not seen as having a terminal condition, and are much less likely than others to be managed palliatively. Some research from the early 2000s supported that conclusion ${ }^{5,6}$. Recently published evidence provides a more nuanced picture regarding progress towards access to palliative care for people with dementia. For example, in the USA, nursing homes appear to be moving towards providing a more palliative approach to end-of-life care for residents with a diagnosis of dementia. Trends in the use of hospice care in the last 100 days of life were compared for over a million deaths of US nursing home residents occurring between 2003 and $2007^{43}$. Over the five years, hospice use for people dying with dementia increased from $25.1 \%$ to $36.5 \%$, and from $26.5 \%$ to $34.4 \%$ for other deaths. The rate of in-hospital deaths remained virtually unchanged. By 2007, people dying with dementia were significantly more likely than others to use hospice care services (OR 1.07, 95\% Cl: 1.04-1.11) and much less likely to die in a hospital (OR 0.76, 95\% Cl: 0.74-0.78). In another recent US study, for those admitted to hospice care, the quality of care for those with a diagnosis of dementia did not seem to differ from others, other than with respect to an excess use of tube-feeding ${ }^{44}$. The Dutch End of Life in Dementia study showed widespread use of appropriate palliative care measures in nursing homes the last week of life. Opioid medication was prescribed to $73 \%$ of those in pain. Shortness of breath was treated with opioids in $71 \%$ of cases, with $74 \%$ receiving oxygen. Bronchodilators and diuretics were used for symptomatic relief. For agitation, nonpharmacological interventions were provided for $62 \%$ of those affected, often combined with anxiolytic or sedative medication. Pain and shortness of breath were mostly treated with opioids and agitation mainly with anxiolytics. At the day of death, $77 \%$ received opioids, and $21 \%$ received palliative sedation ${ }^{45}$. 


\section{EAPC guidelines ${ }^{3}$ relevant to end-of-life care for people with dementia}

\section{Domain 6. Avoiding overly aggressive, burdensome or futile treatment}

6.1 Transfer to the hospital and the associated risks and benefits should be considered prudently in relation to the care goals and taking into account also the stage of the dementia.

6.2 Medication for chronic conditions and comorbid diseases should be reviewed regularly in light of care goals, estimated life expectancy, and the effects and side effects of treatment.

6.3 Restraints should be avoided whenever possible.

6.4 Hydration, preferably subcutaneous, may be provided if appropriate, such as in case of infection; it is inappropriate in the dying phase (only moderate consensus).

6.5 Permanent enteral tube nutrition may not be beneficial and should as a rule be avoided in dementia; skillful hand feeding is preferred (only moderate consensus).

6.6 Antibiotics may be appropriate in treating infections with the goal of increasing comfort by alleviating the symptoms of infection. Lifeprolonging effects need to be considered, especially in case of treatment decisions around pneumonia.

\section{Domain 7. Optimal treatment of symptoms and providing comfort}

7.1 A holistic approach to treatment of symptoms is paramount because symptoms occur frequently and may be interrelated, or expressed differently (e.g., when pain is expressed as agitation).

7.2 Distinguishing between sources of discomfort (e.g., pain or being cold) in severe dementia is facilitated by integrating views of more caregivers.

7.3 Tools to assess pain, discomfort and behaviour should be used for screening and monitoring of patients with moderate and severe dementia, evaluating effectiveness of interventions.

7.4 Both non-pharmacological and pharmacological treatment of physical symptoms, challenging behaviour or discomfort should be pursued as needed.

7.5 Nursing care is very important to ensure comfort in patients near death.

7.6 Specialist palliative care teams may support staff in long-term care settings in dealing with specific symptoms, while maintaining continuity of care. In managing behavioural symptoms, however, palliative care teams may need additional dementia care specialist expertise.

\section{Quality of end-of-life care}

Two recent studies of the quality of end-of-life hospital care for people with dementia in Ireland and Germany reveal significant persisting problems ${ }^{46,47}$. In Ireland, a National Audit of hospital care for people with dementia revealed that many assessments essential to dementia palliative care were not performed ${ }^{46}$. Of the total sample, 76 patients died, were documented to be receiving end-of-life care, and/or were referred for specialist palliative care, and for this group even less symptom assessment was recorded; $27 \%$ received no pain assessment, $68 \%$ no delirium screening, and 93\% no assessment of mood or behavioural and psychological symptoms of dementia. In all, $37 \%$ had antipsychotic drugs during their admission and $71 \%$ of these received a new prescription in hospital, most commonly for agitation. In a German study the opinion of carers was sought regarding end-of-life care for 1241 recently deceased older people, of whom 310 had a diagnosis of dementia $47.42 \%$ of the people with dementia (compared with $36 \%$ of others) died at home, which was the preferred outcome for $95 \%$ of patients and $78 \%$ of relatives. People with dementia were also less likely to die in a hospital ward $(20 \%$ vs $27 \%)$, an intensive care unit (6\% vs $16 \%$ ) or a hospice ( $3 \%$ vs $10 \%$ ). According to information supplied by the relatives, most of the people with dementia suffered in the days before death from symptoms that could have been alleviated; disorientation and confusion (86.9\%); anxiety (61.0\%); tension (59.9\%); shortness of breath $(56.7 \%)$, and pain (52.5\%). While pain was actually a less common experience for people with dementia than others, $36 \%$ of people with dementia vs $27 \%$ of others died with a pressure sore. For people with dementia, end-of-life care at home and in care homes was rated as of significantly better quality than hospital care. Relatives were critical of the quality of care on hospital wards, citing the limited availability of staff and emotional support ${ }^{47}$. 
Box 5.4

\section{Principles of comfort care. Core statements in Canadian Comfort Care Booklett9}

\section{Advanced dementia is a terminal condition}

1. Advanced dementia should be considered a terminal condition with most patients dying from nutrition/hydration or infection problems, especially pneumonia.

\section{Hydration and nutrition issues}

2. Feeding tubes are not recommended only to prolong life at this stage of dementia.

3. Fluids given intravenously or subcutaneously may help some patients but can also contribute to discomfort (increasing bronchial secretions, delaying pain-free coma state) and prolong the dying process.

4. Withholding or withdrawing artificial nutrition/ hydration is an acceptable option in advanced dementia, when swallowing difficulties are irreversible.

5. Withholding or withdrawing artificial nutrition/ hydration is generally not associated with discomfort, with adequate mouth care.

\section{Antibiotics for end-stage pneumonia}

6. When 'comfort care without life prolongation' is the goal, antibiotics can be withheld and treatment will then aim at symptom control

7. Even when pneumonia is treated with antibiotics, clinicians should pay attention to symptom control (e.g. prescribing opioids despite risk of respiratory depression) because pneumonia usually causes significant discomfort.

\section{Use of opioids and sedation}

8. Prescribing opioids may be necessary to control pain or breathing difficulties and is acceptable if the intention is to relieve the patient and not to hasten death.
9. Sedation is useful for some anxious patients and the advantages of less sedation may be less relevant in the context of severe dementia.

\section{Cardiopulmonary resuscitation}

10. Cardiopulmonary resuscitation is not recommended in advanced dementia because it can harm the patient and has very little chance of success.

\section{Hospital transfer}

11. Hospital transfer of the patient with advanced dementia should be exceptional, only to provide comfort by technical means not available in the nursing home.

\section{Medical decision process}

12. In decisions regarding whether or not to use lifeprolonging treatment, the ideal decision-making process is to reach a consensus between the physician, the substitute decision maker and other significant relatives or friends of the patient.

13. The substitute decision maker does not make decisions; his or her role is to give or withhold consent to medical options with regard to the patient's best interests (according to patient values and any written or verbal advanced directives).

14. The doctor does not have the power to impose a management plan on the family. If the substitute decision maker and the physician disagree, they should seek compromise.

\section{Euthanasia}

15. Active life termination (hastening death) is not an acceptable option for advanced dementia.

\section{Good practice guidance on end-of life care for people with dementia}

In the World Alzheimer Report 2013, we highlighted the Alzheimer Europe 2008 position paper and guidelines on end-of-life care ${ }^{48}$. This has now been updated to 2013. In 2014 the European Association for Palliative Care published their White Paper defining optimal palliative care in older people with dementia, which includes recommendations for end-of-life care ${ }^{3}$.

\section{Principles of end-of-life care}

The key objectives of end-of-life care are articulated in the Alzheimer Europe guidelines as maintaining the dignity, personhood and quality of life of the person with dementia, while attending also to carers' needs $^{48}$. Alzheimer Europe also focuses on the need for good communication throughout, and attending to spiritual needs. Their guidelines provide relevant, practical and helpful guidance on pain management; feeding and swallowing problems; constipation, diarrhoea and incontinence; pneumonia and infections; dehydration and mouth care; skin care; maintaining body temperature; use of sedation; restraint, and falls; breathing difficulties; and the moments preceding and following death ${ }^{48}$. The principles of end-of-life care are summarised in the EAPC guidelines ${ }^{3}$ under Domain 6 (avoiding overly aggressive, burdensome or futile treatment), and Domain 7 (optimal treatment of symptoms and providing comfort) (see Box 5.3). 
These are articulated in a slightly different form, and with more focus on the avoidance of burdensome or futile treatment in the Canadian Comfort Care Booklet (see Box 5.4) designed for use by staff in care homes ${ }^{49}$. This has also been evaluated for its cultural relevance and acceptability in Japan and France.

\section{Components of good quality end-of-life care}

It is clear from existing guidelines that good quality end-of-life care, is, to an important extent, about attention to symptom burden. Achieving comfort may involve quite intensive medical management and pharmacological as well as non-pharmacological intervention, alongside avoiding futile and burdensome investigation and management. However dignity, quality of life, and spiritual well-being will be achieved through attention to the overall quality of personcentred care, communication, and the environment in which end-of-life care is provided.

\section{Attention to symptom burden}

Symptom burden for people with dementia is a common problem towards end of life. The most commonly experienced symptoms are pain, pressure sores, shortness of breath, eating and swallowing problems, infections, agitation and other psychological symptoms (Box 5.5). In the Dutch End of Life in Dementia study (2007-2011) the most common symptoms in the last week of life for 330 nursing home residents were pain (52\%), followed by agitation (35\%) and shortness of breath $(35 \%)^{45}$. Pain and agitation were particularly strongly associated with low quality of life at the end-of-life. Death from respiratory infection was associated with the largest symptom burden. Some of the symptoms, in particular pain, are underdetected in patients with dementia ${ }^{50}$. This is likely to result from communication difficulties in advanced dementia, combined with lack of good assessment skills by some health professionals ${ }^{50}$. Under-detection can lead to under treatment of symptoms, and this has been reported as a concern in some studies ${ }^{51}$. On the other hand, over-treatment with burdensome and futile interventions, such as tube-feeding and antibiotics, in the period leading to end of life should also be avoided $^{51}$.

\section{Supporting carers and families}

It has been reported from the USA that while endof-life care for people with dementia was extremely demanding of family carers, they often showed considerable resilience in the face of bereavement; intervention and support services were needed most before the patient's death ${ }^{58}$. Support for carers needs to be culturally sensitive and take into account ethnic differences in caregiving experiences, attitudes to endof-life care and bereavement reactions ${ }^{59}$.
Box 5.5

\section{Symptom burden at the end of life}

- Pain: Depending on the setting, the stage of dementia, and the method of ascertainment, between $20 \%$ and $50 \%$ of people with dementia report some form of pain in the course of their illness progression ${ }^{52}$, with higher proportions affected towards the end of life ${ }^{47,51,53}$. One study found that people with dementia are more likely to experience pain in the last six months of life, compared to cancer patients $(75 \% \text { vs } 60 \%)^{54}$.

- Pressure sores: several studies have recorded the prevalence of pressure ulcers towards the end of life, varying from $17 \%$ in a study of terminal dementia ${ }^{5}$ to $47 \%$ in a study of older adults with advanced dementia living in seven Italian long-term institutions ${ }^{55}$. Pressure sores should be avoidable with good nursing care, and are a key indicator of care quality.

- Shortness of breath: a recent review of the literature identified that shortness of breath is a common symptom in about half to threequarters of people with dementia ${ }^{51}$, and increases closer to death ${ }^{53}$.

- Eating and swallowing problems: Problems with swallowing are common in advanced dementia. However, the use of feeding tubes, while widespread, is controversial, and needs to be evaluated carefully with respect to the preferences of the person with dementia and carer, and the balance of risks and benefits for individual patients. A Cochrane systematic review suggests that tube feeding in people with dementia does not confer any benefit for nutritional status, reduction of pressure sores, or survival time ${ }^{56}$.

- Infections: Pneumonia and other infections are often the direct cause of death for people with dementia. Up to $71 \%$ of dementia deaths are directly linked to pneumonia ${ }^{57}$, a condition which can cause much discomfort, but which can be alleviated through effective palliative care.

- Agitation and other psychological symptoms: It has been estimated that $90 \%$ of people with dementia will develop some form of behavioural and psychological symptoms of dementia (depression, anxiety, hallucinations, delusions, wandering, agitation, aggression), and that over half of people with dementia remain agitated and distressed towards the end of life ${ }^{50}$. 
A consistent theme to emerge from a synthesis of qualitative research into caregivers' perceptions of end-of-life care, was the importance of relationships with professionals as a core component of care quality $^{38}$. Key elements included frequency of contact, provision of information, and support and reassurance for the carers. These seemed to be important issues, regardless of the context of end-of-life care; at home, at a care home, or in hospital. As previously noted, in one German study of end-of-life care, the carers of people with dementia were particularly critical of the quality of care on hospital wards, highlighting the limited availability of staff and of emotional support ${ }^{47}$.

Alzheimer Europe guidelines highlight the concern that carers' commonly feel when part or all of the care of the person with dementia is taken over by professionals - that they may be excluded, and that the person with dementia is not being cared for properly 48 . This scenario is played out with more intensity in the end-of-life phase, as more medical and nursing support is required, again, regardless of care setting. Carers naturally feel that they are best placed to understand the needs and wishes of the person with dementia, and want to share this with the healthcare professionals. Alzheimer Europe recommends that a good relationship and an atmosphere of trust is established when carers feel that their views are properly considered, that they can ask questions, that their concerns and criticisms are dealt with in a positive manner and that they are given every opportunity to participate in the care of the person with dementia ${ }^{48}$. When end-of-life care is provided at hospital or in a care home, carers may want to be permanently present, and this need should be met including the possibility to sleep at the facility. For those dying at home, flexible respite care may allow carers to get some rest with the reassurance that they will be with the person with dementia at the time of death ${ }^{48}$.

The EAPC guidelines ${ }^{3}$ recommend that; families may need support throughout the trajectory, but especially with institutionalisation, with a major decline in health and when death is near (recommendation 9.2); family involvement may be encouraged; many families may wish to be involved in care even when the person is admitted to a care home (9.4); and that professional caregivers should have an understanding of families' needs related to suffering from chronic or prolonged grief through the various stages, and when decline is evident (9.6).

\section{Professional staff training and development}

Communication and shared decision-making are key factors in end of life care. Having trust in doctors and surrounding staff is an essential factor for patients and caregivers during palliative care ${ }^{60}$. However, many nurses and care home staff do not feel well prepared to deal with issues related to end-of-life and dying with dementia, and there is a need to improve training for nursing home and specialist palliative care staff to deal with advanced dementia, and to achieve best practice for people with dementia at the end of life ${ }^{61}$. Symptom management, focusing on pain and behavioural and psychological symptoms, and also ways of approaching and dealing with patients and their families, are two areas that have been highlighted as requiring improvement.

\section{Effectiveness of palliative care approaches in end-of-life care}

There is very little direct evidence regarding the effectiveness of palliative approaches to end-oflife care, and no randomised controlled trials have been carried out to test its effectiveness or costeffectiveness. The lack of relevant evidence in this area is striking.

In a observational cohort study involving 28 care homes (the Dutch End of Life in Dementia study), data was analysed for 148 residents who died after followup. Care plans made at the time of admission were assessed to determine if a palliative 'comfort goal' was agreed at the time. The main outcomes were family satisfaction with care, and the quality of dying. Families were more satisfied with end-of-life care when a comfort goal was established shortly after admission, but only for those residents who died within six months of admission. No association was found between 'comfort goal' care plans and quality of dying ${ }^{62}$.

Other studies have focused on service utilisation and cost outcomes. In the UK the effect of an Appreciative Inquiry intervention, designed to improve end-of-life care for people with dementia living in care homes, on service and hospital care costs was assessed for three care homes before and after implementation of the six month intervention ${ }^{63}$. The intervention aimed to change how care home staff, primary care practitioners and district nurses worked together to address difficulties and uncertainties of providing endof-life care to people with dementia. It was perceived as having a positive impact on working relationships. Following the intervention total service costs fell by $43 \%$, and hospital care costs by a remarkable $88 \%$. In New York, pharmacy costs were compared before and after a palliative care consultation for 60 hospital inpatients with advanced dementia ${ }^{64}$. There was a significant average decrease in overall average daily pharmacy cost from US $\$ 31.16$ to $\$ 20.83$. There was also a significant increase in the proportion of participants taking analgesics, from $55 \%$ to $73 \%$, and a proportionate rise in daily analgesic cost.

\subsection{Summary and conclusion}

This scoping review of the recent literature on palliative care for people with dementia reveals a significant 
upswing in research activity, coupled with increasing advocacy for, and awareness of, the relevance of palliative care principles to dementia care. Much of the research that we have highlighted in this review comprises studies of process, and implementation, that is the extent to which palliative care approaches are being applied in practice, and difficulties, obstacles and barriers to their more widespread uptake and implementation. Much less research relates to the outcomes achieved by palliative care, and how these can be optimised. The lack of any experimental studies (randomised controlled trials) of the effectiveness of advanced care planning, or the implementation of a palliative care approach at any stage of care is very striking. It seems that current guidelines on good practice are almost entirely based upon expert opinion and consensus, rather than evidence ${ }^{3,48}$.

The reasons for this state of affairs are hard to determine. Within the palliative care field in general the evidence-base on palliative care approaches for progressive chronic diseases other than cancer has been slow to develop ${ }^{65}$. As several commentators have highlighted, there are still conceptual issues to be resolved. The concept of advanced dementia is unclear and open to varying definitions and interpretations ${ }^{9}$. The transition into 'end-of-life' phase is also not clearly demarcated ${ }^{2,9}$. The application of a 'palliative care approach' to these phases, and/or its potential wider application across the disease course continues to be debated. Nevertheless the improvement of palliative care services for people with dementia is an acknowledged policy priority for governments across Europe 66 .

Investigators for the European IMPACT project have called for a systematisation of palliative care for people with dementia ${ }^{2}$, with structured care pathways and good practice supported by evidence, and identification of appropriate outcomes to allow the effects of interventions to be measured. The investigators identified five key areas where more clarity was required; the division of responsibilities amongst practitioners of different health and social care disciplines; the structure and function of advanced care planning; the management of rising risk and increasing complexity; boundaries between disease-modifying treatment and palliative care and between palliative and end-of-life care; and the process of bereavement ${ }^{2}$. Support for this call for a more structured approach to policy and planning for the continuum of care for people with dementia, and the place of palliative care within it, comes from a recent review of national dementia strategies ${ }^{67}$. The reviewers examined six transitions covering the dementia journey from symptom recognition to endof-life care and critically evaluated whether and how the national dementia strategies of Australia, England, France, the Netherlands, Norway, Scotland, and the United States addressed each transition. They found that most adequately address earlier transitions in the journey, but fewer strategies address the later transitions. In essence, the focus is upon living well with dementia, with relatively less attention to the complex medical, social and ethical management of the complex physical, cognitive and functional declines that culminate in death.

The EAPC consensus guidelines ${ }^{3}$ also recognise the need for system level initiatives to promote access to better palliative care including; more collaboration between dementia care and palliative care services (recommendation 11.3); economic and system incentives to encourage excellent end-of-life care for patients with dementia (11.6); and national strategies for dementia, for palliative care, end-of-life care, and for long-term care to include palliative care for dementia patients (11.8).

Most would agree that people with dementia should be encouraged and enabled to exercise their autonomy regarding options for future care, consistent with their values and preferences. Early discussions with family carers that acknowledge the likely loss of decisionmaking capacity and their increasing role as proxy decision-makers would be likely to assist carers in assuming this role, and enhance their ability to judge what might be in the person with dementia's best interests. The empowerment of people with dementia needs to be stressed, to emphasise that the palliative care agenda is focused, first and foremost, upon their choices, and their quality of life, rather than cost savings. There is evidence of undermanagement of chronic comorbid physical health conditions, with missed opportunities to improve function and avoid acute crises leading to hospitalisation ${ }^{68,69}$. Palliative care, informed always by patient preferences, avoids futile and burdensome interventions, while ensuring that everything possible is done to maintain comfort. At the level of costs, one would want to avoid 'bad costs' (arising from healthcare that is futile, ineffective and does not improve quality of life), while reinvesting in 'good costs' (that enhance comfort and quality of life). A good example is an overall reduction of pharmacy costs based upon reducing polypharmacy at the end-of-life, but which included a net increase in costs of analgesic medication ${ }^{64}$. Given that there are no curative or disease-modifying treatments available for dementia, it is important to focus upon the specific goals of dementia care, which can include, at various phases and to different degrees, prolongation of life, improvement of function, and comfort ${ }^{3}$. While several studies and reviews have addressed the optimal time for a more palliative approach, none have done so from the perspective of the person with dementia, whose views on these matters should be paramount.

Comprehensive dementia care cannot, and should not be subsumed into a palliative care approach, across the disease course. Nevertheless, palliative care 
principles are applicable at every stage of the journey of care, and much can be learnt from the achievements of the discipline in other progressive chronic disease areas. There is an urgent need for more research, specific to the dementia field, regarding; preferences of people with dementia, and how these can be elicited; the implementation, benefits and harms of advance care planning; and the relative costs and benefits of palliative care assessments and services in the more advanced phases of the condition. Another major gap in the research literature is that of palliative care services and end-of-life issues for people with young onset dementia, who have a higher absolute and relative loss of life years, and, in all likelihood, specific needs ${ }^{70}$.

\section{References}

1 Prince M, Prina M, Guerchet M. World Alzheimer Report 2013. Journey of Caring. An analysis of long-term care for dementia. London: Alzheimer's Disease International, 2013.

2 Iliffe S, Davies N, Vernooij-Dassen M, et al. Modelling the landscape of palliative care for people with dementia: A European mixed methods study. BMC Palliat Care 2013; 12 (1)

3 van der Steen JT, Radbruch L, Hertogh CM, et al. White paper defining optimal palliative care in older people with dementia: a Delphi study and recommendations from the European Association for Palliative Care. Palliat Med 2014; 28: 197-209.

4 Kydd A, Sharp B. Palliative care and dementia--A time and place? Maturitas 2016; 84: 5-10.

5 Mitchell SL, Kiely DK, Hamel MB. Dying with advanced dementia in the nursing home. Arch Intern Med 2004; 164: 321-6.

6 Sampson EL, Gould V, Lee D, Blanchard MR. Differences in care received by patients with and without dementia who died during acute hospital admission: a retrospective case note study. Age Ageing 2006; 35: 187-9.

7 World Health Organization. WHO definition of palliative care. Website http://www.who.int/cancer/palliative/definition/en/ Accessed August 2016. 2009.

8 World Health Organization. Better Palliative Care for Older People. Geneva: World Health Organization, 2004.

9 Hanson E, Hellstrom A, Sandvide A, et al. The extended palliative phase of dementia - An integrative literature review. Dement Lond Engl 2016; published online July 26. DOI:10.1177/1471301216659797.

10 van Riet Paap J, Mariani E, Chattat R, et al. Identification of the palliative phase in people with dementia: a variety of opinions between healthcare professionals. BMC Palliat Care 2015; 14. DOI:10.1186/s12904-015-0053-8.

11 Lynne J, Adamson DM. Living Well at the End of Life. Adapting Health Care to Serious Chronic Illness in Old Age. RAND Corporation, 2003 http://www.rand.org/pubs/white_papers/ WP137.html (accessed Aug 14, 2016).

12 Seymour J, Gott M, Bellamy G, Ahmedzai SH, Clark D. Planning for the end of life: the views of older people about advance care statements. Soc Sci Med 1982 2004; 59: 57-68.

13 Brodaty H, Seeher K, Gibson L. Dementia time to death: a systematic literature review on survival time and years of life lost in people with dementia. Int Psychogeriatr 2012; 24: 1034-45.

14 Guehne U, Riedel-Heller S, Angermeyer MC. Mortality in dementia. Neuroepidemiology 2005; 25: 153-62.

15 Prince M, Acosta D, Ferri CP, et al. Dementia incidence and mortality in middle-income countries, and associations with indicators of cognitive reserve: a 10/66 Dementia Research Group population-based cohort study. Lancet 2012; published online May 22
16 Royal College of Physicians of London. Clinical Standards Department. Royal College of Physicians of London. Concise guidance to good practice: Advance care planning. Clinical Standards Department. 2009(Number 12). 2009. https://www. rcplondon.ac.uk/guidelines-policy/advance-care-planning (accessed Aug 21, 2016).

17 Wong JG, Clare IC, Gunn MJ, Holland AJ. Capacity to make health care decisions: its importance in clinical practice. Psychol Med 1999; 29: 437-46.

18 De Gendt C, Bilsen J, Stichele RV, Deliens L. Advance care planning and dying in nursing homes in Flanders, Belgium: a nationwide survey. J Pain Symptom Manage 2013; 45: 223-34.

19 Lingler JH, Hirschman KB, Garand L, et al. Frequency and correlates of advance planning among cognitively impaired older adults. Am J Geriatr Psychiatry Off J Am Assoc Geriatr Psychiatry 2008; 16: 643-9.

20 Dobalian A. Advance care planning documents in nursing facilities: results from a nationally representative survey. Arch Gerontol Geriatr 2006; 43: 193-212.

21 Robinson L, Dickinson C, Rousseau N, et al. A systematic review of the effectiveness of advance care planning interventions for people with cognitive impairment and dementia. Age Ageing 2012; 41: 263-9.

22 Molloy DW, Guyatt GH, Russo R, et al. Systematic implementation of an advance directive program in nursing homes: a randomized controlled trial. JAMA 2000; 283: 1437-44.

23 Caplan GA, Meller A, Squires B, Chan S, Willett W. Advance care planning and hospital in the nursing home. Age Ageing 2006; 35: 581-5.

24 Hanson LC, Reynolds KS, Henderson M, Pickard CG. A quality improvement intervention to increase palliative care in nursing homes. J Palliat Med 2005; 8: 576-84.

25 Detering KM, Hancock AD, Reade MC, Silvester W. The impact of advance care planning on end of life care in elderly patients: randomised controlled trial. BMJ 2010; 340: c1345.

26 Silveira MJ, Kim SYH, Langa KM. Advance directives and outcomes of surrogate decision making before death. $N$ Engl $J$ Med 2010; 362: 1211-8.

27 Weathers E, O'Caoimh R, Cornally N, et al. Advance care planning: A systematic review of randomised controlled trials conducted with older adults. Maturitas 2016; 91: 101-9.

28 Carrese JA, Mullaney JL, Faden RR, Finucane TE. Planning for death but not serious future illness: qualitative study of housebound elderly patients. BMJ 2002; 325: 125.

29 Poppe M, Burleigh S, Banerjee S. Qualitative Evaluation of Advanced Care Planning in Early Dementia (ACP-ED). PLoS One 2013; 8. DOI:10.1371/journal.pone.0060412.

30 Brazil K, Carter G, Galway K, Watson M, Van Der Steen JT. General practitioners perceptions on advance care planning for patients living with dementia Palliative care in other conditions. BMC Palliat Care 2015; 14: 1-6.

31 Gregory R, Roked F, Jones L, Patel A. Is the degree of cognitive impairment in patients with Alzheimer's disease related to their capacity to appoint an enduring power of attorney? Age Ageing 2007; 36: 527-31.

32 Fazel S, Hope T, Jacoby R. Assessment of competence to complete advance directives: validation of a patient centred approach. BMJ 1999; 318: 493-7.

33 Hamann J, Bronner K, Margull J, et al. Patient participation in medical and social decisions in Alzheimer's disease. J Am Geriatr Soc 2011; 59: 2045-52.

34 Dening KH, Jones L, Sampson EL. Preferences for end-of-life care: A nominal group study of people with dementia and their family carers. Palliat Med 2013; 27: 409-17.

35 Harrison Dening K, King M, Jones L, Vickestaff V, Sampson EL. Advance Care Planning in Dementia: Do Family Carers Know the Treatment Preferences of People with Early Dementia? PLoS One 2016; 11: e0159056.

36 Ayalon L, Bachner YG, Dwolatzky T, Heinik J. Preferences for end-of-life treatment: concordance between older adults with dementia or mild cognitive impairment and their spouses. Int Psychogeriatr IPA 2012; 24: 1798-804.

37 Beck ER, Mcllfatrick S, Hasson F, Leavey G. Health care professionals' perspectives of advance care planning for people with dementia living in long-term care settings: A narrative review of the literature. Dement Lond 2015; published online Sept 16. DOI:10.1177/1471301215604997. 
38 Davies N, Maio Lait G, lliffe S. Quality end-of-life care for dementia: What have family carers told us so far? A narrative synthesis. Palliat Med 2014; 28: 919-30.

39 Ashton SE, Roe B, Jack B, McClelland B. End of life care: The experiences of advance care planning amongst family caregivers of people with advanced dementia - A qualitative study. Dement Lond 2014; published online Sept 3. DOI:10.1177/1471301214548521.

40 The Gold Standard Framework. The GSF Prognostic Indicator Guidance. The National GSF Centre's guidance for cliniicians to support earlier recognition of patients nearing the end of life. 2011; published online Oct. http://www.goldstandardsframework. org.uk/cd-content/uploads/files/General\%20Files/Prognostic\%20 Indicator\%20Guidance\%200ctober\%202011.pdf (accessed Aug 24, 2016).

41 Brown MA, Sampson EL, Jones L, Barron AM. Prognostic indicators of 6-month mortality in elderly people with advanced dementia: A systematic review. Palliat Med 2013; 27: 389-400.

42 Dempsey D. Advance care planning for people with dementia: benefits and challenges. Int J Palliat Nurs 2013; 19: 227-34.

43 Li Q, Zheng NT, Temkin-Greener H. Quality of End-of-Life Care of Long-Term Nursing Home Residents with and without Dementia. $J$ Am Geriatr Soc 2013; 61: 1066-73.

44 Albrecht JS, Gruber-Baldini AL, Fromme EK, McGregor JC Lee DS, Furuno JP. Quality of Hospice Care for Patients with Dementia. J Am Geriatr Soc 2013; 61: 1060-5.

45 Hendriks SA, Smalbrugge M, Hertogh CM, van der Steen JT. Dying with dementia: symptoms, treatment, and quality of life in the last week of life. J Pain Symptom Manage 2014; 47: 710-20.

46 O'Shea E, Timmons S, Kennelly S, de Siun A, Gallagher P, O'Neill D. Symptom assessment for a palliative care approach in people with dementia admitted to acute hospitals: Results from a national audit. J Geriatr Psychiatry Neurol 2015; 28: 255-9.

47 Pinzon LCE, Claus M, Perrar KM, Zepf KI, Letzel S, Weber M. Dying With Dementia: Symptom Burden, Quality of Care, and Place of Death. Dtsch Ärztebl Int 2013; 110: 195-202.

48 Alzheimer Europe. 2008: End-of-Life Care for People with Dementia. 2013; published online Jan. http://www.alzheimereurope.org/Ethics/Ethical-issues-in-practice/2008-End-of-Lifecare-for-people-with-dementia (accessed Aug 26, 2016).

49 Arcand M, Brazil K, Nakanishi M, et al. Educating families about end-of-life care in advanced dementia: acceptability of a Canadian family booklet to nurses from Canada, France, and Japan. Int J Palliat Nurs 2013; 19: 67-74.

50 Sampson EL. Palliative care for people with dementia. BrMedBull 2010; 96:159-74. doi: 10.1093/bmb/ldq024. Epub 2010 Jul 30. 159-74.

51 van der Steen JT. Dying with dementia: what we know after more than a decade of research. JAlzheimersDis 2010; 22: 37-55.

52 Lukas A, Schuler M, Fischer TW, et al. Pain and dementia: a diagnostic challenge. ZGeronto/Geriatr 2012; 45: 45-9.

53 Mitchell SL, Teno JM, Kiely DK, et al. The clinical course of advanced dementia. N Engl J Med 2009; 361: 1529-38.

54 McCarthy M, Addington-Hall J, Altmann D. The experience of dying with dementia: a retrospective study. IntJGeriatrPsychiatry 1997; 12: 404-9.

55 Di Giulio P, Toscani F, Villani D, Brunelli C, Gentile S, Spadin P. Dying with advanced dementia in long-term care geriatric institutions: a retrospective study. JPalliatMed 2008; 11: 1023-8.

56 Sampson EL, Candy B, Jones L. Enteral tube feeding for older people with advanced dementia. CochraneDatabaseSystRev 2009; : CD007209.

57 Burns A, Jacoby R, Luthert P, Levy R. Cause of death in Alzheimer's disease. Age Ageing 1990; 19: 341-4

58 Schulz R, Mendelsohn AB, Haley WE, et al. End-of-life care and the effects of bereavement on family caregivers of persons with dementia. N Engl J Med 2003; 349: 1936-42.

59 Owen JE, Goode KT, Haley WE. End of life care and reactions to death in African-American and white family caregivers of relatives with Alzheimer's disease. Omega(Westport) 2001; 43: 349-61.

60 Heyland DK, Dodek P, Rocker G, et al. What matters most in endof-life care: perceptions of seriously ill patients and their family members. CMAJ 2006; 174: 627-33.

61 Chang E, Hancock K, Harrison K, et al. Palliative care for end stage dementia: a discussion of the implications for education of health care professionals. Nurse EducToday 2005; 25: 326-32.
62 van Soest-Poortvliet MC, van der Steen JT, de Vet HC, Hertogh $\mathrm{CM}$, Deliens L, Onwuteaka-Philipsen BD. Comfort goal of care and end-of-life outcomes in dementia: A prospective study. Palliat Med 2015; 29: 538-46.

63 Amador S, Goodman C, King D, et al. Exploring resource use and associated costs in end-of-life care for older people with dementia in residential care homes. Int J Geriatr Psychiatry 2014; 29: 758-66.

64 Araw M, Kozikowski A, Sison C, et al. Does a palliative care consult decrease the cost of caring for hospitalized patients with dementia? Palliat Support Care 2015; 13: 1535-40.

65 Gomes B, Calanzani N, Curiale V, McCrone P, Higginson IJ. Effectiveness and cost-effectiveness of home palliative care services for adults with advanced illness and their caregivers. Cochrane Database Syst Rev 2013; : CD007760.

66 European Parliament. European Parliament European Initiative on Alzheimer's Disease and Other Dementias. www.europarl.europa. eu/oeil/popups/ficheprocedure.do? lang=en\&reference=2010/208 $4(\mathrm{INI})$.

67 Fortinsky RH, Downs M. Optimizing person-centered transitions in the dementia journey: a comparison of national dementia strategies. Health Aff Millwood 2014; 33: 566-73.

68 Bunn F, Burn AM, Goodman C, et al. Comorbidity and dementia: a scoping review of the literature. BMC Med 2014; 12. DOI:10.1186/ s12916-014-0192-4.

69 Phelan EA, Debnam KJ, Anderson LA, Owens SB. A systematic review of intervention studies to prevent hospitalizations of community-dwelling older adults with dementia. Med Care 2015; 53: $207-13$

70 Koopmans RT, van der Steen JT, Bakker C. Palliative Care in People With Young-Onset Dementia (YOD): An Undiscovered Area! J Am Med Dir Assoc 2015; 16: 1008-9. 


\section{Dementia care in Canada, China, Indonesia, Mexico, South Africa, South Korea and Switzerland}

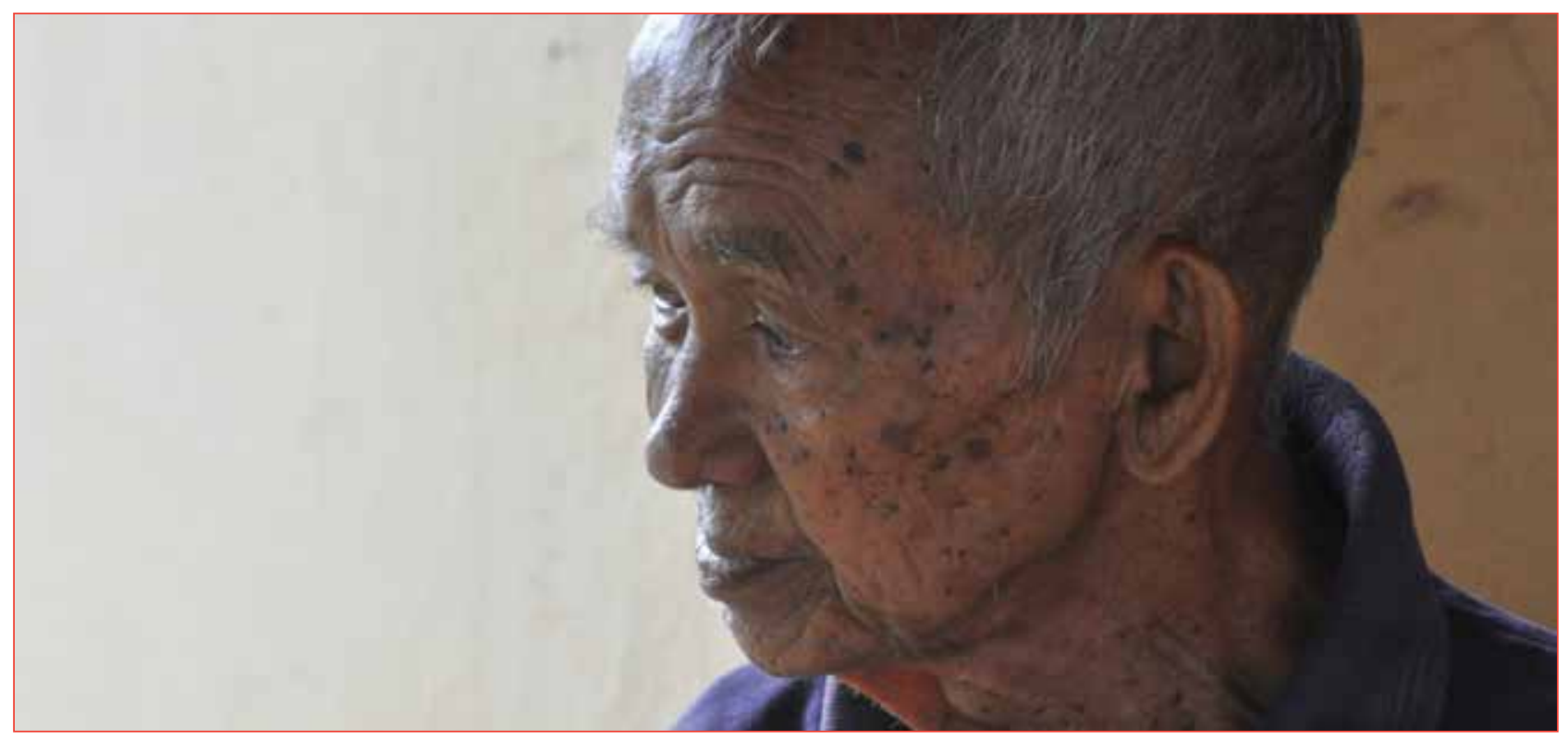

\subsection{Introduction}

In this chapter we explore the context for the implementation of the proposed dementia healthcare pathways in Canada, China, Indonesia, Mexico, South Africa, South Korea and Switzerland, the countries for which we will investigate the cost implications of implementing the dementia healthcare pathways. For each country we consider, briefly, key demographic and socioeconomic characteristics, the prevalence of dementia and estimated numbers of people with dementia in 2015 and 2030, the current dementia and healthcare policy context, other sources of care and support to people with dementia and the main challenges that need addressing in each of the dementia care systems.

These descriptions of the dementia care systems have been produced through a scoping review of both academic and grey literature. Each country description has been revised by academics, officials or members of national Alzheimer's associations. We have also benefitted from research assistance and support from researchers from most of the countries covered, who have enabled us to access information written in languages not spoken by the authors.

The amount of information available for the different countries varied considerably, with, predictably, much more from HIC than for LMIC. Also, in countries where the health and social care systems are highly decentralised, such as Canada, China and Switzerland, there is very limited national level data, or even comparable data for the different regions, between which there may be significant variation.

\subsection{Dementia care in Canada}

Canada, in North America, is the world's second largest country in land mass, and the 38th in terms of population. Most of the population is concentrated in urban centres in the south of the country. The majority of the country's aboriginal population lives on rural reserves, land claim regions in the Arctic or in poor city neighbourhoods (Marchildon, 2013).

Canada is a high-income country, with an advanced industrial economy. It has a federal government structure, with two levels of government of equal constitutional importance: the federal (or central) level and the ten provincial governments. Three Northern territories also have some autonomy, but not to the same degree as the provinces.

\section{Prevalence of dementia}

Following a systematic review and consultation with a panel of national and international experts convened by the Alzheimer Society of Canada, there is consensus that "the Canadian Study of Health and Aging (1994) remains the best and most reliable population data 
source to use as a basis to build present and future prevalence estimates" (Alzheimer Society of Canada, 2016). These are also the same prevalence estimates reported in the World Alzheimer Report 2015 (Prince et al., 2015).

Based on these prevalence rates, the World Alzheimer Report 2015 estimated that in 2015 there were just over 556,000 people with dementia in Canada, of these, $65 \%$ were women and nearly half were aged 85 or more. By 2030 the number of people is expected to rise to 886,000 (see Figure 6.1).

Figure 6.1

Estimated numbers of people with dementia, Canada

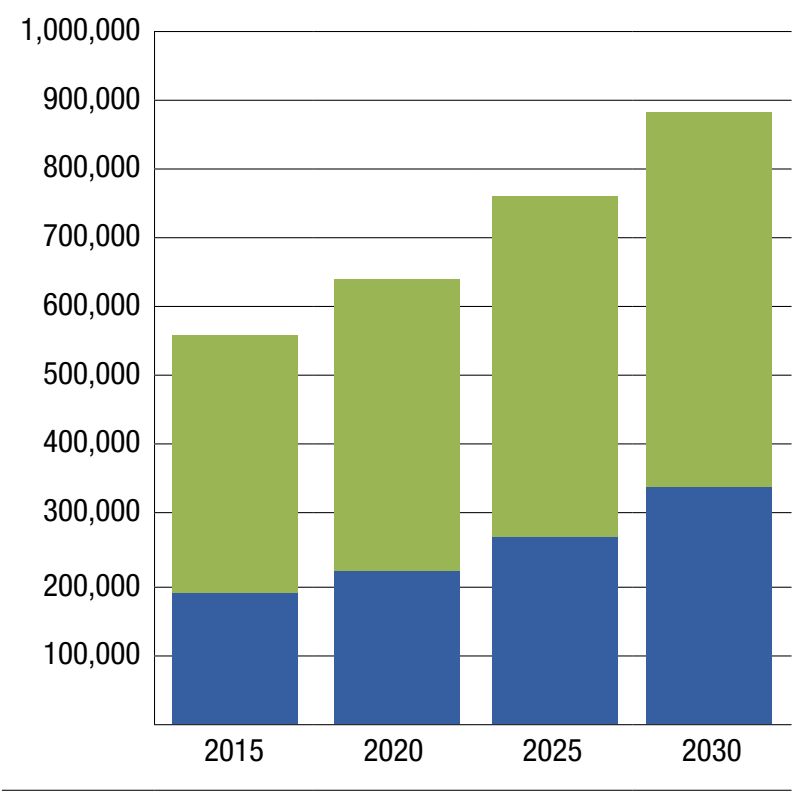

Men Women

Source: World Alzheimer Report 2015 estimates

\section{Policy landscape and healthcare system context}

Canada does not currently have a national dementia strategy, although in 2014 the Health Minister announced plans to develop one. However, many of Canada's provinces have historically developed provincial plans (Rosow et al., 2011). The Alzheimer Society of Canada and the Canadian Medical Association have both been pushing for a national strategy as the prevalence of dementia is rising and with that the economic impact on Canada's already strained health and social care systems.

In part reflecting the lack of a national policy for dementia care and support in Canada, there is very little data available on dementia at national level. While there is good information at provincial level, the information collected is mostly not comparable, making it difficult to bring it together and to provide a national picture of the state of dementia care in Canada.
Studies of the costs of dementia in Canada have reported widely differing estimates, ranging from $\$ 910$ million to $\$ 33$ billion. An expert panel facilitated by the Alzheimer Society of Canada examined the methods and data used in the different studies. The panel agreed that ideally costs of illness studies should take a societal perspective when estimating the consequences of dementia, that the scope should include direct and indirect service-related costs, as well as informal and intangible costs, and that these costs should be compared between populations living with dementia and those without the condition. Based on those criteria, the panel recommended the estimates of the National Population Health Study of Neurological Conditions (Alzheimer Society of Canada, 2016).

According to this study, the costs of dementia in Canada, including the costs of unpaid care, were (\$CAD) 10.4 billion in 2016 and projected to rise to 16.6 billion by 2031 (Public Health Agency of Canada, 2014). The study also reported that costs for people with dementia are estimated to be five-and-half times greater than for older people who do not have dementia. Home care and long-term care are the largest contributors to direct costs. In 2011, family caregivers provided 19.2 million unpaid hours of care.

The main responsibility for healthcare is with the provinces and in practice each of them has its own healthcare system. However, the federal government retains some responsibilities, for example by guaranteeing universal access to healthcare services, some aspects of health and pharmaceutical regulation (Medicare) and the financing and administration of health benefits and services for specific populations (primary care to aboriginal communities, and some services delivered to the Royal Canadian Mounted Police, Correctional Services, the Armed Forces and veterans).

The healthcare system in Canada is predominantly publicly financed (70\%), through a mixture of federal, provincial and territorial taxes (Marchildon, 2013). All provinces have a model consisting of a single-payer hospital and medical care service with a centralised payment system. Medically necessary hospital and physician services are free at the point of use (Medicare). The provincial and territorial governments provide or subsidise prescription drugs, long-term care and home care; these programmes usually require user fees, except for some exempted populations (mostly the older population and the very poor). There is virtually no public coverage for dental care and vision.

There is pressure on health financing in Canada as a result of tax cuts by the federal and provincial governments and continued increases in expenditure. While the outcomes of the Canadian healthcare system compare favourably to those of other high- 
income countries (Marchildon, 2013), there is public dissatisfaction with long waiting times and shortages of services, which, particularly for long-term care, have led to increasing pressures on family caregivers and on other parts of the healthcare system (The Conference Board of Canada, 2015).

\section{Current diagnostic and healthcare pathways}

In Canada the typical healthcare pathway starts with a visit to a family physician (who may be either in a traditional single practice or in an inter-professional primary care team). The family physician acts as the gatekeeper and requests diagnostic tests, prescribes drug therapies and refers to medical specialists as needed. The model of primary care is changing, with less single-doctor practices and more interprofessional primary care teams, as a result of the 10 -year plan of 2004 , which contained a commitment that at least $50 \%$ of all residents should have access to primary care 24 hours a day, 7 days a week. Most hospitals in Canada are public or non-profit, although there are some private for-profit specialised ambulatory and advanced diagnostic services. Hospitals provide some ambulatory care, however this is increasingly being provided in primary care or specialised ambulatory services (Marchildon, 2013).

Although Canada has distinct healthcare systems in each of the provinces, clinical practice in dementia diagnosis and treatment is guided by evidence-based national clinical standards, approved by consensus by the academic and clinical community. The current clinical standards for the diagnosis and treatment of dementia were approved in 2012, at the "Fourth Canadian Consensus Conference on the Diagnosis and Treatment of Dementia (CCCDTD4)" (Gauthier et al, 2012).

As discussed in chapter 2 and Aminzadeh et al (2012), in Canada the national clinical standards argue that most types of dementia can be diagnosed in primary care, and, in line with the previous versions, the fourth version emphasises that the diagnosis and management of dementia should primarily be a primary care responsibility (Moore et al, 2014). Despite this, there is some evidence from Alberta that, in practice and, in comparison with the guidelines and with more specialised diagnostic settings such as the Geriatric Assessment Team, primary care practitioners are underutilising diagnostic and functional assessment tools, not giving sufficient attention to caregiver issues, and underusing community supports (Parmar, 2014). The study also highlights the poor level of coordination between primary care and specialist services, resulting in unnecessary duplication of assessments.

Variations in practice, also with respect to the national clinical standards, have also been observed across different areas. A study comparing the provision of dementia healthcare in three areas of Canada found variability, which was particularly marked for the provision of advance care planning and day programme services. Variation was found both between and within provinces (Tam-Tham et al, 2016).

Due to its geography, providing care to people in rural and remote communities is challenging in Canada. A study that involved surveying local home care assessors about availability of dementia care services in Saskatchewan found a significant lack of availability of diagnostic services such as dementia screening, multidisciplinary team assessments and post-diagnostic support (counselling, registers for individuals and caregivers, caregiver support groups) (Morgan et al., 2015). There is growing research on the use of telehealth to deliver care and support to people with dementia and caregivers in rural areas (for example Conn et al, 2013 and O'Connell et al, 2014).

There are also differences in the treatment and care of people living in residential care homes, who are being diagnosed at a later stage than those living in the community. A study in Ontario found that people in residential care were four times more likely to be diagnosed with dementia at a later stage than those who receive home care (Bartfay et al, 2016).

\section{Other care and support for people with dementia and their families}

Rehabilitation and long-term care policies and services, including home and community care, palliative care and support for informal carers, vary considerably among provinces and territories, as does the provision of long-term care in residential homes and assisted chronic care facilities (Marchildon, 2013).

The support for family caregivers is a provincial responsibility. Each province and territory has its own priorities, generally set out as part of a package of home care services. Since 2002, the federal government has provided tax credits for eligible caregivers. Employed caregivers also have a right to 26 weeks of paid leave as part of the Compassionate Care Benefit part of the Employment Insurance Programme.

\section{Challenges that need to be addressed}

A national dementia strategy for Canada would create better opportunities to coordinate the provincial efforts in dementia research and in the improvement of clinical and community-based programmes. Alzheimer Society of Canada argues that this is particularly important in the light of the projected increases in the numbers of people living with dementia in Canada (Alzheimer Society of Canada, 2015) and proposes the creation of a Canadian Alzheimer's Disease and Dementia Partnership with research, prevention and living well with dementia as its strategic objectives. 
While Canada has established healthcare pathways to deliver care to people with dementia, there is evidence that some sectors of the population have difficulties accessing care, including those living in rural and remote locations, the aboriginal communities, and people living in long-term care accommodation.

\subsection{Dementia care in China}

China is the country experiencing the greatest overall increase in numbers of older people in the world, with the population aged 60 or above projected to increase from around 200 million in 2015 to 490 million by 2050 . The number of people aged 80 or above is projected to grow by over $439 \%$ in the same period, from 22 to 121 million (United Nations, 2016).

Mainland China (which this section describes) is classified as an upper-middle income economy by the World Bank. Its economy has expanded rapidly since the start of market reforms in 1978, which have lifted more than 800 million people out of poverty (World Bank, 2015). Since the global financial crisis, annual economic growth has slowed, from $14 \%$ in 2007 to $6.5 \%$ in 2015.

\section{Prevalence of dementia}

The World Alzheimer Report 2015 estimated that there were just over 9.5 million people with dementia in China, which was $20 \%$ of the total number of people in the world with dementia. By 2030, the number of people living with dementia in China is expected to rise to over 16 million (see Figure 6.2).

Figure 6.2

Estimated numbers of people with dementia, China

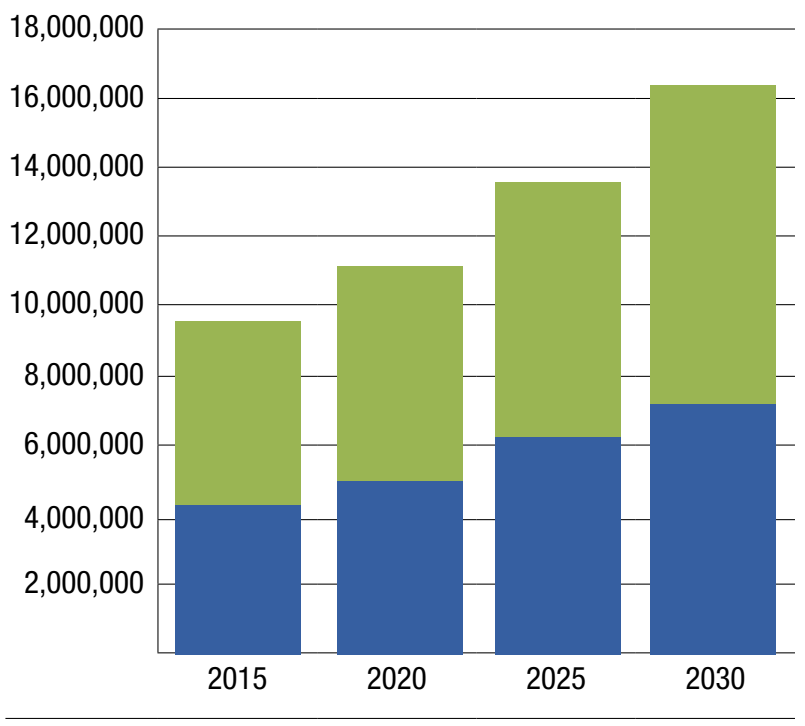

Men $\square$ Women

Source: World Alzheimer Report 2015 estimates

\section{Policy landscape and healthcare system context}

Meeting the needs of very large numbers of people living with dementia and other age-related conditions is challenging for China, not just because of the scale, but also because of the speed of demographic change. It has been estimated that, at the current rate, China will experience in 26 years the same change in population that took 115 years in France (China Joint Study Partnership, 2016).

The Chinese government has embarked on major health policy reforms, which resulted in the achievement of near-universal healthcare coverage for its entire population by 2011. Coverage grew from less than $50 \%$ of the population in 2005, to $95 \%$ in 2011 (Yu, 2015). This required a very substantial funding commitment, with public expenditure on health more than doubling between 2009 and 2013 (Meng et al, 2015). China has joined Japan and the Republic of Korea in achieving universal health coverage before becoming a high-income country (Yu, 2015).

Having successfully extended the breadth of health coverage (in terms of the numbers of people covered), the major challenges now are to increase its scope (in terms of the comprehensiveness and quality of services) and its depth (the degree of financial protection), which remain insufficient (Liang and Langenbrunner, 2013). This new phase of reforms happens in a context of slower economic growth which, coupled with demographic and epidemiological pressures, means that serious consideration needs to be given to economic sustainability (China Joint Study Partnership, 2016).

\section{Improving the delivery of healthcare}

The market-oriented healthcare reforms of the 1980s included the introduction of competition between the three tiers of the healthcare system (primary care, secondary and tertiary hospitals), and the introduction of direct out-of-pocket payments directly to healthcare providers. This took the traditional gatekeeping role away from primary care doctors (Xu et al, 2010).

Despite the launch of reforms that prioritised a primary care practitioner system in 2009, much of the recent growth in healthcare facilities and utilisation in China has been concentrated in the hospital sector. Between 2002 and 2013, the number of tertiary and secondary hospitals increased by $82 \%$ and $29 \%$ respectively. At the same time there was a small decline (6\%) in the number of primary care providers. Between 2010 and 2014, the percentage of healthcare provision that took place in hospitals increased from 34.9 to $39.1 \%$, whereas the proportion of activity in primary care dropped from 61.9 to $57.4 \%$ (China Joint Study Partnership, 2016). The system has been described as "hospital-centric", fragmented and volume-driven, and China now has more hospital beds per 1,000 
population than either Canada, UK, US or Spain (China Joint Study Partnership, 2016).

The lack of success of primary care in China can be attributed to the lack of a gatekeeping role by primary care practitioners (PCPs), an ineffective referral system between the three tiers of healthcare provision, little public trust in the quality of care provided in primary care and the restricted list of drugs that can be prescribed (Zou et al, 2015, Mash et al, 2015, Wu and Lam, 2016). People can bypass the primary care system and access the same care directly at a hospital (although at a higher cost, and usually further away).

While the current lack of gatekeeping role by PCPs can be addressed by further reforms to the reimbursement systems, the perceived lack of quality of primary care reflects important differences in the qualifications and pay of PCPs compared to doctors working in hospitals (Wang et al, 2012). The majority of primary care health workers only have post-school training (China Joint Study Partnership, 2016). In contrast, for doctors to practice in secondary (or township health centres) and tertiary hospitals, they must pass the national Licensed Doctors Examination or the Licensed Assistant Doctors Examination after at least three years' medical education at a medical college (Xu et al., 2014). Currently, only $38 \%$ of licensed doctors and $21 \%$ of registered nurses are working in primary care (Wu and Lam, 2016).

Primary care in China is gradually evolving from the "barefoot doctors" provision developed across the whole country in the 1950s and which had a huge impact on population health. These "barefoot doctors" were usually farmers who received 3 to 6 months training by urban doctors to enable them to practice medicine in rural areas (Wu and Lam, 2016). In the 1980s an exam was introduced; those who passed could continue to practice as "village doctors" and those who didn't became health workers (Weiyuan, 2008).

There are concerns that the "village doctors" are ageing and that it will be difficult to replace them without substantial investment and changes in their working conditions, income and pension entitlements. Moreover, since 2006 the government has prioritised medical education to international standards and there has been less emphasis on training village doctors ( $\mathrm{Xu}$ et al., 2014). Primary care is a relatively new discipline in standard medical schools, is often taught by public health specialists and is seen as low status, thus not attracting many students (Mash et al, 2015).

A national directive in 2011 set a target of 2 to 3 licensed primary care doctors (GPs) per 10,000 people. The average number in 2013 was 1.07 , but the ratio was below 1 in poorer parts of China. To meet the target, an additional 130,000 GPs would be needed (Wu and Lam, 2016).

\section{Improving financial protection}

China has made big improvements in protecting the population from the risk of very high out-of-pocket healthcare costs. The share of out-of-pocket payments has decreased compared to total health expenditure, from a high point of $60 \%$ in 2001 to $32 \%$ in 2014 , which is just under the average for other uppermiddle income countries (33\%), although still above WHO's recommended level of $20 \%$ for reducing the risk of impoverishment as a result of disease (Liang and Langenbrunner, 2013 and China Joint Study Partnership, 2016).

There are, however, important differences in the degree of coverage afforded by the three insurance schemes available in China: an urban scheme for those in formal employment, another urban scheme for those who are not employed or in informal employment, and a rural scheme. Because reimbursement levels and service coverage are much lower in the rural than in the urban insurance schemes, rural populations have more restricted access to healthcare (Meng et al, 2015). Those who cannot afford health insurance premiums and out-of-pocket medical bills are also covered by the Medical Assistance Program (MA) (Liang and Langenbrunner, 2013).

One of the main health policy goals for the government is to establish a consolidated health insurance system by 2020 . A consolidated system would not only be able to improve some of the inequity and portability difficulties related to the current fragmented system, but the examples of Taiwan and South Korea suggest that it could also reduce administration costs (Meng et al, 2015), thereby contributing to efficiency improvement. The consolidation of the health insurance scheme could also provide an opportunity for designing new service packages and reimbursement schemes that favour cost-effective services, and for using alternative payment services to the current feefor-service approach (Meng et al, 2015).

\section{Next reform steps}

It is expected that the next (13th) Five-year Development Plan 2016-2020 will seek to address many of the issues outlined above in the so called "deep water" phase of health reform (China Joint Study Partnership, 2016); in particular, "strengthening the three-tiered system, including primary care and community-based services, human resources reform, optimising use of social insurance, and encouraging private investment ("social capital") to sponsor healthcare. Policies also support "people first principles" such as building harmonious relationships with patients, promoting greater care integration 
between hospitals and primary care facilities through tiered service delivery and use of multidisciplinary teams and facility networks, shifting resources towards the primary level, linking curative and preventive care" (China Joint Study Partnership, 2016, p. xvii).

\section{China's national policy on dementia}

There is no specific National Dementia Plan in China, but dementia has been prioritised (together with autism, schizophrenia and depression) in the National Five-year plan for Mental Health (2015-2020). The main objectives of this plan include the development of integrated services, training of mental health specialists, improvement of rehabilitation services and community- and family-based supports, and the promotion of social awareness and mitigation of social stigma (The State Council of the PRC, 2015).

\section{The costs of dementia in China}

Although national data on the costs of dementia care and support in China is not yet readily available, there are some studies that give an indication of the health and care costs of dementia in China. As with many other countries, the studies are difficult to compare, as they take different perspectives (e.g. some include only health costs, some include societal costs) and refer to different populations (people accessing hospitals, compared to general population).

In one national hospital-based survey in 2009 , the total out-of-pocket (OOP) monthly cost per person with dementia averaged US $\$ 487$. Of this, US $\$ 56$ was spent on doctor visits, US\$137 on drug therapy, US\$139 on hospital visits, and US $\$ 155$ on housekeeping services. The costs of providing care by family members, in terms of reported forgone employment, ranged from US\$88 to US\$614 (Mould-Quevedo, et al., 2013). The total cost of healthcare far exceeded average per capita disposable income (US\$210 for urban dwellers and US\$63 for rural dwellers) (National Bureau of Statistics of China, 2010). It should be noted that, because these estimates are based on a survey of people attending tertiary hospitals (which involve large out-of-pocket payments), and who have been diagnosed with dementia, it is likely that the sample is of higher socio-economic status than average and not fully representative of the costs experienced by other people living with dementia.

Using the cost estimates from Mould-Quevedo et al (2013), another study modelled the impact on the Chinese economy of care provision (in both the formal and informal sectors) to people with Alzheimer's disease. This study estimated that the impact on the economy will exceed US\$1 trillion in 2050 (at 2011 prices), and notably, $62 \%$ of the total cost was attributable to the loss of formal labour from unpaid family caregivers (Keogh-Brown, et al., 2016).
While the studies above were based on a sample of people using hospital services, there are also cost estimates from a geographically defined population from the 10/66 study, covering all of the population aged 65 or above in a defined urban population (Xicheng, Beijing), and a rural population (Dixang). From this base, Liu (2013) estimated the attributable costs of dementia in China in 2008 international dollars and from a public sector perspective as $\$ 8,687$ per person per year. Of this total, $\$ 148$ was for medical care, $\$ 1,195$ for paid social care and $\$ 7,344$ for unpaid family care. The study also investigated the total cost of services used and found that the total costs of medical care (including public and out-of-pocket payments) were $\$ 5,243$ per year for people with dementia living in the urban area, compared to $\$ 313$ for people living in the rural area (Liu, 2013).

There is little information available on the unit costs of care for people with dementia in China. A Delphi panel study by Yu et al (2015) gathered consensus on the unit costs for people with dementia living in urban areas. Unit costs, in RMB, included figures of 30,000 per month for hospital inpatient stays, 1,600 for a "diagnosis hospitalisation", 500 for biological analysis, 1,050 for an MRI scan and 100 for the cognitive assessment scale. The cost of a caregiver or a nursing home place was 6,000 per month.

\section{Current diagnostic and healthcare pathways}

People with dementia in China are underdiagnosed and undertreated. Access to care by people with dementia, as in many other countries, is hampered by beliefs that it is a natural part of the ageing process (Patel et al, 2016). Stigma may also play a role: a qualitative study in both rural and urban China found that stigma around dementia was characterised by fear, reluctance and avoidance to engage with people with dementia. The study also revealed low awareness about dementia among family caregivers and the assumption that declining cognitive functioning is a normal part of ageing (Hsiao et al, 2015).

A population-based caregiver survey in four Chinese cities found that only $26.9 \%$ of people with dementia had received a diagnosis. Only $21.3 \%$ reported receiving a recommendation for their family member with dementia to take medication and only $2 \%$ used any medication (Chen et al, 2013). A Delphi panel of doctors in urban China considered that only $10 \%$ of people with dementia were diagnosed and, of those, only $21 \%$ used any medication (Yu et al., 2015).

Primary care doctors are often inadequately trained and may be reluctant or unable to detect, diagnose or manage dementia (Patel et al, 2016). A qualitative study by Wu et al in Lanxi reported that the three rural physicians they interviewed (who were all older than 60 ) had only received short-term training in basic 
healthcare to become village doctors. They appeared to have poor knowledge of dementia and did not use any formal screening instruments for diagnosis. They considered ageing to be the cause of dementia and were not aware of any treatments. According to one of the doctors interviewed: "In the countryside, there is a common notion that going to the doctor for this kind of illness [dementia] is a waste of money since it cannot be cured" (Wu et al., 2016 p.162).

Lack of training in dementia diagnosis and care is also a problem in highly specialised tertiary hospitals. Jia et al (2015) implemented a training intervention in 36 tertiary hospitals in China. At baseline they found that only 6 of the 36 hospitals had a memory clinic, and only 47 doctors (out of 1,361 working in neurology) had been trained in the dementia area. Only $0.1 \%$ of outpatients visiting the hospitals received a diagnosis of dementia and, of those who did have a diagnosis, only $23.6 \%$ received anti-dementia medication. After the intervention, 205 doctors had been trained in dementia care and all 36 hospitals had memory clinic services. The diagnosis rate increased four-fold (to $0.41 \%$ ) and $67.5 \%$ of those diagnosed received medication.

The Delphi panel study by Yu et al. (2015) suggests that people with dementia with neuropsychiatric symptoms were more likely to be diagnosed and treated by psychiatric departments, and more likely to be hospitalised.

\section{Other care and support for people with dementia and their families}

The care and support of people with dementia is, both by culture and law, a family responsibility. The involvement of the government in long-term care is relatively recent, other than the provision of institutional care to people without family or resources (the "Three No's: no children, no income and no relatives"). The use of institutional care has therefore been associated with stigma (Feng et al, 2012, Wu et al, 2016). However, demographic and socio-economic changes have made it impossible to continue to rely almost exclusively on family care, and the fulfilment of family obligations through the purchase of care is increasingly considered to be acceptable.

The government aims to establish three tiers of services for people who need care: (i) home care as the basis; (ii) community-based services as support; and (iii) institutional care as the last resort. In practice, the availability of home and community-based support is limited and the government policy efforts have focussed on increasing the availability of institutional care (Wu et al, 2016).
A survey by Wu et al (2016) in the Lanxi county found that available day care services were targeted at healthy older people and were not used by any individuals with dementia. Specialist community-based dementia-specific services such as day care, respite, caregiver support and case management only exist in a few major urban centres.

Home care tends to be provided by informal workers, with low qualifications and who have usually migrated from rural areas. As there are no subsidies or public support for home care in most regions, this kind of service tends only to be used by those who are better off. The use of paid care at home by people with dementia is much higher in the wealthier urban areas. A survey by Li et al (2013) in the Zheijiang province found that, of people in need of care, $5.9 \%$ used paid care in rural areas, compared to $36.9 \%$ in urban areas. The study also found that support from children was the most important source of income in rural areas among those who paid for care, whereas in urban areas older people (or their spouses) were more likely to be able to pay for their own care.

The 10/66 study found slightly bigger differences in their survey of older people in an urban population (Xicheng, Beijing) and a rural one (Dixang). Only 2\% of people in need of care in the rural area used paid care, compared to $45 \%$ in the urban area. The study also gives an indication of the impact of unpaid care provision on the family's economic situation: while only $4 \%$ of urban family carers reported having cut back on work to provide care, the figure was $48 \%$ for rural carers (Liu et al, 2009).

As a result of the government's focus on institutional care, provision of this service has grown enormously. In 1980 there were only 4 facilities (all governmentrun) in Tianjin, but numbers increased to 13 by 1990 , 68 by 2000 and 157 by 2010 . Of these 157, 20 were government-run and 137 private. There have been similar rates of growth in other areas such as Nanjing and Beijing (Feng et al, 2012).

In 2010 there were an estimated 40,000 institutional care facilities (with 3.15 million beds) in the whole of China, which amounted to about half as many longterm care beds per 1,000 of older people as in most developed countries. The 12th Five-Year Plan set out plans to double the number of beds by 2015 to reach a ratio of 30 beds per 1,000 older people (Feng et al, 2012).

For people with dementia the evidence so far suggests that the quality of care in many institutions is problematic. In fact, many institutions refuse to admit people with dementia (Yu et al, 2015; Wu et al., 2016), partly because staff are not adequately trained to manage the behavioural and psychological symptoms. Even in care homes that in principle do not 
admit people with dementia, there are nevertheless residents with dementia, as the symptoms can develop after admission. A systematic review of staff and care in long-term care institutions in China found that the reported percentage of residents with cognitive impairment ranged from $13 \%$ to $66 \%$ (Song et al, 2014).

In their qualitative study in Lanxi, Wu et al. (2016) found that none of the residents with dementia in nursing homes were receiving any dementia-related medication and that, despite having higher charges for people with dementia, none of them provided medical, psychological or rehabilitative support for the condition.

An important development that is likely to have a positive impact on the ability of older people to afford care and support has been the launch of the rural pensioners' pension scheme in 2009 and the merger of the rural and urban pension schemes in 2014. These developments have resulted in a trebling of the number of people covered by the old age pension system. By the end of 2013 , approximately $80 \%$ of the population of working age and above were covered by a pension system (MOHRSS, 2013 and ILO, 2014).

\section{Challenges that need to be addressed}

While China has made big improvements in the coverage of healthcare, access to care, treatment and support by people with dementia is very limited. The literature suggests that the following issues should be addressed to improve the current situation:

- Lack of awareness about the fact that dementia is not a natural part of ageing, accompanied by stigma, may be a major reason why people with dementia have relatively low contact with healthcare services. Where they do access services, this tends to be via psychiatric care and as a result of behavioural symptoms (Wu et al., 2016).

- Very limited training about dementia for healthcare professional at all levels, particularly with regards to standard diagnostic procedures, medication and non-pharmacological interventions.

- The current lack of a gatekeeping role for primary care doctors means that people can access specialist hospital services directly if they wish. The perceived low quality of primary care (and low professional qualifications of village doctors) is a major reason why people prefer to use hospital care despite higher out-of-pocket payments and having to travel longer distances.
- The affordability of healthcare remains a very important problem, particularly for people in rural areas, as out-of-pocket payments are relatively high. The consolidation of the three health insurance schemes may help reduce inequalities in affordability of healthcare between the rural and urban areas.

- Despite a stated policy that people should be able to remain at home for as long as possible, most of the expansion in long-term care services has been in institutional care. There are concerns about the ability of nursing home staff to care adequately for people with dementia, mostly as a result of lack of training.

- In families with low incomes in rural areas the provision of unpaid care can contribute to further impoverishment, as family carers may have to give up work to support their relatives (Liu et al, 2009). Families with higher incomes can more easily afford to pay for private care at home or nursing home fees, and very poor people without family support can access free care through social assistance. The expansion of the social insurance system to cover long-term care could help reduce the financial risks associated with dementia, as demonstrated by pilot schemes in various cities such as Qingdao (Yang et al., 2016).

\subsection{Dementia care in Indonesia}

Indonesia, in South East Asia, is formed by over 14,000 islands and is home to more than 300 ethnic groups. More than half of the population lives on the island of Java.

In economic terms, Indonesia has been classified by the World Bank as a "low-middle income economy". It has experienced a period of sustained economic growth since 2009 , and has made great progress in the reduction of poverty, from about half of the population in 1999 to $11 \%$ in 2015 (World Bank, 2015). While services and industry contribute most to gross domestic product, agriculture remains the largest sector in terms of employment. Insufficient infrastructure development poses a challenge to continued economic growth, and the country's food security weaknesses were recently exposed by an extended drought in 2015. There is a large gap in resources and prosperity between urban and rural areas, which affects the availability of care for people with dementia and the support available to their families.

\section{Prevalence of dementia}

Indonesia is the world's fourth most populated country. Its large population (over 257 million people in 2015) is relatively young compared to other countries in South East Asia. However, even with the relatively low proportion of older people compared to other 
countries, Indonesia is still ranked eighth in the world in terms of the overall number of older people.

There are no locally generated estimates of the prevalence of dementia in Indonesia so far. Using data from comparable countries, the World Alzheimer Report 2015 estimated that in 2015 there were just over 556,000 people with dementia in Indonesia. By 2030 the number of people is expected to rise to nearly 2.3 million (see Figure 6.3).

\section{Figure 6.3}

\section{Estimated numbers of people with dementia, Indonesia}

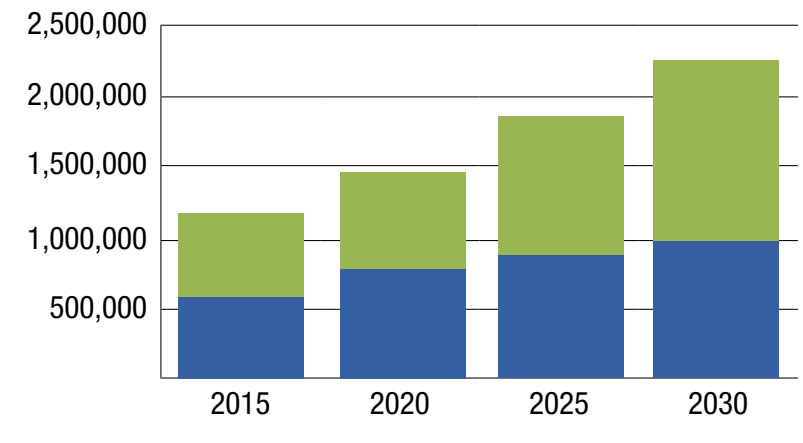

Men Women

Source: World Alzheimer Report 2015 estimates

A local study of the prevalence of dementia in Yogyakarta found a very high prevalence of dementia among older people, and also of risk factors for dementia (Alzheimer's Indonesia, 2016). It will be important to understand how social and economic changes are affecting risk factors for dementia and consider those in public health policy.

Education, for example, which is (inversely) linked to dementia risk, has changed dramatically in the last few decades. While half of the population currently aged over 70 years are literate, literacy rates among the younger generation (18-34) are close to $100 \%$ (Priebe and Howell, 2014).

\section{Policy landscape}

Despite the increasing importance of dementia, and its growing impact on society, dementia has been a low priority health issue in Indonesia. However, the Indonesian Ministry of Health launched the first National Dementia Plan in March 2016, accompanied by a pledge of $\$ 105,000$ to support its implementation. The Indonesian National Dementia Plan focuses on improving the quality of life of people with dementia and their caregivers, raising awareness, reducing stigma and minimising the risk of dementia. In particular, the plan includes:

- Awareness, risk reduction, promotion of healthy lifestyles
- Advocacy - human rights for people living with dementia and their family carers

- Access to information and quality services

- Early detection, diagnosis, holistic management of cognitive problems

- Strengthening human resources and the overall system infrastructure

- Promoting a life-course approach

- Supporting research on cognition and dementia

Another important development was the launch, in 2014 , of Indonesia's universal healthcare programme, Jaminan Kesehatan Nasional (JKN), with the aim of providing health insurance to the entire population by 2019. The JKN brings together various state-owned health insurance schemes that previously covered parts of the population. It is funded by contributions from those in employment and a government subsidy to cover those without employment and resources (Mboi, 2015). There is a strong policy impetus to improve access to and quality of healthcare in Indonesia, although the starting point is one of wide differences between different regions, and between urban and rural areas.

\section{Current diagnostic and healthcare pathways}

There is almost no data available on Indonesia's health and social care services for people with dementia, which reflects the low profile of dementia in Indonesia until very recently. Alzheimer's Indonesia (ALZI) and others have helped us gather some information which we have used to provide a picture of the current situation.

While there are some specialist dementia healthcare services in Indonesia, these are currently available to very few people; for example, there are specialist dementia services in eight public hospitals and ten private hospitals, and there are five memory clinics (four public and one private).

The community-based primary care centres (Pukesmas) in principle provide diagnostic and continuing care through general practitioners. However, of nearly 9,000 Pukesmas, only $42 \%$ provide general healthcare services for older people, and many GPs are unable to provide diagnostic services for dementia due to lack of training. The quality and range of services available is very different between urban and rural areas: many Pukesmas in rural areas are only able to provide very basic care. In many cases, the local health workers consider dementia symptoms a normal part of ageing and do not diagnose or refer people presenting those symptoms.

Access to dementia diagnosis and care is also hampered by a prevalent belief in families that dementia is a normal part of ageing and lack of 
knowledge about the existence of treatments for some of the symptoms of dementia.

Where specialist dementia services are provided, these appear to be of very high quality and reflect international practice. For example, an anecdotal report by Nicole Batsch (2015) describes a memory clinic in Yogyakarta:

"I visited the clinic in Yogyakarta which was established when the hospital built a new building three years ago. Dr. Astuti and her team offer diagnostic support and behavioral interventions and see about three new patients each day. Patients and families often seek treatment after struggling at home with behavioral challenges many years after symptoms first emerge. A formal diagnosis takes about three days to complete and includes brain scans, neuropsychological testing and other tests to look for acute causes. The clinic uses some Western instruments such as the Mini-Mental Status Exam (MMSE) that have been validated in Bahasa Indonesia (the national Indonesian language) and other cultural adaptations. For example, one test uses pictures of elephants and camels."

The team also offers Cognitive Stimulation Therapy and patients visit the clinic on a regular basis to take part in this evidence-based intervention that has been translated into Bahasa Indonesian, as well as participate in other activities."

The Ministry of Health, in collaboration with Alzheimer's Indonesia and medical professionals, is developing a Guideline for Dementia Risk Reduction and Management in Primary Care Centres which is expected to be launched towards the end of 2016 .

\section{Other care and support for people with dementia and their families}

In Indonesia there is a strong sense of filial obligation, and families of people with dementia are the main providers of care.

There are a few examples of community-based care and support for people with dementia in the formal sector, for example there are only three day centres in urban areas in Jakarta and East-Java, and two of them are private and too expensive for people with limited resources to access. Until recently there has been relatively little involvement by NGOs, but Alzheimer's Indonesia, created three years ago, is now running caregiver support groups in Jakarta, West Java, Central Java, East Java and Yogyakarta. These caregiver support groups are mainly in urban areas and provide information about caring for people with dementia and promote peer support and networking.
There are also a few examples of institutional care, but these are rare and target the very wealthy. While some wealthier families are in a position to pay others to provide care, there is a very strong cultural preference for that care to be provided in the family setting. The care is provided by informal paid workers, who usually live with the families. Sometimes these paid helpers are integrated into the family structure as adopted children or nieces (Schröder-Butterfill and Fithry, 2014). It is expected that, as the size of the middle class rises, as well as migration, the number of these "paid informal carers" will increase. It will be important to include the training of these paid informal carers in dementia policy.

As part of the Jakarta Smart City Initiative, the Jakarta Government and Alzheimer's Indonesia are collaborating to help make Jakarta more dementiafriendly. The Jakarta Government has developed an app, called Qlue, which, among other features, includes reports of missing people. When people are found wandering, a trained team of social workers will screen them for dementia and other health conditions, while the family are located. Under this initiative Alzheimer's Indonesia is providing dementia training to staff from Jakarta's Health and Social Departments, primary care doctors and their teams, social workers and other civil servants.

\section{Challenges that need to be addressed}

There are very low levels of awareness of dementia among healthcare staff, particularly in primary care health services and in rural areas, which limits their ability to diagnose and care for people affected by dementia. Training health professionals on dementia is needed, as is funding the development of dementia services.

Lack of understanding of the difference between normal ageing and dementia means that most people do not seek help, and therefore miss opportunities to have some of their symptoms treated or to obtain support.

The availability of family care is expected to change in the next few decades due to declines in fertility, increased migration, and increased labour force participation by women. Also, there are very high rates of widowhood for women, in part due to the tradition for women to marry older men, and in part because of other social and cultural factors, such as women not being able to remarry in some ethnic groups. Childlessness is also relatively high among the older population (Schröder-Butterfill and Fithry, 2014).

While Indonesia has achieved important reductions in poverty, it affects older people disproportionately, in part because older people are more likely to remain in the informal economy in rural areas, and in part 
because pension coverage remains very low (only $8 \%$ of older people have a formal pension). Older people also have much lower literacy rates than younger generations. Poorer older people, given the same health conditions as their wealthier counterparts, are much less likely to use healthcare services, particularly in rural areas and particularly women (Priebe and Howell, 2014).

\subsection{Dementia care in Mexico}

Mexico is the third largest territory in Latin America and its population of around 120 million people in 2015 makes it the second most populated in the continent (INEGI 2015). Close to $80 \%$ of the population live in urban areas. There are marked inequalities in Mexico, the most disadvantaged groups are people in the southern states, women, children and indigenous groups. Despite major reforms aiming to reduce poverty and inequality, just under $10 \%$ of the population live in extreme poverty. A high share (60\%) of employment in Mexico is in the informal sector, which affects the revenues available for publicly funded healthcare and other social protection programmes, given their links to taxation (OECD, 2016). Mexico's indigenous groups represent about $16 \%$ of the population and, despite recent policy efforts, continue to face major difficulties accessing healthcare, education and employment (Servan-Mori et al., 2014).

\section{Demographic and prevalence data}

There are estimates of the prevalence and incidence rates of dementia in Mexico from two nationally representative surveys, the Mexican Health and Aging Study (MHAS) and the National Health and Nutrition Survey 2012 (ENSANUT), and also data from the 10/66 study.

Data from the MHAS, a prospective panel study of ageing and health in Mexico, found that prevalence of dementia was 6.1 percent in the population aged 60 years and above, with estimated incidence rate of 27.3 per 1,000 person-years for dementia (Mejia-Arango \& Gutierrez Robledo 2011). This study also found that prevalence rates of dementia decreased with higher educational level and that hypertension, diabetes and depression were risk factors for dementia. Estimates from the ENSANUT 2012 survey showed a prevalence of dementia of 7.9 percent (Manriquez et al., 2013).

The 10/66 study estimated a prevalence of dementia of 7.4 percent in urban areas and 7.3 percent in rural areas (Llibre-Rodríguez et al, 2008), similar to estimates from ENSANUT 2012, and an incidence of 30.4 per 1,000 person-years (Prince et al, 2012).

The World Alzheimer Report 2015 estimated that in 2015 there were just over 800,000 people with dementia in Mexico, and of these $64 \%$ were women.
By 2030 the number of people is expected to rise to just over 1.5 million.

Figure 6.4

Estimated numbers of people with dementia, Mexico

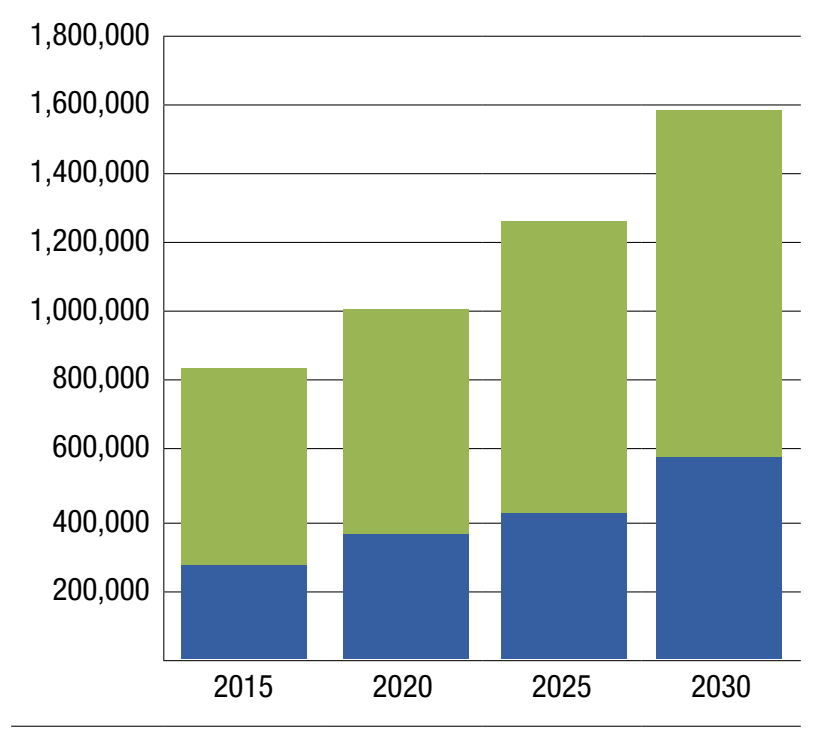

Men Women

Source: World Alzheimer Report 2015 estimates

With regard to risk factors for dementia, Mexico has particularly high rates of obesity: between 2000 and 2012 the rates of people considered to be overweight or obese increased from $62.3 \%$ to $71.3 \%$ of the adult population, and one in three children is overweight or obese. Diabetes is also increasing rapidly, affecting $15.9 \%$ of adults, more than double the OECD average of $6.9 \%$ (OECD, 2016).

\section{Policy landscape}

In 2014 the National Institute of Geriatrics, in collaboration with the National Neurology and Neurosurgery Institute, the National Public Health Institute, the Mexican AD Federation and the National Institute for Older Adults (INAPAM) published the Alzheimer's Plan of Action (APA). The Plan is in line with Federal health legislation regarding development and health of the populations.

The main objective of the Plan is to promote the wellbeing of people with dementia and their families through strengthening the response of the Mexican Health System and ensure equal access to adequate services (Gutierrez-Robledo and Arrieta-Cruz, 2015).

The Plan's aims are:

- Increasing awareness and eliminating stigma and negative stereotypes.

- Increasing access to sound and current information for health professionals, people with dementia and their caregivers. 
- Developing a comprehensive care model in line with the needs and characteristics of the country.

- Supporting the development of multidisciplinary research in order to better understand the process of Alzheimer's disease and other dementias.

- Increasing the training of all health professionals and caregivers so they can better manage their care provision.

- Strengthening prevention strategies and programmes to combat chronic diseases as risk factors for Alzheimer's disease and other dementias and curtail their incidence, as well as providing timely diagnosis and treatment.

In terms of implementation of the Plan, most progress has been achieved in the training of health professionals and in raising awareness among the general public. In line with the National and the Regional Plan on Alzheimer's disease, the National Institute of Geriatrics generated three training strategies. First, a Diploma in Alzheimer's disease and other dementias, a 160-hour course designed with a multidisciplinary perspective and guided by experts in the topic. The other strategies include an online course 'Principles of the person-centred care model for people with dementia' for health professionals, and an open online course titled 'What we need to know' and offered through the Tele-education platform of the Ministry of Education. By mid-2016, 200 health professionals had completed the person-centred care course, while close to 5,000 people had registered for the online open course. This high response is seen as an important way to work towards reducing general beliefs in society that memory loss is a normal and unavoidable part of the ageing process, as well as on increasing knowledge on risk factors and prevention strategies.

\section{Health system context}

Healthcare services in Mexico are provided through a variety of insurance systems, each with its own staff, clinics and hospitals. The insurance systems offer different levels of care to different groups and with different outcomes, thereby entrenching inequality in access to healthcare among different sectors of the population. The largest insurance systems are the Instituto Mexicano del Seguro Social (IMSS), which covers people in salaried formal employment, and the Instituto de Seguridad y Servicios Sociales de los Trabajadores del Estado (ISSSTE), which covers federal and state level government employees. There is also a network of Servicios Estatales de Salud, or government-funded State Health Services (SHS), for those without employment-linked insurance. In 2004, with the aim of achieving universal health coverage, the government introduced the Seguro Popular (SP), which extended publicly-funded health insurance to 50 million Mexicans who were previously uninsured.
Prior to Seguro Popular, these individuals would have had access to SHS but been liable to pay a user fee. The package of services covered by Seguro Popular has been continuously expanded, now covering 95\% of presentations to clinics and hospitals. However, access, quality and use of services vary by region, ethnicity, and socio-economic characteristics (Angel et al., 2016).

Mexico has lower availability of healthcare services than most OECD countries. In 2013 it had 2.2 practising doctors, 2.6 practising nurses and 1.6 hospital beds per 1,000 population (compared to the OECD averages of 3.3, 9.1 and 4.8 respectively) (OECD, 2016). The number of doctor consultations per capita in the public system is also very low: 2.8 per capita compared to the OECD average of 6.6. These low rates may reflect unmet healthcare needs among those with fewer resources, and also that those who are better off opt to use private healthcare instead, due to dissatisfaction with the quality or accessibility of services provided by the health insurance institutions. Out-of-pocket payments represent $45 \%$ of health system revenue and $4.0 \%$ of household expenditure (OECD, 2016).

The OECD's assessment of the Mexican health care system highlights that as well as being unequal, the lack of coordination between the different insurance schemes results in huge inefficiencies, with $10 \%$ of the national health budget being spent on administration. Millions of people belong to more than one insurance scheme, and millions more are not aware of belonging to any scheme (OECD, 2016).

The OECD also highlights that primary care is not as developed as it should be, with people not registered with a named primary care doctor and opening hours restricted. Instead, people often seek care from hospital emergency departments and from pharmacies that offer consultations with a physician. This reduces the opportunities for prevention and care coordination (OECD, 2016).

An important strength of the Mexican health care system has been the adoption of a consolidated drug purchasing mechanism at the federal level. The Comisión Coordinadora para la Negociación de Precios de Medicamentos y otros Insumos para la Salud (CCNPMIS, Coordinating Commission for the Negotiation of Prices of Pharmaceuticals and other Health Inputs) was set up in 2008 and it coordinates an annual negotiation process with pharmaceutical companies for the products included in the Mexican national formulary. This strategy seems to have been successful in reducing drug prices in Mexico (OECD, 2016). 


\section{Current diagnostic and healthcare pathways}

As in most middle- and low-income countries, some specialist dementia healthcare services are available in Mexico, but are available to very few people; those in Mexico City or other large cities, or those who can access the private health sector. As with other health problems, there is high inequality in dementia diagnosis and treatment, as those few with enough financial resources who access private services get timely and accurate diagnosis and quality treatment practices and recommendations for caregivers, while the majority of older adults have no access to such care.

In public health institutions older adults' first contact is with family doctors or general practitioners who are not only untrained to provide an accurate diagnosis of dementia, but have no accurate knowledge of the disease or its progress, and still very often think that memory loss and changes in behaviour are normal consequences of ageing. Therefore, even where some services are available at the second or tertiary care levels, few people may be referred for specialist care (Lopez-Ortega, 2016).

A qualitative study of the experiences of families of people with dementia reported that most general practitioners were not equipped to recognize early signs of cognitive impairment and as a result did not feel prepared to offer treatment. This resulted in caregivers looking to the private sector for support, but this was often out of financial reach (Juarez-Cedillo et al., 2014).

The cost of anti-dementia drugs in Mexico is much lower than in other LMIC, reflecting the early availability of locally produced generics (Suh et al, 2009) and the role of the consolidated drug purchasing system.

\section{Other care and support for people with dementia and their families}

Mexico lacks national long-term care policies and services. Most care for people with dementia is provided by family members within the household who have little or no training or knowledge of Alzheimer's disease and other dementias. In addition, given there are no special benefits such as tax incentives, monetary support or respite care to support family caregivers.

While some public day-care services are available for older adults, most are for functional and independent older adults while just a few cater for people with dementia.

In some states there is support from voluntary nongovernmental organisations, mainly through the provision of training, group support and some day-care services. FEDMA, the Mexican Alzheimer's Federation, was created in 2002 and is currently the largest association with 21 registered state-level organisations and 46 support groups. As part of their work, they organise national meetings that include activities and talks for people with dementia, their family members and caregivers. They have also been fundamental in the consolidation of a movement to improve the lives of people affected by dementia in the country (Torres Castro, Martinez Ruiz and Arrieta Cruz, 2015).

\section{Challenges that need to be addressed}

In 2016, the national Alzheimer's Plan of Action is still at the beginning of its implementation. While there has been important progress in the training of professionals and efforts to improve awareness and knowledge about dementia, achieving the Plan's aims of improving the treatment, care and support of people with dementia will also require a wider reform of the healthcare system. In particular, the current fragmentation and unequal coverage of the different insurance schemes and the lack of a strong primary care system need to be addressed in order to deliver adequate care and support to people with dementia and other chronic health conditions.

In addition, there is a need to consider the creation of personal and social care public strategies to support caregivers, ensure that the costs of providing unpaid care are not excessive and detrimental to their quality of life, and at the same time guaranteeing care that enables people with dementia to live well. The government will also need to consider the sustainability of the current degree of reliance on family care: smaller family sizes, internal and international migration rates, and women's increasing participation in the labour force and activities outside the home, pose future challenges to the availability of family care and support for older adults (Gutierrez Robledo, Lopez-Ortega, Arango Lopera, 2012).

\subsection{Dementia care in South Africa}

South Africa is classified as an upper-middle income country by the World Bank (2015), with an abundant supply of natural resources, well-developed financial, legal, communications, energy and transport sectors. South Africa experienced average annual economic growth of approximately $5 \%$ in real terms between 2004 and 2007, but this has since slowed, largely as a result of the global economic recession, and from 2008 to 2012 , growth was just above $2 \%$ (Statistics South Africa, 2016).

South Africa's population reached nearly 55 million in 2015. It is experiencing rapid growth in the number of older adults and the proportion of older adults in the population. There are currently 4.4 million adults aged 60 and above in South Africa, 9.5\% of whom are aged 80 and above (Statistics South Africa, 2015). This older 
population is expected to increase to 7 million by 2030 (Statistics South Africa, 2014a). The country's fertility rate of 2.3 is lower than anywhere else on the African continent.

The legacy of the 1948 to 1994 Apartheid era remains a challenge: it is the third most unequal country in the world and unemployment is high, particularly among black young people (CIA, 2016). The large inequalities in South Africa mean that the country has simultaneously to deal with both increases in "diseases of prosperity", associated with longer life expectancies, and "diseases of poverty" (Bongani and Benatar, 2014). The "quadruple disease burden" in South Africa comprises: a large prevalence of communicable diseases (especially HIV/AIDS and tuberculosis); noncommunicable diseases (such as high blood pressure and diabetes); high maternal, neonatal and child death rates; and deaths from injuries and violence (Rispel, 2016).

The HIV/AIDS epidemic has had a major impact on the population's health and associated care needs and provision, and also on the structure of families. In 2003 the government introduced an ambitious programme to provide antiretroviral therapy (ART) to all people with HIV infection. Spending on HIV increased at an annual average rate of $48.2 \%$ between 1999 and 2005 . At least 2 million out of the 6 million South-Africans infected with HIV receive ART (Bongani and Benatar, 2014).

\section{Demographic and prevalence data}

The World Alzheimer Report 2015 estimated that in 2015 there were nearly 186,000 people living with dementia in South Africa, of whom nearly $75 \%$ were women. By 2030 the number of people is expected to rise to nearly 275,000 (see Figure 6.5).

Figure 6.5

\section{Estimated numbers of people with dementia, South Africa}

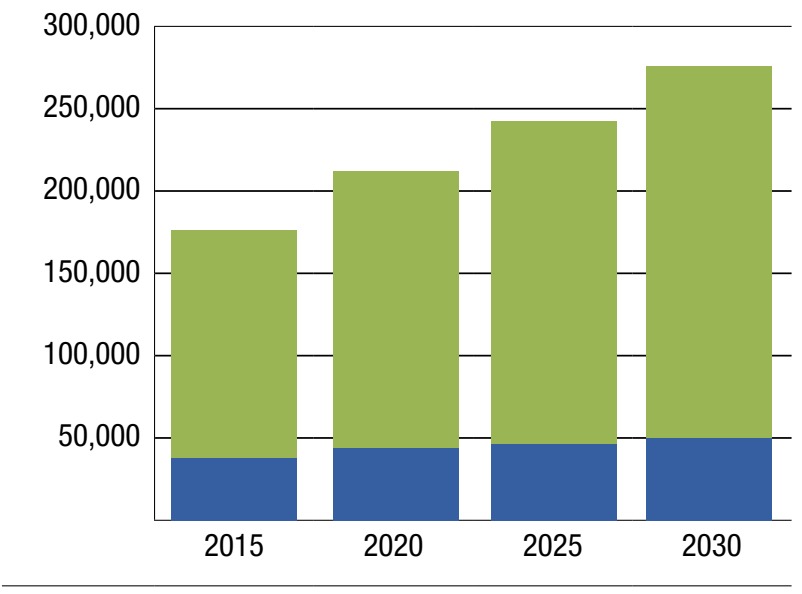

Men Women

Source: World Alzheimer Report 2015 estimates
Increasing numbers of adults in South Africa are affected by disorders associated with neurodegeneration such as traumatic brain injury, alcohol dependence and HIV infection. The prevalence of HIV-associated dementia (HAD) is 15 to $30 \%$ in untreated populations with late-stage disease. Older adults, already at increased risk of non-AIDS-related dementias, are also most likely to have untreated HIV. It is difficult to quantify the impact that this has and will have on the numbers of people with dementia (de Jager et al., 2015).

\section{Policy landscape and healthcare system context}

\section{National policy on dementia}

At present there is no national dementia plan for South Africa. The lack of policies specifically focused on dementia reflects very low awareness of the prevalence and impact of dementia, and in practice results in very few services oriented towards people with dementia, except for some memory clinics developed by hospitals and community services provided by NGOs (Kalula and Petros, 2011).

There has, however, been important investment in broader mental health services, following implementation of national policy guidelines in 1997. Since then, the 2002 Mental Health Act emphasised the human rights of those with mental health conditions and promoted the development of mental healthcare within the general health system and community-based care (Lund et al., 2008). In 2013, the National Health Council adopted a Mental Health Policy Framework (MHPF) and the Strategic Plan for South Africa. This framework includes eight key objectives which aim to further transform mental health services, ensuring that access is available for all who need it (Stein, 2014). This Mental Health Policy Framework emphasises longer term aspirations which align with South Africa's broader health sector development goals and endeavours to reduce the burden of untreated mental disorders across the country.

Awareness and understanding of dementia among the population is very low, which has important implications for individuals' propensity to seek healthcare and support for dementia, and may also put them at risk of abuse and harm related to the conflation of dementia symptoms with witchcraft (Benade 2012, De Jager et al 2015, Khonje et al, 2015). In a survey of knowledge, attitudes and practices towards people with dementia in the township of Khayelitsha, 28\% of the sample thought that dementia was associated with witchcraft and $26 \%$ thought it was a punishment (14\% from God and 18\% from the ancestors). $15 \%$ of 
respondents believed traditional healers could cure dementia (Khonje et al., 2015).

\section{The health system context}

The Apartheid-era inequities are reflected in both the need for and availability of health and social care. Rural areas in the country have largely underdeveloped infrastructures and few health or social care services.

South Africa's health system consists of a public sector that covers the majority of the population, a private sector, and non-profit sector. The disparity between the healthcare services available to those in the public and private sector is illustrated in some striking statistics presented by Bongani and Benatar (2014): annual per capita expenditure is ten times higher in the private sector than in the public sector ( $\$ 1,400$ compared to $\$ 140)$. The public health sector is staffed by $30 \%$ of doctors in the country, who serve 40 million uninsured people (84\% of the population). Approximately $16 \%$ of the population have private insurance, which provides access to the remaining $70 \%$ of the country's doctors, who work full-time in the private sector. It has been estimated that up to $25 \%$ of uninsured people pay out of pocket for private sector care.

Primary healthcare clinics form the core of the public health systems. They are the first point of access for people in need of healthcare. They are publicly funded and free at the point of use. There are currently 4,200 such clinics in South Africa, 1,600 of which have been built or upgraded since 1994. People who require specialist treatment can be referred to district hospitals (the second tier of the healthcare system). There are also academic (tertiary) hospitals, which serve as teaching hospitals and where more advanced diagnostic procedures and treatments are provided. For 2.5 million South Africans, their nearest clinic is more than 5 kilometres away from their homes (Jobson, 2015).

The private sector is mostly financed through medical schemes. There are more than 110 schemes, covering nearly 8 million beneficiaries. Care is provided via independent healthcare providers and private hospitals. There are 238 private hospitals, 188 in urban areas and 50 in rural areas (Jobson, 2015).

There are severe workforce pressures in the public sector in South Africa (Rispel, 2016). The 2012 National Health Facilities Baseline Audit surveyed 3,356 clinics and community health centres and found that half of them had no visiting doctors; $84 \%$ had no assistance from a pharmacist or pharmacy assistant; $11 \%$ had no lay counsellors. Despite the very high unemployment rates, the average vacancy rate in the healthcare sector across South Africa is 31\%, ranging from 13 to $40 \%$ across different provinces (Jobson, 2015).
In order to address the huge imbalances in the healthcare system, the South African government has committed to implementing a National Health Insurance (NHI) system. The White Paper published in 2015 commits to implementing NHI over a 14-year period. During the initial first five years, the plans will focus on strengthening the delivery of services and improving quality. The second five-year phase will involve rolling out an $\mathrm{NHI}$ card to all of the population, introducing unique identifiers, and abolishing out-ofpocket payments in public hospitals. The third and final phase will focus on ensuring the functionality of the system. It is envisaged that the private medical aids may supply "top-up" services over and above the publicly covered package of services. The funding mechanisms for the new $\mathrm{NHI}$ scheme have not yet been decided (Health eNews, 2015).

\section{Current diagnostic and healthcare pathways}

There is limited awareness of dementia among health professionals, particularly in rural areas. Primary healthcare services concentrate on acute and "treatable" conditions and HIV in particular. Practitioners often consider dementia symptoms to be part of normal ageing and have no understanding of the care and treatment options available (Kalula and Petros 2014, De Jager et al, 2015).

The lack of understanding of dementia among healthcare staff can mean that, even when dementia is identified, the belief that there is nothing than can be done to treat it can result in people being excluded from further care. For example, in a Soweto township where nurses had been trained to discriminate between dementia and delirium, those with delirium were referred for further treatment, whereas those with dementia were returned home for family care (Prince et al, 2007).

There are very few specialists dedicated to dementia care. South Africa has fewer than ten geriatricians and fewer than five old-age psychiatrists for a population of over 4 million older people (Kalula and Petros, 2014). Some hospitals have opened memory clinics in an effort to improve the care they provide to people with dementia. Diagnostic care pathways used in these clinics differ from those followed in private hospitals in South Africa. For example, a detailed study of the caseload and practices at a clinic in Cape Town suggests that some of the "standard" screening tools, such as the MMSE and other tests in the neuropsychology battery, may not be appropriate, resulting in false positives as a result of low levels of education of many of the people visiting the clinic. Also the clinic did not use brain imaging routinely, which may influence diagnostic accuracy (Kalula et al, 2010). The study also reported that lack of awareness of dementia among primary care health professionals and family members may result in delays in referrals, which 
may explain the higher severity of dementia observed in this clinic at the time of diagnosis, compared to international data.

The use of anti-dementia medication is very low, even among those who are diagnosed. Cost is the major barrier: these medications are not included in the Essential Drug List for public healthcare facilities and are rarely covered by private health insurance plans (De Jager et al, 2015). The report from the memory clinic in Cape Town suggests that the prescription of drugs is primarily focussed on the management of behavioural symptoms; the review found anti-depressants were prescribed to $43 \%$ of patients, despite only $15 \%$ having been diagnosed with depression, and the most common dementia-specific prescription was for traditional anti-psychotics. Only $2 \%$ of patients who could afford acetylcholinesterase inhibitors had them prescribed (Kalula et al, 2010).

Analysis of prescription data from a national community pharmacy group showed that, of just over 575,000 people who were prescribed central nervous system drugs, only 1,231 (2\%) people had been prescribed medication for dementia. In total 5,264 anti-dementia drugs were prescribed and of these $46 \%$ prescriptions were for donepezil and $37 \%$ for memantine. The average cost per product was (US) $\$ 76.44$, in 2010 prices. The study also found that there was very low continuity of prescription: nearly half of the patients only had one or two prescriptions during the year and only $31 \%$ were prescribed six or more times. The authors consider that affordability may have played a role (Truter et al, 2013). The study also reports that, of those who had been prescribed anti-dementia drugs, 23\% were also prescribed anti-psychotic drugs, most often risperidone (53\%) or quetiapine (31\%).

\section{Other care and support for people with dementia and their families}

Most of the care to people living with dementia is provided by families, primarily by female family members, even in urban areas. Of the people attending a memory clinic in Cape Town, 79\% were being cared for by their families and 6\% were in care homes (Kalula et al, 2010).

Welfare payments for older adults and their family carers in the form of the Older Persons Grant and Grant-in-Aid are expected to encourage the provision of family care by providing financial compensation to those who cannot work as a result of providing care. There is some concern that the most vulnerable older adults - likely to include those with dementia - are the least likely to claim either grant.

Alongside family-based care provision, South Africa is the only country in sub-Saharan Africa to have a developed formal care system for older people. Public expenditure on long-term care amounts to $0.2 \%$ of
GDP (Scheil-Adlung, 2015) and there is also private and not-for-profit sector provision. The availability and accessibility of formal long-term care has been strongly shaped by the Apartheid policies that privileged institutional care for white older people. By $1997,87 \%$ of the welfare services budget was spent on residential services and facilities, primarily for white older adults (Ministry for Welfare and Population Development, 1997).

Subsequent policies have attempted to address racial inequity in access to residential facilities and public spending. Current provision of residential care is subsidised only for older adults with most advanced functional disability and who qualify for the meanstested Older Persons Grant. To receive subsidies, older adults must apply directly to facilities. However, facilities are overwhelmingly concentrated in formal urban areas $(79 \%)$, with few located in rural areas (16\%) and informal settlements $(5 \%)$ that contain the highest proportions of poor older adults (Freeman, forthcoming).

Community-based care and support services, promoted as alternatives to the residential care model that is understood to be culturally challenging, have proliferated. These are largely unregulated, and typically of two tiers: competitive private for-profit home-based nursing care services that cater to more affluent, typically urban populations, and non-profit, often under-resourced services offered by charitable or faith-based organisations that cater to populations of poor older adults without recourse to family or community care. Despite policy support for nonresidential non-dementia specific long term care, state subsidy of services for vulnerable older adults is widely considered to be inadequate (Freeman, forthcoming).

A qualitative study of the attitudes and responses of staff in care homes to distressed behaviour of residents with dementia found that less than half of all the staff reported having received specific training to care for people with dementia and those who did had attended only a one-day workshop. The study also found that none of the homes offered any structured activities or therapeutic services for residents with dementia. Although some of the staff members reported using medication to manage distressed behaviour, the majority reported a preference for carerelated approaches (Van Wyk et al, 2016).

There are two national dementia associations: Alzheimer's South Africa and Dementia SA. As well as raising awareness and campaigning to improve dementia care services and policy, both organisations provide training to formal and informal caregivers and run support groups, which are usually led by a trained caregiver (Benade, 2012). A few other NGOs, including 
religious groups, also provide services for older people (de Jager et al, 2015).

\section{Challenges that need to be addressed}

A recent paper by De Jager et al (2015 p.190) sets out a list of priorities for the improvement of dementia healthcare and treatment in South Africa:

- Robust prevalence data using culturally-relevant screening tests

- Earlier diagnosis and intervention options

- De-stigmatisation and increased awareness

- Increased preparedness and service provision

- Integration of older persons' needs and rights into national health policies across all sectors, e.g. health and justice, adequate protection of vulnerable people with dementia from abuse and neglect

- Prioritised research funding

- Education at all levels, including communities, to better manage people with dementia and enable them to live meaningful and purposeful lives

- Training and skills development for healthcare providers

- Career advancement for professionals in geriatric medicine and related disciplines

There is considerable scope for improving access to health and social care services for people with dementia. There is limited evidence about dementia in South Africa. The evidence we have found highlights the importance of ensuring that primary care services have adequate staff, knowledge and resources to be able meet to the needs of those with non-curable conditions such as dementia, the barriers to access to anti-dementia drugs as a result of their lack of inclusion in the Essential Drugs List, and the lack of support to families providing care.

\subsection{Dementia care in South Korea}

The Republic of Korea, often referred to as South Korea, is located in East Asia and constitutes the southern part of the Korean Peninsula. It shares land borders with the Democratic People's Republic of Korea to the north, and maritime borders with China to the west and Japan to the east. In the last fifty years South Korea's economy has grown very rapidly. It is now a high income country, with GNI per capita of $\$ 27,090$ (World Bank, 2015). It has a population of 50 million and is the world's 15th largest economy.

South Korea has experienced very rapid ageing since the year 2000; between 2000 and 2015 it experienced the fourth fastest rate of ageing in the world, and between 2015 and 2030 it is expected to be the second fastest ageing country in the world. The percentage of the population aged 60 or more was estimated to be
$18.5 \%$ in 2015 and is projected to reach $31 \%$ by 2030 (UN, 2015).

\section{Demographic and prevalence data}

Using data from the 2012 Nationwide Survey on Dementia Epidemiology of Korea (NaSDEK) and the 2010 Census, the prevalence of dementia in 2012 was estimated to be of $9.18 \%$ by the National Dementia Institute. Applying age and gender standardised dementia rates to the national population projections, in 2015 there would be over 648,000 people with dementia in South Korea, projected to increase to nearly $1,272,500$ by 2030 (National Dementia Institute, 2016).

The World Alzheimer Report 2015 estimates were lower, suggesting that in 2015 there were just over 478,000 people with dementia in South Korea, increasing to just over a million by 2030 (see Figure 6.6).

Figure 6.6

Estimated numbers of people with dementia, South Korea

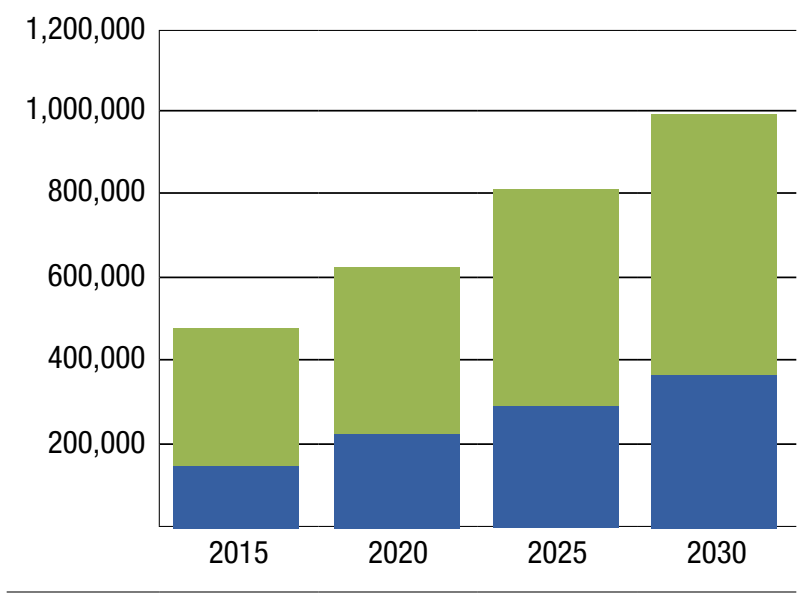

Men Women

Source: World Alzheimer Report 2015 estimates

\section{Policy landscape and healthcare system context}

\section{Cost of dementia}

In 2013, the annual cost of dementia in South Korea was estimated to be about US $\$ 10$ billion, which would represent about $0.7 \%$ of its GDP. The importance of the costs of dementia as a share of GDP is expected to rise to about $2 \%$ by 2050 (Kim, 2016).

The costs of caring for a person with dementia in South Korea were estimated to be US\$ 19,104 in 2015 (National Dementia Institute, 2016). A previous study reported that, of the total costs of dementia, $38 \%$ were direct health costs, $17 \%$ were direct long-term care costs, and $45 \%$ were indirect costs, including the opportunity costs of unpaid family care and productivity losses. The costs of caring for people with severe dementia were found to be 2.7 times higher 
than for people with mild (questionable) dementia (Kim et al, 2011).

\section{National Dementia Plans and policy}

South Korea is now on its third National Dementia Plan. The first was launched in 2008 and focused on prevention, early diagnostic, development and coordination of infrastructures and management, and improving awareness. The second plan, in 2012, addressed the same priorities but had a stronger focus on supporting family members. In 2012 the Dementia Management Act (DeMA) established a statutory basis for organisation of the National Dementia Plans.

Under the Dementia Management Act, the state is required to produce a comprehensive plan for dementia every 5 years. The Act also mandates that the state should manage a dementia case register and collect statistics on epidemiology and the management of the condition. This has led to the 'Nationwide Study on the Prevalence of Dementia in Korean elders 2008' (Choi et al, 2009), the 'Study on Dementia Prevalence 2012' (Ministry of Health and Welfare, 2013), and the forthcoming 'Study on Dementia Prevalence 2016'.

The Act also established institutions to coordinate dementia treatment, care and support. The National Institute of Dementia, at the Seoul National University Bundang Hospital, has a central management role, and coordinates regional Dementia Centres in the 17 regions ( 13 have been established so far, 4 more are expected to open before the end of 2016). The Dementia Centres provide education to healthcare professionals and conduct research, as well as establishing and running local awareness campaigns, including the Dementia Partners programme (Sim, 2016). The Act also established Dementia Counselling Centres in every Public health centre and the National Dementia Helpline.

The 3rd National Dementia Plan of 2016 aims to create a dementia friendly society to enable people with dementia and their carers live well. The four principles of the plan are:

1. Community-based prevention and management of dementia

2. Convenient and safe diagnosis, treatment, and care for people with dementia

3. The reduction of the care burden for family caregivers of people with dementia

4. Support for dementia research through research, statistics and technology

Current dementia policy priorities in South Korea include:

1. The establishment of a user-based dementia management system with wider coverage and the consideration of the 'care pathway'
2. Improved balance and coordination between treatment, care and welfare services, using evidence-based planning and quantification of outcomes

\section{Building 'Dementia-Friendly Communities'}

\section{Healthcare system context}

South Korea achieved universal health coverage in 1989, 12 years after the introduction of social health insurance. Since 2000 there has been a single payer national insurance system, the National Health Insurance, with uniform contributions and benefits. Prior to that, there were three different types of insurance schemes and more than 350 insurance providers (Kwon, 2015). A small proportion of the population with very low incomes is covered by the separate Medical Aid Programme (MAP) (Robertson et al, 2014).

The delivery of healthcare is mostly private, except for some public health facilities that provide medically necessary services at central, regional and municipal levels. The Ministry of Health and Welfare has a central role in health planning and policy formulation and implementation. Regional governments are responsible for managing regional medical centres and each municipality is in charge of health centres and subcentres and primary healthcare posts.

The National Health Insurance is run by two quasipublic bodies, the National Health Insurance Service (NHIS) and the Health Insurance Review and Assessment Service (HIRA).

Although there is universal health coverage, outof-pocket payments (OOP) are high and there is no fee regulation for private providers. This means that private providers have incentives to induce demand for expensive new services and technologies which, sometimes because there is no evidence that they are cost-effective, are not included in the National Health Insurance benefit package. Voluntary health insurance is growing in importance.

Patients contribute up to $20 \%$ of the costs of inpatient care and between 30 and $60 \%$ of outpatient care costs. There are exemptions from OOP for the poor and discounted rates for those with low incomes (Robertson, 2014).

There is no gatekeeping role in the healthcare system, which means that people are able to choose their care providers. Their choices reveal a high preference for high-tech medical care, usually preferring to access tertiary care hospitals directly, despite having to pay higher OOP. Up to $90 \%$ of primary care is provided by independent private providers in single-handed and group practices, operating from both clinics and offices, and hospital settings (Robertson, 2014). 
Table 6.1

Ministry of Health and Welfare official Key Performance Indicators (KPI) for the 3rd National Dementia Plan

\begin{tabular}{|c|c|c|c|c|c|}
\hline & KPI & Current & Goal (2018) & Goal (2020) & Note \\
\hline \multirow[t]{2}{*}{ General } & $\begin{array}{l}\text { Yearly \% increase in the } \\
\text { dementia prevalence rates }\end{array}$ & $\begin{array}{l}(2012-15) \\
2.14 \%\end{array}$ & $\begin{array}{l}(2016-18) \\
1.64 \%\end{array}$ & $\begin{array}{l}(2018-20) \\
1.14 \%\end{array}$ & $\begin{array}{l}\text { Reduced increase in prevalence by } \\
\text { early management of risk factors } \\
\text { for dementia }\end{array}$ \\
\hline & Dementia Awareness score & 64.7 & 75 & 80 & $\begin{array}{l}\text { Based on the Nationwide Survey } \\
\text { on Dementia Awareness }\end{array}$ \\
\hline \multirow[t]{2}{*}{ Community } & $\begin{array}{l}\text { Number of leading secondary } \\
\text { schools and universities to } \\
\text { overcome dementia }\end{array}$ & 11 & 80 & 160 & $\begin{array}{l}5 \text { per metropolitan area in 2018, } \\
10 \text { in } 2020\end{array}$ \\
\hline & Number of Dementia Partners & 100,000 & 300,000 & 500,000 & - \\
\hline \multirow{4}{*}{$\begin{array}{l}\text { Treatment \& } \\
\text { care for people } \\
\text { with dementia }\end{array}$} & $\begin{array}{l}\text { Introduction of the Family } \\
\text { Caregiver Counselling Fee to NHI }\end{array}$ & - & - & - & Introduce to the NHI in 2017 \\
\hline & $\begin{array}{l}\text { Introduction of 24-hour Visiting } \\
\text { Respite Service }\end{array}$ & - & - & - & Introduce in 2017 \\
\hline & $\begin{array}{l}\text { Addition of specialized care } \\
\text { services for people with } \\
\text { dementia in nursing homes }\end{array}$ & $\begin{array}{l}\text { Pilot } \\
\text { program }\end{array}$ & - & - & Introduce in 2016 \\
\hline & $\begin{array}{l}\text { Prevalence of physical abuse in } \\
\text { older adults with dementia (\%) }\end{array}$ & 0.16 & 0.13 & 0.10 & $\begin{array}{l}949 \text { reports of physical abuse in } \\
2014\end{array}$ \\
\hline \multirow[t]{2}{*}{$\begin{array}{l}\text { Family } \\
\text { caregivers }\end{array}$} & $\begin{array}{l}\text { Average QOL of at-home } \\
\text { caregivers }\end{array}$ & 5.23 & 5 & 4.7 & $\begin{array}{l}\text { Based on the Nationwide Survey } \\
\text { on Dementia Care of Korea } \\
\text { (14-point scale, lower scores } \\
\text { indicate better quality of life) }\end{array}$ \\
\hline & $\begin{array}{l}\text { Cumulative number of on/offline } \\
\text { self-help groups }\end{array}$ & - & 160 & 320 & $\begin{array}{l}10 \text { per metropolitan area in } 2018 \text {, } \\
20 \text { in } 2020\end{array}$ \\
\hline $\begin{array}{l}\text { Research \& } \\
\text { Statistics }\end{array}$ & $\begin{array}{l}\text { Publication of the Dementia } \\
\text { Research and Statistics Annual } \\
\text { Report }\end{array}$ & - & Publication & - & Publish in 2017 \\
\hline
\end{tabular}

Source: National Institute of Dementia (2016)

In 2012, there were 34 regional medical centres directly under regional governments and 254 health centres accountable to municipalities. There were also 1,315 Health sub-centres and 1,895 primary healthcare posts, providing basic health services in areas without easily accessible health centres (Kwon, 2015).

\section{Current diagnostic and healthcare pathways}

The first National Dementia Plan was launched as a result of concerns about the low level of diagnosis of people with dementia: in 2008 up to $67 \%$ of people with dementia had not been diagnosed (Jo et al, 2008). This plan introduced the National Dementia Early Detection programme (NDeED), which offers all older people access to dementia screening and access post-diagnostic services (including the reimbursement of medication if this is prescribed). The NDeED programme has resulted in a substantial increase in diagnosis rates. As part of the drive to enhance awareness and timely diagnosis of dementia, a self-screening digital app "Check Dementia" has been made available, as well as a National Dementia Helpline and guidelines to help people reduce their risk of dementia (Kim, 2016).

Out of 6 million people over the age of 65,2 million people are screened for dementia. One third of them go onto the next stage and get a diagnosis at a government-run centre, and the other two thirds either do not have sufficient symptoms for a diagnosis, or go to private centres, or do not seek further help. In the end, $25 \%$ of those screened are diagnosed with dementia (Kim, 2016).

Based on data from National Health Insurance claims, the total number of people who used in/outpatient medical and pharmaceutical services for dementia treatment under the National Health Insurance was 377,901 in 2014, the total value of benefits was $\$ 912$ million (USD) (NHIS \& HIRA, 2015). 
The Dementia Counselling Centres, set up in every local Public Health Centre, provide early dementia screening. This service is financed by the National Health Promotion Fund and local government and in 2015 it was used by 52,000 people (Ministry of Health and Welfare, 2016).

People with dementia may be prescribed one of four suggested medications (Donepezil, Galantamine, Rivastigmine, Memantine) and can claim up to \$26 USD per month towards its cost, but reimbursement is subject to strict criteria which require Mini Mental State Exam or Clinical Dementia Rating scores to reach a certain level in order to receive insurance coverage. A study of the persistence in anti-dementia pharmacological treatments found that more than 3 in 4 patients discontinued therapy within one year from initiation. People living in metropolitan cities had better continuation rates than those in other areas, which may reflect regional variation in treatment accessibility and clinical practice (Ahn et al, 2015).

\section{Other care and support for people with dementia and their families}

\section{Long-term care system context}

In 2008, Korea introduced a mandatory long-term care social insurance scheme, covering all older people and also younger people with particular conditions such as dementia and stroke. The long-term care insurance ( $\mathrm{LTCl}$ ) scheme is run by the National Health Insurance Scheme (NHIS), which added an additional contribution to the existing health scheme and the government provides additional funding from taxation. Eligibility is assessed by the local NHIS offices.

Initially the eligibility assessment only considered ability to perform Activities of Daily Living (ADLs), which meant that people with dementia were often not considered eligible. It was estimated that approximately $27 \%$ of people with dementia in need of care had been excluded from services under the LTCI (Ministry of Health and Welfare 2012, cited by Chon, 2014). This situation has now been addressed and there is now an additional "special grade for dementia" eligibility (Chon, 2014; Yoo, 2016). This has been enhanced by the Dementia Support Policy which aims to provide support specifically to people who have mild dementia with no or little physical impairment. Support can include day and night care, cognitive stimulation training by trained staff, and respite for caregivers (Yoo, 2016).

Those who are eligible for LTCI benefits can contract directly with provider agencies, and benefits are mostly provided in kind. The basic packages of care are set by national guidelines which define the maximum amount of benefits for each category. Residential care or nursing home care is provided by long-term care facilities, licensed nursing homes, retirement homes, and licensed residential establishments. Home care or community care includes support for ADL needs at home, bathing service, nursing care at home, and day care services. Cash benefits are only available to those in remote areas or islands where there is no formal care provision. When cash benefits are used, these are of lesser value than benefits in kind. Quality assurance is based on staff qualifications and staffing ratios. People who want to work as care workers are required to complete a 240-hour training course and pass a national qualification exam (Kwon et al, 2015).

In 2013 , over 115,000 people for whom dementia was reported as the 'primary disease' were beneficiaries of LTCI. They represented $34 \%$ of the total number of LTCI beneficiaries. Of these, 63,000 were in care homes and 52,000 received home care benefits, representing, respectively, $50 \%$ and $25 \%$ of the total number of beneficiaries (data from the NHIS, provided by the National Institute of Dementia, 2016).

\section{Other care and support}

Family caregivers provide much care and support for people with dementia. Data from a 2010 survey shows that people with dementia received on average 299 minutes per day of care from unpaid family caregivers, and it was estimated that the yearly opportunity cost of that care per person amounted to US $\$ 3,076$ on average (Kim et al, 2011).

As well as health and long-term care services, since 2013 there has been a National Dementia Helpline, open 24 hours a day, that provides information on the availability of practical support, as well as giving emotional support. Approximately $20 \%$ of people who call the helpline ask for advice on providing care and seek emotional support. People can approach the National Dementia Helpline via its online presence or through a mobile phone app 'Companion' (Kim, 2016). In 2015 the Helpline received nearly 55,000 calls and its budget for 2016 amounts to US $\$ 1.24$ million (Ministry of Health and Welfare, 2015).

The National Dementia Plans have also involved efforts to create dementia friendly communities and increase awareness, including a campaign to encourage people to become "Dementia Partners", which involves watching a 30-minute online video and completing a quiz (Kim, 2016).

\section{Challenges that need to be addressed}

The Republic of Korea has made important commitments to improve the quality of life of people with dementia and address their care, treatment and support needs, through the development of national dementia policy, ensuring universal coverage for both 
Table 6.2

Expenditure on LTC insurance by beneficiaries with dementia, in KRW million

\begin{tabular}{|l|l|r|r|r|r|r|}
\hline \multicolumn{2}{|c|}{} & \multicolumn{1}{|c|}{2010} & \multicolumn{1}{c|}{2011} & \multicolumn{1}{c|}{2012} & \multicolumn{1}{c|}{2013} & $\begin{array}{l}\text { Annual } \\
\text { increase rate }\end{array}$ \\
\hline \multirow{3}{*}{$\begin{array}{l}\text { Beneficiaries } \\
\text { with dementia }\end{array}$} & Amount paid by beneficiaries & 111,498 & 139,939 & 158,843 & 189,651 & \\
\cline { 2 - 7 } & Amount paid by insurer & 758,121 & 915,792 & $1,008,834$ & $1,266,841$ & $18.80 \%$ \\
\cline { 2 - 6 } & Total & 869,619 & $1,055,731$ & $1,167,677$ & $1,456,492$ & \\
\hline
\end{tabular}

Source: National Assembly Budget Office. Status and Improvement of the Dementia Management. 2014.

health and social care, and ensuring that the needs of people with dementia were considered in the LTIC eligibility criteria. The routine collection of data provides an opportunity to monitor the degree to which needs are being met and inform future policies.

The current dominance of fee-for-service payments for healthcare and lack of a gate-keeping role for primary care providers is resulting in incentives for mostly private providers to induce demand for care that may not be necessary or cost-effective, and in people being exposed to large out-of-pocket payments. To ensure the sustainability of the National Health Insurance System, it has been argued that it necessary to consider a stronger gate-keeping role for primary care and increase the role of prospective payment and capitation (Kwon et al, 2015). These authors also highlight the need for better coordination between health and social care, and the persistence of health inequalities between different socioeconomic groups, rural and urban areas and between genders (Kwon et al, 2015).

With respect to long-term care, it may be necessary to strengthen the regulatory and monitoring systems, which are considered to be inadequate, as they allow opportunistic and sometimes illegal behaviour by service providers and the provision of care of poor quality (Chon, 2014).

It is also recognised that the support of people with dementia in long-term care facilities requires a better management system and improved professional education (Yoo, 2016).

\subsection{Dementia care in Switzerland}

Switzerland, officially known as the Swiss Confederation, is a federal republic organised in three levels of government: the federal (confederation) level, 26 cantons and 2352 municipalities. Switzerland's political system has been described as being the closest in the world to a direct democracy, as almost all important issues are decided through public referendum (De Pietro, 2015). Most of the country is occupied by the Alps and the majority of its 8 million population live on the Swiss plateau.
In 2015 the Swiss economy generated a GDP of about $\$ 482$ billion (current PPP), with the third highest percapita income in Europe of $\$ 58,600$. More than 70 percent of its income originates in the services sector, which employs an even higher share of the workforce.

Switzerland is one of the countries with the most equal income distribution (Gini-coefficient of household incomes of 28.7 in 2012) and unemployment is low, at 3.3 percent. Switzerland is highly dependent on international trade and since the financial crisis of 2008 has seen slow growth, in line with its European neighbours. This has led to stagnant per-capita income in recent years. The country is in a favourable public finance situation with a public debt to GDP ratio of 33 percent (2015 estimate) and a small budget surplus (CIA, 2016).

\section{Demographic and prevalence data}

Although there have been several epidemiological studies that recruited representative samples of the general population, none of these was purposely designed to estimate the prevalence and incidence of dementia and its impact. Therefore, there are at present no national estimates of the prevalence of dementia in Switzerland. However, based on data from similar countries and on national demographic data and projections, the World Alzheimer Report 2015 estimated that in 2015 there were just under 134,000 people with dementia in Switzerland. By 2030 the number of people is expected to rise to 194,000 (see Figure 6.7).

Data on standardised death rates (SDR) for Switzerland show that dementia is likely to be an increasingly important cause of death. Between 1995 and 2012, the SDR for dementia almost doubled for women (from 17.6 to $33.9 \%$ ) and increased by $72 \%$ for men (from 16.7 to $28.7 \%$ ). This large increase is likely to be due to a combination of changes in coding, proportional reductions in mortality for other causes (such as cardiovascular diseases), as well as increases in the numbers of people who receive a diagnosis of dementia (De Pietro, 2015). 
Figure 6.7

Estimated numbers of people with dementia, Switzerland

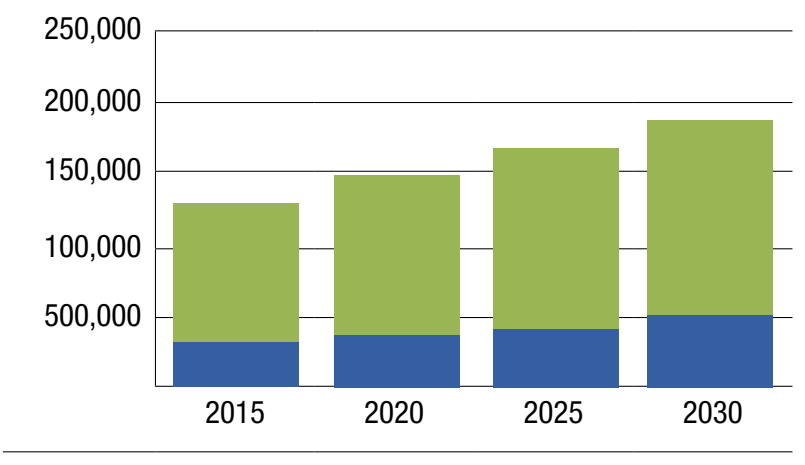

Men Women

Source: World Alzheimer Report 2015 estimates

\section{Policy landscape and healthcare system context}

Policy-making in Switzerland is carried out in consultation between the federal government, the cantons, representatives of insurers and providers, and public participation. In this context, the National Dialogue on Health Policy has developed several specific national strategic planning documents, often related to a wider Health2020 strategy. One of these strategic planning documents was the National Dementia Strategy for 2014-2017, which was approved by the National Health Policy Dialogue at the end of 2013 (FOPH, 2014). Its overarching objectives are: the improvement of dementia awareness and information, the development of dementia-appropriate services (including improvements in diagnostic and care coordination), improved quality of care (through the development of care guidelines and development of dementia-specific skills among all involved in the care of people with dementia, and the social and health workforce at large), monitoring activities of existing programmes and of the implementation of the national strategy at a cantonal level; and improved availability of comparable data and research so that future dementia care planning can be based on evidence.

\section{Costs associated with dementia}

The societal costs of dementia in Switzerland were estimated to be 6.9 billion \$US in 2009. The highest percentage of costs was for care home expenditure (48.1\%), followed by unpaid care $(43.5 \%)$, home care (known as Spitex, 5.0\%), hospital costs (2.5\%), general practitioner (GP) visits $(0.4 \%)$, anti-dementia medication (0.4\%) and memory clinics $(0.2 \%)$ (ECOPLAN 2010, Kraft et al, 2010). Based on these estimates, the average direct healthcare costs per person with dementia living at home (including hospital inpatient stays, GP and specialist visits, anti-dementia medication and memory clinic inputs) was 3,644 \$US per year in 2009. This figure is likely to be higher now, as at the time of the report it was estimated that only about a third of those affected in the older population had a diagnosis, whereas more recent reports suggest that the proportion may now be higher, as there has been an increase in the number (and capacity) of memory clinics (ECOPLAN, 2013).

\section{Health system context}

Since 1996 everyone in Switzerland has access to healthcare through the Mandatory Health Insurance (MHI) system. The insurers who take part in the $\mathrm{MHI}$ system cannot refuse to insure individuals, and the cantons subsidise people who otherwise could not afford the insurance premiums. The premiums are community-rated and usually determined at canton level and cannot take account of the person's age, gender, income or health conditions. The benefits are regulated by the federal government and include most GP and specialist services, inpatient care and other services prescribed by a physician. MHI companies offer types of policy, which differ according to the amounts that people have to pay before the coverage kicks in (the deductible), and the degree they are able to choose their providers. In recent years there has been an increase in the policies that restrict the choice of providers (managed-care style), reaching 60\% in 2013 (De Pietro, 2015).

Expenditure on health in Switzerland is among the highest in Europe; in 2013 it amounted to $11.5 \%$ of GDP (US\$ 6,187, measured in PPP), although, unlike in other countries, this includes a large proportion of long-term care costs. Out-of-pocket expenditure is also high compared to other European countries, at 26\% (De Pietro, 2015).

The Swiss healthcare system gives people access to any physician or hospital directly (there is no gatekeeping role by GPs) and most ambulatory care is provided by self-employed physicians. However, the growth in plans that restrict access to physicians (and that involve gatekeeping and often care coordination by a GP) has also resulted in an increase in physicians that form part of physician networks and health maintenance organisations (HMOs) (De Pietro, 2015).

\section{Current diagnostic and healthcare pathways}

The Swiss Alzheimer's Association maintains that less than $50 \%$ of people with dementia are diagnosed, with the main barriers to diagnosis being identified as societal (lack of awareness, denial, stigma) and professional, including lack of GP training and expertise (Alzheimer Europe, 2013).

In Switzerland dementia can be diagnosed by GPs or by specialist doctors. GPs are likely to refer more complex cases to memory clinics or multi-disciplinary teams, but people are also able to self-refer to memory clinics and specialists (Alzheimer Europe, 2014). Nevertheless, most people with dementia symptoms 
are usually diagnosed by a general practitioner $(\mathrm{FOPH}$, 2014).

The frequency of visits after a diagnosis of dementia is at the discretion of the doctor responsible for the first diagnosis. Moreover, anti-dementia drugs are routinely prescribed and reimbursed, but they tend to be discontinued once people fall below a certain MMSE score, which is used to inform clinical decisions and as a marker of lack of response to the symptomatic treatments, despite the absence of the validity of any such MMSE threshold (Alzheimer Europe, 2014). In addition, the reimbursement rules are that $A C h E l s$ can be prescribed until the MMSE score is equal to or greater of 10 points (out of 30), and memantine can be prescribed (and reimbursed) to people with MMSE scores between 3 and 19 (ECOPLAN, 2010).

Among people in care and nursing homes, two surveys covering different cantons found that just over $40 \%$ of residents had dementia (47\% in Bartelt, 2012 and 41\% in Curt et al, 2012). However, both studies also found that a much higher percentage of residents, $68 \%$ and 82\% (Bartelt 2012 and Curt et al, 2012 respectively) had significant cognitive impairment that was compatible with dementia or mild cognitive impairment.

The Bartelt (2012) study, which gathered data on over 26,500 residents in 386 homes in 14 cantons, also collected information on the use of selected drugs. Compared to residents without a diagnosis of dementia, residents with dementia were more likely to have been prescribed anti-psychotics (44\% compared to $20 \%$ ) and slightly more likely to have been prescribed anti-depressants ( $46 \%$ compared to $41 \%)$. In contrast, they were less likely to have been prescribed pain-relief medications (32\% compared to $36 \%$ for milder pain killers, $9 \%$ compared to $12 \%$ for stronger pain relief). Further, of those who had been prescribed anti-psychotics, $29 \%$ were still taking them six months later, suggesting inappropriate long-term use, given the association with risk of major cerebrovascular events and mortality.

Despite the comprehensiveness and overall good quality of the existing national strategy/plan (above), there is at present no systematic, standardised approach to the care of people with dementia, neither are there consistent mechanisms for people with dementia and their families to access information about sources of care and support. The availability of services varies widely across the country and within cantons. People may find information from the GP or specialist, social workers, sickness funds, counselling services. In this context, the Alzheimer's Association plays a key role in helping people navigate the system and in supporting their ongoing needs (Alzheimer Europe, 2014). The Swiss Network of memory clinics provides the standards for the inpatient and outpatient services concerning diagnostic procedures and standards, and the minimum requirements of the service that needs to encompass medical specialists (geriatricians, old age psychiatrists or neurologists) and neuropsychologists. However, no standard recommendations for long-term care standards exist at present at a national level, and memory clinics are mainly responsible for diagnosis and treatment/drugs prescription.

\section{Other care and support for people with dementia and their families}

The $\mathrm{MHI}$ covers some of the costs of long-term care, when this is prescribed by a physician and after a needs assessment. Care can be provided at a nursing home or by home care services (known as Spitex). The amount that $\mathrm{MHI}$ covers depends on the severity of the needs, as determined by the needs assessment. The non-medical costs of care (social and recreational services) and hotel costs are not covered by the $\mathrm{MHI}$. For institutional care, households pay about $37 \%$ of costs, the $\mathrm{MHI}$ covers about $18 \%$ and the old-age and disability insurance also covers about $17 \%$. The remainder is funded by the cantons, municipalities, other social insurance or other private sources (De Pietro, 2015).

Cantons are formally responsible for the organisation of long-term care but this is usually delegated to the municipalities. Institutional care is usually provided in nursing homes or nursing departments of oldage or disability homes, while home care nursing services are provided by the "Spitex" services. Family carers provide large amounts of care, and there is considerable use of paid informal care provided by migrant workers (van Holten, Jähnke \& Bischofberger, 2013, cited in De Pietro, 2015).

A survey of the Swiss Alzheimer's Association found that approximately $50 \%$ of people with dementia live at home, and the other half in care homes. They interviewed people living at home who are in touch with services and found that, of those, over $50 \%$ attend day care (63\% men, $49 \%$ women), $55 \%$ use home care services provided by Spitex (women 66\%, men $49 \%$ ), about $25 \%$ of people with dementia have stayed in care homes for short periods of time and $17 \%$ have used specialised information services (ECOPLAN, 2013). The majority of people who receive Spitex home care services also have care from a family (usually unpaid) caregiver.

There is no national system of financial benefits for unpaid family carers, but several cantons and municipalities have introduced certain daily or monthly payments for caring relatives. Some cantons have formalised family care by employing relatives through Spitex providers. Also, family carers can claim pension benefits if their pension fund contributions have been lowered because of caregiving (De Pietro, 2015). 
The Swiss Alzheimer's Association and other (private and public) service providers offer a wide range of services for people with dementia and their family caregivers. The services include day care services, self-help groups for people with dementia, counselling services and Alzheimer cafés. They also offer support and respite for family caregivers and dementia-friendly holidays for people with dementia and their caregivers. The Alzheimer's Association has also embarked on a project to create dementia friendly communities which is starting to deliver more innovative services which are tailored to the possibilities of the different villages (Swiss Alzheimer's Association, 2016).

\section{Challenges that need to be addressed}

Switzerland has a well-established health service which guarantees access to care for the entire population, and there is general satisfaction with the level and quality of care (De Pietro, 2015). Based on the arguments made by the Alzheimer's Association of Switzerland (2016) and De Pietro (2015), the following should be addressed to better meet the needs of people with dementia and caregivers:

- Improved awareness of dementia, to ensure that people and professionals understand the difference between dementia and normal ageing.

- Improvement in the coordination of existing services.

- Development of dementia-specific pathways in hospitals.

- Improved access to support in the early stages of dementia and development of consistent postdiagnostic support. Many of the benefits from the $\mathrm{MHI}$ are only triggered when people reach high levels of physical dependency.

- People with dementia and their family caregivers are exposed to high out of pocket costs, particularly where people spend a long time in nursing homes. Family caregivers who give up their jobs to provide care are also exposed to financial risks in later life.

- A nationwide epidemiological study should be conducted to determine dementia prevalence, incidence and to quantify its burden, including costs and caregivers' health and social circumstances. Epidemiological data are crucial to inform health services organisation, improve quality, standardisation, and comprehensiveness of care, and reduce direct and indirect costs of dementia through better and sustainable investments in the health and social sectors.

- Consideration of the potential for improving efficiency of the healthcare system. Current health expenditure is already relatively high and the system will need to prepare to meet the needs of larger numbers of people with dementia and other chronic conditions, in the coming decades.

\section{References}

Ahn S-H, Choi N-K, Kim Y-J, Seong J-M, Shin J-y, Jung S-Y, Park B-J (2015) Drug persistency of cholinesterase inhibitors for patients with dementia of Alzheimer type in Korea. Archives of Pharmacological Research 38:1255-1262.

Alzheimer Europe (2013) Dementia in Europe Yearbook 2013 http:// www.alzheimer-europe.org/Publications/Dementia-in-EuropeYearbooks [accessed 22 August 2016].

Alzheimer Europe (2014) National care pathways for people with dementia living at home. Dementia in Europe Yearbook $2014 \mathrm{http} / /$ www.alzheimer-europe.org/Publications/Dementia-in-EuropeYearbooks [accessed 22 August 2016]

Alzheimer Society of Canada (2015) The Canadian Alzheimer's Disease and Dementia Partnership: Strategic Objectives - A collective vision for a national dementia strategy for Canada Toronto, Alzheimer Society of Canada. [accessed 11 $11^{\text {th }}$ August 2016].

Alzheimer Society of Canada (2016) Prevalence and Monetary Costs of Dementia in Canada. Toronto, Alzheimer Society of Canada. http://www. alzheimer.ca/ /media/Files/national/Statistics/prevalence_summary_e. pdf [accessed 9th August 2016].

Alzheimer's Indonesia (2016) Personal communication.

Aminzadeh F, Molnar FJ, Dalziel WB, Ayotte D. A Review of Barriers and Enablers to Diagnosis and Management of Persons with Dementia in Primary Care. Can Geriatr J 2012; 15: 85-94.

Angel JL, Angel RJ, López-Ortega M, Gutiérrez Robledo LM, Wallace RB (2016) Institutional Context of Family Eldercare in Mexico and the United States. Journal of Cross-Cultural Gerontology, 31(3): 327-336.

Bartelt G (2012) Auswertung von RAl-Daten im Aufrag der Schweizerischen Alzheimervereiningung. Technischer Bericht. St Gallen, Q-Sys AG.

Bartfay E, Bartfay WJ and Gorey KM (2016) Dementia care in Ontario, Canada: evidence of more timely diagnosis among persons with dementia receiving care at home compared with residential facilities. Public Health 130: 6-12.

Batsch N. (2015) What I learned about dementia care in Indonesia. https://www.linkedin.com/pulse/what-i-learned-dementia-careindonesia-nicole-batsch (accessed 4 August 2016).

Benade S (2012) Support services for people suffering from dementia in the rural areas of Kwa-Zulu

Natal, South Africa. Dementia 11(2): 275-277.

Bongani MM and Benatar SR (2014) Health and Health Care in South Africa - 20 Years after Mandela. New England Journal of Medicine. 371(14): 1344-1353.

Chen S, Boyle LL, Conwell Y, Chiu H, Li L, and Xiao S. (2013). Dementia care in rural China. Mental health in family medicine, 10(3): 133-141.

China Joint Study Partnership (2016) Deepening Health Reform In China Building High-Quality And Value-Based Service Delivery. Washington DC, World Bank.

Choi, M et al. (2009) Nationwide Study on the Prevalence of Dementia in Korean elders 2008: a final report to Ministry of Health and welfare, Seoul National University Hospital

Chon Y (2014) The Expansion of the Korean Welfare State and Its Results - Focusing on Long-term Care Insurance for the Elderly. Social Policy \& Administration 48 (6): 704-72.

CIA (2016) World Factbook https://www.cia.gov/library/publications/theworld-factbook/geos/sz.html [accessed 21 August 2016].

Conn DK, Madan R, Lam J, Patterson T and Skirten S (2013) Program evaluation of a telepsychiatry service for older adults connecting a university-affiliated geriatric center to a rural psychogeriatric outreach service in Northwest Ontario, Canada. International Psychogeriatrics, 25 : 1795-1800.

Curt L, Berthou A, Rey J-C, Laurent A (2012) Analyse des demences de type Alzheimer dans la base de donnees PLAISIR de Mai 2012 (Cantons de Geneve, Jura, Neuchatel et Vaud). Rapport a l'attention de l'Association Alzheimer Suisse. Lausanne, Institute de Sante et d'Economie.

De Jager CA. Joska, JA, Hoffman M, Borochowitz KE, Combrinck MI (2015) Dementia in rural South Africa: A pressing need for epidemiological studies. South African Medical Journal 105(3): 189-190. De Pietro C, Camenzind P, Sturny I, Crivelli L, Edwards-Garavoglia S, Spranger A, Wittenbecher F, Quentin W. (2015) Switzerland: Health system review. Health Systems in Transition. 17(4):1-288.

ECOPLAN (2010) Kosten der Demenz in der Schweiz. Schlussbericht im Auftrag der Schweizerischen Alzheimervereinigung. Bern, ECOPLAN. ECOPLAN (2013) Grundlagen für eine Nationale Demenzstrategie. Demenz in der Schweiz: Ausgangslage. Bern, ECOPLAN.

Feng Z, Zhan HJ, Feng X, Liu C, Sun M, and Mor V (2011). An industry in the making: The emergence of institutional elder care in urban China. Journal of the American Geriatrics Society, 59(4): 738-744. 
Feng Z, Liu C, Guan X and Mor V (2012) China's rapidly aging population creates policy challenges in shaping $A$ viable long-term care system. Health Affairs, 31(12): 2764-73.

FOPH (2016) National Dementia Strategy http://www.bag.admin.ch/ themen/gesundheitspolitik/13916/index.html?lang=en [accessed 22 August 2016].

Fu R, Wang Y, Bao H, Wang Z, Li Y, et al. (2014) Trend of Urban-Rural Disparities in Hospital Admissions and Medical Expenditure in China from 2003 to 2011. PLOS ONE 9(9): e108571.

Gauthier S, Patterson C, Chertkow H, Gordon M, Herrmann N, Rockwood K, Rosa-Neto P, Soucy JP on behalf of the CCCDTD4 participants (2012) 4th Canadian Consensus Conference on the Diagnosis and Treatment of Dementia. Can. J Neurol Sci 2012:39; Suppl 5: S1-S8.

Gutiérrez Robledo LM, López-Ortega M, Arango Lopera VE (2012) The state of elder care in Mexico. Current Translational Geriatrics and Gerontology Reports, 1:183-189. DOI 10.1007/s13670-012-0028-z.

Gutiérrez Robledo LM and Arrieta-Cruz I. (2015) Dementia in Mexico: The need for a National Alzheimer's Plan. Gaceta Medica de Mexico 151:620625.

Health e-news (2015) White paper: National Health Insurance for South Africa https://www.health-e.org.za/2015/12/14/white-paper-nationalhealth-insurance-for-south-africa/ [accessed 16 August 2016].

Hsiao HY, Liu Z, Xu L, Huang Y and Chi I (2015). Knowledge, Attitudes, and Clinical Practices for Patients With Dementia Among Mental Health Providers in China: City and Town Differences. Gerontology and Geriatrics Education, 1-17.

Instituto Nacional de Estadistica y Geografia, INEGI. 2015. Encuesta Intercensal (2015). Panorama sociodemográfico de México 2015. Mexico: Instituto Nacional de Estadística y Geografía. Available at:http:// internet.contenidos.inegi.org.mx/contenidos/productos//prod_serv/ contenidos/espanol/bvinegi/productos/nueva_estruc/702825078065.pdf Instituto Nacional de Geriatría. (2014). Plan de acción Alzheimer y otras demencias. México. 2014. México: Instituto Nacional de Geriatría, Secretaría de Salud.

International Labour office. Geneva. (2014) World social protection report: building economic recovery, inclusive development and social justice (2014/2015) retrieved from http://www.ilo.org/wcmsp5/groups/ public/---dgreports/---dcomm/documents/publication/wcms_245201. pdf [accessed 18 August 2018].

Jia, J., Zuo, X., Jia, X. F., Chu, C., Wu, L., Zhou, A., et al. (2016). Diagnosis and treatment of dementia in neurology outpatient departments of general hospitals in China. Alzheimer's \& Dementia 12(4): 446-453.

Jo MJ, Kim KW, Kim MH, Kim MD, Kim BJ, Kim SK, Kim JL, Moon SW (2008) National study on the prevalence of dementia in Korean elders. Seoul National University Hospital, Ministry of Health and Welfare, Korea.

Jobson M (2015) Structure of the healty system in South-Africa Khulumani support group http://www.khulumani.net/active-citizens/ item/1164-the-health-system-in-south-africa-actions-to-secure-theright-to-health-in-south-africa.html [accessed 16 August 2016]

Juarez-Cedillo T, Jarillo-Soto EC and Rosas-Carrasco O (2014). Social Representation of Dementia and Its Influence on the Search for Early Care by Family Member Caregiver. American Journal of Alzheimer's Disease \& Other Dementias, 29(4) 344-353.

Kalula SK, Ferreira M, Thomas KGF, De Villiers L, Joska JA, Geffen LN (2010) Profile and management of patients at a memory clinic. South African Medical Journal 100(7): 449-451.

Kalula SK and Petros G. (2011) Responses to dementia in less developed countries with a focus on South Africa. Global Aging 7(1):3140.

Keogh-Brown MR, Jensen HT, Arrighi HM, Smith RG (2016) The impact of Alzheimer's disease on the Chinese economy. EBioMedicine. 4:184-190.

Khonje V, Milligan C, Yako Y, Mabelane M, Borochowitz KE and de Jager CA (2015) Knowledge,

Attitudes and Beliefs about Dementia in an Urban Xhosa-Speaking Community in South Africa. Advances in Alzheimer's Disease, 4: 21-36. Kim, K. Kwak, K. Kim, M et al 32. (2011) A study on Dementia elderly: a final report to Ministry of Health and welfare, Seoul National University Bundang Hospital.

Kim K (2016) An overview of the Third National Dementia plan of Korea. In Banerjee S, Farina N, Hughes L, Kim K, Sim E (eds) UK-Korea Initiative: Optimizing the Impacts of National Dementia Strategies. Available from https://www.bsms.ac.uk/_pdf/cds/korea-presentations/ optimizing-the-impacts-of-national-dementia-strategies-uk-finalsubmitted-25-4-16.pdf [accessed August 2016].

Kraft E, Marti M, Werner S, Sommer H (2010) Cost of dementia in Switzerland. Swiss Medical Weekly 140:w13093.

Kwon S, Lee T-J, Kim C-Y (2015) Republic of Korea Health System
Review. Health Systems in Transition, 5 (4), Asia Pacific Observatory on Public Health Systems and Policies.

Li M, Zhang Y, Zhang Z, Zhang Y, Zhou L, Chen K (2013) Rural-Urban Differences in the Long-Term Care of the Disabled Elderly in China. PLOS (ONE).8(11) e79955.

Liang $L$ and Langenbrunner JC (2013) The long march to universal coverage: lessons from China. Washington, DC: The World Bank.

Liu Z, Albanese E, Li S, Huang Y, Ferri CP, Yan F, Sousa R, Dang W and Prince M (2009) Chronic disease prevalence and care among the elderly in urban and rural Beijing, China - a 10/66 Dementia Research Group cross-sectional survey. BMC Public Health, 9:394.

Liu Z (2013) Economic Costs of Dementia in Low and Middle Income Countries. London: King's College. https://kclpure.kcl.ac.uk/portal/ en/theses/economic-costs-of-dementia-in-low-and-middle-incomecountries(9d90e06c-022d-4db0-a877-e84f859531e4).html [accessed $14^{\text {th }}$ August 2016].

Llibre Rodríguez JJ, Ferri CP y Acosta D et al. (2008) Prevalence of dementia in Latin America, India, and China: a population-based crosssectional survey. Lancet, 372:464-74.

Lopez-Ortega M (2016). Personal communication.

Lund C, Kleintjes S, Campbell-Hall V, Mjadu S, Petersen I, Bhana A

Kakuma R, Mlanjeni B, Bird P, Drew N, Faydi E, Funk M, Green A,

Omar M, and Flisher AJ. (2008). Mental health policy development and implementation in South Africa: a situation analysis. Phase 1 Country report. Cape Town: Mental Health and Poverty Project.

Manrique-Espinoza B, Salinas-Rodríguez A, Moreno-Tamayo KM, Acosta-Castillo I, Sosa-Ortiz AL, Gutiérrez-Robledo LM, Téllez-Rojo MM. (2013). Condiciones de salud y estado funcional de los adultos mayores en México. Salud Publica Mex, 55(supl 2), S323-S331.

Marchildon G (2013) Canada: Health system review. Health Systems in Transition, 2013; 15(1): 1 - 179.

Mboi, N. (2015) Indonesia: On the Way to Universal Health Care, Health Systems \& Reform, 1:2, 91-97.

Mejia-Arango $S$ and Gutierrez-Ortega LM (2011). Prevalence and Incidence Rates of Dementia and Cognitive Impairment No Dementia in the Mexican Population: Data from the Mexican Health and Aging Study. Journal of Aging and Health, 23(7), 1050-1074.

Meng Q, Fang H, Liu X, Yuan B and Xu J (2015) Consolidating the socia health insurance schemes in China: towards an equitable and efficient health system. The Lancet. 386: 1484-92.

Ministry for Welfare and Population Development. (1997). White Paper For Social Welfare. In D.o. Welfare (Ed.). Pretoria.

Ministry of Health and Welfare. (2013) Official Release of Study on dementia prevalence 2012. Republic of Korea.

Ministry of Health and Welfare. (2015) Budget and Fund Management Plan for 2016. Republic of Korea.

Ministry of Health and Welfare. (2016) Elderly health \& welfare Services guide 2016. Republic of Korea.

Ministry of Human Resources and Social Security of the P.R.C. 2001-13. 人力资源和社会保障事业发展统计公报 [Annual Statistical Bulletins on Human Resources and Social Security Development] (Beijing). http://www.mohrss.gov.cn/SYrlzyhshbzb/dongtaixinwen/ buneiyaowen/201405/t20140528_131110.htm [accessed 18 August 2016].

Moore A, Patterson C, Lee L, Vedel I and Bergman H (2014) Fourth Canadian Consensus Conference on the Diagnosis and Treatment of Dementia: Recommendations for family physicians. Canadian Family Physician 60(5): 433-438.

Morgan DG, Kosteniuk JG, Norma J. Stewart EO, O'Connell ME, Kirk A, Crossley M, Dal Bello-Haas

V, Forbes D and Innes A (2015) Availability and Primary Health Care Orientation of Dementia-Related Services in Rural Saskatchewan, Canada, Home Health Care Services Quarterly, 34:3-4, 137-158.

Mould-Quevedo J F, Tang B, Harary E, Kurzman R, Pan S, Yang J, and Qiao J (2013). The burden of caring for dementia patients: caregiver reports from a cross-sectional hospital-based study in China. Expert Review of Pharmacoeconomics and Outcomes Research, 13(5), 663673.

National Bureau of Statistics of China. (2012, March 29). China Statistical Yearbook 2010. Retrieved from www.stats.gov.cn/tjsj/ ndsj/2010/indexeh.htm.

National Health Insurance Service. Health Insurance Review \& Assessment Service. (2015) National Health Insurance Statistical Yearbook 2014.

National Institute of Dementia (2016) Personal Communication O'Connell M, Crossley M, Cammer A, Morgan D, Allingham W, Cheavins B, Dalziel D, Lemire M, Mitchell S and Morgan E (2014) Development and evaluation of a telehealth video-conferenced support group for rura spouses of individuals diagnosed with atypical early-onset dementias. Dementia 13(3): 382-395. 
OECD (2015) OECD Economic Surveys: Mexico, January 2015. OECD Publishing, Paris.

OECD (2016) OECD Reviews of Health Systems: Mexico 2016, OECD Publishing, Paris.

Parmar J, Dobbs B, McKay R, Kirwan C, Cooper T, Marin A and Gupta $\mathrm{N}$ (2014) Diagnosis and management of dementia in primary care Exploratory study. Canadian Family Physician 60(5): 457-465.

Patel V, Xiao S, Chen H, Hanna F, Jotheeswaran AT, Luo D, Parikh R, Sharma E, Usmani S, Yu Y, Druss BG and Saxena S (2016) The magnitude of and health system responses to the mental health treatment gap in adults in India and China. The Lancet [Available online May 2016].

Priebe, J. and F. Howell (2014). Old-age poverty in Indonesia: Empirical evidence and policy options - A role for social pensions. TNP2K Working Paper 07-2014. Tim Nasional Percepatan Penanggulangan Kemiskinan (TNP2K), Jakarta, Indonesia.

Prince M, Livingston G and Katona C. (2007). Mental healthcare for the elderly in low-income countries: A health systems approach. World Psychiatry, 6(1): 5-13.

Prince MJ, Acosta D, y Ferri CP, et al. (2012). Dementia incidence and mortality in middle-income countries, and associations with indicators of cognitive reserve: a 10/66 Dementia Research Group population-based cohort study. Lancet, 380:50-8.

Prince M, Wimo A, Guerchet M, Ali G-C, Wu Y-T, Prina M (2015) The Global Impact of Dementia: An analysis of prevalence, incidence, cost and trends. World Alzheimer Report 2015, Alzheimer's Disease International, London.

Public Health Agency of Canada (2014) Mapping Connections: An Understanding of Neurological Conditions in Canada - The National Population Health Study of Neurological Conditions. Ottawa. Public Health Agency of Canada. Available at: http://www.phac-aspc.gc.ca/ publicat/cd-mc/mc-ec/index-eng.php [Accessed May 2016].

Rispel $L$ (2016) Analysing the progress and fault lines of health sector transformation in South Africa. In: Padarath A, King J, Mackie E Casciola J, editors. South African Health Review 2016. Durban: Health Systems Trust. http://www.hst.org.za/publications/south-african-healthreview-2016 [accessed 16 August 2016].

Robertson R, Gregory S and Jabbal J (2014) The social care and health systems of nine countries. London, The King's Fund.

Rosow K, Holzapfel A, Karlawish JH, Baumgart M, Bain LJ and Khachaturian AS (2011) Countrywide Strategic Plans on Alzheimer's disease: Developing the framework for the international battle against Alzheimer's disease. Alzheimer's \& Dementia 7(6): 615-621.

Scheil-Adlung X. (2015) Long-term care protection for older persons: review of coverage deficits in 46 countries. International Labour Office, Geneva.

Schröder-Butterfill E and Fithry TS. (2014) Care dependence in old age: preferences, practices and implications in two Indonesian communities. Ageing and Society no. 34 (3):361-387.

Servan-Mori E, Torres-Pereda P, Orozco E, Sosa-Rubi SG. (2014). An explanatory analysis of economic and health inequality changes among Mexican indigenous people, 2000-2010. International Journal for Equity in Health. 13:21.

Sim (2016) The challenge of metropolitan/provincial dementia centres of Korea. In Banerjee S, Farina N, Hughes L, Kim K, Sim E (eds) UKKorea Initiative: Optimizing the Impacts of National Dementia Strategies. Available from https://www.bsms.ac.uk/_pdf/cds/korea-presentations/ optimizing-the-impacts-of-national-dementia-strategies-uk-finalsubmitted-25-4-16.pdf [accessed August 2016].

Statistics South Africa (2014a). Census 2011: Profile of older persons in South Africa. Pretoria: Statistics South Africa.

Statistics South Africa. (2015). Mid-year population estimates. Statistical release.

Stein D (2014) A new mental health policy for South Africa, South

African Medical Journal, 104(2): 115-116.

Suh G-H, Wimo A, Gauthier S, O'Connor D, Ikeda M, Homma A

Dominguez J and Yang BM (2009) International price comparisons of

Alzheimer's drugs: a way to close the affordability gap International

Psychogeriatrics, 21:6, 1116-1126.

Swiss Alzheimer's Association (2016) personal communication.

Tam-Tham H, Nettel-Aguirre A, Silvius J, Dalziel W, Garcia L, Molnar

$F$ and Drummond N (2016) Provision of dementia-related services in Canada: a comparative study. BMC Health Services Research 16:184, 1-9.

The Conference Board of Canada (2015) Federal Policy Action to Support the Health Care Needs of Canada's Aging Population. Available at: https://www.cma.ca/Assets/assets-library/document/en/advocacy/ conference-board-rep-sept-2015-embargo-en.pdf [Accessed May 2016].

The State Council of the PRC (2015) The national five-year plan

for mental health (2015-2020). http://www.gov.cn/zhengce/ content/2015-06/18/content_9860.htm [accessed June 2016, in Chinese].

Torres Castro S, Martinez Ruiz A \& Arrieta Cruz I. (2015). Plan de Accion Alzheimer Mexico. Working Paper. Mexico: Instituto Nacional de Geriatria. Truter I (2013) Antipsychotic drug prescribing to patients with dementia in a South African patient population. African Journal of Pharmacy and Pharmacology 7(41): 2755-2762.

United Nations, Department of Economic and Social Affairs, Population Division (2015). World Population Prospects: The 2015 Revision, custom data acquired via website. http://esa.un.org/unpd/wpp/DataQuery/ (accessed 19 ${ }^{\text {th }}$ June 2016).

Wang G, Cheng Q, Zhang S, et al. (2008). Economic impact of dementia in developing countries: an evaluation of Alzheimer-type dementia in Shanghai, China. China Journal of Alzheimer's Disease, 15, 109-115.

Wang Y, Wilkinson M, Ng E, and Cheng K (2012) Primary care reform in China. The British Journal of General Practice 62(603): 546-547.

Weiyuan C (2008) China's village doctors take great strides. Bulletin of the World Health Organisation, 86(12):914-915.

WHO (2013) Mental health action plan 2013-2020. Geneva: World Health Organization.

Wong SL, Gilmour H, Ramage-Morin PL. (2016) Alzheimer's disease and other dementias in Canada. Health Reports. 27(5).

World Bank (2016) http://data.worldbank.org/about/country-andlending-groups, accessed $15^{\text {th }}$ June 2016).

Wu C, Gao L, Chen S, Dong H. (2006) Care services for elderly people with dementia in rural China: a case study. Bulletin of the World Health Organisation, 94(3):167-73.

Wu D and Lam TP. (2016) Underuse of primary care in China: The scale, causes and solutions. Journal of the American Board of Family Medicine. 29(2):240-247.

Wyk A, Manthorpe J, Clark C (2016) The behaviours dementia care home staff in South Africa find challenging: An exploratory study, Dementia, [Published Online].

Xu J, Wang W, Yongbin L, Zhang J, Pavlova M, Liu H, Yin P and Lu X (2010) Analysis of factors influencing the outpatient workload at Chinese health centres. BMC Health Services Research 10:151.

Xu H, Zhang W, Gu L, Qu Z, Sa Z, Zhang X and Tian D (2014). Aging village doctors in five counties in rural China: situation and implications. Human Resources for Health, 12(36)

Yang W, He AJ, Fang L and Mossialos E (2016) Financing institutional long-term care for the elderly in China: a policy evaluation of new models. Health Policy and Planning, first published online July 03, 2016. Yoo A (2016) Dementia support policy and the role of the Long-Term Care Insurance in Korea. In Banerjee S, Farina N, Hughes L, Kim K, Sim $\mathrm{E}$ (eds) UK-Korea Initiative: Optimizing the Impacts of National Dementia Strategies. Available from https://www.bsms.ac.uk/_pdf/cds/koreapresentations/optimizing-the-impacts-of-national-dementia-strategiesuk-final-submitted-25-4-16.pdf [accessed August 2016].

Yu H (2015) Universal health insurance coverage for 1.3 billion people: What accounts for China's success? Health Policy 119: 1145-1152.

Yu X, Chen S, Chen X, Jia J, Li C, Liu C, Toumi M and Milea D (2015) Clinical management and associated costs for moderate and severe Alzheimer's disease in urban China: a Delphi panel study. Translational Neurodegeneration 4:15.

Zou Y, Zhang X, Hao Y, Shi L and Hu R (2015) General practitioners versus other physicians in the quality of primary care: a cross-sectional study in Guangdong Province, China. BMC Family Practice 16:134. 


\section{CHAPTER 7 \\ Cost implications of the dementia healthcare pathways}

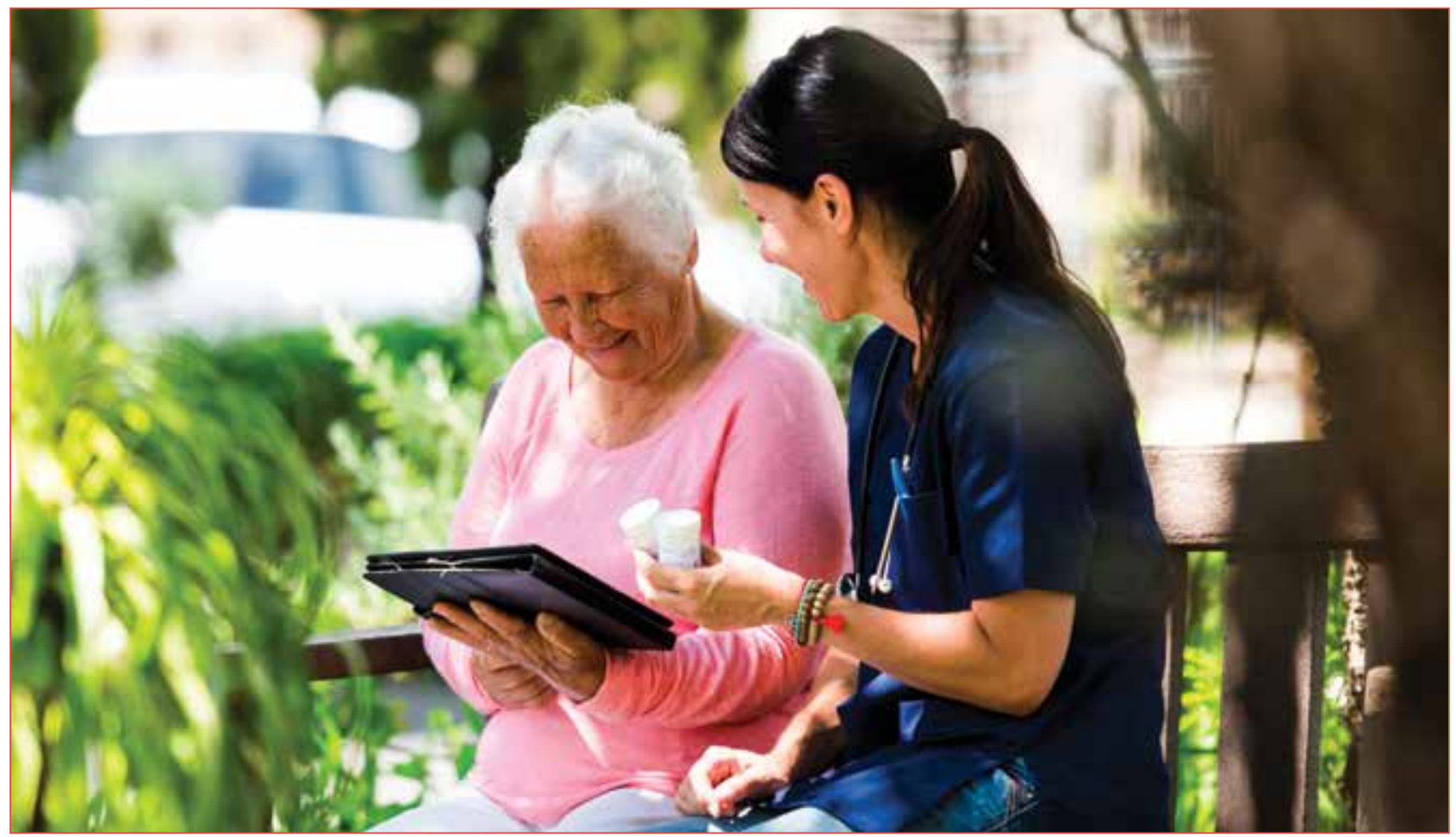

\subsection{Care pathways modelling}

\section{Introduction}

We constructed illustrative healthcare pathways for people with dementia, for the purposes of the economic modelling exercise. Of course, people with dementia use healthcare services regardless of whether or not they have received a dementia diagnosis. However, our focus was upon dementiafocused healthcare services, offered and received as a consequence of the condition having been formally identified. For high income countries, the specialist care pathways were based upon those reviewed in Chapter $1^{1,2}$, supplemented by the UK NICE-SCIE clinical guideline ${ }^{3}$. We then created an alternative 'task-shifted/task-shared' care pathway, in which many activities were designated to be carried out by primary care physicians (PCPs) or case managers (primary care nurses) instead of specialists. We were then able to estimate the annual aggregate and per capita costs under each of these assumptions, both for the current year, and also as the coverage of these services was progressively scaled up from $50 \%$ to $75 \%$ through to 2030 . For low and middle income countries, we assumed that those people managed by specialist services would follow a similar care pathway to those in HIC. Currently, we assumed that 5\% (low and lower middle income countries) to 10\% (upper middle income countries) of people with dementia have received a diagnosis, and that all of these will be diagnosed and managed through the limited available specialist healthcare sector. We then assumed that an increase in coverage, to $50 \%$ by 2030 , would be achieved through provision of evidence-based diagnosis and management provided by nonspecialist, mainly primary care services, with training and support from specialist services, where available. This care pathway was based upon the evidencebased recommendations of the WHO Mental Health Gap Action Programme ${ }^{4,5}$, and its accompanying intervention guide ${ }^{6}$.

All of the pathways were based upon the principle that continuing care would be provided to all patients, from the time of diagnosis, with regular reviews and followups. We divided the pathways into three phases; the first year post-diagnosis; a subsequent 'continuing care' phase; and an end-of-life phase in the last year before death. We estimated that, of the prevalent pool of people with dementia who had received a diagnosis, $16 \%$ would have received their diagnosis in the previous year, and $14 \%$ would be in the end-of-life phase. 


\section{Duration, frequency and intensity of care inputs, and casemix of clients}

For the purpose of costing the care pathways, we first needed to estimate the duration of care inputs, the intensity/frequency of care inputs, and the casemix of clients by which care pathways would be stratified. We generated the estimates from a survey of the Medical and Scientific Advisory Panel of Alzheimer's Disease International, and for the purposes of validity, compared these, where possible, with estimates from the literature. We received 23 responses to the survey, with 11 providing sufficiently complete data to be used to generate estimates. These responses came from practitioners working in 8 countries (Australia, United Kingdom, Greece, Netherlands, Spain, Switzerland, Turkey, USA). For the most part, estimates were fairly consistent among respondents, with a greater variance noted for BPSD admission for the assessment (number of days not minutes) and for the total duration of post-diagnostic support programme in months.

We used the mean response, or the median when the distribution of responses was significantly skewed. Response to the survey questions are summarised in Tables 7.1 to 7.3 below.

Table 7.1

Typical duration of care inputs across the care pathway

\begin{tabular}{|l|l|}
\hline & $\begin{array}{l}\text { Estimated time } \\
\text { (in minutes, if not } \\
\text { otherwise specified) }\end{array}$ \\
\hline Diagnosis & \\
\hline GP appointment triggering referral & 20 \\
\hline Memory clinic clinical assessment & 65 \\
\hline $\begin{array}{l}\text { Memory clinic neuropsychological } \\
\text { assessment }\end{array}$ & 90 \\
\hline Memory clinic neuroimaging & $\mathrm{n} / \mathrm{a}$ \\
\hline Post-diagnostic feedback ${ }^{\star *}$ & 40 \\
\hline Initial treatment & 20 \\
\hline Baseline assessment for AChEls & 30 \\
\hline Follow-up assessment for AChEls & 20 \\
\hline Continuing care & 20 \\
\hline Routine review & 25 \\
\hline $\begin{array}{l}\text { BPSD baseline comprehensive } \\
\text { assessment }\end{array}$ & 30 \\
\hline BPSD admission for assessment & 10 days \\
\hline BPSD geriatrician assessment & 20 \\
\hline BPSD management plan review & 20 \\
\hline
\end{tabular}

* In an audit survey of Australian memory clinics (2009) the total assessment time was a mean of 235 minutes $^{7}$

${ }^{* *}$ In the Australian audit the mean feedback time was 45 minutes $^{7}$
Table 7.2

Typical intensity/frequency of care inputs across the care pathway

\begin{tabular}{|c|c|}
\hline Care component & Estimated intensity of care \\
\hline \multicolumn{2}{|l|}{$\begin{array}{l}\text { Diagnosis (Immediate } \\
\text { follow-up plans after } \\
\text { initial diagnosis) }\end{array}$} \\
\hline $\begin{array}{l}\text { No significant cognitive } \\
\text { morbidity }\end{array}$ & No follow-up \\
\hline $\mathrm{MCl}$ & Every 9 months \\
\hline Uncomplicated dementia & $\begin{array}{l}\text { Post-diagnostic support } \\
\text { programme was the modal } \\
\text { response }\end{array}$ \\
\hline \multicolumn{2}{|l|}{ Initial treatment } \\
\hline AChEls or memantine $\mathrm{Rx}$ & $\begin{array}{l}\text { Baseline assessment, one review } \\
\text { on medication and six monthly } \\
\text { when stabilised }\end{array}$ \\
\hline $\begin{array}{l}\text { Average duration of } \\
\text { treatment (in months) for } \\
\text { those that start treatment } \\
\text { with AChEls or memantine }\end{array}$ & 40 months \\
\hline \multicolumn{2}{|l|}{ Continuing care } \\
\hline $\begin{array}{l}\text { Uncomplicated mild } \\
\text { dementia }\end{array}$ & Annual review \\
\hline $\begin{array}{l}\text { Uncomplicated moderate } \\
\text { or severe dementia }\end{array}$ & Every 9 months \\
\hline BPSD & $\begin{array}{l}\text { Baseline assessment } \\
\text { Repeated assessments: } 50 \% \\
3 \text { visits on average } \\
10 \% \text { would require admission for } \\
\text { assessment } \\
25 \% \text { would require referral to } \\
\text { geriatrician or physician }\end{array}$ \\
\hline
\end{tabular}

\section{High income country care pathways}

For the high income country specialist care pathway, activities in the year of diagnosis comprised: making the diagnosis; assessing eligibility for cognitive enhancer medication (acetylcholinesterase inhibitors (AChEls) or memantine), and initiating these prescriptions where appropriate; providing postdiagnostic support; offering cognitive stimulation therapy; offering caregiver education, training and support; assessing behavioural and psychological symptoms of dementia (BPSD) and providing interventions where appropriate. Continuing care would comprise: regular reviews; ongoing medication review for those taking AChEls or memantine; case management; and a pathway for the assessment and management of newly incident BPSD. Dementia severity at time of diagnosis, and among continuing 
Table 7.3

Specific questions regarding casemix

Question/care component

Estimate

\begin{tabular}{|c|c|c|}
\hline Diagnosis & & \\
\hline \multirow[t]{5}{*}{$\begin{array}{l}\text { At memory clinic presentation, what } \% \text { of clients are considered to have the following } \\
\text { conditions? * }\end{array}$} & $\begin{array}{l}\text { No relevant cognitive } \\
\text { morbidity? }\end{array}$ & $17 \%$ \\
\hline & $\mathrm{MCl}$ ? & $27 \%$ \\
\hline & Mild dementia? & $34 \%$ \\
\hline & Moderate dementia? & $16 \%$ \\
\hline & Severe dementia? & $6 \%$ \\
\hline \multirow{4}{*}{$\begin{array}{l}\text { For the current memory clinic caseload, what } \% \text { of clients are considered to have the } \\
\text { following conditions? }\end{array}$} & $\mathrm{MCl} ?$ & $26 \%$ \\
\hline & Mild dementia? & $38 \%$ \\
\hline & Moderate dementia? & $25 \%$ \\
\hline & Severe dementia? & $11 \%$ \\
\hline \multicolumn{3}{|l|}{ Initial treatment } \\
\hline $\begin{array}{l}\text { What } \% \text { of clients present (at the time of diagnosis) with significant BPSD requiring } \\
\text { further assessment/management planning? }\end{array}$ & & $20 \%$ \\
\hline $\begin{array}{l}\text { What } \% \text { of all those who receive a diagnosis of dementia are considered eligible for } \\
\text { AChEls and/or memantine? }\end{array}$ & & $70 \%$ \\
\hline $\begin{array}{l}\text { What } \% \text { of all those who are eligible for AChEls and/or memantine start treatment? } \\
\text { (treatment uptake)?** }\end{array}$ & & $80 \%$ \\
\hline \multicolumn{3}{|l|}{ Continuing care } \\
\hline \multirow{3}{*}{$\begin{array}{l}\text { In one year of FU, what } \% \text { of those with mild, moderate, and severe dementia, require } \\
\text { assessment and a management plan for new BPSD problems }\end{array}$} & Mild dementia? & $10 \%$ \\
\hline & Moderate dementia? & $30 \%$ \\
\hline & Severe dementia? & $50 \%$ \\
\hline
\end{tabular}

\section{Notes}

* For Dutch Memory Clinics audited in 2009, 59\% of referrals were diagnosed with dementia, $24 \%$ with $\mathrm{MCl}$ and $15 \%$ with no cognitive disorder ${ }^{8}$. For the Croydon Memory Service audit, of those with a diagnosis of dementia, $84 \%$ had minimal or mild dementia, $16 \%$ moderate, and $1 \%$ severe at time of diagnosis $^{9}$. For Australian Memory clinics (2009), $7 \%$ had no cognitive impairment, $20 \%$ had MCl, $69 \%$ had dementia, and $4 \%$ had no diagnosis ${ }^{7}$ ** According to the Croydon Memory Service evaluation, $48 \%$ of those considered eligible for AChEls or memantine commenced treatment ${ }^{9}$

care patients, was used to estimate the prevalence and annual incidence of BPSD. After initial assessment, it was assumed that a proportion of BPSD cases would require admission, referral to a geriatrician, intervention and follow-up. At the endof-life phase we assumed that additional palliative care assessments and services would be provided by a specialist palliative care nurse. A summary of the activities that we assumed could be shifted from specialist providers to non-specialists working at primary care level or in the community is provided in Box 7.1.

\section{Low and middle income country care pathways}

For the low and middle income countries, it was assumed that dementia healthcare would be provided by a community healthcare worker (CHW) providing outreach in the community, a case manager (CM facility-based primary care nurse) and the primary care physician (PCP). The key elements of the mhGAP guideline for dementia diagnosis and management are summarised in Box 7.2. Community case-finding by $\mathrm{CHWs}$ would be used to boost detection ${ }^{10,11}$, alongside indicated screening by PCPs of those presenting with subjective memory impairment before diagnosis was made by PCPs. It was assumed that $5 \%$ of patients would be referred to specialist services because of mhGAP 'red flags' identified at this stage (e.g. young onset, unusual presentation). Initial caregiver education, training and support would be provided by the $\mathrm{CHW}$ administering the 10/66 Dementia Research Group 'Helping Carers to Care' intervention ${ }^{12,13}$. This includes assessment of needs for care, met and unmet, family circumstances, knowledge and beliefs, and behavioural and psychological problems. The mhGAP guidelines highlight the need for assessment and management of physical comorbidity to optimise physical health. 
Box 7.1

\section{Summary of task-shifted activities for the counterfactual task-shifted/ task-shared high income country care pathway}

\begin{tabular}{|l|l|}
\hline Activity & $\begin{array}{l}\text { Task-shifting from } \\
\text { specialist care } \\
\text { providers to }\end{array}$ \\
\hline Memory clinic assessment & $\begin{array}{l}20 \% \text { PCP } \\
80 \% \text { CM }\end{array}$ \\
\hline Post diagnostic feedback & CM \\
\hline $\begin{array}{l}\text { Baseline assessment for } \\
\text { AChEls/memantine }\end{array}$ & PCP \\
\hline $\begin{array}{l}\text { Initial follow-up for AChEls/ } \\
\text { memantine }\end{array}$ & CM \\
\hline Post-diagnostic support & $\begin{array}{l}\text { Community healthcare } \\
\text { worker }\end{array}$ \\
\hline $\begin{array}{l}\text { Caregiver education, training } \\
\text { and support }\end{array}$ & $\begin{array}{l}\text { Community healthcare } \\
\text { worker }\end{array}$ \\
\hline BPSD assessment & PCP \\
\hline BPSD follow-up & $\begin{array}{l}20 \% \text { PCP } \\
80 \% \text { CM }\end{array}$ \\
\hline Case management & CM \\
\hline $\begin{array}{l}\text { Ongoing review of AChEls/ } \\
\text { memantine }\end{array}$ & $\begin{array}{l}20 \% \text { PCP } \\
80 \% \text { CM }\end{array}$ \\
\hline Regular reviews & $\begin{array}{l}20 \% \text { PCP } \\
80 \% \text { CM }\end{array}$ \\
\hline
\end{tabular}

PCP = Primary Care Physician

$\mathrm{CM}=$ Case Manager

(primary care practice nurse)

We assumed that this would be provided by the $\mathrm{CHW}$ through the forthcoming WHO Integrated Care for Older People (I-COPE) guideline for the assessment and management of physical comorbidity by the $\mathrm{CHW}$, with referral pathways back to the $\mathrm{PCP}^{14}$. Postdiagnostic support would be provided by the CHW. Cognitive stimulation would be provided by caregivers, trained by the $\mathrm{CHW}$. Cognitive enhancer medication (AChEls or memantine) could be initiated by the PCP, and follow-up provided by the CM. In the continuing care phase six-monthly routine review assessments of care arrangements, physical health and BPSD would be shared by the $\mathrm{CHW}$ and $\mathrm{CM}$. Further intervention sessions, as required, would be provided by the CHW, with a proportion of patients referred back to PCP for clinical evaluation. We assumed that $20 \%$ would be referred back to specialist care services at this stage. At the end-of-life phase we assumed that additional palliative care assessments and services would be provided by the PCP and CM.

\subsection{Costing methods}

\section{Estimation approach}

In order to estimate the costs of the care pathways in each of the countries in 2015 and 2030, we constructed spreadsheet models to calculate the numbers of people who go through each stage of the care pathways (given the estimated numbers of people with dementia and the assumed diagnosis rates) in a given year. We then multiplied the numbers who go through each stage by the amount of contact time with different health professionals involved in that stage, and the other inputs used (neuroimaging, bloodtesting and anti-dementia drug prescriptions). Each of the inputs were then costed by multiplying the time or

Box 7.2

\section{Key elements of WHO mhGAP}

1. Case-finding in the community by nonspecialist community health workers, with referral to primary care for assessment and diagnosis

2. Targeted screening by primary healthcare facility non-specialists (nurses and/or doctors) of those referred from the community, and where indicated (subjective memory complaints), among attendees, followed by a brief diagnostic assessment

3. Assessment of needs for care, met and unmet, family circumstances, knowledge and beliefs, behavioural and psychological problems, physical health status and nutrition

4. Immediate attention interventions to address BPSD, and optimise physical and mental health

5. Prescribe acetylcholinesterase inhibitors, or memantine, where indicated

6. Administration of a brief intervention to educate, support and train family carers

7 Consider a cognitive stimulation intervention, training family carers to administer this at home

8. Regular reviews of care arrangements, physical health status, and emergent behavioural and psychological symptoms (BPSD)

9. Non-pharmacological treatment/management of depression and BPSD 
Box 7.3

\section{Assumptions used in the modelling}

The numbers of people with dementia in 2015 and 2030, for each of the countries, are those estimated in the World Alzheimer Report $2015^{15}$.

Diagnostic rates are assumed to be $10 \%$ in LMIC and $50 \%$ in $\mathrm{HIC}$ in 2015 and to rise to $50 \%$ and $75 \%$ respectively by 2030 .

Between 2015 and 2030, the unit costs of care are assumed to grow in line with the OECD projected GDP per capita, to reflect increases in the real costs of care ${ }^{16}$.

amounts used by their unit costs.

\section{Data and unit cost sources}

It was not possible in the time available to find a source of up-to-date comparable unit costs of care that covered all the elements of the dementia healthcare pathways for all the countries in the study. Therefore, we searched for published unit costs (sometimes available from costing studies) and also gathered information from academics or members of local Alzheimer Societies in each of the countries. To ensure we had a complete set of costs for each country, we also estimated an "internationally comparable" set of unit costs using UK data. To cover all the unit costs for the inputs used in the pathway, we used the UK's Unit Costs of Health and Social Care volume produced by the Personal Social Services Research Unit ${ }^{17}$, which have been compiled using full economic costings. These have been complemented with NHS reference costs ${ }^{18}$, British National Formulary costs of prescriptions ${ }^{19}$, data from a study of models of diagnostic and assessment of dementia ${ }^{20}$, and cost information from specific interventions ${ }^{21,22}$.

In order to convert the unit costs of healthcare in the UK to costs relevant to the countries in this study, we have used a similar approach to that used by $\mathrm{Liu}^{23}$, who also used UK unit costs to derive local costs for a number of low and middle income countries, by adjusting them for each of the countries using ratios estimated from local unit costs of care available for 2008 from the WHO Choice database ${ }^{24}$.

We then used the following method:

1. Assemble the reference unit costs for all the services and interventions from the UK for 2014-15.

2. Convert the UK unit costs to international dollars, according to purchasing power parity (PPP) for 2015 obtained from the World Bank ${ }^{25}$.
3. Calculate the ratio between the costs of services available from WHO CHOICE (expressed in 2008 international dollars) for each of the countries and the UK.

4. Convert the UK costs expressed in international dollars (2015) to "local" unit costs by applying the ratios obtained for the differences between the countries in 2008 for similar services.

5. Adjust the new local unit costs to reflect changes in PPP between the different countries and the UK between 2008 and 2015. This was done by calculating the change in PPP for all the countries between the two time points and indexing to the difference observed in the UK.

This method assumes that the relationships between the unit costs of healthcare services among all the project countries are fixed, except for changing in line with changes in PPP. An important consideration is that, under full economic costing, the cost of General Practitioner's (GP) time in the UK is higher than that of a specialist doctor ${ }^{17}$. This is likely to reflect some very specific characteristics of the British healthcare system and the role of primary care that may not be relevant to all the countries in this study, and therefore we sought to adjust the costs of different types of doctors using local data (sometimes on wages) whenever possible.

Another cost item for which we have particularly looked for local costs information has been medication. To simplify the modelling, we considered only donepezil and memantine. An important consideration is that those drugs are now off patent in many countries (some may now be available as generics). The costs of drugs, therefore, will vary according to whether the drug is still under patent, the extent to which generics are prescribed in each country, and other prescription costs. For example, in Canada generic drugs represent $29 \%$ of the value of the pharmaceutical market, and $70 \%$ of the volume, whereas in Switzerland the figures are 18\% and $17 \%$ respectively ${ }^{26}$. The most recent article comparing the costs of these medications internationally was by Suh et $\mathrm{al}^{27}$, and it reports, for a number of countries (including Mexico, South Korea and Switzerland), the costs of donepezil and memantine, in terms of the final price of drug paid by a government, a health insurer or a patient (not including mark-ups, taxes and other costs), in 2007. Given that the patent for donepezil expired in $2010^{28}$ and that in most countries memantine is also off-patent (or about to become so as Supplementary Protection Certificates are expiring in many countries ${ }^{29}$ ), a new version of the study by Suh et al would help clarify the relative costs of cognitive enhancing drugs for people with dementia in different countries. 


\section{Local cost information}

Unlike the costs available from the UK's Unit Costs of Health and Social Care volume, for most countries we only found data on fees, which - particularly where these fees are those reimbursed by a public payer may not represent the full economic cost of providing the service. However, given the substantial differences in the relative costs of the different services and inputs observed between the countries in the study, we considered it preferable to include local data where possible.

All costs were converted to US dollars and, when they related to earlier years, they were uprated to 2015 using the GDP per capita growth rates available from the World Bank's Open Data website ${ }^{25}$.

\section{Unit costs data for Canada}

The unit costs of care in Canada vary by province. We were not able to find national figures, but used data from Ontario and assumed that there would not be a large disparity between Ontario and the other provinces and territories. We did not find unit costs produced using full economic costings or a single source. For the unit costs of doctors' time, we used the reimbursement fees that health providers can charge to the insurance system ${ }^{30}$. For unit costs for nurses and community health workers, we used unit costs published in a study by the Ontario Health Technology Assessment services and assumed that the cost of a community health worker and a personal support worker would be equivalent ${ }^{31}$. The costs of neuroimaging were obtained from a study by Bermingham ${ }^{32}$ and the cost of donepezil was obtained from Ontario's Drug Benefit Formulary Index ${ }^{33}$. Memantine is not covered by Ontario's drug plan, as a generic version may not be available in Canada yet.

\section{Unit costs for China}

A Delphi panel on the diagnosis and treatment of people with dementia in urban China reported estimates of the costs of hospitalisations, biological analysis and neuroimaging ${ }^{34}$. There are large differences in the salaries of doctors in China between primary and secondary care settings, and between urban and rural areas. We did not find data on staff costs we could use directly, but we were able to use data on wages in different care settings from Wu et $\mathrm{al}^{35}$ to adjust the UK-based comparable unit costs to reflect the differences in doctors between different types of doctors and settings in China. Data on the costs of donepezil was available from a specialised website ${ }^{36}$.

\section{Unit costs for Indonesia}

We are grateful to ALZI (Alzheimer's Indonesia) for consulting local experts, who provided costs of care for the costs of donepezil and memantine and MRI scans.

\section{Unit costs for Mexico}

For Mexico we found a recent study on the costs of neurocysticercosis ${ }^{37}$, which reported the unit costs of care for some staff and inputs included in the dementia care pathways (inpatient costs per day and CT/MRI scans). We have assumed that the costs for people with dementia, per unit of input, would be the same as for those with neurocysticercosis. For the difference between the costs of GPs and specialist doctors, we used the differential in wages available from the OECD Health Database ${ }^{26}$. For the costs of donepezil and memantine, we used data from Suh et $\mathrm{al}^{27}$, uprated to 2015 prices.

\section{Unit costs for South Africa}

Unit costs data for staff inputs was obtained from a study on the human resource and costs requirements for a task-shifted approach to primary mental healthcare in rural settings in South Africa ${ }^{38}$. Data on the costs of anti-dementia drugs were used from a study of prescription data ${ }^{39}$.

\section{Unit costs for South Korea}

A study on the cost-effectiveness of an opportunistic screening programme for dementia in South Korea provided data on the costs of anti-dementia drugs, MRI scans and blood tests ${ }^{40}$. We also obtained data from staff and hospital stay costs from a study of the economic burden of diabetes ${ }^{41}$. For drugs, we used uprated data from Suh et $\mathrm{al}^{27}$.

\section{Unit costs for Switzerland}

Alzheimer's Society of Switzerland provided us with data for the Vaud canton for the costs of staff, MRI scans, drugs and dementia-specific blood tests. Data on the costs of hospital stays was obtained from a study on the relative prices of hospital stays in various OECD countries ${ }^{42}$.

Further details on the unit costs assembled for this report can be made available on request.

\subsection{Results}

The total costs of the dementia healthcare pathway are relatively small, particularly for 2015 when the rates of diagnosis are low (we have assumed 10\% for LMIC and $50 \%$ for HIC, as described in section 7.1). Compared to total health expenditure, the cost of the pathways ranges from $0.5 \%$ in South Korea, to $0.007 \%$ in South Africa, suggesting that the cost of the pathways is reasonably affordable compared to overall health spending. 
Table 7.4

Estimates of the cost implications of the healthcare pathways for Canada, China, Indonesia, Mexico, South Africa, South Korea and Switzerland for 2015, in US\$ (and 2015 prices)

\begin{tabular}{|c|c|c|c|c|c|c|c|c|c|c|}
\hline & \multicolumn{2}{|l|}{ Canada } & \multirow{2}{*}{$\begin{array}{l}\text { China } \\
\begin{array}{l}\text { Task- } \\
\text { shifted }\end{array}\end{array}$} & \multirow{2}{*}{$\begin{array}{l}\text { Indonesia } \\
\text { Task- } \\
\text { shifted }\end{array}$} & \multirow{2}{*}{$\begin{array}{l}\text { Mexico } \\
\begin{array}{l}\text { Task- } \\
\text { shifted }\end{array}\end{array}$} & \multirow{2}{*}{$\begin{array}{l}\text { South } \\
\text { Africa } \\
\text { Task- } \\
\text { shifted }\end{array}$} & \multicolumn{2}{|c|}{ South Korea } & \multicolumn{2}{|c|}{ Switzerland } \\
\hline 2015 & Specialist & $\begin{array}{l}\text { Task- } \\
\text { shifted }\end{array}$ & & & & & Specialist & $\begin{array}{l}\text { Task- } \\
\text { shifted }\end{array}$ & Specialist & $\begin{array}{l}\text { Task- } \\
\text { shifted }\end{array}$ \\
\hline $\begin{array}{l}\text { Cost of the } \\
\text { pathways, in } \\
\text { million US\$ }\end{array}$ & 379 & 220 & 124 & 12 & 3 & 2 & 532 & 505 & 171 & 130 \\
\hline As $\%$ of GDP & 0.0245 & 0.0142 & 0.0011 & 0.0014 & 0.0003 & 0.0007 & 0.0386 & 0.0367 & 0.0257 & 0.0196 \\
\hline $\begin{array}{l}\text { As } \% \text { of } \\
\text { total health } \\
\text { expenditure }\end{array}$ & 0.203 & 0.118 & 0.022 & 0.047 & 0.010 & 0.007 & 0.511 & 0.486 & 0.217 & 0.165 \\
\hline $\begin{array}{l}\text { Cost of the } \\
\text { pathway per } \\
\text { person with } \\
\text { dementia US\$ }\end{array}$ & 682 & 396 & 13 & 10 & 4 & 11 & 1,111 & 1,057 & 1,279 & 973 \\
\hline $\begin{array}{l}\text { Cost of the } \\
\text { pathway } \\
\text { per person } \\
\text { diagnosed with } \\
\text { dementia US\$ }\end{array}$ & 1,364 & 792 & 130 & 199 & 39 & 113 & 2,223 & 2,113 & 2,558 & 1,946 \\
\hline
\end{tabular}

Note: Assuming 50\% diagnosis rate in HIC (Canada, South Korea and Switzerland) and 10\% in LMIC (China, Indonesia, Mexico and South Africa).

In HIC, the cost of specialist pathway per person with dementia ranges from $\$ 682$ (US) in Canada, to $1,279 \$$ in Switzerland. The task-shifted pathway is nearly $40 \%$ cheaper than the specialist pathway in Canada, although for Switzerland and South Korea the difference is smaller: $24 \%$ and $5 \%$ respectively. In the LMIC, the cost of the task-shifted pathway ranges from nearly $4 \$$ per person with dementia in Mexico, to $13 \$$ in China. Interestingly, these results are not in line with the order in which these countries would be ranked in terms of relative income levels.

In order to understand the differences in the costs

Table 7.5

Proportional contributions to the total costs of the pathway

\begin{tabular}{|l|l|l|l|l|l|l|l|l|l|l|}
\hline & \multicolumn{2}{|l|}{ Canada } & China & Indonesia & Mexico & \multicolumn{2}{l|}{$\begin{array}{l}\text { South } \\
\text { Africa }\end{array}$} & \multicolumn{2}{l}{ South Korea } & \multicolumn{2}{l|}{ Switzerland } \\
\hline & Specialist & $\begin{array}{l}\text { Task- } \\
\text { shifted }\end{array}$ & $\begin{array}{l}\text { Task- } \\
\text { shifted }\end{array}$ & $\begin{array}{l}\text { Task- } \\
\text { shifted }\end{array}$ & $\begin{array}{l}\text { Task- } \\
\text { shifted }\end{array}$ & $\begin{array}{l}\text { Task- } \\
\text { shifted }\end{array}$ & Specialist & $\begin{array}{l}\text { Task- } \\
\text { shifted }\end{array}$ & $\begin{array}{l}\text { Specialist } \\
\text { Task- } \\
\text { shifted }\end{array}$ \\
\hline Staff & $67.9 \%$ & $50.4 \%$ & $4.59 \%$ & $16.60 \%$ & $42.77 \%$ & $15.16 \%$ & $8.6 \%$ & $4.2 \%$ & $39.1 \%$ & $23.3 \%$ \\
\hline Neuroimaging & $7.4 \%$ & $2.5 \%$ & $1.37 \%$ & $1.62 \%$ & $0.50 \%$ & $0.53 \%$ & $1.1 \%$ & $0.2 \%$ & $6.0 \%$ & $1.6 \%$ \\
\hline $\begin{array}{l}\text { Anti-dementia } \\
\text { drugs }\end{array}$ & $19.7 \%$ & $34.0 \%$ & $91.98 \%$ & $81.50 \%$ & $54.72 \%$ & $84.00 \%$ & $88.8 \%$ & $93.4 \%$ & $48.0 \%$ & $63.1 \%$ \\
\hline Hospital stays & $5.0 \%$ & $9.6 \%$ & $1.32 \%$ & $0.22 \%$ & $1.98 \%$ & $0.25 \%$ & $1.5 \%$ & $1.8 \%$ & $5.4 \%$ & $8.0 \%$ \\
\hline Other & $0.1 \%$ & $3.5 \%$ & $0.7 \%$ & $0.1 \%$ & $0.0 \%$ & $0.1 \%$ & $0.0 \%$ & $0.4 \%$ & $1.4 \%$ & $4.0 \%$ \\
\hline
\end{tabular}

of the care pathway in the different countries, and also why the change from a specialist pathway to a task-shifted pathway makes a much bigger difference in Canada than in South Korea, it is important to consider the relative costs of the various components of the pathway across countries. As discussed in section 7.2, while differences in staff costs reflect to a large extent income levels in the different countries, there are very large differences in the unit costs of cognitive enhancer medication that reflect each country's policy on generic medicines as well as other factors. Table 7.5 shows the proportion of the total costs of the pathway that are attributable to staff, 
neuroimaging, medications, hospital stays and other elements. The table shows very large inter-country differences in the relative importance of medication costs compared to the other components of the pathway. For the task-shifted pathways, while staff costs represent $50 \%$ of costs in Canada, they only represent just over $4 \%$ in China and South Korea. In fact, the costs of medications represent over $90 \%$ of the costs of the pathway in China and South Korea, followed by $84 \%$ in South Africa, $81 \%$ in Indonesia and $63 \%$ in Switzerland.

This relative importance of the costs of drugs also explains why in Canada, where drugs are relatively cheap, there is a much larger difference between the cost of the specialist and the task-shifted pathways, compared to South Korea and Switzerland.

Between 2015 and 2030, we have assumed that the changes in the costs of the pathway will be driven by three variables: growth in the numbers of people with dementia, growth in the unit costs of care, and assumptions made about the increase in diagnostic coverage.

While the numbers of people with dementia will grow by at least a quarter in these 15 years, they will more than double for South Korea and nearly double for Mexico and Indonesia (Chart 7.1).

Given the assumptions explained earlier (section 7.2), which include an increase in the diagnosis rate to reach $75 \%$ in $\mathrm{HIC}$ and $50 \%$ in $\mathrm{LMIC}$, and assuming that the differences between the costs of cognitive enhancer medications between countries remains the same, the costs of the care pathways in 2030 would be as detailed in table 7.6.

With regards the changes in the unit costs of care, we assumed that, between 2015 and 2030, unit costs will grow in line with growth in GDP per capita, as
Chart 7.1

$\%$ change in the numbers of people with dementia, 2015 - 2030

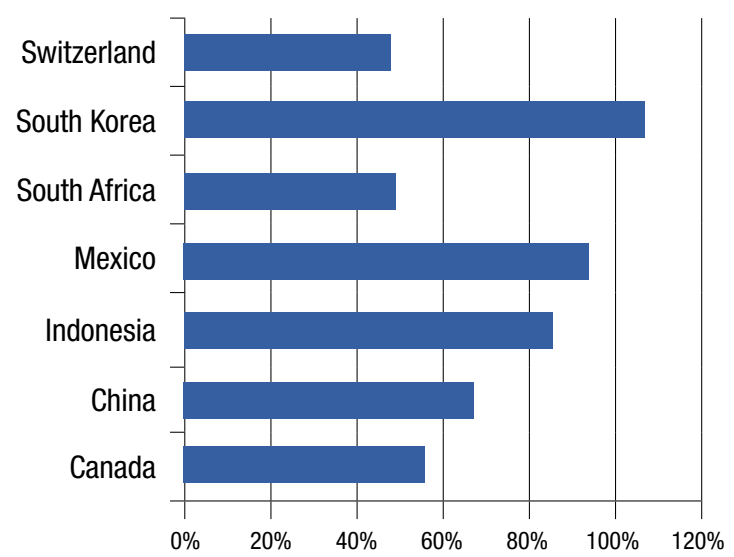

projected by the OECD ${ }^{16}$. This assumption was explored in the World Alzheimer Report 2015 projections of the costs of dementia, which compared the performance of the consumer price index (CPI) and GDP per capita as predictors of the growth of the costs of care per person between 2010 and 2015 . In the sensitivity analysis carried out for that study it was found that using the CPI may underestimate the growth in the costs of salaries and services in rapidly growing economies. Most studies that project the future costs of healthcare (for example, by the OECD ${ }^{43}$ and the European Commission ${ }^{44}$ ) project together increases in consumption (or use) of healthcare services and increases in the unit costs of those services. In this report we project changes in volume and unit costs separately and, particularly because of the emphasis on staff costs of the pathways, using GDP per capita as a proxy for increases in wages was a reasonable assumption.

In order to illustrate the sensitivity of the estimates to pharmaceutical costs, in Table 7.7 we show the

Table 7.6

Estimates of the cost implications of the healthcare pathways for Canada, China, Indonesia, Mexico, South Africa, South Korea and Switzerland for 2030, in US\$, assuming differences in costs of cognitive enhancer medications remain as they are today

\begin{tabular}{|c|c|c|c|c|c|c|c|c|c|c|}
\hline & \multicolumn{2}{|l|}{ Canada } & \multirow{2}{*}{$\begin{array}{l}\text { China } \\
\text { Task- } \\
\text { shifted }\end{array}$} & \multirow{2}{*}{$\begin{array}{l}\text { Indonesia } \\
\text { Task- } \\
\text { shifted }\end{array}$} & \multirow{2}{*}{$\begin{array}{l}\text { Mexico } \\
\begin{array}{l}\text { Task- } \\
\text { shifted }\end{array}\end{array}$} & \multirow{2}{*}{$\begin{array}{l}\text { South } \\
\text { Africa }\end{array}$} & \multicolumn{2}{|c|}{ South Korea } & \multicolumn{2}{|c|}{ Switzerland } \\
\hline 2030 & Specialist & $\begin{array}{l}\text { Task- } \\
\text { shifted }\end{array}$ & & & & & Specialist & $\begin{array}{l}\text { Task- } \\
\text { shifted }\end{array}$ & Specialist & $\begin{array}{l}\text { Task- } \\
\text { shifted }\end{array}$ \\
\hline $\begin{array}{l}\text { Cost of the } \\
\text { pathways, in } \\
\text { million US\$ }\end{array}$ & 756 & 438 & 2,660 & 384 & 48 & 26 & 1,652 & 1,568 & 334 & 251 \\
\hline As $\%$ of GDP & 0.0357 & 0.0207 & 0.0094 & 0.0205 & 0.0025 & 0.0046 & 0.0804 & 0.0763 & 0.0362 & 0.0272 \\
\hline $\begin{array}{l}\text { Cost per } \\
\text { person with } \\
\text { dementia US\$ }\end{array}$ & 914 & 530 & 164 & 169 & 30 & 93 & 1,641 & 1,558 & 1,723 & 1,294 \\
\hline
\end{tabular}


Table 7.7

Estimates of the healthcare pathway costs in 2030 if the cost of anti-dementia drugs in all the countries was the same as in England (2015 prices in US\$, uprated with each country's projected GDP per capita growth rate)

\begin{tabular}{|l|l|l|l|l|l|l|l|l|l|l|l|}
\hline & \multicolumn{2}{|l|}{ Canada } & China & Indonesia & Mexico & $\begin{array}{l}\text { South } \\
\text { Africa }\end{array}$ & \multicolumn{2}{l|}{ South Korea } & \multicolumn{2}{l|}{ Switzerland } \\
\hline 2030 & Specialist & $\begin{array}{l}\text { Task- } \\
\text { shifted }\end{array}$ & $\begin{array}{l}\text { Task- } \\
\text { shifted }\end{array}$ & $\begin{array}{l}\text { Task- } \\
\text { shifted }\end{array}$ & $\begin{array}{l}\text { Task- } \\
\text { shifted }\end{array}$ & $\begin{array}{l}\text { Task- } \\
\text { shifted }\end{array}$ & Specialist & $\begin{array}{l}\text { Task- } \\
\text { shifted }\end{array}$ & $\begin{array}{l}\text { Specialist } \\
\text { Task- } \\
\text { shifted }\end{array}$ \\
\hline $\begin{array}{l}\text { Cost of the } \\
\text { pathways, } \\
\text { in million } \\
\text { US\$ }\end{array}$ & 629 & 311 & 260 & 24 & 27 & 5 & 213 & 129 & 186 & 103 \\
\hline $\begin{array}{l}\text { As \% of } \\
\text { GDP }\end{array}$ & 0.0297 & 0.0147 & 0.0009 & 0.0013 & 0.0014 & 0.0009 & 0.0104 & 0.0063 & 0.0202 & 0.0112 \\
\hline $\begin{array}{l}\text { Cost per } \\
\text { person with } \\
\text { dementia } \\
\text { US\$ }\end{array}$ & 761 & 377 & 16 & 11 & 17 & 17 & 212 & 120 & 960 & 530 \\
\hline
\end{tabular}

impact of a policy scenario in which the cost of drugs in all the countries was the same as in England today (where generic versions of these medications are widely prescribed). By taking out the variation from drug prices, the results show that the cost difference between the specialist and task-shifted pathways for HIC is of approximately $40 \%$. For LMIC the differences in pathway costs between countries become much smaller and, most importantly, the care pathways become much more affordable.

\section{Discussion}

\section{Limitations}

The estimates presented here show that the results are very sensitive to the assumptions made about the unit costs of care. As this project was carried out in a relatively short time, it was not possible to investigate thoroughly the unit costs in each of the countries. Our results demonstrate the importance of improving the ready availability of internationally comparable, up-todate information on the unit costs of care.

\section{The costs of the pathways in context}

The costs of the task-shifted pathways are relatively low compared to overall healthcare spending and are also low compared to estimates of the overall cost of healthcare services by people living with dementia. We have estimated that the cost of the pathway in 2015 , per person diagnosed, would range from $\$ 39$ per year in Mexico (or 3.9\$ per person with dementia), to $\$ 2,113$ in South Korea $(\$ 1,057$ per person with dementia). The overall costs of healthcare use by people with dementia will include costs related to dementia as well as costs related to treating other health conditions. In the World Alzheimer Report 2015, the estimated direct yearly costs of healthcare per person with dementia ranged from $\$ 93$ per person in the Asia South region, to $\$ 12,761$ in North America. As discussed in other chapters, the implementation of dementia pathways could potentially result in a reduction of some of the other costs of health and social care; the costs due to late or missed diagnosis, and to poor quality of care, such as unplanned crisis admissions into hospitals. The overall costs of dementia, including the costs of social care and unpaid family care were estimated to range from $\$ 872$ in Asia South to $\$ 56,218$ in North America per person, per year.

If low-cost generic anti-dementia drugs became more widely available, particularly in low and middle income countries, the healthcare pathways would become much more affordable.

\section{Task-shifted pathways in the context of the healthcare systems in each country}

\section{Canada}

Because the Canadian national clinical standards for dementia already emphasize the role of primary care in the diagnostic and routine care of people with dementia (see Chapter 6), the healthcare pathway of people with dementia in Canada is already in the process of task-shifting. The role of primary care doctors as gatekeepers also supports a task-shifted approach, as does the relatively high ratio (48\%) of GPs as a proportion of all physicians ${ }^{26}$. The cost of donepezil is also relatively low in Canada, although memantine is not currently included in the drug plans of Ontario and possibly other provinces, as it is only now coming off patent protection and there is no generic version available yet. 


\section{China}

While a task-shifted approach in China could build on the existing infrastructure of rural primary care services to expand the reach of dementia care, there are important structural barriers that would need addressing. Because the existing primary care services are perceived as being of poor quality, and they do not have a gatekeeping role, people prefer to access care in secondary and tertiary hospitals, even if that is much more expensive and if it requires travelling long distances (see Chapter 6). The cost of anti-dementia drugs in China is very high, particularly compared to that of care, treatment and support delivered by staff, and so, without wide access to generic medicines and curbs on the ability of doctors to charge very high drug prescription fees to supplement their income, it may not be cost-effective to include anti-dementia drugs in the pathway.

\section{Indonesia}

In the context of the recent launch of Indonesia's National Dementia Plan in 2016 and its universal health insurance programme in 2014, there is a potential opportunity to ensure that the expansion of healthcare coverage avoids some of the structural barriers to the implementation of task-shifted dementia care pathways, such as the lack of a gatekeeping role for primary care, and lack of awareness about dementia. For primary care to be able to take the central role required in a task-shifted pathway would require improved training of GPs as well as increased coverage. The cost of anti-dementia drugs is very high in Indonesia, particularly compared to staff and other healthcare costs.

\section{Mexico}

The financing and provision of healthcare in Mexico is fragmented, with different insurance systems that offer different levels of care, to different groups of people. The availability of healthcare services in Mexico is relatively low and primary care only plays a small role. Dementia-specific care is mostly provided at specialist level and in larger cities. The National Dementia Plan of 2014 involves an ambitious training programme for health professionals as well as raising awareness among the public (see Chapter 6). In order for Mexico to be able to develop task-shifted dementia care pathways it would be necessary to strengthen the role of primary care and ensure a consistency across the different insurance schemes. The costs of anti-dementia drugs in Mexico are relatively low, which means that, if there was an improvement in the diagnostic rates, the cost of increased prescriptions would be relatively low.

\section{South Africa}

South Africa's healthcare system faces very important challenges from HIV/AIDs, tuberculosis and other "diseases of poverty", while at the same time experiencing an increase in diseases associated with longevity. With regard to the adoption of dementia healthcare pathways, primary healthcare clinics are well established as the first point of access and there is experience, particularly in the mental health area, in task-shifted models of care. The main challenge appears to be the competing claims to limited resources, exacerbated by inequities in access to care, stigma about dementia and lack of professional training and awareness. Dementia drugs are not currently included in the Essential Drug List for public health facilities, reflecting the low priority status of dementia.

\section{South Korea}

South Korea is preparing for a very large increase in the numbers of people with dementia. It launched its third National Dementia Plan in 2016, with the main goals of creating a dementia-friendly society and enabling people with dementia and carers to live well. To meet these ambitious goals, in the context of a very large increase in the numbers of people with dementia, it will be important for South Korea to consider more sustainable ways to deliver care. The current system lacks a gatekeeping role for primary care providers and enables providers to induce demand for care that is not cost-effective or necessary. Without a reform of the current fee-for-service payment system and the introduction of a gatekeeping role for primary care, it would be difficult to implement a task-shifted healthcare pathway. The costs of anti-dementia drugs are high in South Korea.

\section{Switzerland}

Despite the adoption of a National Dementia Strategy for 2014-2017, at present the care of people with dementia lacks a systematic and standardised approach, and the rate of diagnosis of dementia, assumed to be $50 \%$, seems relatively low for one of the countries with the highest per capita health spending in the world. While the Swiss system was characterised by no gatekeeping role by GPs and direct access to specialists, an increasing number of people are covered by health maintenance organisations (HMOs) that restrict access to specialists and involve a gatekeeping and care coordination role by GPs. The cost of drugs in Switzerland is very high, reflecting relatively low rates of generic medicines use. 


\section{Policy implications}

Structural barriers to the implementation of the care pathways:

- With the exception of Canada and South Africa, in most of the countries we have looked at, people are able to access specialist care directly, without a gatekeeping role for primary care. The ease of access to specialist care, in combination with a perception that primary care is of lower quality (a view that is particularly marked in China), may be important barriers to the take-up of a task-shifted dementia healthcare pathway.

- The prescription costs of anti-dementia drugs are very high in some of the countries (China, Indonesia, South Korea and Switzerland), in part because of drugs remaining under patent, lack of consolidated purchasing, and reluctance to use generic medicines. This is aggravated in some countries by doctors using additional prescription fees to supplement their incomes. Given these very high costs, it may be that those drugs would not even be cost-effective in some of those countries, particularly when the cost of other types of treatment, care and support are comparatively much cheaper due to low wages. Ensuring that people in low- and middle-income countries have access to anti-dementia drugs at equitable prices, that are at least not higher than in high-income countries, will become an increasingly important issue particular because such a large number of people in LMIC may be denied access due to lack of affordability.

\section{References}

1 Abbey J, Palk E, Carlson L, Parker D. Clinical Practice Guidelines and Care Pathways for People with Dementia Living in the Community. Brisbane, Australia: Queensland University of Technology, $2008 \mathrm{http}: / /$ eprints.qut.edu.au/17393/1/17393.pdf (accessed Aug 14, 2016).

2 Odenheimer G, Borson S, Sanders AE, et al. Quality improvement in neurology: dementia management quality measures. Neurology 2013; 81: 1545-9.

3 NICE/ SCIE. Dementia; supporting people with dementia and their carers in health and social care - National Clinical Practice Guideline Number 42 - updated May 2016. National Institute for Health and Care Excellence, 2006 https://www.nice.org.uk/ Guidance/cg42 (accessed Aug 20, 2016).

4 World Health Organization. WHO Mental Health Gap Action Programme (mhGAP). 2009. http://www.who.int/mental_health/ mhgap/en/ (accessed Aug 16, 2016).

5 Dua T, Barbui C, Clark N, et al. Evidence-based guidelines for mental, neurological, and substance use disorders in low- and middle-income countries: summary of WHO recommendations. PLoSMed 2011; 8: e1001122.

6 World Health Organization. mhGAP intervention guide for mental, neurological and substance use disorders in non-specialized health settings: mental health Gap Action Programme (mhGAP). Geneva: WHO, 2010.

7 Woodward MC, Woodward E. A national survey of memory clinics in Australia. Int Psychogeriatr 2009; 21: 696-702.

8 Ramakers IH, Verhey FR. Development of memory clinics in the Netherlands: 1998 to 2009. Aging MentHealth 2011; 15: 34-9.

9 Banerjee S, Willis R, Matthews D, Contell F, Chan J, Murray J. Improving the quality of care for mild to moderate dementia: an evaluation of the Croydon Memory Service Model. Int $J$ GeriatrPsychiatry 2007; 22: 782-8.

10 Shaji KS, Arun Kishore NR, Lal KP, Prince M. Revealing a hidden problem. An evaluation of a community dementia case-finding program from the Indian 10/66 dementia research network. Int $J$ Geriatr Psychiatry 2002; 17: 222-5.

11 Ramos-Cerqueira AT, Torres AR, Crepaldi AL, et al. Identification of dementia cases in the community: a Brazilian experience. JAmGeriatrSoc 2005; 53: 1738-42.

12 Gavrilova SI, Ferri CP, Mikhaylova N, Sokolova O, Banerjee S, Prince M. Helping carers to care-The 10/66 dementia research group's randomized control trial of a caregiver intervention in Russia. IntJGeriatrPsychiatry 2008; published online Sept 23

13 Guerra M, Ferri CP, Fonseca M, Banerjee S, Prince M. Helping carers to care: the 10/66 dementia research group's randomized control trial of a caregiver intervention in Peru. RevBrasPsiquiatr 2010; published online July 2.

14 Jotheeswaran A, Dias A, Philp I, Beard J, Patel V, Prince M. Identifying common impairments in frail and dependent older people: validation of the COPE assessment for non-specialised health workers in low resource primary health care settings. BMCGeriatr 2015; 15:123. doi: 10.1186/s12877-015-0121-1.: 123-0121.

15 Prince M, Wimo A, Guerchet M, Ali G-C, Wu Y-T, Prina M (2015) The Global Impact of Dementia: An analysis of prevalence, incidence, cost and trends. World Alzheimer Report 2015, Alzheimer's Disease International, London.

16 Johansson, Å. et al (2013) Long-Term Growth Scenarios, OECD Economics Department Working Papers, No. 1000, OECD Publishing. http://dx.doi.org/10.1787/5k4ddxpr2fmr-en

17 Curtis L and Burns A (2015) Unit costs of health \& social care. PSSRU, University of Kent, Canterbury. http://www.pssru.ac.uk/ project-pages/unit-costs/2015/index.php [accessed 11 August 2016].

18 Department of Health (2015) NHS reference costs 2014-2015. https://www.gov.uk/government/publications/nhs-referencecosts-2014-to-2015 [accessed August 2016].

19 NICE (2016) British National Formulary http://www.evidence.nhs. uk/formulary/bnf/current/ [accessed 11 August 2016].

20 Hawkins J. (2015) Models of Dementia Assessment and Diagnosis: Indicative Cost Review. NHS England.https://www. england.nhs.uk/wp-content/uploads/2015/09/mods-demntlassessmnt-diag-cost.pdf [accessed August 2016].

21 Knapp M, Thorgrimsen L, Patel A, Spector A, Hallam A, Woods $B$ and Orrell M (2006) Cognitive stimulation therapy for people with dementia: cots-effectiveness analysis. British Journal of Psychiatry 188: 574-580. 
22 Knapp et al (2013) Cost effectiveness of a manual based coping strategy programme in promoting mental health of family carers of people with dementia (the START (STrAtegies for RelaTives) study): a pragmatic randomized controlled trial, British Medical Journal, 347:6342.

23 Liu Z (2013) Economic Costs of Dementia in Low and Middle Income Countries. PhD thesis, King's College London. https:// $\mathrm{kclpure.kcl.ac.uk/portal/en/theses/economic-costs-of-dementia-}$ in-low-and-middle-income-countries(9d90e06c-022d-4db0a877-e84f859531e4).html [accessed August 2016].

24 WHO (2011) WHO CHOICE Unit Cost estimates for services delivery http://www.who.int/choice/cost-effectiveness/inputs/ health_service/en/ [accessed August 2016].

25 World Bank (2016) Open Data website. http://data.worldbank.org/ [accessed August 2016]

26 OECD (2016) OECD Health Statistics 2016. Available at http:// www.oecd.org/els/health-systems/health-data.htm [accessed August 2016).

27 Suh G-H, Wimo A, Gauthier S, O'Connor D, Ikeda M, Homma A, Dominguez J and Yang BM (2009) International price comparisons of Alzheimer's drugs: a way to close the affordability gap International Psychogeriatrics, 21:6, 1116-1126.

28 FDA (2009) FDA Approves Generic Aricept to Treat Dementia Related to Alzheimer's Disease. Press Release, U.S. Food and Drug Administration. http://www.fda.gov/NewsEvents/Newsroom/ PressAnnouncements/ucm194173.htm [accessed August 2016].

29 Genericsweb (2014) More memantine SPCs expire in April. GENERICS bulletin 18 April 2014. Available at http://www. genericsweb.com/Pipeline\%20Watch/Pipeline\%20Watch\%20 April\%202014\%20-\%20Memantine.pdf [accessed August 2016]

30 Ministry of Health and Social Care Ontario (2015) Schedule of Benefits for physician Services under the Health Insurance Act (Effective April 1, 2016). http://www.health.gov.on.ca/english/ providers/program/ohip/sob/physserv/sob_master20160406.pdf [accessed August 2016].

31 Medical Advisory Secretariat. Aging in the community: summary of evidence-based analyses. Ontario Health Technology Assessment Series 2008; 8(1).

32 Bermingham SL. (2014) The appropriate use of neuroimaging in the diagnostic work-up of dementia: an economic literature review and cost-effectiveness analysis. Ont Health Technol Assess Ser [Internet]. 2014 February;14(2):1- 67. Available from: http://www.hqontario.ca/evidence/publications-and-ohtacrecommendations/ontario-healthtechnology-assessment-series/ imaging-for-dementia. [accessed August 2016].

33 Ontario Drug Benefit Index, available at https://www.formulary health.gov.on.ca/formulary [accessed August 2016].

34 Yu X, Chen S, Chen X, Jia J, Li C, Liu C, Toumi M and Milea D (2015) Clinical management and associated costs for moderate and severe Alzheimer's disease in urban China: a Delphi panel study. Translational Neurodegeneration 4:15.

35 Wu D, Wang Y, Lam KF, et al. Health system reforms, violence against doctors and job satisfaction in the medical profession: a cross-sectional survey in Zhejiang Province, Eastern China. BMJ Open 2014;4: e006431. doi:10.1136/bmjopen-2014-006431.

36 https://www.315jiage.cn/x-WeiFenLei/94566.htm [accessed August 2016].

37 Bhattarai R, Carabin H, Proano JV, Flores-Rivera J, Corona T, Flisser A and Budke CM (2015) Cost of neurocysticercosis patients treated in two referral hospitals in Mexico City, Mexico. Tropical Medicine and International Health. 20(8): 1108-1119.

38 Petersen I, Lund C, Bhana A, Flisher AJ, Mental Health and Poverty Research Programme Consortium (2012) A task shifting approach to primary mental health care for adults in South Africa: human resource requirements and costs for rural settings. Health Policy and Planning; 27:42-51.

39 Truter I (2013) Antipsychotic drug prescribing to patients with dementia in a South African patient population. African Journal of Pharmacy and Pharmacology 7(41): 2755-2762.

40 Yu S-Y, Lee T-J, Jang S-H, Han JW, Kim TH, Kim KW (2015) CostEffectiveness of Nationwide Opportunistic Screening Program for Dementia in South Korea. Journal of Alzheimer's Disease 44: 195-204.

41 Kim G, Lee Yh, Han MH, Lee EK, Kim CH, et al. (2016) Economic Burden of Hypoglycemia in Patients with Type 2 Diabetes Mellitus from Korea. PLoS ONE 11(3): e0151282. doi: 10.1371/journal. pone.0151282
42 Koechlin F, Konijn P, Lorenzoni L and Schreyer P (2014). Comparing Hospital Prices and Volumes Across Countries: A New Approach. Paper presented at the IARIW conference, Rotterdam 2014. Available from: http://www.iariw.org/papers/2014/ LorenzoniPaper.pdf [accessed August 2016].

43 De La Maisonneuve, C. and J. Oliveira Martins, (2013) A projection method for public health and long-term care expenditures, Economics Department Working Papers No. 1048, OECD, Paris.

44 European Commission (2015) The 2015 Ageing Report. European Economy 3|2015, DG Economic and Financial Affairs, Brussels. 


\section{CHAPTER 8}

\section{Summary and conclusion}

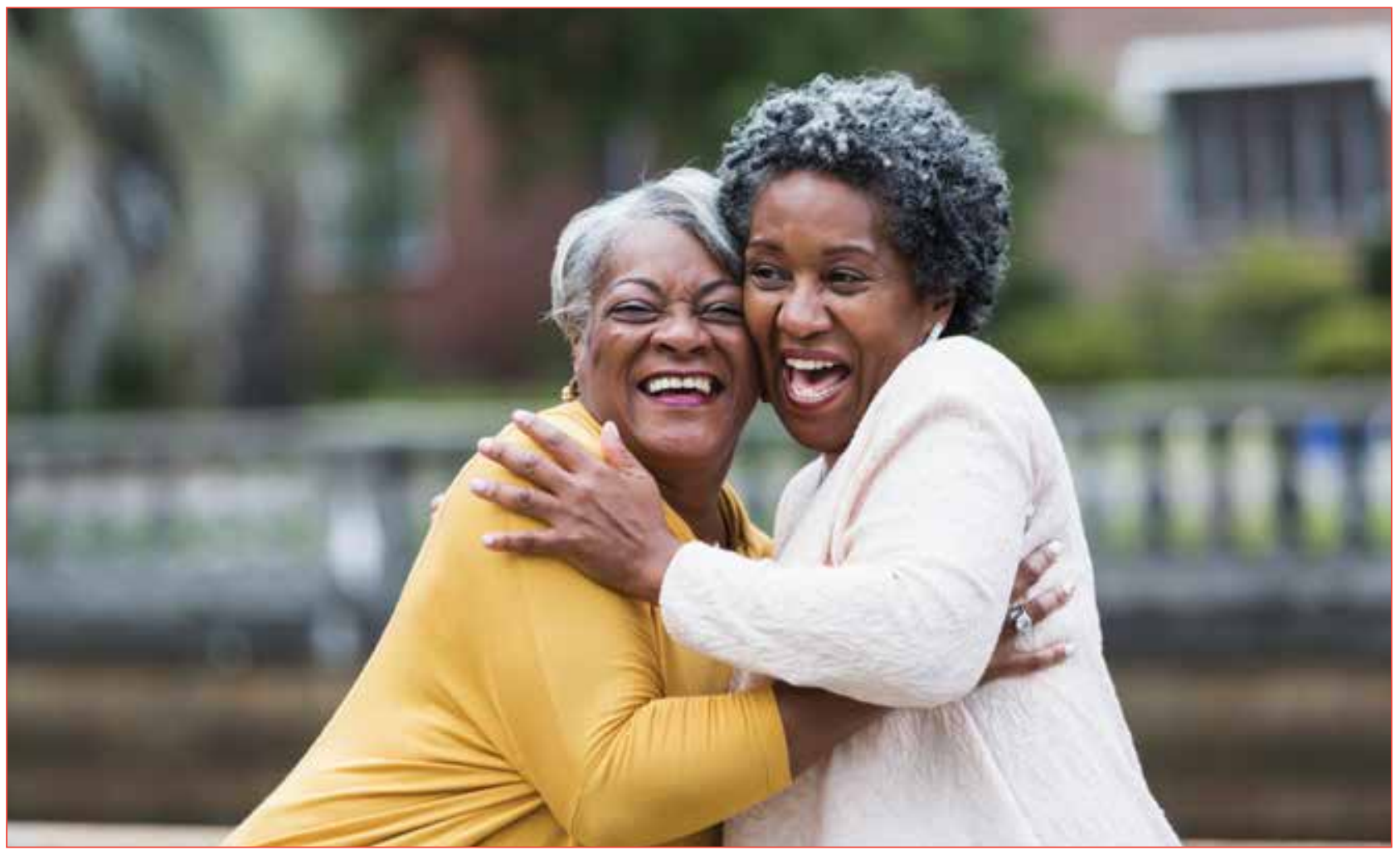

\subsection{Introduction - the scope of this report}

For this year's World Alzheimer Report, we have focused upon healthcare for people with dementia, and the systems and services required to deliver it. The backdrop to this report is the fundamental challenge faced by governments and health systems around the world - how can we increase the current very low levels of coverage of diagnostic, treatment and continuing care services, while maintaining or improving quality, and at the same time keeping costs under control? It seems self-evident that this requires an increase in the efficiency with which services are delivered.

Accordingly, we have focused upon three main strategies:

1. task-shifting and task-sharing, whereby care previously delivered by specialist services is transferred to non-specialists in community and primary care, trained and supported by specialists;

2. case management, in which a new cadre of professionals is responsible for assessing, planning, facilitating and coordinating care for people with dementia and their carers;

3. the introduction of care pathways, which systematise the planning, resourcing and delivery of continuing care, with explicit elements of assessment and care, facilitated communication and coordination of roles, and documentation and monitoring of processes and outcomes.

We have reviewed the latest evidence for the potential role of primary care services in delivering dementia healthcare (Chapter 2), the effectiveness of case management (Chapter 3), approaches for limiting and better managing hospitalisation of people with dementia (Chapter 4), and palliative and end-of-life care (Chapter 5).

Finally, in a selection of countries (Chapter 6), we explored the potential impact of task-shifting on future dementia healthcare costs, as numbers of people affected increase, and coverage of basic diagnostic and continuing care services improves (Chapter 7). Having defined outline healthcare pathways for people living with dementia for relatively well-resourced high income countries (HIC), and less well-resourced middle income country (MIC) settings, we estimated the increasing costs of care from 2015 to 2030, accounting for projected increases in the numbers of people living with dementia, and a projected increase in diagnostic coverage from $50 \%$ to $75 \%$ in $\mathrm{HIC}$ and from $10 \%$ to $50 \%$ in MIC. We assumed that the increased coverage in MIC would be achieved through implementation of task-shifted care pathways, while for HIC we compared 
specialist care pathways with more task-shifted alternatives.

\subsection{Summary of review findings}

\section{Models of healthcare delivery}

Healthcare is at the core of the system of treatment and support for people with dementia and their carers. Healthcare professionals, and services have important roles to play across the course of the condition; promoting brain health; providing a timely diagnosis with post-diagnostic information and support; signposting community support services; initiating treatments where appropriate; optimising physical health and managing comorbidities; assessing and managing behavioural and psychological symptoms.

Dementia is not just another diagnosis on the lengthening list of comorbidities that most of us face as we age. It changes everything, not least future expectations of life, and independence. It impairs one's ability to recognise and report new symptoms, seek help, and manage one's own health conditions. Therefore, it has profound implications for the management of all health issues for the person with dementia, and the way that healthcare needs to be planned and delivered for people with dementia in general.

\section{Healthcare for people with dementia needs to be}

- continuous; treatment options, care plans and needs for support need to be monitored and reviewed as the condition evolves and progresses

- holistic; treating the whole person, not single conditions, organs or systems, mindful of that person's unique context, values and preferences

- integrated; across providers, levels of care, and health and social care systems

Currently, healthcare systems struggle to provide adequate coverage of diagnostic services, and care is too often fragmented, uncoordinated, and unresponsive to the needs of people with dementia and their families at the time when they arise.

In high income countries, dementia healthcare systems tend to be highly specialised, from diagnosis onwards, with very little formal recognition of the role of primary care services, or allocation of tasks to this sector. This is probably also true for low and middle income countries, where diagnostic coverage is low, but such services as are available are provided by a very limited number of specialists.

As the numbers of people affected and the demand for services increase, it is unlikely that full coverage of dementia healthcare services can be attained or afforded using the current specialist care model. There are other limitations too. Seamless and continuing care is beyond the capacity and reach of specialist services working in isolation. The specialist model of dementia care does not facilitate holistic management of, or care-coordination for, complex multimorbidities. These are core functions of primary healthcare.

Task-shifting and task-sharing, including but not limited to increasing the role and competencies of primary healthcare services within the system, will be the core strategies for increasing the coverage of diagnosis and continuing care. Collaborative or shared-care models distribute tasks between primary and secondary care services in a structured and organised fashion.

Case management may be an important strategy for increasing treatment coverage, and improving integration and coordination of care. More research is needed to clarify the best ways of delivering this promising intervention. Evidence to date suggests that case management needs to be adequately resourced by skilled staff with manageable caseloads, and implemented such that case managers have the authority to work with all stakeholders and providers.

The introduction of evidence-based care pathways, linked to process and outcome indicators, should help to improve adherence to healthcare quality standards, and allow transparent monitoring of treatment coverage and effective treatment coverage.

\section{The role of primary care}

We conducted a scoping review of recent research evidence on the role of primary care within the dementia healthcare system, including evidence regarding the effectiveness of primary care services in the detection and diagnosis of dementia, and in the provision of continuing care, when compared with specialist healthcare services. We also assessed evidence on strategies and interventions to enhance the quality of care provided by primary healthcare services.

Dementia is currently under-detected, underdiagnosed, under-disclosed, under-treated and under-managed in primary care. This reflects the status quo, in which the roles and responsibilities of primary care have not been explicitly defined, with minimal basic curriculum and in-service training, and where care processes are not supported by evidence-based clinical guidelines or care pathways.

When primary care physicians (PCPs) do take responsibility for dementia care evidence suggests that this is similar in its outcomes to the care provided by specialists, even though care processes may be less scrupulously adhered to. There is much scope for improvement, with some well-evaluated examples of system and service level innovations to support a more 
prominent role of primary care services in diagnosis, and post-diagnostic and continuing care.

Recognition of dementia in primary care can be boosted by in-service education and training, which seeks to alter attitudes and perceptions as well as providing technical skills, and when there is a practicebased component in which specialists guide and mentor non-specialists to recognise and diagnose dementia.

Indicated screening using cognitive tests can support timely diagnosis by responding to concerns raised by patients and carers. However, general screening, of all older attendees or all those registered to a primary care service, cannot currently be recommended, and should not be carried out, in advance of more research evidence on benefits, harms and cost-effectiveness.

In most settings, dementia diagnosis is not explicitly recognised as being within the capacity of nonspecialist services. Nevertheless, we identified several successful examples of memory clinics established in primary care, and run by PCPs supported by nurse practitioners. No studies have compared the accuracy of diagnoses made by non-specialists and specialists. More research is needed into good practice for diagnostic disclosure (a 'diagnosis well made'). Several studies indicate underperformance, and a need for more training and support for this important activity.

The post-diagnostic phase bridges from the 'diagnosis well made' to a system of continuing care in the context of declining function and increasing needs for care and support. One randomised controlled trial from the Netherlands indicated the outcomes of care in the year post-diagnosis with mild dementia were no worse when provided by PCPs than when provided by specialists $^{1}$, and costs were similar ${ }^{2}$. However, this and other studies also suggest that some care processes are more commonly adhered to by specialists (including anti-dementia medication, information provided to carers, and referral to community support).

The potential benefits of the full range of postdiagnostic support activities (as for example advocated by Alzheimer Scotland in their ' 5 pillars' model) have yet to be evaluated. The targeting and delivery of post-diagnostic support needs to be thought through carefully, since needs and preferences will vary considerably among people with dementia and their carers. In two recent large European randomised controlled trials no benefits for either the person with dementia or the carer could be identified from implementation of psychosocial education, training and support interventions in the early post-diagnostic phase.

Primary care services struggle to deliver high quality continuing care for people with dementia, even in systems where their role has been made more explicit. Educational interventions alone have no impact on guideline adherence and evidence based management. There is some evidence that case management interventions may be beneficial. Appropriately skilled case managers could increase the capacity of primary care to respond to the needs of people with dementia and their carers, freeing up the PCP from time-consuming routine assessments, interventions, and care coordination activities.

There have, as yet, been no evaluations of case management, located in primary care, with system level planning and resourcing to support that activity. Not surprisingly, research-led initiatives to introduce primary care case management without this support have had limited success.

Attention needs to be given to the optimal roles of specialists within a more task-shifted and task-shared healthcare model. Neurologists, psychiatrists and geriatricians have quite different clinical training, and, while sharing some generic skills, are unlikely to have equivalent competencies across the full range of activities linked to the assessment and management of dementia. Much of the activity where specialist expertise is generic could be taken on by non-specialists in primary care, while ensuring that the relevant specialist expertise can be accessed for complex assessment and management problems.

Task-shifted models of care require specialist support, both while they are being established (design, training, handing over the task), and continuously thereafter (referral, supervision, mentoring and support). This requires modification of specialist roles and responsibilities, away from frontline patient care, and towards capacity-building activities at the lower levels of the health system. In low and middle income countries, expansion of the specialist sector will need to be balanced with investment in primary care services that are supported to deliver care with high coverage.

\section{Care coordination, through case management}

We conducted a scoping review of recent research evidence regarding the effectiveness of case management, wherever it is located within the health and social care system, with respect to outcomes for people with dementia and their carers, and evidence for improved efficiency of delivery of health and social care.

The Case Management Society of America (CMSA) describes case management as "a collaborative process of assessment, planning, facilitation and advocacy for options to meet an individual's health 
need through communication and available resources to promote quality cost-effective outcomes".

Case management, in theory, has numerous potential benefits for people with dementia; reducing the burden of the disease; identifying and managing evolving needs over the disease course; facilitating access to services; and providing advice (including about advanced care planning).

Despite a large number of trials, and some promising findings, the effectiveness of case management remains unclear. Positive effects (reduced or delayed transition into care homes, better adherence to care standards, and reduced unmet needs) were found in some studies. Evidence for effects on carer strain and psychological morbidity, and the quality of life of the person with dementia and their carer, is weak.

The biggest limitation is the lack of evidence regarding the impact of case management on the efficiency with which healthcare is delivered, and overall costeffectiveness, mainly because most studies do not report on the relevant outcomes - service utilisation and cost. Effects on hospitalisation were generally not significant. While a few studies indicated a modest reduction in healthcare costs in the medium term, the absence of evidence on cost-effectiveness is striking.

The evidence-base is also limited because of the wide variation in the types of case management intervention studied. Some focused mainly on delivering information and support for carers, with little care coordination. Providers of case management included specialist dementia care services, primary care, community social care and third sector (nongovernmental) organisations. The intensity of the intervention, and the capacity of the case manager to perform their role also varied among studies. More research needs to be undertaken to clarify the effective components of case management, and the most effective modes of delivery.

Evidence to date suggests that effectiveness may be enhanced when there is; a manageable caseload for delivering interventions with the required intensity; clear role definition with adequate preparation and training; and empowerment of the case manager to access and coordinate care across providers and sectors. These factors should be borne in mind when developing new services.

Most importantly, no opportunity should be lost for rigorous evaluation of this promising service innovation, whether as part of a research experiment (a randomised controlled trial), or a roll out into routine care. The necessary level of system-level planning, integration and support may be hard to achieve in the research/experimental context, so non-randomised evaluations of 'real world' scale up may provide the best evidence of potential effectiveness.

Future evaluations need to include a comprehensive set of process and outcome measures, which should include service utilisation and cost, as well as clinical and quality of life outcomes for the person with dementia and their carer. Greater consistency in outcome measures would support future evidence synthesis through meta-analysis.

\section{Hospital care}

We conducted a scoping review of hospitalisation of people with dementia seeking to clarify the extent of and reasons for hospitalisation, the associated harms, the excess healthcare costs, the effectiveness of approaches to avoid hospitalisation, and reduce harm and improve outcomes for those who are admitted.

People with dementia are more likely to be admitted to general hospital than people of similar age and medical infirmity, particularly for falls-related accidents and injuries, urinary tract and respiratory infections, and chronic disease complications that might have been averted with better management in the community.

On the other hand, people with dementia are less likely to be admitted for interventional procedures that could enhance quality of life, including cataract surgery, vascular catheterisation and stenting, cholecystectomy, and cancer care.

In HIC the costs of healthcare are substantially higher for people with dementia than age-matched controls, with a substantial proportion arising from hospitalisation. The increased utilisation and costs (both for all healthcare services and for inpatient admissions) is apparent for at least the year prior to diagnosis, reaches a peak in the year after diagnosis, and then declines but still to an elevated level compared with matched controls.

The process of hospital care is more complicated for people with dementia, with significant cost implications. They have longer hospital stays and require more nursing resources than others. At least some of the incremental costs may be intrinsic to the complexities of inpatient dementia care.

People with dementia are particularly vulnerable to harm and poor outcomes in the context of an admission, most particularly from a constellation of hospital acquired infections, delirium, agitation and falls, all of which impact adversely on length of stay. Both delirium and dementia can reduce capacity for informed consent, and impair motivation and adherence with investigations, procedures, treatments and rehabilitation. 
Mortality rates are exceptionally high during admission and somewhat higher after discharge. However, the high mortality rates may reflect, in part, a tendency to admit people with dementia at the very end of life. In HIC, up to two-fifths of people with dementia die in hospital, while deaths in care homes are the most frequent outcome. In LMIC deaths in hospital are at least as common as in HIC. However, home is the commonest place of death, with almost no deaths in care home settings.

More research is need into service and system level interventions to avoid hospitalisation, specifically of people with dementia. Community interventions have been mostly ineffective, although there is more evidence to support multidisciplinary assessment and management, than case management. Few of the interventions had a clinical medical focus, they did not target the common reasons for admission (control of chronic conditions, and prevention of unintentional injuries, acute infections and dehydration), and relied upon specialist secondary care providers with little interaction or integration with primary care.

Emergency Departments are often the portal of admission for people with dementia, and represent a last chance to prevent unnecessary hospitalisation. The literature highlights the need for comprehensive multidimensional geriatric assessment, including detection of dementia and delirium. There have been no trials of interventions, but a non-randomised study, of a geriatric rapid assessment and triage service, did demonstrate reduced admissions, and shorter lengths of stay ${ }^{3}$.

'Hospital at home' refers to services provided by health professionals in the patient's own home, in situations when inpatient hospitalisation would otherwise be necessary. The cost-effectiveness of this approach has been demonstrated for conditions including pneumonia, exacerbations of chronic obstructive pulmonary disease, deep vein thrombosis, cellulitis and end-of-life care. While we identified several examples of such services being established for people with dementia, we could find no formal evaluations. A large randomised controlled trial is currently being conducted in the Netherlands, with results expected in $2018^{4}$.

Reducing rates of hospitalisation for people with dementia will likely require community-based and outreach services that are resource-intensive and maintained over relatively long periods of time. Therefore, while the costs of hospital admission are high and concentrated, the potential for cost-savings may be illusory. Furthermore, costs would be shifted from acute hospital to community health and social care, which would require adjustments to budgets and resource allocation.
For people with dementia who are admitted to general hospital inpatient settings, there is a tension between prioritisation of task-centred acute care for the indication for admission, and the acknowledged need to provide person-centred dementia care.

Advocated actions are mainly at the systems level, focusing on managerial and workforce development; providing an appropriate care environment; fostering a positive care culture; changing attitudes; and cultivating a better understanding of the challenges for the person with dementia, for carers, and for inpatient healthcare staff.

Most reviews and reports emphasise that simply introducing a mental health liaison service, or a dementia specialist nurse, or a special dementia care unit will not suffice. Unless these are properly integrated into the wider hospital and health service management structure, with clear ownership, they will struggle to function properly. What is needed is a wholescale restructuring of the culture of hospital care, which first and foremost accords adequate priority, in resources and planning, to the needs of people with dementia.

Concern is expressed in all recent reviews at the lack of rigorous evaluation of services that commissioners are advocating and providers are implementing. Wellconducted large scale randomised controlled trials, providing clear evidence of cost-effectiveness are largely lacking.

There is a body of evidence that the quality of hospital care can be improved, with enhanced staff and service-user satisfaction, but evidence on the tractability of the key health system economic indicators (length of stay and readmission rates) is much weaker.

\section{Palliative and end-of-life care}

We reviewed the latest evidence on palliative and endof-life care for people living with dementia, updating the review that we conducted for the World Alzheimer Report 2013.

Dementia is a life-limiting illness with no disease modifying treatments, and deaths of people with dementia are increasingly common. End-of-life care and advanced care planning are closely related issues, since advanced care planning allows people with dementia to think through, and state preferences for, future care options. Many important decisions will need to be taken at a time when their capacity to contribute to them may be significantly compromised.

Concerns have been raised regarding the lack of access for people with dementia to good quality end-of-life care, specifically specialist palliative care 
services, although there is some evidence, from some $\mathrm{HIC}$, that the situation may be improving.

The applicability of a palliative approach to dementia care continues to be debated, given the lack of consensus regarding the definition of 'advanced' dementia and the lack of a clearly demarcated 'end-oflife' phase. Some have argued for its relevance across the disease course, while others contend that this does no more than restate the need for good quality personcentred dementia care.

There may be no specific palliative phase; the specific goals of dementia care can include, at various phases, and to different degrees, prolonging life, improving function, and achieving comfort (palliation). While several studies and reviews have addressed the optimal time for a more palliative approach, none have done so from the perspective of the person with dementia, whose views should be paramount.

Advanced care planning discussions can be challenging for people with dementia, their families, and healthcare professionals. The optimal timing to initiate the discussions is debated, although there is consensus that advance decisions, if made early, will need to be revisited and reviewed over time. All professionals providing care for people with dementia need training in the required skills, and structured approaches for the discussion and recording of its outcomes may be beneficial.

People with dementia should be encouraged and enabled to exercise their autonomy in options for future care, consistent with their values and preferences.

Early discussions with family carers that acknowledge the likely loss of decision-making capacity and their increasing role as proxy decision-makers would assist carers in assuming this role, and enhance their ability to judge the person with dementia's best interests.

Empowerment of people with dementia needs to be stressed, to emphasise that the palliative care agenda is focused upon their choices, and their quality of life, rather than cost savings. Palliative care avoids futile and burdensome interventions, while ensuring that everything possible is done to maintain comfort. The aim is to avoid 'bad costs' (healthcare that is ineffective and does not improve quality of life), while reinvesting in 'good costs' (care that enhances comfort and quality of life).

Calls have been made for a better systematisation of palliative care for people with dementia, with structured care pathways, good practice supported by evidence, and identification of appropriate outcomes to allow the effects of interventions to be measured.
Research to date has focused on the extent to which palliative care approaches are being applied in practice, and the barriers to their more widespread uptake and implementation. Much less research has been conducted into the outcomes of palliative care, and how these can be improved, with no trials of the effectiveness of advanced care planning, or palliative care at any stage of care. Current good practice guidelines are almost entirely based upon expert opinion and consensus.

More clarity is needed regarding; the division of responsibilities among different health and social care disciplines; the structure and function of advanced care planning; the management of rising risk and increasing complexity; boundaries between diseasemodifying treatment and palliative care and between palliative and end-of-life care.

There is also a policy gap regarding end-of-life care for people with dementia. While improving palliative care services for people with dementia is an acknowledged policy priority for many HIC governments, most current national dementia strategies do not adequately address the issue. In essence, the focus is upon living well with dementia, with relatively less attention to the complex medical, social and ethical management of the physical decline that leads to death.

There is an urgent need for more research, specific to the dementia field, regarding; preferences of people with dementia, and how these can be elicited; the implementation, benefits and harms of advance care planning; and the relative costs and benefits of palliative care assessments and services in the more advanced phases of the condition. Another major gap in the research literature is that of palliative care services and end-of-life issues for people with young onset dementia.

\subsection{Discussion and conclusion}

Four main themes emerged from the reviews conducted for this report; the need to systematise care processes; the challenges of managing complexity; the need for more research to inform policy and practice; and the potential for efficiency, through moderating costs while scaling up coverage of basic dementia healthcare services.

\section{Systematisation of care processes}

There is a need for much greater systematisation of care processes for people with dementia. This should include standards of care at different phases of the condition; role specification ('who does what'); clear referral indications and pathways; and relevant process and outcome indicators to be measured. Taken together, this would constitute a care pathway for dementia, and care pathways are now a more or 
less universal structural component of chronic disease care for other conditions (for example diabetes, hypertension, and cancer care). Care pathways are much more explicit than guidelines, strategies and plans, enabling service performance to be monitored and quality improvement strategies to be implemented. Arguably, the lack of explicit care pathways in dementia healthcare is the single largest contributor to fragmented care, and to the lottery that people with dementia and their carers experience in accessing care and support that is effective, responsive, and continuing. While, in principle, different elements of a fragmented care system can each designate their own care pathways, value is added when these interact with each other, or, preferably, can be wholly integrated. This is only likely to occur when there is a guiding hand with responsibility for the central planning and resourcing of the health and social care systems. This is a strength for many OECD countries, but some rich and well-resourced countries (notably the USA), and middle income countries (for example India and many countries in Latin America) are relatively weak in this regard. Governments in low resource countries generally retain control over their more limited healthcare systems.

\section{Managing complexity}

Much more effort needs to be applied to the effective management of complex multimorbidities in dementia healthcare, in particular chronic physical health conditions. As highlighted in this review, this issue is given far too little attention in, for example; evidencebased guidelines for management of other chronic diseases; the training of PCPs for dementia care; the role of case managers and the outcomes studied in trials of this intervention; the design of community interventions that aim to reduce hospitalisation rates; and the development of the palliative care approach to dementia care. Notably, of the few examples of care pathways identified in this review, only that developed by the WHO addressed the issue of comorbidity. There is evidence that chronic comorbid physical health conditions are undermanaged, with missed opportunities to improve function and avoid acute crises leading to hospitalisation.

At the same time, we need to acknowledge the paucity of evidence to inform management of physical comorbidity. Dementia, as we have noted, changes everything. Aside from complicating the delivery of care, it may affect the nature of other conditions and their response to treatments. Most trials, even those conducted among older people, tend to exclude those with dementia, and/or complex multimorbidities, hence the evidence-base will not necessarily generalise to these groups. For example, antidepressant treatment for depression is moderately efficacious for older people in general, but probably not for people with dementia and depression ${ }^{5}$. We know very little regarding the benefits and harms of standard treatments for hypertension (antihypertensive medications) and dyslipidaemia (statins) for people with dementia, but we do know that blood pressure and cholesterol levels, and body mass fall with the onset and progression of dementia, regardless of treatment ${ }^{6}$. Likewise there is no evidence-base to guide the optimum management of diabetes in dementia, in particular the optimum target level of glycaemic control $^{6}$. Hypoglycaemic attacks may be particularly harmful for people with dementia.

There have been calls for people with dementia to be included in the debate about approaches to the management of multimorbidities in older people ${ }^{7}$. Their values and preferences may differ in important ways from those who do not live with dementia, as may the outcomes that are most important to them. Mortality, a key outcome for most cardiovascular disease trials, may be considered less important than quality of life, while side effects may be particularly undesirable. Beneficial or harmful effects on cognition may be particularly critical. In the management of complex multimorbidity, the relative priority to be accorded to interventions that might prolong life, improve function or increase comfort needs to be determined according to the best interests of the person with dementia, whether communicated autonomously, through an advanced directive or by a carer as proxy decisionmaker.

We need to do more to help people with dementia to optimise their physical health, maintain their nutrition and hydration, and reduce their risks for falls, infection and delirium. Attention needs to be given to medication management and polypharmacy. These should be considered integral components of dementia healthcare, alongside the review of the condition itself and its cognitive, psychological and behavioural effects. Multidimensional geriatric assessment and management shows some evidence of efficacy in improving health outcomes and, possibly, reducing risk of hospitalisation. Such interventions should be well within the expertise of non-specialist primary care services. Arguably, the inadequate management of multimorbidity may represent the biggest weakness in the currently prevailing specialist models of dementia care, and the strongest argument for the greater involvement of primary care in the coordination and delivery of community care.

\section{Need for more research}

In the opening section of this review, we highlighted the priority that had recently been accorded to research questions relating to the effective and efficient delivery of health and social care for people with dementia. In each of the subsequent chapters we have identified important evidence gaps. The lack of experimental evidence from well-conducted randomised controlled 
trials has been particularly striking. Thus, there is no evidence at all regarding the effectiveness of advanced care planning, or palliative care for people with dementia. Despite a large number of trials, there is no evidence regarding the cost-effectiveness of case management. No trials have been carried out of interventions specifically designed to prevent hospitalisation of people with dementia. There is very little evidence to support widely advocated innovations in hospital care for those that are admitted. We have also suggested the need for more task-shifting 'noninferiority' trials examining the quality, acceptability and safety of different elements of the care pathway, delivered by non-specialist compared with specialist services. The lack of evidence in these areas is notable given the strategic priority attached to them by policymakers.

We would argue that there is a need for researchers to work more closely with policymakers, healthcare providers and research funders to ensure that research is relevant and translatable. The collaboration with policymakers and healthcare providers is particularly critical in the evaluation of health service and system innovations. Some of the interventions reviewed here seem naïve in their conceptualisation, in that they are delivered by the research team with little integration with existing services and systems. Such interventions have limited generalisability, and are likely to have limited efficacy. Policymakers and providers have the ability to implement innovations, and should be encouraged to do so in a way that permits evaluation, and, where possible, experiment. Researchers should work with policymakers and providers to ensure that the innovations that they propose to evaluate are policy relevant, fully implementable in the context of the research evaluation, and capable of being taken to scale in the event that effectiveness and costeffectiveness are demonstrated.

\section{Coverage, costs and efficiency}

Increasing the coverage of dementia care will increase the share of the population who are treated which, coupled with the increasing numbers of people affected, will require additional healthcare spending on dementia.

Countries around the world face a considerable challenge in scaling up dementia care in the context of increasing numbers of people affected. In Canada for example, numbers of people with dementia will increase $58 \%$, from 556,200 to 885,700 from 2015 to 2030. However, assuming that over the same period, treatment coverage increases from $50 \%$ to $75 \%$, the numbers treated would more than double (an increase of $339 \%$, from 278,100 to 664,275 ). In middle income countries the challenge is even greater. In China, for example, we are assuming that in 2015 only $10 \%$ or $0.95 \mathrm{~m}$ of the $9.5 \mathrm{~m}$ people with dementia would be receiving treatment. By 2030 numbers affected would have nearly doubled to $16.2 \mathrm{~m}$. Targeting $50 \%$ treatment coverage would mean $8.1 \mathrm{~m}$ under treatment, a near nine-fold increase from 2015.

In this context, a move towards a less specialised, more task-shifted model of care can be advocated on two grounds. First, mobilising the untapped potential of the non-specialist primary care workforce can alleviate resource constraints hence enabling scaling up to take place. This is a particularly critical issue for lower resourced low and middle income countries. Secondly, this strategy is likely to optimise productive efficiency. Productive efficiency is attained when more healthcare services are provided at a given quality and cost, or, alternatively, the same healthcare services are provided at a given quality, but at a lower $\operatorname{cost}^{8}$. Under either scenario, the costs of care per person are assumed to fall. In a task-shifted model of care, the human resource and fixed costs of non-specialist primary care should in principle be lower than those for hospitalbased specialist care. Our modelling exercise supports this assumption; in Canada the per capita cost of the task-shifted care pathway is $43 \%$ lower, and in Switzerland $25 \%$ lower than that of the specialist care pathway. The productive efficiency of the task-shifted pathway is clearly demonstrated in the case of Canada. Assuming a specialist care pathway, the total cost of the pathway would increase by $9 \%$ from 2015 to 2030 , from \$US379m to $\$ 756 \mathrm{~m}$. However, if the system were transitioned to a task-shifted model the cost in 2030 would be $\$ 438 \mathrm{~m}$. This would imply that costs would have increased by only $16 \%$ despite a $339 \%$ increase in numbers of people with dementia treated.

The potential increases in productive efficiency associated with the introduction of a more task-shifted model of care are clearly attractive. However, it is important to consider the practical implications of such a transition. Non-specialists would be taking on new, and to some extent unfamiliar tasks, for which they will need training, mentoring, supervision and support, provided by specialists. As highlighted in Chapter 6 , and discussed in Chapter 7, the preparedness of primary care services to assume these roles will vary greatly among countries, with very different levels of population coverage, workforce resources and competencies, and capacity to provide continuing care for chronic diseases, as opposed to curative interventions for acute conditions. In-service training is therefore only one component of the systemstrengthening and capacity building that would be required. Whatever the baseline level, there would need to be greater investment in primary care services, including, possibly, the development of a new cadre of case managers to assist PCPs with continuing care. Case managers might focus on dementia care, care of frail and dependent older people in general, or chronic disease care in general depending upon the burden of disease, and the extent of unmet needs within each 
population. In low and middle income countries, good quality continuing care for chronic diseases requires transformative system change ${ }^{9,10}$, which will not be achieved overnight. Change will be incremental, and in the course of this transition cost-savings will be unlikely to be realised. Over time, as tasks are shifted successfully to the primary care level, commissioners will be able to shift budgets from secondary to primary care and per capita costs of care may fall. In reality though, the main benefits of task-shifting may be the unlocking of resource capacity to meet the increasing demand. There is also the possibility that task-shifted and task-shared care may be of higher quality; more local, more holistic and personalised, and more comprehensive, integrated and continuous. This will only be achieved with the support and expertise of specialist services, but with more clearly defined roles and functions.

Scaling up dementia care would seem to be affordable, in principle, in all countries included in our review. Current annual costs of core dementia healthcare pathways, per person treated, range from US\$1364 to US\$ 2558 in HIC and from US\$ 40 to US\$ 199 in MIC.

The total costs of the dementia pathways are estimated to be around $0.2 \%$ of total health expenditure in the $\mathrm{HIC}$ and as little as $0.05 \%$ in the MIC. After scaling up, and accounting also for the increasing numbers of people with dementia, costs would have doubled in HIC (although this increase would be mitigated by a move towards a more task-shifted system of care) and increased 15- to 30-fold in MIC. Some of these increased costs of dementia healthcare pathways might be offset through increased coverage of good quality dementia care, reducing costs resulting from the lack of timely access to appropriate healthcare by people with dementia. For example, in the UK, the 'excess' cost of unnecessary hospital admissions and their adverse consequences amounts to $£ 265$ million (US\$ 351m) in the UK, or around $£ 330$ (US\$ 437) per person with dementia. In HIC generally, the cost of social care for people with dementia, particularly that provided in care homes, dwarfs that of healthcare. There is good quality evidence, from many studies, that education, support and training for carers can delay or prevent transition into care homes ${ }^{11}$.

One critical issue remains to be discussed. The cost of anti-dementia drugs had a large impact on the total cost of the dementia healthcare pathway where low cost generic versions of acetylcholinesterase inhibitors and memantine were not yet available. This was particularly the case in middle income countries, where staff costs were, proportionately, relatively modest. Increased access to low-priced generic drugs by 2030 would make the dementia pathways, for example, up to $150 \%$ more affordable in Indonesia, and $92 \%$ in China. This will be a particularly important issue if and when new and more effective treatments become available.
The central goal of the G7 Global Action on Dementia is to develop a disease modifying treatment for dementia by 2025 . This is likely to be beyond the vista of our modelling exercise, which projects costs through to 2030. However, the development and marketing of such treatments will raise important issues of equity and justice. The World Health Organization 'Call for Action' on dementia ${ }^{12}$, unanimously supported by 80 nation states, refers to the inalienable human rights of those affected, and to the need to give special and focused attention to low and middle income countries, emphasising the need for;

"a universal health coverage and an equity-based approach in all aspects of dementia efforts, including facilitation of equitable access to health and social care for people living with dementia and their caregivers".

We should not forget the lessons of the HIV/AIDS epidemic, where a global campaign, led by activists from low and middle income countries, was required to secure a supply of the new antiretroviral drugs at affordable prices. The rate limiting step, after the affordability of medications was addressed, was the weakness of healthcare delivery systems in low resource settings to identify and treat those affected. While much progress has been made, this problem is still being addressed.

We need to focus, now, on achieving high coverage of dementia diagnosis and continuing care, both to ensure access to current evidence based treatments and support, and to create systems and platforms with the capacity to deliver, with equity, much more effective treatments in the future. 


\section{References}

1 Meeuwsen EJ, Melis RJF, Van Der Aa GCHM, et al. Effectiveness of dementia follow-up care by memory clinics or general practitioners: randomised controlled trial. BMJ 2012; 344: e3086.

2 Meeuwsen E, Melis R, van der Aa G, et al. Cost-effectiveness of one year dementia follow-up care by memory clinics or general practitioners: economic evaluation of a randomised controlled trial. PloS One 2013; 8: e79797.

3 Wright PN, Tan G, lliffe S, Lee D. The impact of a new emergency admission avoidance system for older people on length of stay and same-day discharges. Age Ageing 2014; 43: 116-21.

4 ZonMw - Hospital At Home care program for patients with dementia and an acute medical crisis - Samenvatting. http:// www.zonmw.nl/nl/projecten/project-detail/hospital-at-homecare-program-for-patients-with-dementia-and-an-acute-medicalcrisis/samenvatting/ (accessed July 18, 2016).

5 Banerjee S, Hellier J, Dewey M, et al. Sertraline or mirtazapine for depression in dementia (HTA-SADD): a randomised, multicentre, double-blind, placebo-controlled trial. Lancet Lond Engl 2011; 378: 403-11.

6 Prince M, Albanese E, Guerchet M, Prina M. World Alzheimer Report 2014. Dementia and Risk Reduction. An analysis of Protective and Modifiable Risk Factors. London: Alzheimer's Disease International, 2014.

7 Bunn F, Burn AM, Goodman C, et al. Comorbidity and dementia: a scoping review of the literature. BMC Med 2014; 12. DOI:10.1186/ s12916-014-0192-4.

8 Fulton BD, Scheffler RM, Sparkes SP, Auh EY, Vujicic M, Soucat A. Health workforce skill mix and task shifting in low income countries: a review of recent evidence. HumResourHealth 2011; 9:1. doi: 10.1186/1478-4491-9-1.: 1-9.

9 Epping-Jordan JE, Pruitt SD, Bengoa R, Wagner EH. Improving the quality of health care for chronic conditions. QualSaf Health Care 2004; 13: 299-305.

10 Beaglehole R, Epping-Jordan J, Patel V, et al. Improving the prevention and management of chronic disease in low-income and middle-income countries: a priority for primary health care. Lancet 2008; 372: 940-9.

11 Olazaran J, Reisberg B, Clare L, et al. Nonpharmacological therapies in Alzheimer's disease: a systematic review of efficacy. DementGeriatrCogn Disord 2010; 30: 161-78.

12 World Health Organization. Call for action by the participants in the First WHO Ministerial Conference on Global Action Against Dementia (Geneva, 16-17 March 2015. 2015. http://www.who.int/ mental_health/neurology/dementia/call_for_action/en/ (accessed Sept 15, 2016). 

Alzheimer's Disease

International

\section{About ADI}

Alzheimer's Disease International (ADI) is the international federation of Alzheimer associations throughout the world. Each of our 85 members is a nonprofit Alzheimer association supporting people with dementia and their families. ADI's mission is to strengthen and support Alzheimer associations, to raise awareness about dementia worldwide, to make dementia a global health priority, to empower people with dementia and their care partners, and to increase investment in dementia research.

\section{What we do}

- Support the development and activities of our member associations around the world.

- Encourage the creation of new Alzheimer associations in countries where there is no organisation.

- Bring Alzheimer organisations together to share and learn from each other.

- Raise public and political awareness of dementia.

- Stimulate research into the prevalence and impact of Alzheimer's disease and dementia around the world.

- Represent people with dementia and families on international platforms at the UN and WHO.

\section{Key activities}

- Raising global awareness through World Alzheimer's Month ${ }^{\text {TM }}$ (September every year).

- Providing Alzheimer associations with training in running a non-profit organisation through our Alzheimer University programme.

- Hosting an international conference where staff and volunteers from Alzheimer associations meet each other as well as medical and care professionals, researchers, people with dementia and their carers.

- Disseminating reliable and accurate information through our website and publications.

- Supporting the 10/66 Dementia Research Group's work on the prevalence and impact of dementia in developing countries.

- Supporting global advocacy by providing facts and figures about dementia, and monitoring as well as influencing dementia policies.

ADI is based in London and is registered as a non-profit organisation in the USA. ADI was founded in 1984, has been in official relations with the World Health Organization since 1996 and has had consultative status with the United Nations since 2012.

You can find out more about ADI at www.alz.co.uk/adi 
Alzheimer's Disease International: The International Federation of Alzheimer's Disease and Related Disorders Societies, Inc. is incorporated in Illinois, USA and is a 501(c)(3) not-for-profit organization
Alzheimer's Disease International 64 Great Suffolk Street London SE1 OBL UK

Tel: +44 2079810880

www.alz.co.uk
Alzheimer's Disease International 